\title{
Flood inundation and broader ecosystem service modelling in a data sparse catchment; application of LUCI to Marokopa, NZ
}

by

Raiatea Barlow Kameta

A thesis submitted to Victoria University of Wellington in partial fulfillment of requirements for the degree of Master of Science (Physical Geography)

School of Geography, Environment and Earth Sciences

Victoria University of Wellington, New Zealand

2019 


\section{Abstract}

Event magnitude, societal vulnerability, and exposure define hazard impact. In New Zealand, flooding is the most common and damaging hazard at the decadal scale. Residents within the Marokopa catchment (west coast of the Waikato region) identify flood and erosion as significant local hazards. Flooding is influenced by a diverse range in factors, from environmental factors in the catchment, such as hydrology and climate, to socio-political policies and community awareness. Each of these factors is themselves influenced by climate change, and therefore requires study at the local and national scales

A mixed-methods approach was used to analyse flood and erosion through application of the Land Use and Capability Indicator (LUCI). Qualitative analysis along with rainfall-runoff, inundation, and holistic ecosystem service (ES) modelling are used to evaluate both flood and erosion extent, but also influencing factors. This research used a unique, mixed-methods approach to research a traditionally quantitative topic, improve on the understanding of karstic rainfall-runoff modelling and support LUCI development through application in a geomorphologically distinct location.

Local knowledge facilitated both temporal and spatial outlining of flood and erosion extent at macro and catchment-scales. Bespoke rainfall-runoff modelling of the Marokopa upper catchment defined localised rainfall, seasonality and the karstic system as significant influences on runoff, with poor to excellent model-fit. Preliminary inundation findings outlined tidal, upper catchment bank-overflow, and overland flow as significant mechanisms of flooding. Finally, flood and erosion mitigation ecosystem services were modelled, with synergistic comparisons also analysed. Priority areas for future land management and hazard mitigation investment include the Marokopa floodplains $\sim 5 \mathrm{~km}$ inland from the coast. Novel integration of physical and social observations outlines current flood risk extent and evaluates factors which contribute to flooding, providing a thorough knowledge base for future flood modelling within the Marokopa catchment. 
Ehara taku toa e te toa takitahi engari he toa takimano.

My strength is not that of a single person, but that of many - Here Huata 


\section{Acknowledgements}

A Master's thesis, apparently, takes a village. To the below people, I give my heartfelt thanks.

For help with all-things-modelling and greatly utilised patience and understanding, I thank my supervisors Bethanna Jackson and Deb Maxwell.

For the monetary support towards academic, living costs and conference fees I acknowledge the VUW Tu Horomata and Deep South Vision Mātauranga scholarship, FSRG grant and Waikato-Tainui scholarships.

I'd like to thank Cathy O'Callaghan (Waitomo District Council) for her support. Information and data were also given by Waikato Regional Council (Rick Liefting, Sophie Marsh, Doug Stewart) and NIWA (Kathy Walter, Seema Singh, Rob Bell).

He aha te mea nui o te Ao? He tāngata, he tāngata he tāngata. Endless thanks to the interview participants, Mirumiru marae, and wider Marokopa community.

For the lending of ears, encouragement, technical or general support, I thank Becky, Amanda, Rewi, MAI Poneke, Tipene, Bianca, Keith, the SGEES Admin team, Hariaty and Patricia. Outside of VUW, I thank Dawn Magner and Mere Kepa.

For the tea breaks, thank you to the $\mathrm{CO} 421 \mathrm{crew}$. Cheers for reminding me of the all-important work-life balance!

Finally, for inspiration, love, and unwavering support I thank my Mum, Dad, sister (Muriwai), Papa (Raymond), Nana (Rewa), Koro (John), Nan (Florence) and wider whanau. 


\section{Table of Contents}

Abstract....................................................................................

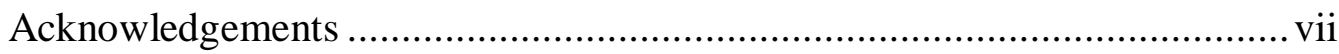

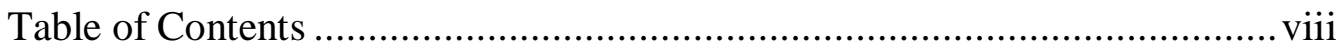

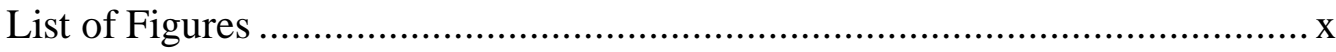

List of Tables ..........................................................................................

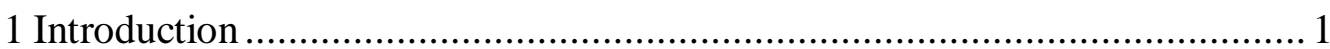

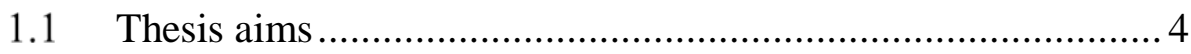

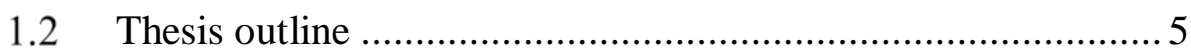

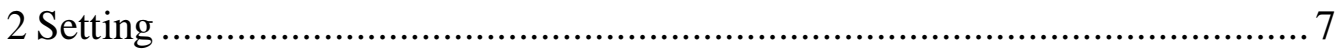

2.1 Marokopa hazards description and processes ....................... 8

2.2 Flooding factors at Marokopa ............................................ 9

3 Background and literature review ................................................... 25

3.1 Flood definitions..................................................... 25

3.2 Causes and factors in flooding ........................................ 26

3.3 Hydrological, hydrodynamic, and ecosystem service models . 37

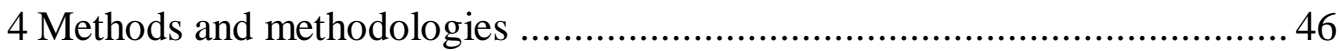

4.1 Land Use and Capability Indicator (LUCI) ......................... 46

$4.2 \quad$ Flood modelling................................................................ 47

$4.3 \quad$ Ecosystem service modelling .......................................... 53

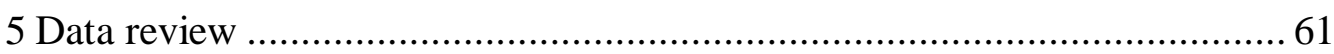

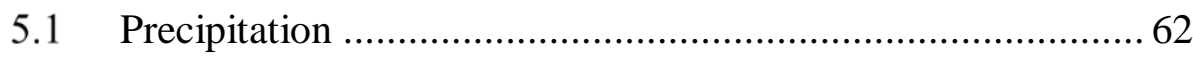

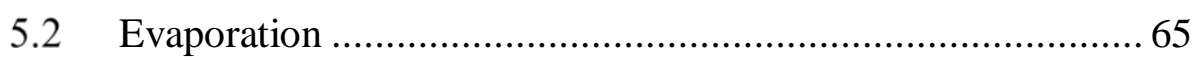

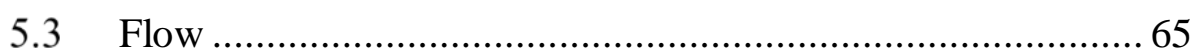

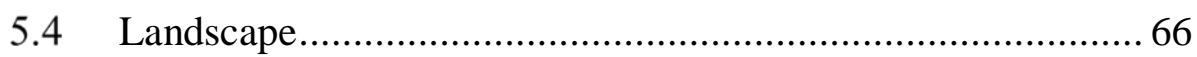

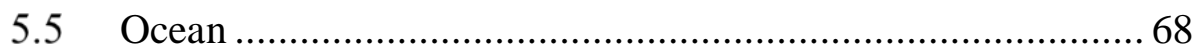

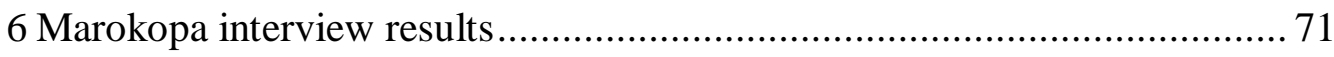

6.1 Flooding at Marokopa: where, when, what, how …............... 72

6.2 Rainfall, erosion and flood dynamics are interconnected........ 76

6.3 Erosion at Marokopa; where, when, what, how .................... 77

6.4 Land Management/Ecosystem services: .............................. 79

6.5 Karst hydrology, factors and sources................................. 86

6.6 Summary of qualitative results and findings......................... 88 
7 Flood modelling results

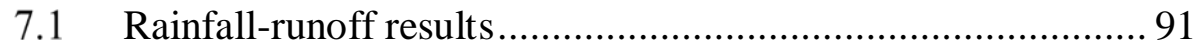

7.2 Preliminary inundation model results and data.................... 109

7.3 Ecosystem service modelling results ................................ 113

8 Agricultural activity, water quality, and trade-off results....................... 121

8.1 Ecosystem service trade-off results ................................. 123

8.2 Other ES service/trade-off land management discussion. ..... 127

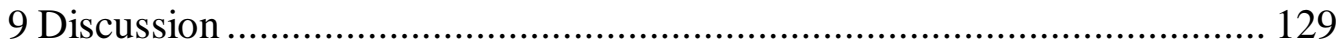

9.1 Aim 1: identify Marokopa flood and erosion risk ................ 129

9.2 Aim 2: identify Marokopa erosion and flood factors ............ 132

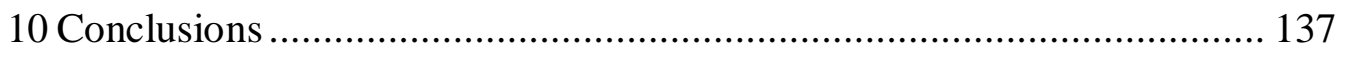

10.1 Future Work ......................................................... 139

10.2 Final Conclusions ..................................................... 140

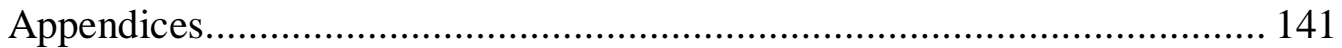

A. Definitions, abbreviations, acronyms ................................. 141

B. New Zealand Ecosystem Service Review........................... 143

C. Flood management examples ........................................... 145

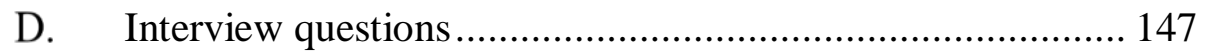

E. Ecosystem Service model parameters ............................... 149

F. Rainfall-runoff parameter seasonal parameter sets .............. 150

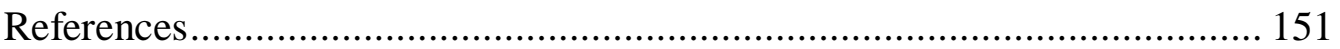




\section{List of Figures}

Figure 1: Location map for Marokopa................................................................ 2

Figure 2: Factors that influence Marokopa flooding......................................... 3

Figure 3: Elevation map of Marokopa catchment............................................... 7

Figure 4: Photograph capturing storm surge waves....................................... 9

Figure 5: Marokopa 'base' catchment geology................................................... 10

Figure 6: Marokopa ‘top' catchment geology.................................................. 11

Figure 7: Slope of the Marokopa catchment......................................................... 12

Figure 8: Land cover of the Marokopa catchment............................................. 14

Figure 9: Marokopa catchment soils.................................................................. 15

Figure 10: Map of rainfall across Waikato.......................................................... 16

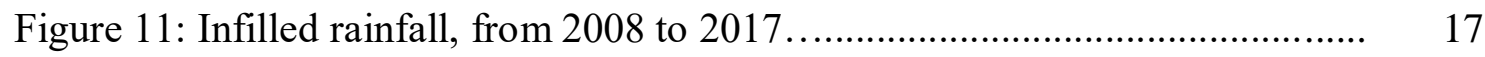

Figure 12: Marokopa rainfall recurrence intervals for historical data.................. 17

Figure 13: Mean daily temperatures.............................................................. 19

Figure 14: Marokopa Falls flow duration curve................................................ 21

Figure 15: Water quality testing locations..................................................... 22

Figure 16: Residence time of Marokopa estuary................................................ 23

Figure 17: Background chapter overview and structure.................................... 25

Figure 18: Marokopa, with flood factors outlined............................................ 27

Figure 19: Water cycle with multiple, simplified pathways............................... 27

Figure 20: Different scale karst landforms, recharge types and flow paths........ 30

Figure 21: Te Kuiti limestone/karst structures................................................. 32

Figure 22: New Zealand ecosystem service research....................................... 44

Figure 23: Project methods........................................................................ 46

Figure 24: Rainfall-runoff model................................................................. 49

Figure 25: Nash-Sutcliffe fastflow parameter plot for a summer flood................ 50

Figure 26: Inundation modelling process.......................................................... $\quad 52$

Figure 27: Standard LUCI ecosystem service components............................... 54

Figure 28: HydTopo modelling process............................................................. 56

Figure 29: Flow mitigation tool process...................................................... 57

Figure 30: Trade-off ES process................................................................... 59

Figure 31: Marokopa and locations where surrounding data was recorded........ 61

Figure 32: Dataset duration......................................................................... $\quad 62$

Figure 33: Hourly rainfall records ................................................................ 63

Figure 34: Infilled Te Kuiti hourly rainfall record.............................................. 64

Figure 35: Marokopa falls flow..................................................................... 65

Figure 36: Annual New Zealand precipitation..................................................... 66

Figure 37: Average New Zealand monthly temperatures..................................... 66

Figure 38: Annual average New Zealand evaporation......................................... 66

Figure 39: Marokopa catchment stream network............................................ 67

Figure 40: Marokopa catchment land cover...................................................... 67

Figure 41: Marokopa catchment soils.......................................................... 67 


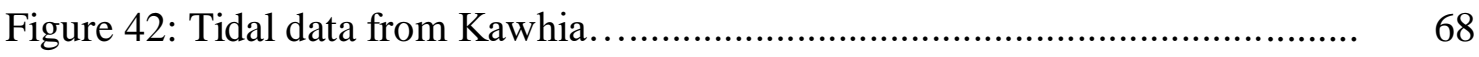

Figure 43: Themes taken from interviews................................................... 71

Figure 44: Comparison of Marokopa water level and wave diversion.................. 81

Figure 45: Marokopa Falls flow with 12 modelled flood periods indicated......... 91

Figure 47: Observed autumn/spring flood flow and rainfall............................. 94

Figure 48: Observed winter floods flow and rainfall......................................... $\quad 96$

Figure 49: Reservoir volumes.......................................................................... 97

Figure 50: Differences in rainfall event impact................................................... $\quad 98$

Figure 51: Comparison of flows between seasonal flows................................... 99

Figure 52: Modelled flood event...................................................................... $\quad 100$

Figure 53: Modelled, observed summer flood with associated rainfall................. 103

Figure 54: Observed autumn/spring flood with associated rainfall...................... 104

Figure 55: Observed winter flood with associated rainfall................................ 106

Figure 56: Model error for modelled period....................................................... 107

Figure 57: Model error for year period........................................................ 108

Figure 58: Historical flood extents................................................................. 111

Figure 59: Flood mitigation within the Marokopa catchment............................. 114

Figure 60: Flood interception within the Marokopa catchment........................... 115

Figure 61: CTI-calculated erosion vulnerability................................................ 117

Figure 62: RUSLE-calculated erosion vulnerability........................................ 118

Figure 63: ES Sediment delivery within the Marokopa catchment...................... 119

Figure 64: Relative agricultural utilisation...................................................... 121

Figure 65: Nitrogen stream concentrations...................................................... 122

Figure 66: Phosphorus stream concentrations................................................. 123

Figure 67: ES trade-off output: erosion and flooding...................................... 124

Figure 68: Non-weighted trade-off map.......................................................... 125

Figure 69: Weighted trade-off map................................................................. 126

Figure 70: Relationship between thesis aims and methods................................. $\quad 129$ 


\section{List of Tables}

Table 1: Rainfall recurrence intervals for the Marokopa region................... 18

Table 2: Changes in tidal range with increasing sea level rise .................... 20

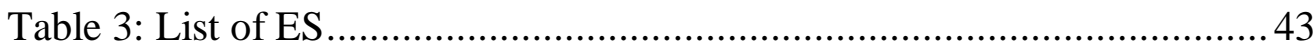

Table 4: Range of tested HydTopo parameters ......................................... 56

Table 5: Flood with order by season shown ........................................... 101

Table 6: Floods with associated NSE values ............................................ 101

Table 7: Historical floods, identified by interview participants.................. 109

Table 8: Flood and erosion factors ........................................................ 132

Table 9: Definitions of commonly used thesis terms. ............................... 141

Table 10: List of literature used within the ES research review. ................ 143

Table 11: Coding of NZ ES research....................................................... 144

Table 12: Aggregated NZ ES services.................................................. 144

Table 13: Flood management strategies. ................................................... 145

Table 14: Ecosystem service modelling parameters................................. 149

Table 15: Model parameters................................................................... 150 


\section{Introduction}

River flooding is internationally one of the most damaging natural hazards (Barredo, 2007; Kellens et al., 2013; Kron, 2005). Global flooding costs for a high greenhouse gas emissions scenario ( RCP $8.5^{1}$ ), without flood adaptation, are estimated at US\$14 trillion annually (Jevrejeva et al., 2018). In New Zealand, flooding is the most frequent and damaging hazard at the decadal scale; a function of a dynamic climatic, geomorphic, and geological setting (King et al., 2008). 70\% of New Zealand emergency declarations from 1963 to 2007 were flood-related, with the 55 major floods since 1968 resulting in an estimated cost of NZ\$626 million (Ministry of Civil Defence \& Emergency Management, 2010). These floods were significant due to the level of community preparedness and the towns environmental flood setting.

Flooding has many definitions, as detailed in Section 3.1. This thesis defines the process of flooding as bank-breaching river water or 'inundation'. As a hazard, flooding is the combined result of event magnitude, vulnerability and exposure. Magnitude defines the depth, extent and duration of flooding. Vulnerability relates to identifying and preparing for events and exposure to the social and physical setting (Kron, 2005). Furthermore, flooding is influenced by a diverse range of factors: from environmental factors such as hydrology and climate; to sociopolitical policies, and community awareness. Each of these factors are influenced by climate change, and therefore requires study at the local and national scales.

Climate change-related floods (2010 to 2017) have cost New Zealand's economy over NZ\$120 million (Frame et al., 2018). Furthermore, the uncertainty in climate change scenarios is significant (Arnell \& Gosling, 2016). Recent research has focused on flood risk and preparing for climate change (Bhatt et al., 2017; Ministry for the Environment, 2017). However, analyses of New Zealand hazards, detail little around the impacts of fluvial hazards and the link between identifying risks and mitigating them (Carrivick \& Tweed, 2016; Hughes et al., 2015; Whitman et al., 2013). To understand the mitigation and adaptation strategies needed by different communities an assessment of flooding impacts and factors that influence

\footnotetext{
${ }^{1}$ Representative Concentration Pathway (see Appendix A for full list of abbreviations and definitions).
} 
flooding is needed. Moreover, the impacts of climate change on flooding must be improved and applied at the global, national and regional scales.

Residents of Marokopa, a coastal township $80 \mathrm{~km}$ south-west from Hamilton (Figure 1), identified flood and erosion as significant hazards, with flood events recorded as far back as 1986. This thesis focuses on flooding as the primary hazard for the Marokopa area, but also provide high-level erosion hazard analysis (Section 7.3). Marokopa currently experiences intense rainfall events $(28,45$, and $50 \mathrm{~mm} / \mathrm{hr}$ for 1 in 5, 50, and 100-year recurrence events (ARI). These are projected to increase to $37.5,60.1$, and $67.6 \mathrm{~mm} / \mathrm{hr}$ for the same ARI under climate change RCP 8.5 projected conditions. The Marokopa area unit has a small year-round population of 20 at the village and 1,500 in the district (Statistics New Zealand, 2013). Like many townships across New Zealand, Marokopa has significant community and cultural value beyond its immediate residents. Every year, several hundred tourists visit Marokopa (Paget, 2009). Moreover, Mirumiru marae, which is less than $3 \mathrm{~m}$ above sea level, hosts groups ranging from 20 to 200 annually.

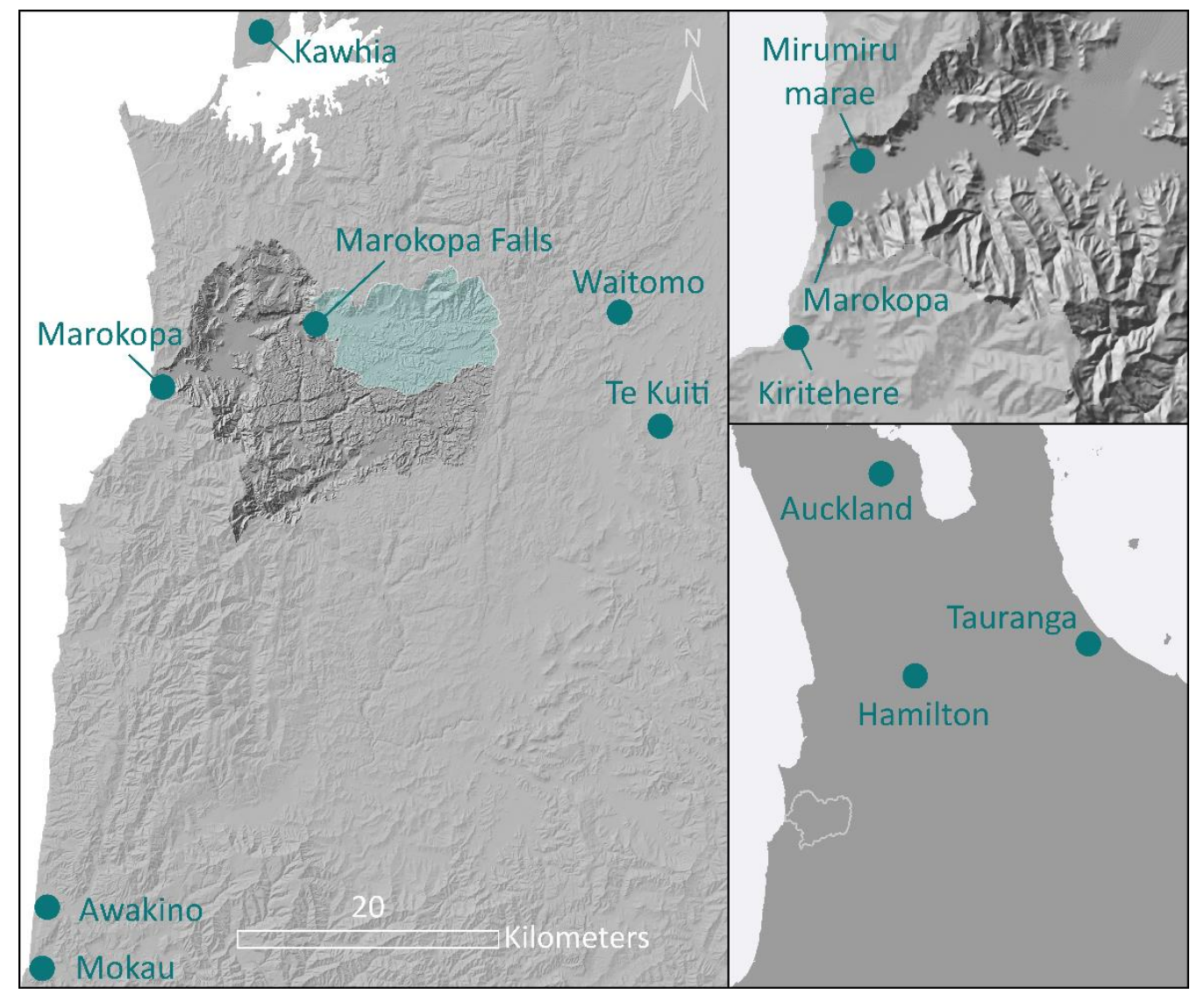

Figure 1: Location map for Marokopa, and surrounding townships. 
Due in part to its coastal location, the Marokopa village setting is a dynamic link between inland sediment-laden flood water and the rising, storm-surging seas which are to be exacerbated by climate change (Figure 2). Two types of flood modelling are used within this study: traditional hydrological and flood inundation modelling, and holistic ecosystem service (ES) modelling. The first models how rainfall and flow relate, how floodwaters breach river-banks and where the breaching water floods the surrounding area. The second method simulates how the landscape mitigates processes such as flooding and erosion. Due to data limitations and rainfall-runoff modelling of the hydrologically-complex upper karst catchment, inundation modelling was not completed (Bakalowicz, 2005; Hartmann et al., 2017). Instead, we present preliminary findings around historical flood extent to provide insights for future inundation modelling.Traditional hydrological

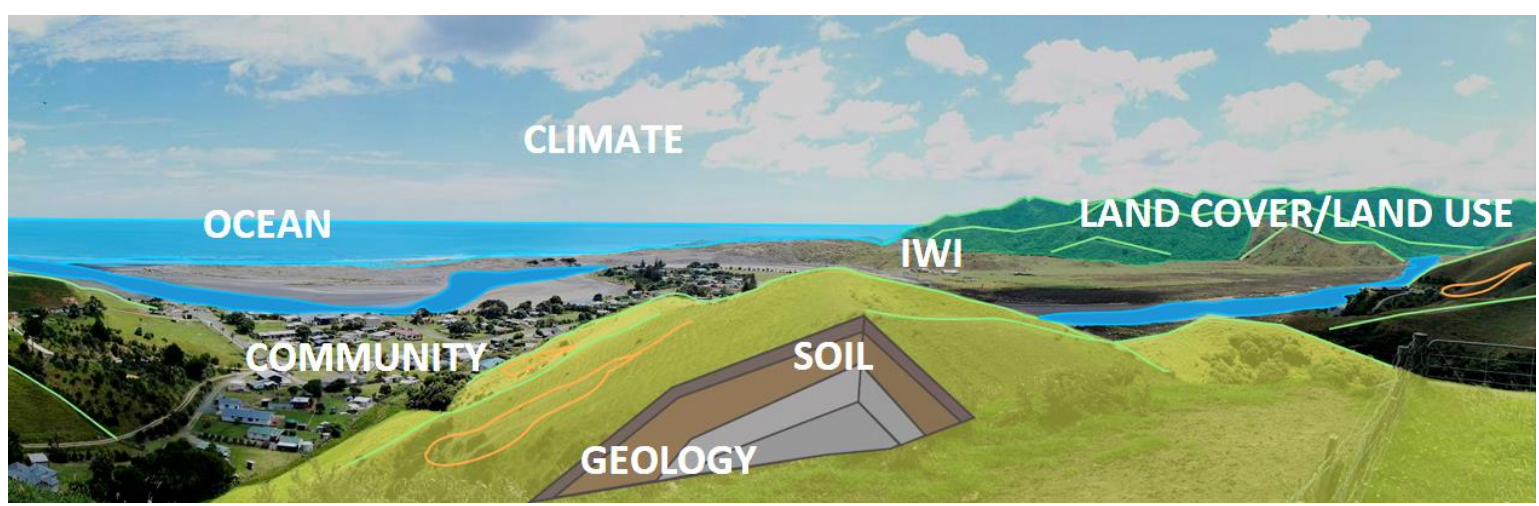

Figure 2: Factors that influence Marokopa flooding.

modelling (rainfall-runoff modelling) requires high-resolution datasets. Highresolution rainfall and flow were only available at Te Kuiti and Marokopa Falls (25 and $8 \mathrm{~km}$ from Marokopa, respectively) (Figure 3). Te Kuiti rainfall is used as a far-field correlative for Marokopa Falls rainfall-runoff modelling and eventual Marokopa floodplain inundation modelling. The lack of flow and flooding information was compensated for by the use of qualitative experiences of Marokopa residents. Twelve residents were interviewed in order to contextualise modelled flood risk results (Section 4.2.1 \& Chapter 6).

A bespoke rainfall-runoff model defines the catchment relationship between Te Kuiti rainfall and Marokopa Falls flow to derive peak flows for future inundation modelling. ES modelling evaluates the benefits gained from the landscape, across many disciplines: culturally, socially, biologically, and hydrologically. We use the Land Use and Capability Indicator (LUCI) to model Marokopa catchment flood and 
erosion mitigation, sediment delivery, agricultural productivity, and water quality benefits. Data required for this modelling includes nationally available topography, soil, and land cover datasets. Once services are overlaid, flows of water and sediment are simulated to identify opportunities for synergistic land management decisions.

\subsection{Thesis aims}

Flood hazards are holistically described using novel methods of both flatwater inundation and ES modelling and are aided by community hazard description. From hazard-identification stems holistic management structures that account for all sides of a given problem to improve Marokopa catchment sustainability. We apply this holistic approach at the data-scarce Marokopa catchment, focusing on the following research questions:

- To evaluate the erosion and flood risk within the Marokopa catchment

- To identify the physical, social and political factors in erosion and flooding within the Marokopa catchment

We use interviews to contextualise historical flood and erosion experiences while also applying a bespoke rainfall-runoff model and ecosystem services tools to meet the above research aims. Further objectives are derived below:

a) Qualitative

- Engage with the local community

- Record the community understandings and experiences of flooding and erosion within the Marokopa

b) Rainfall-runoff modelling

- Investigate the controlling physical processes of water through the Marokopa catchment by comparing the observed and modelled response to rainfall at Marokopa Falls.

c) Inundation modelling

- Compile the necessary data for future inundation modelling

d) Ecosystem modelling

- To apply LUCI to the Marokopa catchment to understand the spatial aspect of its ecosystem services and help identify priority areas for land management around flood and erosion mitigation. 


\subsection{Thesis outline}

Chapter 1 (Introduction) of this thesis relates global climate to the local scale, focusing on Marokopa (New Zealand). The flood risk research aims are detailed in several objectives. Traditional rainfall-runoff modelling of the Marokopa catchment is supplemented by local knowledge due to its data-sparse nature. However, to yield tangible and useful results for the community, ecosystem services are also used to outline where the flood risk is, and how land management can mitigate it.

Chapter 2 (Setting) provides an overview of the Marokopa catchment setting and relevant environmental and climatic characteristics. The flood and erosion hazards are reviewed and then connected to the different factors that influence hazard magnitude within the Marokopa catchment. These factors include the geology, geomorphology, land cover, soil, climate, and marine conditions.

Chapter 3 (Background and literature review) outlines the problem and influencing factors of flooding within a Marokopa context, and is followed by a review of two approaches to hazard modelling: traditional inundation modelling and holistic ecosystem services modelling.

Chapter 4 (Methods and methodology) summarises the different methodologies and methods used, including a brief overview of the qualitative methodologies, hydrological rainfall-runoff, inundation, and Land Use and Capabilities Indicator (LUCI) ecosystem service models.

Chapter 5 (Data review) evaluates the datasets and sources used within this thesis, including an overview of how data was sourced and what processing was needed before different datasets were used within hydrological, hydraulic or ecosystem service modelling.

Chapter 6 (Marokopa interview results) details the experiences of 12 Marokopa catchment residents. These interview participants ("participants") describe previous flood and erosion events within Marokopa and the factors that influence these hazards such as land management, climate, geology, land cover, and soil type. The roles of public and private entities are explored not only in identifying hazards but also in mitigating or adapting to them. 
Chapter 7 (Flood modelling results) describes the outcomes from the rainfallrunoff, preliminary inundation and ecosystem service modelling that pertains to flooding or erosion.

Chapter 8 (Agricultural activity, water quality and trade-off results) builds on the potential for ecosystem service modelling, with broader services. As agricultural activities and water quality are important locally, ecosystem service model results outline areas for future single, and multi-service improvement.

Chapter 9 (Discussion) details the use of qualitative interview findings, quantitative rainfall-runoff, inundation and ecosystem modelling results in meeting the aims of this research (Chapter 1). Each method describes Marokopa flood risk differently. Qualitative accounts provide historical, local accounts of flooding, rainfall-runoff modelling provides a detailed account of upper catchment flow peak conditions, preliminary inundation modelling outlines differences in the assumed relationship between flow and flood extent, while ecosystem services present highlevel analysis for targeted flood and erosion mitigation. Beyond flood analysis, each method contributes to the evaluation of climate, geology, topography, soils, land management, marine conditions and the community in flood impact.

Chapter 10 (Conclusions) summarises the thesis findings and future considerations. 


\section{Setting}

Marokopa is situated $80 \mathrm{~km}$ south-west of Hamilton, on the west coast of the central North Island, New Zealand (Figure 3). This chapter focuses on the Marokopa flooding hazard but also aims to outline erosional hazards. Flooding and erosion pathways are influenced by catchment characteristics such as geology, geomorphology, land cover, soil, climate, and ocean dynamics (Section 3.2.1). As these factors influence flooding, they are used within our rainfall-runoff, inundation, and ecosystem service modelling to varying degrees.

LocationThe Marokopa catchment spans approximately $364 \mathrm{~km}^{2}$ with the main $40.5 \mathrm{~km}$ long Marokopa river fed by $533 \mathrm{~km}$ of tributaries (Land, Air, Water, Aotearoa, 2018). The catchment is bounded to the north by the Maungaakohe (344m a.s.1) and Kahakaharoa (317m a.s.l) ranges; Waitomo to the east; and the Pomarangi ranges (469m a.s.l) to the south (Land Information New Zealand, 2018).

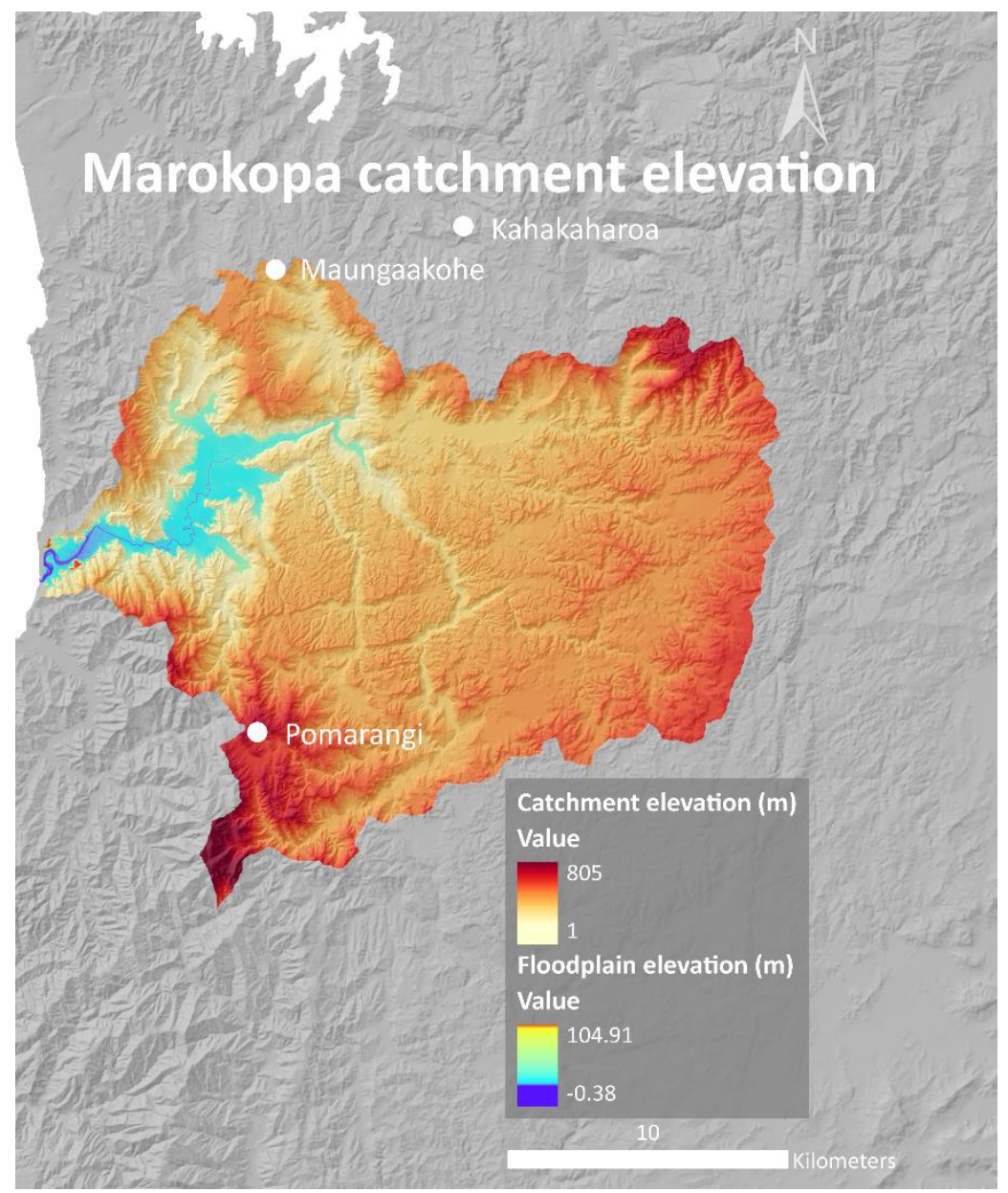

Figure 3: Elevation map of Marokopa catchment (data source: LINZ). 


\subsection{Marokopa hazards description and processes}

\section{Water and sediment processes}

Water and sediment are largely interconnected throughout fluvial processes (McKergow et al., 2010; Vercruysse et al., 2017). Climate, land cover, soil type, and geology control these macro-scale processes (Dons, 1987). Generally, these processes include sediment erosion from landscapes, transport across terrestrial or fluvial environments, and finally deposition. Erosion begins when soil is separated by physical or chemical weathering and then entrained by water or wind. Soil transport is impeded by entrained vegetation or overflow, altering the time and paths taken for sediment to travel from source to sink. Depending on the sediment size and river flow, deposition may occur locally or after the sediment has been suspended for some time within the river (Vercruysse et al., 2017). While waterways provide transport for sediment, they can also contribute to the physical erosional process, causing bank erosion and altering channel paths and depths (Spiekermann et al., 2017). Within this feedback-loop, sediment that is eroded can also change the temperature, turbidity, and chemistry of river flows (Ryan, 1991). These processes show that flooding and erosion are interconnected. Therefore, research that outlines one should acknowledge and provide mitigation and adaptation for both. Little peer-reviewed research has focused on Marokopa flooding and erosion. Therefore grey literature, resident's experiences, and field visits have informed this thesis' knowledge of erosion and flooding at Marokopa.

\section{Flooding}

Marokopa flooding occurs throughout all seasons and is determined by multiple factors, which change according to each event. Furthermore, large floods are commonly exacerbated by king-tide or storm surge conditions which can block water from leaving the catchment (Figure 4). Flood inundation is primarily dependent on precipitation duration and soil moisture conditions. If conditions are dry before the storm, then floodwaters will recede more quickly. According to Participant $\mathrm{K}$, flooded flow clears a week after an intense rainfall event with subsequent large volumes of debris deposited on banks and roads. 


\section{Erosion}

Marokopa township is bounded by steeply sloping farmland. In the upper catchment, heavy rainfall promotes mass-movement failures where the hydraulic conditions overcome the frictional forces of the soils. At the river mouth, the intertidal spit experiences two types of erosion with flood events and erosive aeolian processes, particularly during flood events (Chappell, 2014; Phillips \& Mead, 2009).

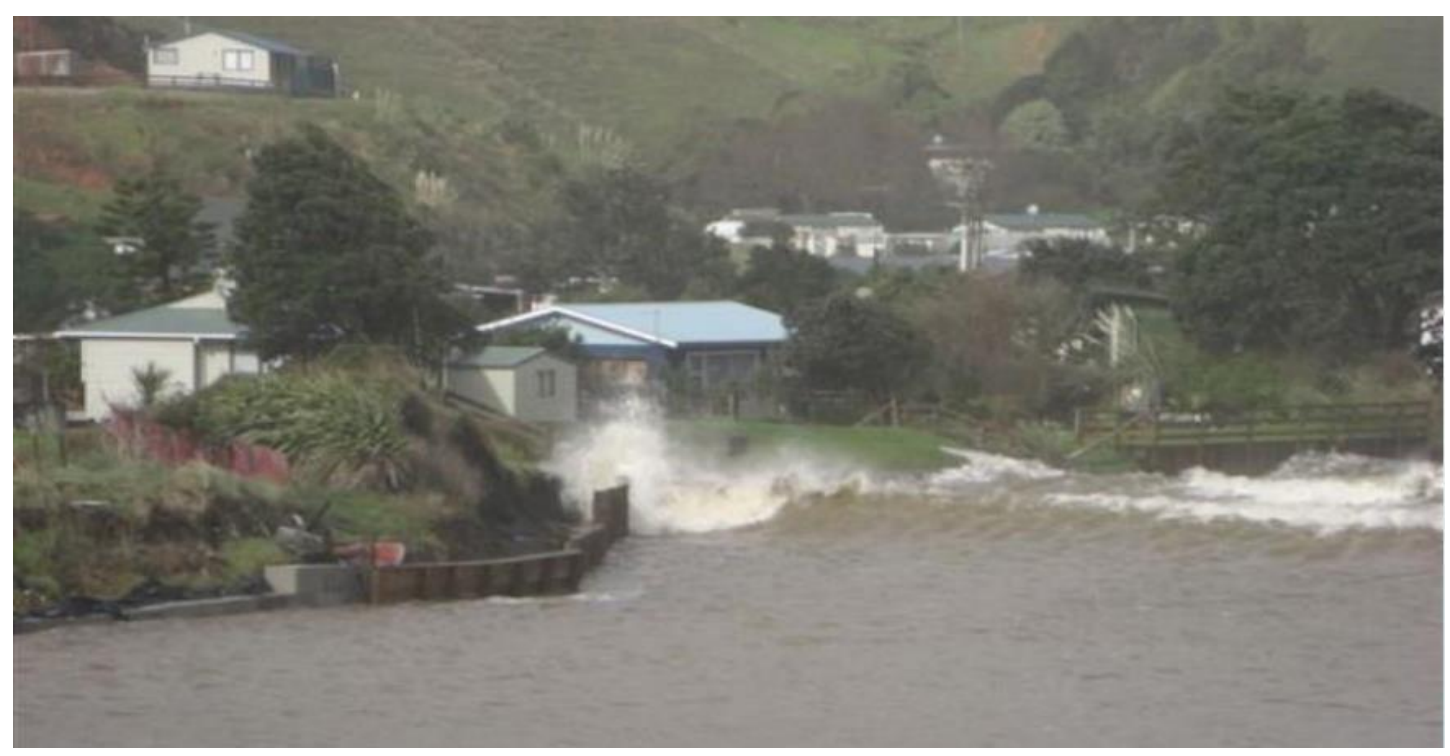

Figure 4: Photograph capturing storm surge waves taken by a Marokopa resident.

\subsection{Flooding factors at Marokopa}

\section{Community}

Marokopa is home to some 1,500 homeowners and residents. Residents live throughout the catchment, with several properties opposite the river-mouth. Other farming families live further inland and into the mountains. The tāngata whenua (Ngāti Peehi, Te Kanawa, Kinohaku) of the area, some of which reside as bachowners, whakapapa [link genealogically] back to Mirumiru marae (Māori Maps, n.d).

\section{Geology}

Water flow is linked to the geology, divided into 'base' and 'top' units (Figure 5, Figure 6), within the Marokopa catchment. Erosion has exposed Triassic, and Jurassic age silt-sand interbeds and Permian greywacke (Scarsbrook et al., 2008). 
These lithologies extend up to $10 \mathrm{~km}$ inland from the west Waikato coast, and between the townships of Awakino to the south and Port Waikato in the north (Stevens, 2012). National-scale folding resulted in the Kawhia syncline, followed by sandy-limestone deposition, sedimentation, and faulting. Today the Taharoa Fault Zone, Mangaohae, Marokopa, and Whareorino faults increase porosity and flow connectvity (Edbrooke, 2005). Spanning an area from Te Anga through to the Waitomo Caves and Te Kuiti regions, the limestone-dominated Te Kuiti group and its subsequent karstification has a significant effect on local hydrology (Gunn, 1978). The geology is expressed on the surface by daylit cave systems, "failed" grounds (cave system exposure due to cave roof collapse) and dolines ("tomo") (Osborne, 2002; Scarsbrook et al., 2008).

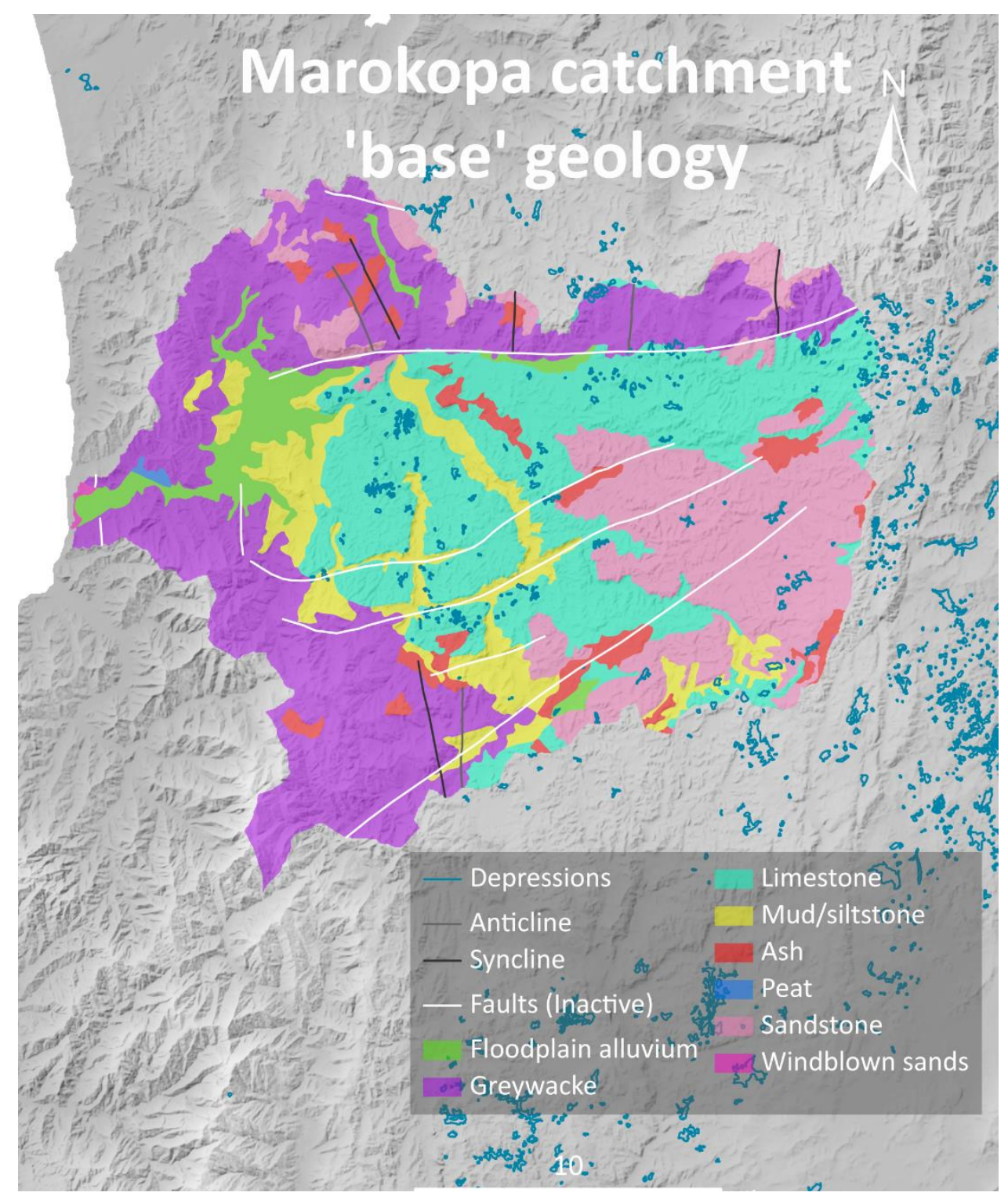

Figure 5: Marokopa 'base' catchment geology (source: LRIS, GNS Science 2008). 


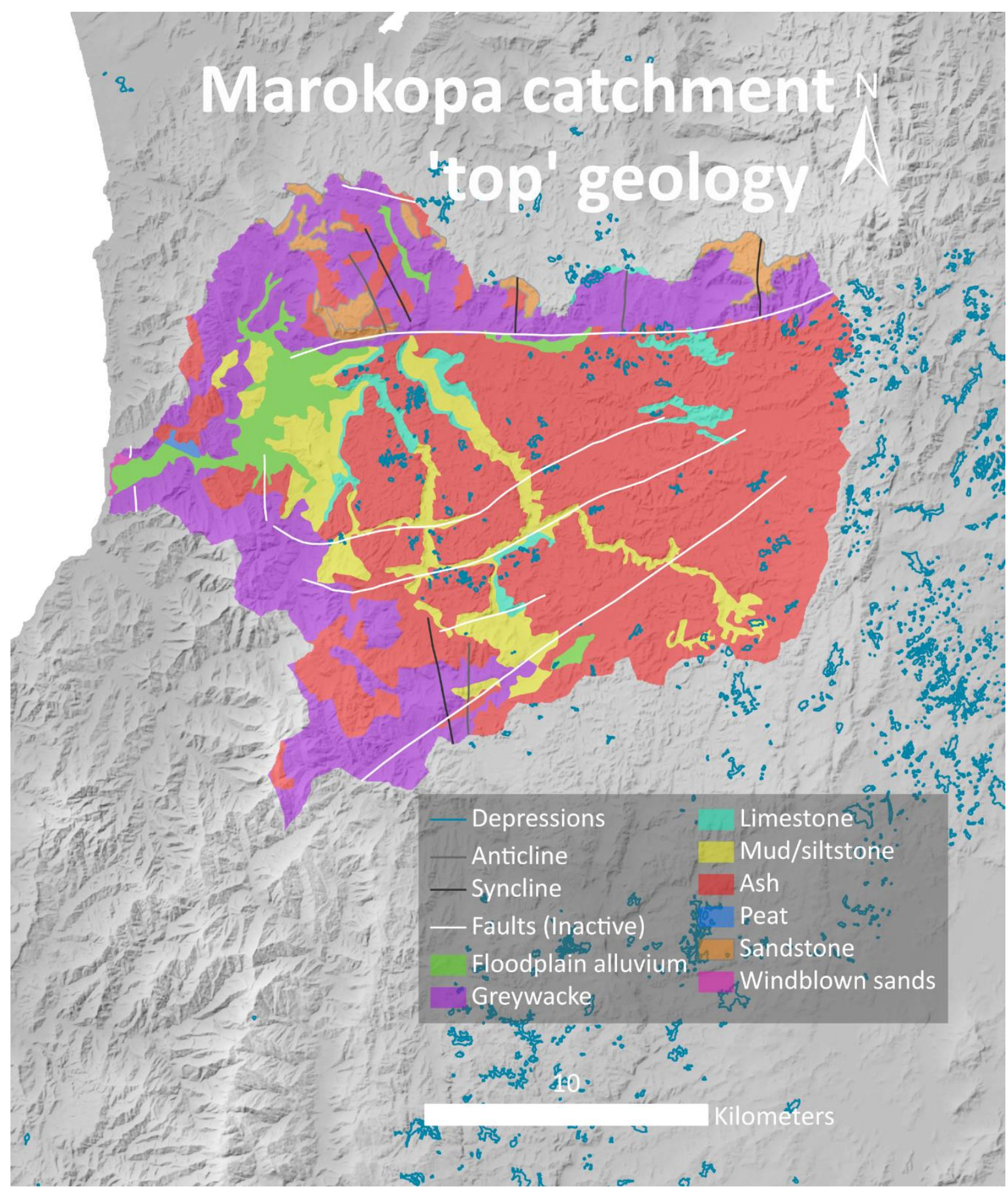

Figure 6: Marokopa ‘top’ catchment geology (data source: LRIS, GNS Science 2008).

Geomorphology

Marokopa township is on the coastal floodplain at the mouth of the meandering Marokopa River. Regionally rivers drain to the west, including the Awakino, Mohakatino, Mokau, and Tongapourutu. Steeply sided ranges are the expression of folded limestone strata. Most of the Marokopa catchment is steeply dipping $\left(21^{\circ}+\right.$, towards the north and west, south-west of the catchment) (Figure 7). The movement 
of the Marokopa fault has promoted weaknesses in the rocks that has been exacerbated by mechanical weathering (Edbrooke, 2005; Zammit, 2014).

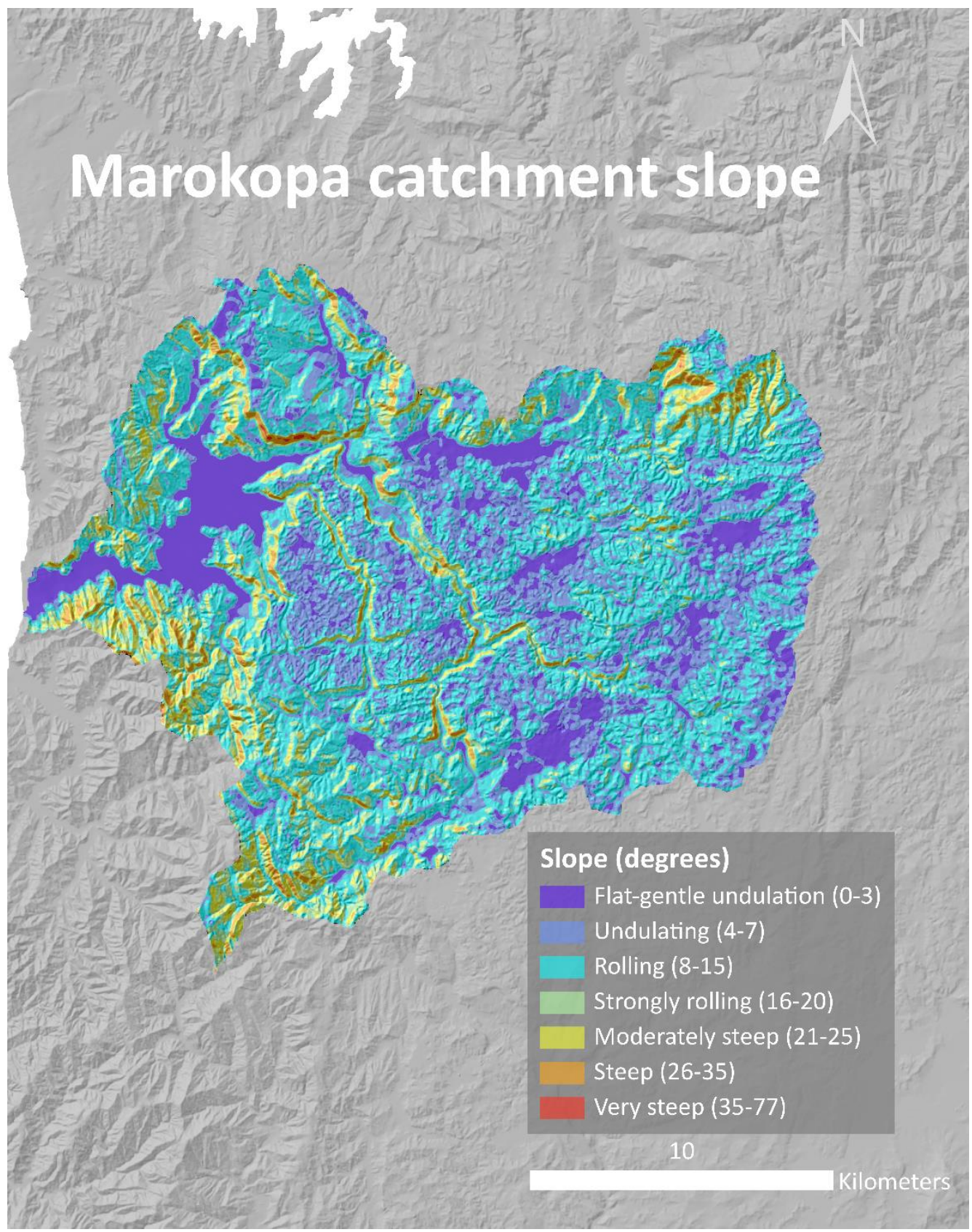

Figure 7: Slope of the Marokopa catchment (data source: LRIS).

Land Cover

Land use or cover influences the infiltration rates and connectivity of waterways and is measured in multiple ways within New Zealand (Mohammad \& Adam, 2010; Shi et al., 2007). The Land Cover Database (LCDB), uses remote sensing to classify surface features into cover "classes" (Kingi, 2014; Land Resource Information Systems, 2015; Zammit, 2014). "High Producing Exotic Grassland" (HPEG) makes up 60\% of the Marokopa catchment (Figure 8), with 
the rest largely made up of forests. A $2-5 \mathrm{~km}$ wide strip of Indigenous vegetation, (conifer, broadleaved, and beech species), covers the mountainous regions between the more populated inland and the coast. The geomorphology characterises the upper catchment with a different hydrologic environment to the lower Marokopa catchment. The lower, flatter regions consist of exotic grassland. Furthermore, only two $500 \mathrm{~m}$ and $100 \mathrm{~m}$ long strips of wetland vegetation occur within Marokopa.

\section{Soil}

Soil porosity and permeability influence the storage and passage of water through a catchment. AgResearch ${ }^{2}$ defines Marokopa village as having brown soil. In contrast, the Fundamental Soil map classifies the catchment as having a range of soil types, with moderately to poorly draining soils (Figure 9) (Newsome et al., 2008). Mottled Orthic Brown (Marokopa hills) soils have vast geographic extent, are largely variable, and well-drained (Hewitt, 1993). Silt/clay soils (Marokopa floodplains) are frequently saturated but have slow infiltration rates. Allophanic (upper catchment) soils have low erodibility, permeability, high water holding capacity, and good drainage (Hewitt, 1998b). Moreover, loam soils also have high water storage but poor drainage while peat soils are organic-rich soils. Recent soils also have high water holding capacity but also the potential for erosion and are found on steep slopes (Hewitt, 1998b). Bed rock (with little to no soil) is found near the coast and is impermeable and therefore has low water holding capacity (Ballinger, 2011; Houlbrooke \& Monaghan, 2009; Irrigation New Zealand, n.d.; O'Leary, 2010). Soils largely reflect the underlying geology, as they generated from basement weathering (Humphreys \& Wilkinson, 2007). Acidic orthic allophanic soils overlay ash geology and orthic brown soils overlay mudstone. This pattern is consistent with waterways, which have eroded down into the lower geology. Future research should include ground-truthing studies or land cover and geology, not undertaken here due to time constraints.

\footnotetext{
${ }^{2}$ Previously New Zealand Pastoral Agriculture Research Institute Limited.
} 


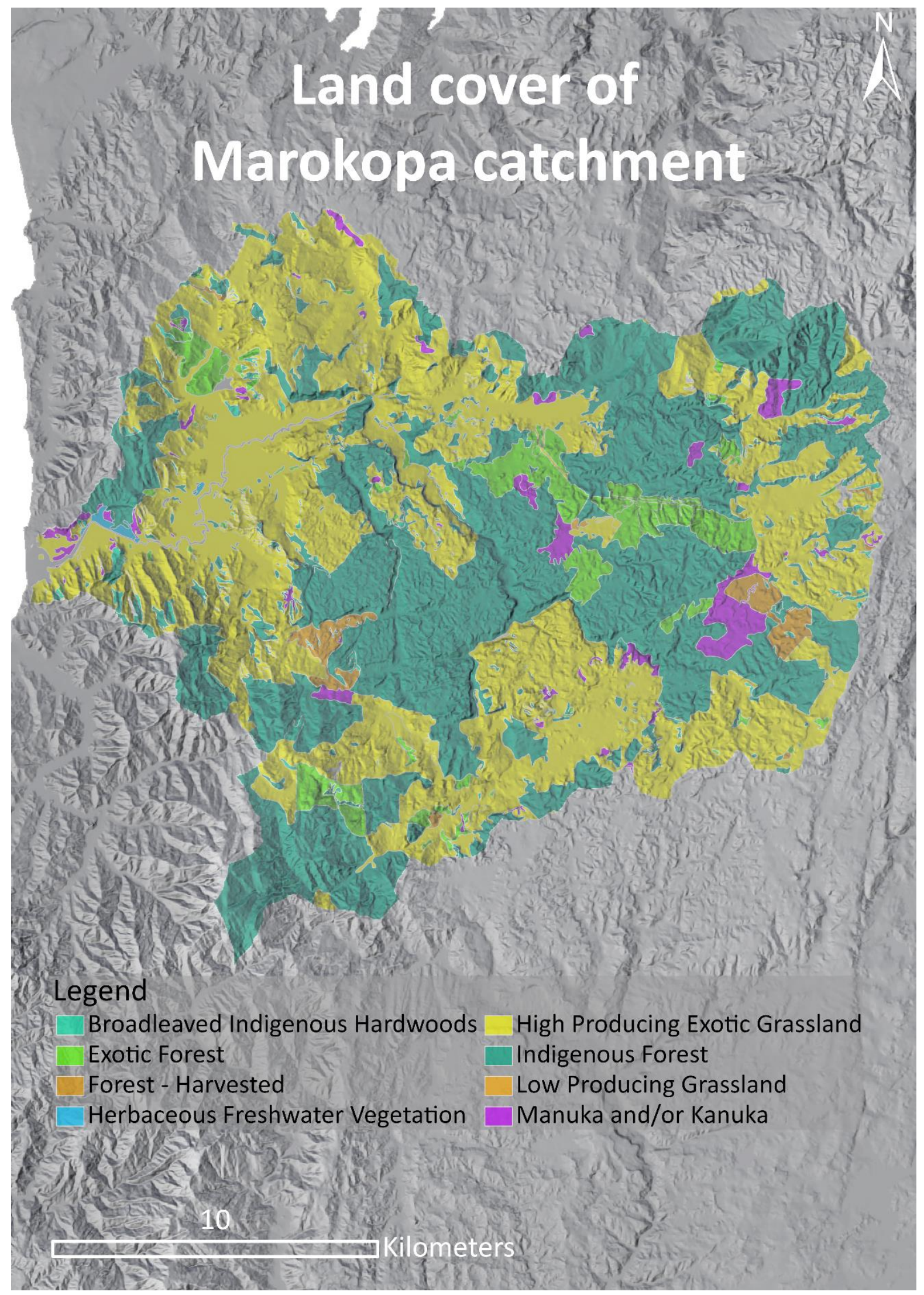

Figure 8: Land cover of the Marokopa catchment (data source: NZLRIS). 


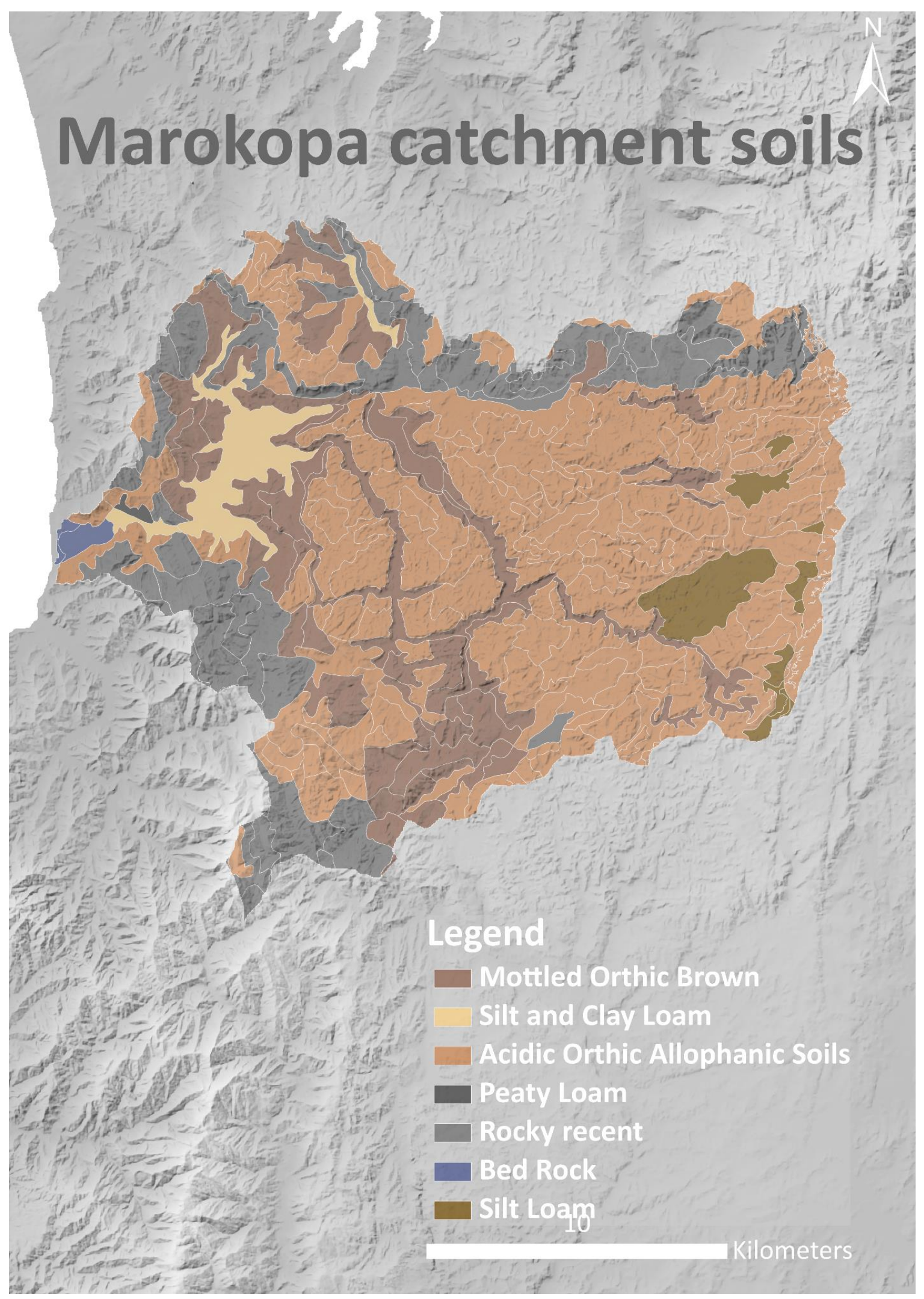

Figure 9: Marokopa catchment soils (data source: NZLRIS).

Climate

The climate in Marokopa is temperate with high precipitation, minimum temperatures, and humidity relative to the rest of the Waikato region (Chappell, 
2014). Extreme differences between the summer and winter climates occur, resulting from the larger regional westerly climate and ocean dynamics, further detailed below.

\section{Wind}

The southern hemisphere's tropical cyclone season lasts from November to April (Chappell, 2014). Strong easterly winds and heavy rainfall characterise storms of tropical origin. The climate of the Waikato's west coast is dominated by the cyclonic systems that traverse the Tasman Sea (Chappell, 2014). Maximum daily windspeeds, taken from the nearest station in Awakino were on average 14.7 $\mathrm{m} / \mathrm{s}$ with a minimum wind speed of $4.6 \mathrm{~m} / \mathrm{s}$ and maximum of $40.7 \mathrm{~m} / \mathrm{s}$. The highest average wind speeds occur from August to October (Chappell, 2014).

\section{Rain}

A combination of topography and predominate north-easterly wind influence the rainfall of south-west Waikato rainfall (Figure 10). The 30-year median annual precipitation average from 1981 to 2010, shows that Marokopa has relatively high precipitation when compared with the rest of the Waikato region, at $\sim 2000 \mathrm{~mm} / \mathrm{yr}$. However, residents report that both drought and extreme rainfall events can occur in summer.

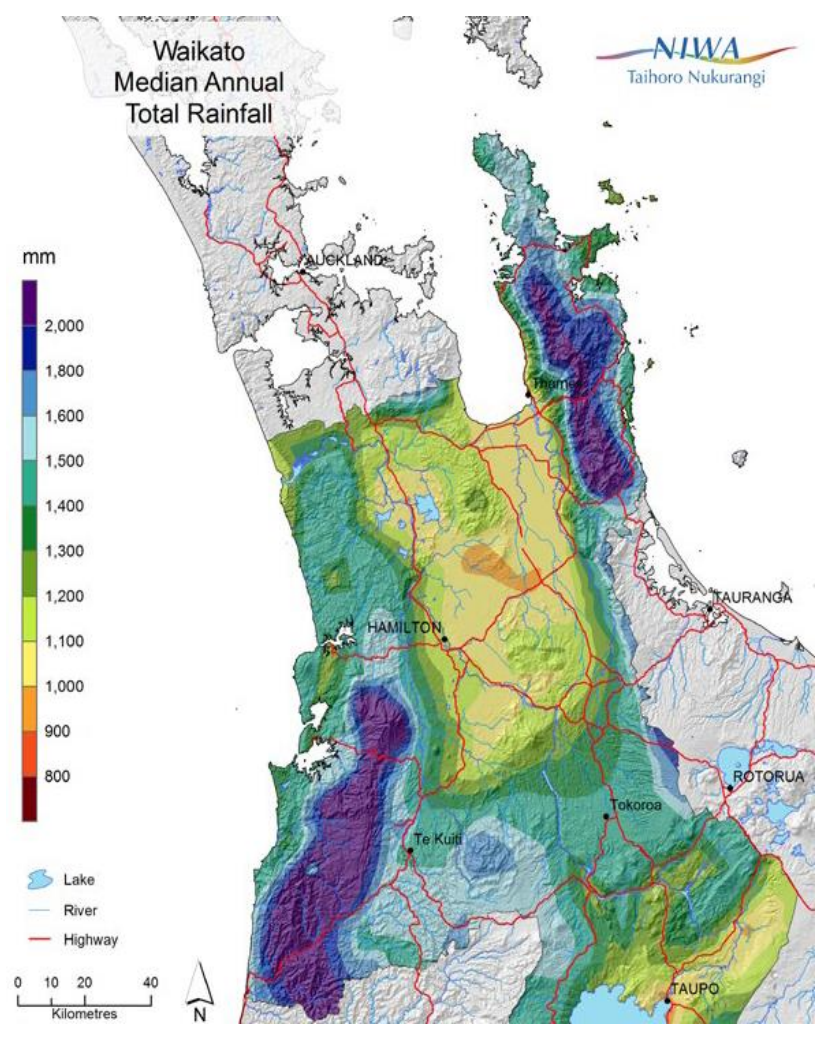

Figure 10: Map of rainfall across Waikato (Chappell, 2014). 
Rain is most intense over the mountainous Waitomo region, where orographic precipitation occurs due to the uplifting of saturated westerly winds. Monthly precipitation peaks in July and declines across January and February. Large rainfall events occur throughout the year, including several events of over $25 \mathrm{~mm}$ per hour (Figure 11, Figure 12) (Chappell, 2014; Wang et al., 2015).

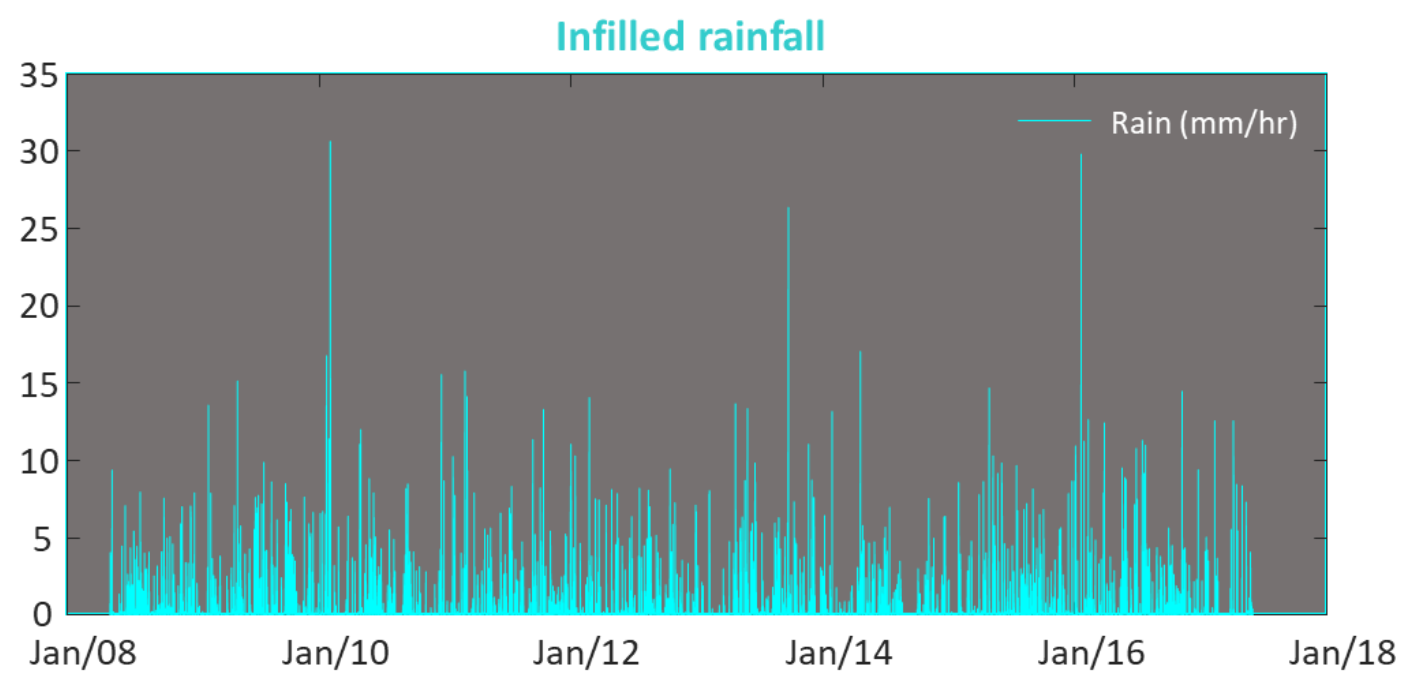

Figure 11: Infilled rainfall, from 2008 to 2017.

Historical and RCP8.5-projected rainfall intensity recurrence intervals (RI) were compiled for Marokopa (Figure 12, Table 1). The rainfall depth for a 50-year recurrence interval for a 24 -hour period is $\sim 6 \mathrm{~mm} / \mathrm{hr}$ while, for the high emissions scenario of the same period, it is slightly higher at $\sim 7 \mathrm{~mm} / \mathrm{hr}$. For the $1 \mathrm{hr}$ period it increases from $45 \mathrm{~mm} / \mathrm{hr}$ (current) to $60 \mathrm{~mm} / \mathrm{hr}$ (future). For the 100-year recurrence interval, the 24-hour rainfall increases from $6.4 \mathrm{~mm} / \mathrm{hr}$ (current) to 7.8 $\mathrm{mm} / \mathrm{hr}$ (future). For the 1 hour the rainfall intensity changes even more, from $\sim 50.1$

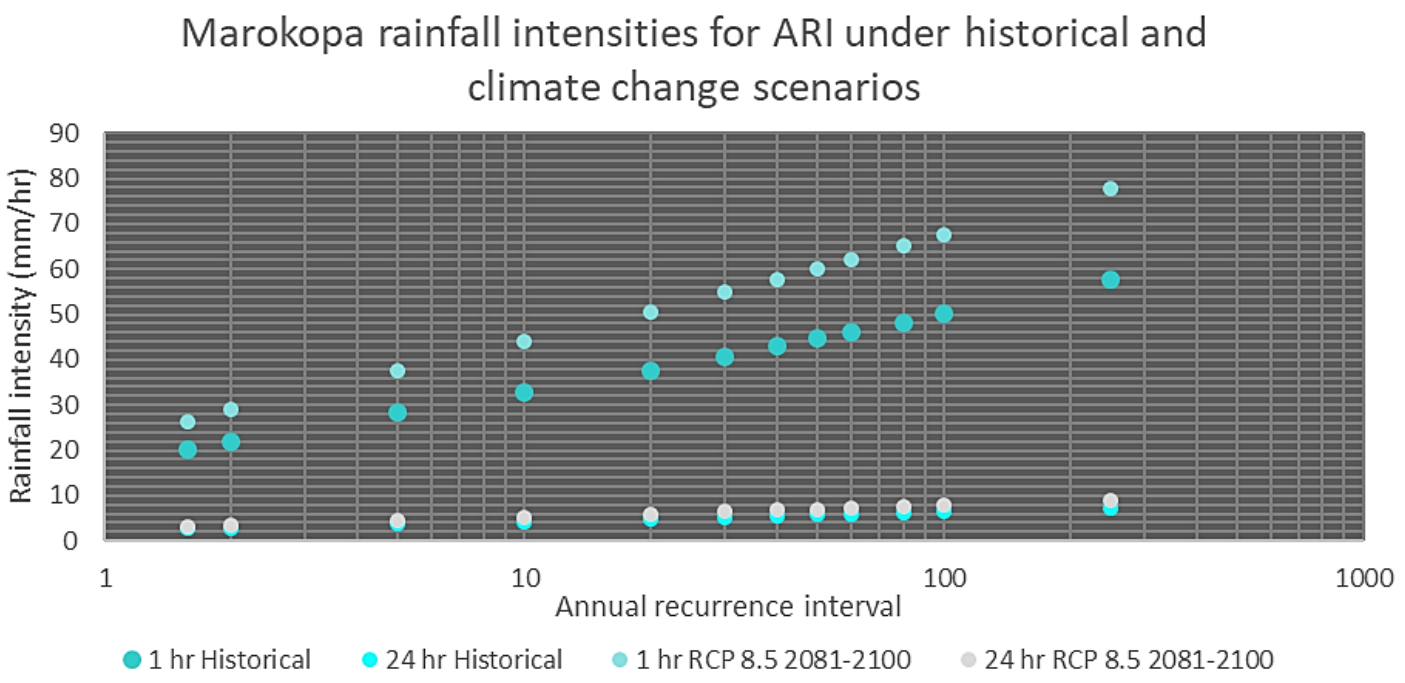

Figure 12: Marokopa rainfall recurrence intervals for historical data (data source: NIWA). 
$\mathrm{mm} / \mathrm{hr}$ (current) to $67.6 \mathrm{~mm} / \mathrm{hr}$ (future) (National Institute of Water and Atmospheric Science, 2017).

Table 1: Rainfall recurrence intervals for the Marokopa region (data source: NIWA).

\begin{tabular}{|c|c|c|c|c|c|c|}
\hline \multicolumn{7}{|c|}{ Rainfall intensities ( $\mathbf{m m} / \mathrm{hr}$ ): Historical Data } \\
\hline ARI & $\mathbf{1 0 m}$ & $\mathbf{1 h r}$ & $\mathbf{1 2 h r}$ & $\mathbf{2 4 h r}$ & $\mathbf{4 8 h r}$ & $\mathbf{1 2 0 h r}$ \\
\hline $\mathbf{1 . 5 8}$ & 56.1 & $\mathbf{2 0 . 2}$ & 4.31 & $\mathbf{2 . 7 1}$ & 1.67 & 0.861 \\
\hline $\mathbf{2}$ & 61.3 & 22 & 4.68 & 2.94 & 1.81 & 0.932 \\
\hline $\mathbf{5}$ & 79.1 & 28.2 & 5.94 & 3.72 & 2.29 & 1.17 \\
\hline $\mathbf{1 0}$ & 92.6 & 32.9 & 6.88 & 4.3 & 2.64 & 1.35 \\
\hline $\mathbf{2 0}$ & 107 & 37.7 & 7.85 & 4.9 & 3.01 & 1.53 \\
\hline $\mathbf{3 0}$ & 115 & 40.7 & 8.44 & 5.26 & 3.23 & 1.64 \\
\hline $\mathbf{4 0}$ & 122 & 42.9 & 8.87 & 5.52 & 3.38 & 1.72 \\
\hline $\mathbf{5 0}$ & 127 & 44.6 & 9.2 & 5.73 & 3.51 & 1.78 \\
\hline $\mathbf{6 0}$ & 131 & 46 & 9.48 & 5.9 & 3.61 & 1.84 \\
\hline $\mathbf{8 0}$ & 138 & 48.3 & 9.92 & 6.17 & 3.78 & 1.92 \\
\hline $\mathbf{1 0 0}$ & 143 & 50.1 & 10.3 & 6.39 & 3.9 & 1.98 \\
\hline $\mathbf{2 5 0}$ & 165 & 57.6 & 11.7 & 7.28 & 4.44 & 2.25 \\
\hline \multicolumn{2}{|c|}{ Rainfall intensities (mm/hr): RCP8.5 for the period $2081-2100$} \\
\hline ARI & $\mathbf{1 0 m}$ & $\mathbf{1 h r}$ & $\mathbf{1 2 h}$ & $\mathbf{2 4 h r}$ & $\mathbf{4 8 h r}$ & $\mathbf{1 2 0 h r}$ \\
\hline $\mathbf{1 . 5 8}$ & 73.4 & 26.4 & 5.2 & 3.2 & 1.92 & 0.961 \\
\hline $\mathbf{2}$ & 80.6 & 28.9 & 5.7 & 3.48 & 2.1 & 1.05 \\
\hline $\mathbf{5}$ & 105 & 37.5 & 7.35 & 4.47 & 2.69 & 1.34 \\
\hline $\mathbf{1 0}$ & 124 & 44 & 8.56 & 5.2 & 3.12 & 1.55 \\
\hline $\mathbf{2 0}$ & 143 & 50.7 & 9.81 & 5.94 & 3.57 & 1.76 \\
\hline $\mathbf{3 0}$ & 155 & 54.8 & 10.6 & 6.39 & 3.83 & 1.89 \\
\hline $\mathbf{4 0}$ & 164 & 57.7 & 11.1 & 6.72 & 4.02 & 1.99 \\
\hline $\mathbf{5 0}$ & 171 & 60.1 & 11.6 & 6.97 & 4.18 & 2.06 \\
\hline $\mathbf{6 0}$ & 177 & 62 & 11.9 & 7.2 & 4.3 & 2.12 \\
\hline $\mathbf{8 0}$ & 186 & 65.2 & 12.5 & 7.53 & 4.51 & 2.22 \\
\hline $\mathbf{1 0 0}$ & 193 & 67.6 & 12.9 & 7.8 & 4.66 & 2.29 \\
\hline $\mathbf{2 5 0}$ & 224 & $\mathbf{7 7 . 8}$ & 14.8 & 8.89 & 5.3 & 2.6 \\
\hline
\end{tabular}

\section{Temperature}

Terrestrial median annual temperatures from 1981 to 2010 are consistent across the northern Waikato area $\left(14-15^{\circ} \mathrm{C}\right)$ (Figure 13). The median summer temperature average showed that the Waikato west coast was relatively cool $\left(22^{\circ} \mathrm{C}\right)$ compared to the inland areas with Hamilton at $23.5^{\circ} \mathrm{C}$. However, over the same period, the winter median daily minimum temperature is lowest around Taupo $\left(2^{\circ} \mathrm{C}\right)$ compared to the West Coast $\left(7^{\circ} \mathrm{C}\right)$ (Chappell, 2014). Seasonal variations across Waikato are consistent, with June and February as the highest and lowest temperature months. 

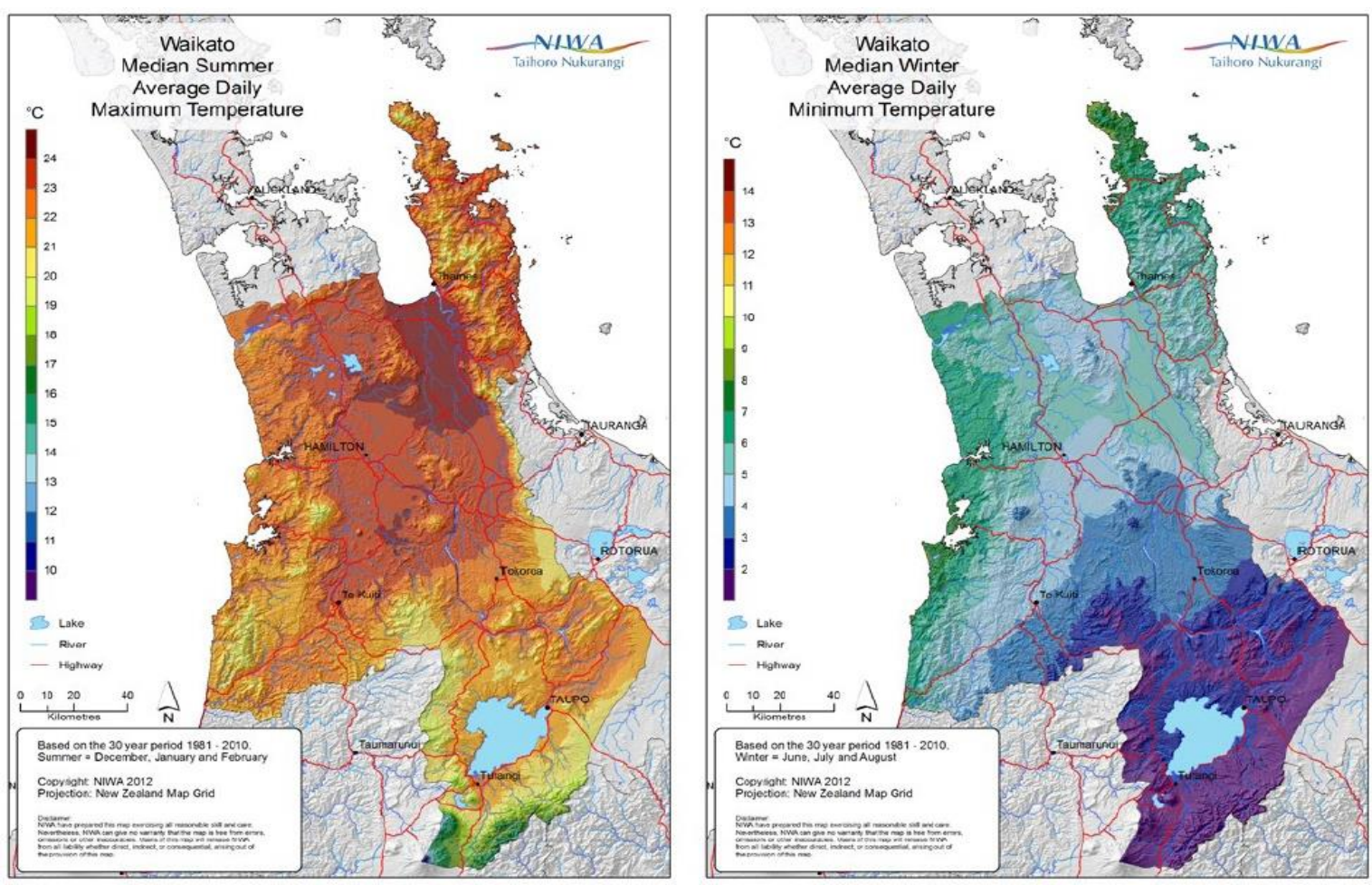

Figure 13: Mean daily temperatures with summer (left) and winter (right) over the 30-year period from 1981 to 2010 (Chappell, 2014).

\section{Solar radiation}

Sunlight hours vary spatially across the Waikato. Marokopa has a relatively low median annual sunshine amount, with $\sim 1825$ hours compared to the highest number of hours which was seen to the east of Taupo ( 2050 hours) (Chappell, 2014).

\section{Humidity}

Humidity also changes seasonally, peaking in summer and falling in winter. Te Kuiti measures a vale of $90 \%$ humidity in June, with a low of $78 \%$ across November, December and January (Chappell, 2014).

\section{Evaporation}

Evaporation is the process of water changing phase and becoming vapour. Actual evaporation values are often less than potential evaporation due to limited water availability (Chappell, 2014; Penman, 1948). The potential evaporation (PET) calculation accounts for wind speed, surface and air temperature, saturation vapour pressure, relative humidity, sunlight hours, and sky visibility. Peak evaporation is seen in January, minimum evaporation in June, with an average annual PET of 740mm (Chappell, 2014). 


\section{Ocean dynamics}

Oceanic changes significantly impact Marokopa flooding, most notably king tides and storm surge. Tidal range measurements are from Kawhia wharf, the nearest tidal record (20 km away). At high tide, the ocean is $2 \mathrm{~m}$ higher than during low tides (Atkin \& Mead, 2017). Furthermore, storm surges impact the coastal sea level in two ways, with optimum swells coming from a south-west direction (National Institute of Water and Atmospheric Science, n.d.). When the surge is incoming, the nearshore environment loses water as the pressure is lower out at sea. As the surge comes inland with the low-pressure system, the water level rises 20$90 \mathrm{~cm}$ (Stephens et al., 2015). Participants describe king-tides and storm surges as some of the most important factors in fluvial flooding. Climate change (sea level rise and more extreme rainfall) is likely to significantly increase the impact of both theses processes (Table 2).

Table 2: Changes in tidal range with increasing sea level rise due to climate change (Atkin \& Mead, 2017).

\begin{tabular}{|c|c|c|c|}
\hline & Current $(\mathrm{m})$ & SLR: $0.5 \mathrm{~m}$ & SLR: $1 \mathrm{~m}$ \\
\hline Maximum tidal height & 1.26 & 1.76 & 2.26 \\
\hline Estimated storm tide range & $1.37-2.07$ & $1.87-2.57$ & $2.37-3.07$ \\
\hline
\end{tabular}

Long waves (short-period tidal waves) at Kawhia have a period of two hours, instead of the 12-hour period of standard tides, and can increase the likelihood of bank breaching waves at Marokopa by exacerbating the effects of high tides and storm surges (Stephens et al., 2015). Overlying these processes are the larger-scale relative mean sea level changes which have both seasonal and long-term trends with summer sea levels $\sim 50 \mathrm{~cm}$ lower than winter (Stephens et al., 2015). While sea level rise varies regionally, due to sedimentation and tectonics, the two closest sea level records to Marokopa both increase (Auckland with $1.60 \pm 0.08 \mathrm{~mm} /$ year and New Plymouth with $1.37 \pm 0.16 \mathrm{~mm} /$ year) (Ministry for the Environment, 2017).

\section{Fluvial hydrology}

Marokopa river is fed by several tributaries in the upper catchment. Water use across the river varies, with tourism in the upper catchment, due to the limestone caves and structures. Other uses of the river include recreational fishing, three 
surface water abstractions, and hydro-power generation (Speedies Rd). The water resource is "nearly fully allocated" with 3.9 1/s available (Zammit, 2014). Due to this wide usage, Marokopa river has "large economic importance for the region and local community"(Zammit, 2014).

\section{Flow}

The flow characteristics of Marokopa Falls are described below. The mean flow at Marokopa Falls for the period of April 1979 to November 2018 is 4.64 cumecs, with a minimum flow of 1.29 cumecs, and a maximum of 116.57 cumecs (National Institute of Water \& Atmospheric Research, 2019). 11 events are described in more depth in Chapter 7. Flow duration curves are logarithmic cumulative frequency plots that show the proportion of time river flow is equalled or exceeded (Searcy, 1959) (Figure 14). $90 \%$ of the time flows (or $90 \%$ of flows) equal or exceed $2 \mathrm{~mm} /$ hour. There is a near-linear relationship between time and flow between 30 and $90 \%$ of the time. However, flows increase significantly when looking at the highest $30 \%$ of flows, which increase in value from $\sim 1.8(30 \%)$ to $2.4(20 \%), \sim 3.3$ $(10 \%)$ and $\sim 4.5 \mathrm{~mm} / \mathrm{hr}(5 \%)$ of flows.

Flow duration

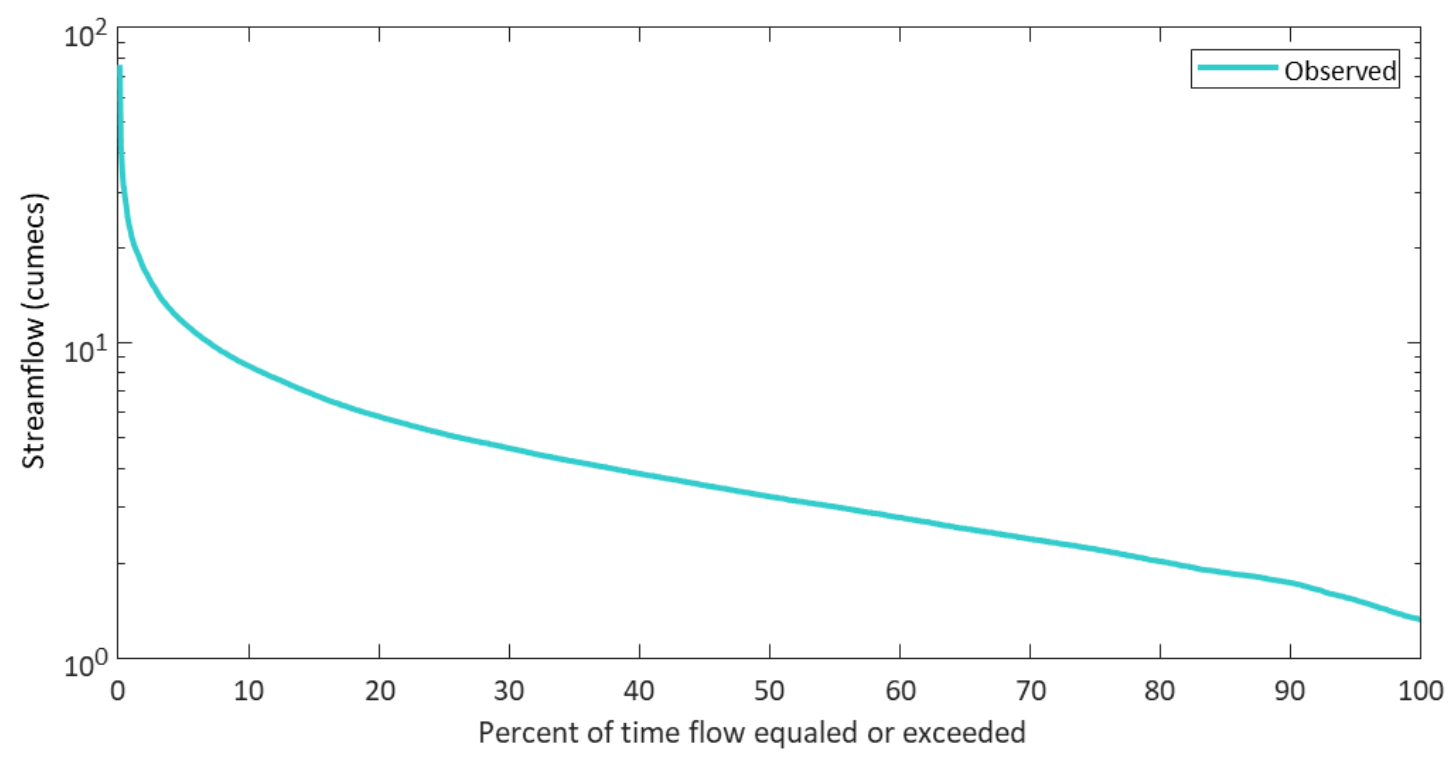

Figure 14: Marokopa Falls flow duration curve, showing the percentage of different volume flows seen at this location (data source: NIWA). 


\section{Water quality}

Water quality, as well as water quantity, are important to the local community. The water quality of the Marokopa river is partially dependent on inflows from tributaries (Land, Air, Water, Aotearoa, 2019). Water quality worsens towards the lower catchment (Figure 15). The upper catchment Mangapohue stream (4) has an "excellent" five-year median Macroinvertebrate Community (MCI) of 135.2, 29 value for taxonomic richness (5-year median), and 62.1\% EPT (macroinvertebrates sensitive to water pollution), representing a healthy environment and species diversity. Downstream at Te Anga Rd (3), the Marokopa river has a slightly lower MCI of 124.1, and an EPT of 56\%, showing a decline in water EPT richness and a "possible decline" in water quality. At Tawarau river (2), the MCI has dropped to 112.4 , with a "likely degrading" trend with a 24.5 value for taxonomic richness and $51.8 \%$ EPT. At the Speedies Rd site(1), Escherichia coli (E. Coli) bacteria has a five year median of $140 \mathrm{n} / 100 \mathrm{ml}$ in the best $50 \%$ compared with OLRS (Other

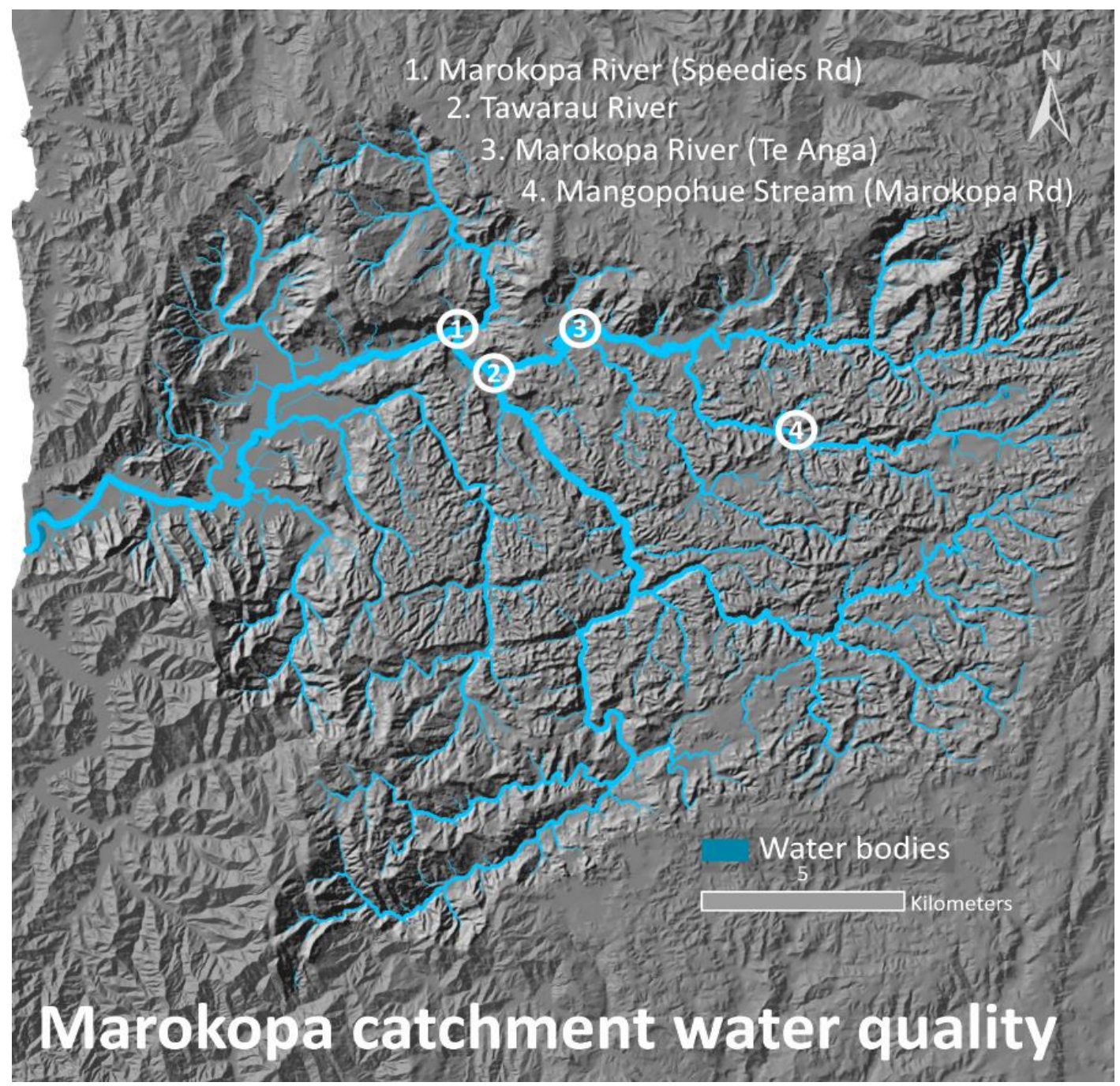

Figure 15: Water quality testing locations, numbered from lowest to highest elevation in catchment. 
Lowland Rural Sites). Clarity is "likely degrading", with a turbidity value of 4.05 NTU. Nitrogen is also "very/likely degrading" even while comparatively low compared to OLRS. Finally, dissolved phosphorus at this site is the highest, compared to OLRS, "likely degrading" but with total phosphorus in the best $50 \%$ of OLRS, and "likely improving"(Land, Air, Water Aotearoa, 2019). These water quality measurements show that as more tributaries converge, water quality worsens. This worsening is likely due to the impact of farming within the area.

\section{Estuary}

Estuaries are the link between terrestrial and marine processes. At Marokopa, the estuary is also where flooding and erosion are significant hazards. Greer et al. (2016) found that the Marokopa river has a small estuary high tide area $\left(0.6 \mathrm{~km}^{2}\right)$, resulting in significantly lower residence times compared to other west coast harbours and estuaries. The residence time is the time taken for water to leave an outlined area. High tide volume for Marokopa River estuary is $1.024 \times 10^{6} \mathrm{~m}^{3}$ and has a considered "high flow" for its size (Greer et al., 2016). During "low flows" the residence times were mostly less than 1.5 days, with some surface/edge features affecting outflow (Figure 16). The highest residence values were seen approximately $1-2 \mathrm{~km}$ up the river, possibly highlighting a shallowing in land/river gradient and a widening of the river.

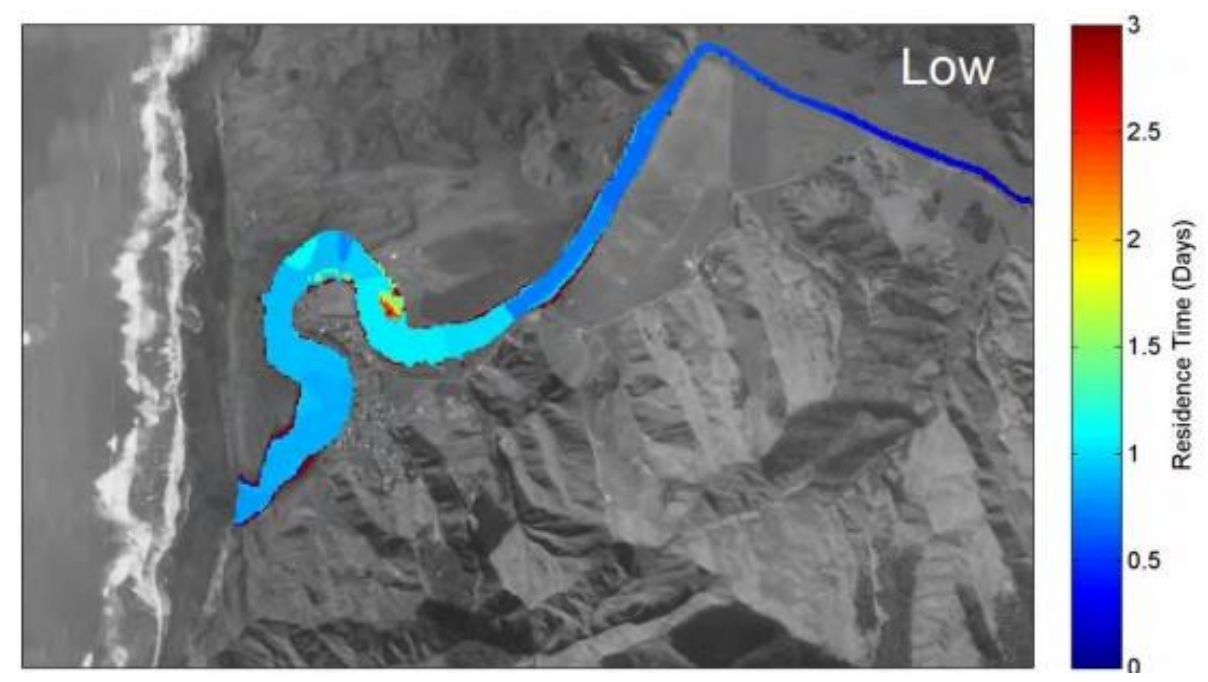

Figure 16: Residence time of Marokopa estuary under a low flow regime. Tracer released during a mid-tide range, under high tide conditions (Greer et al., 2016).

Medium flow resulted in water being flushed from the estuary in less than one day while high flows resulted in residence times of less than half a day. A 
comparison of wind strength and directions from Port Taharoa found that southwesterly scenario reduced the estuary residence time by a short two days, whereas north-easterlies reduced the estuary residence time by six days, compared with a no-wind scenario. Water residence times for the Marokopa estuary were studied under normal conditions. However, the local community state that tidal influence on Marokopa flooding is significant. No studies currently quantify the tidal influence on flooding.

\section{Conclusions}

- Marokopa has a distinct environmental and hydrological setting. Due to the combination of steeply dipping terrain at the lower catchment and karst hydrology in the upper catchment, water passes quickly through the landscape.

- Due to the largely pastoral land cover, worsening downstream water quality and large erosion events are seen throughout the region.

- Sea level rise, storm surge and tides significantly influence Marokopa flooding and erosion. 


\section{Background and literature review}

Flooding has multiple definitions, factors, and modelling approaches, which are described in this chapter using the structure below (Figure 17). Section 3.1 outlines various definitions of flooding, including quantitative and qualitative means. Following this, Section 3.2 describes the factors which influence flooding, including physical catchment features, climatic conditions, social context and flood management strategies. Finally, Section 3.3 reviews hydrological (rainfall-runoff), hydraulic (inundation) and ecosystem modelling approaches to flood risk, critiquing the different methods used.

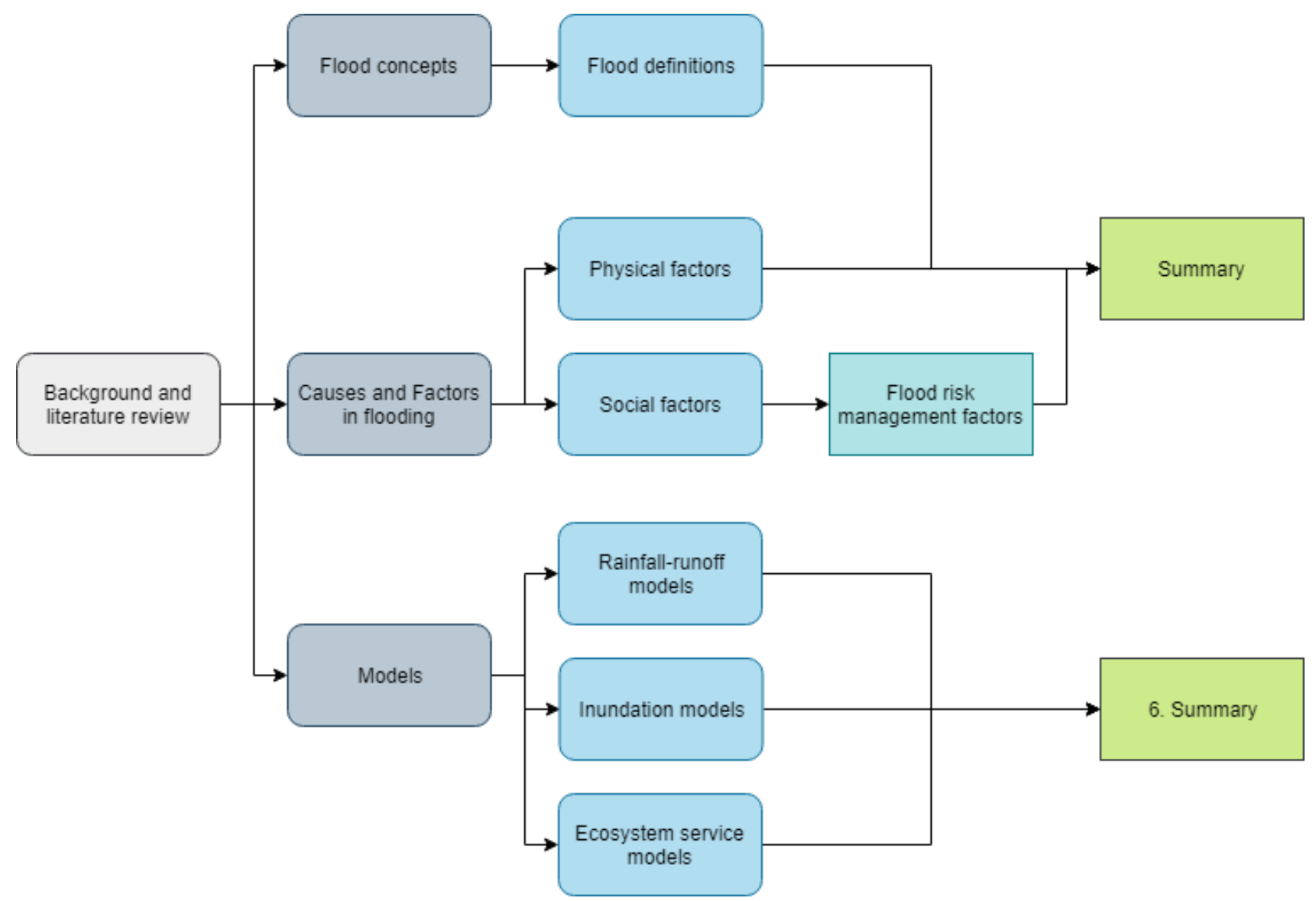

Figure 17: Background chapter overview and structure.

\subsection{Flood definitions}

Flooding is defined as a terrestrial process by some and as marine inundation to others. Marine inundation is the process of marine waters breaching nonestuarine areas and is synonymous with storm surge, tsunami, and sea level rise (Flick et al., 2012). These marine processes significantly increase the impacts of terrestrial flooding at Marokopa. Terrestrial overland flow or water moving across 
the surface of the earth also claims the descriptor "flooding". It is a scientifically described process, a lived-experience, and a life-giving ecosystem support system in some cases while being a hazard in others (Bayley, 1991; Junk et al., 1989). While this thesis defines flooding as bank-breaching inundation, this phenomenon can be quantitatively and qualitatively described. Quantitatively, flood magnitude can be defined by river flow speeds, maximum flood extent that breaches river banks (or stopbanks), the depth of flooded water or the duration of those floodwaters (Bhatt et al., 2017; Smith, 1997; Teng et al., 2017; Waikato Regional Council, n.d). Qualitatively, flood experiences have also been used to discern the vulnerability and impacts of floods on livelihoods. Such analysis allows for the communication of local problems to improve future flood protection (Fuchs et al., 2017; Hudson et al., 2019; Vojinovic et al., 2016).

\section{Flood factors}

Physical drivers such as precipitation, topography, geology, catchment characteristics, land cover, the ocean, and climate change determine event magnitude (Section 3.2.1). Moreover, socio-political measures, policies and modelling approaches aim to identify and minimise flooding vulnerability, and exposure (Section 3.2.2). Together, these physical and social flooding factors contribute to the impact of a flood event. Finally, flood risk management is both a physical and social/political construct This chapter describes the historical and modern approaches to defining flooding before reviewing hydrological (rainfallrunoff), hydrodynamic (inundation) and ES models in Section 3.3.

\subsection{Causes and factors in flooding}

Many factors contribute to the size and impact of hazards. Figure 18 outlines the factors that impact flooding within the Marokopa catchment. These factors are further detailed in the following section. Water is topographically funnelled across and underneath the earth's surface as geological layers and soil types respond in different ways. Agricultural grasses (HPEG) can cause quick runoff in some areas (Figure 8). Other land cover types such as forestry can intercept rainfall and connect it to underground storages, although these hydrological relationships depend on how land cover and soil type overlap and whether there are internal variations.

Additionally, with climate change, intense precipitation event magnitude and frequency are projected to increase locally. Moreover, tides and storm surges will 
also increase due to sea level rise. Factors that impact flooding include the physical, social factors, and the flood management strategies used. The risk of flooding is predicted based on the flood conditions themselves and our response to potential flooding.

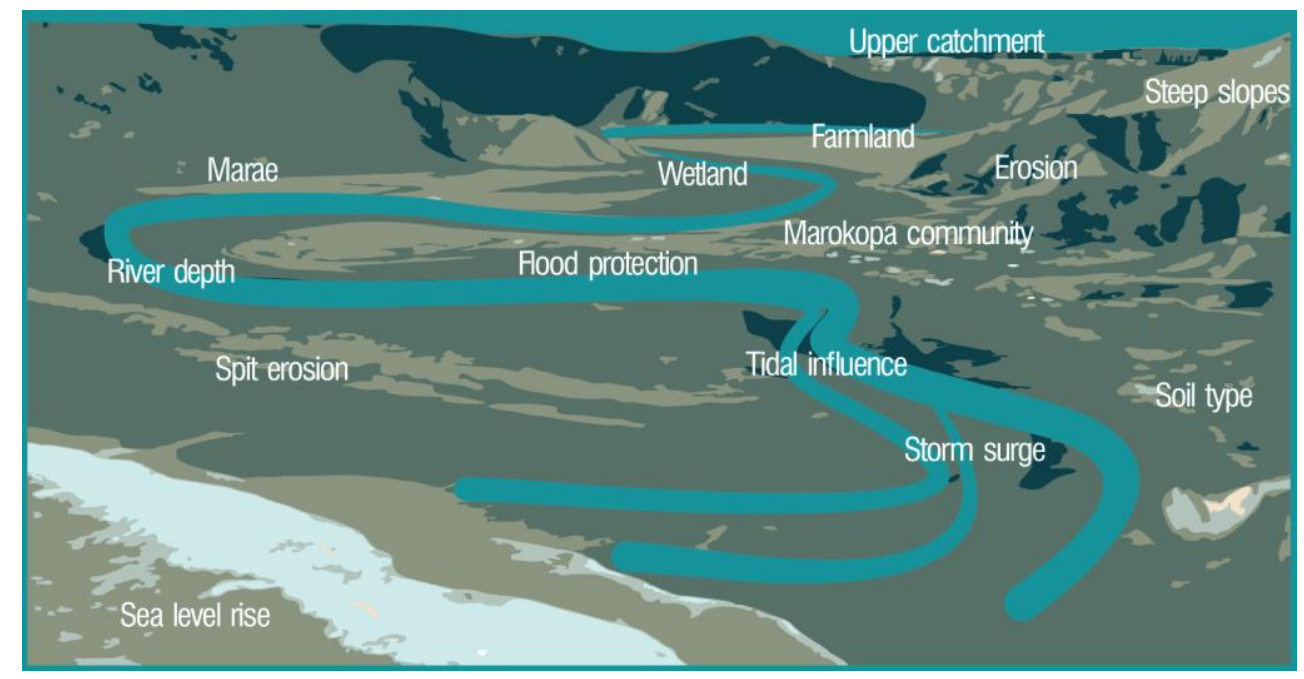

Figure 18: Marokopa, with flood factors outlined.

\subsubsection{Physical factors in flooding}

Water can take many different paths through a catchment (Figure 19). Upon precipitation, water enters a catchment's hydrological cycle and interacts with the different land covers, potentially being intercepted by vegetation, before either infiltrating or flowing over the earth's surface. Infiltration can occur anywhere and subsequently, water can take many routes. These routes are simplified into the following three. A "fastflow" component represents water which quickly enters the stream from a variety of sources. Secondly, water can travel laterally in the nearsubsurface as "throughflow" or percolates through to the lower groundwater. This lower "baseflow" eventually reconnects with the surface or ocean groundwater (Ward \& Robinson, 1990). As water returns to the surface it may collect and form

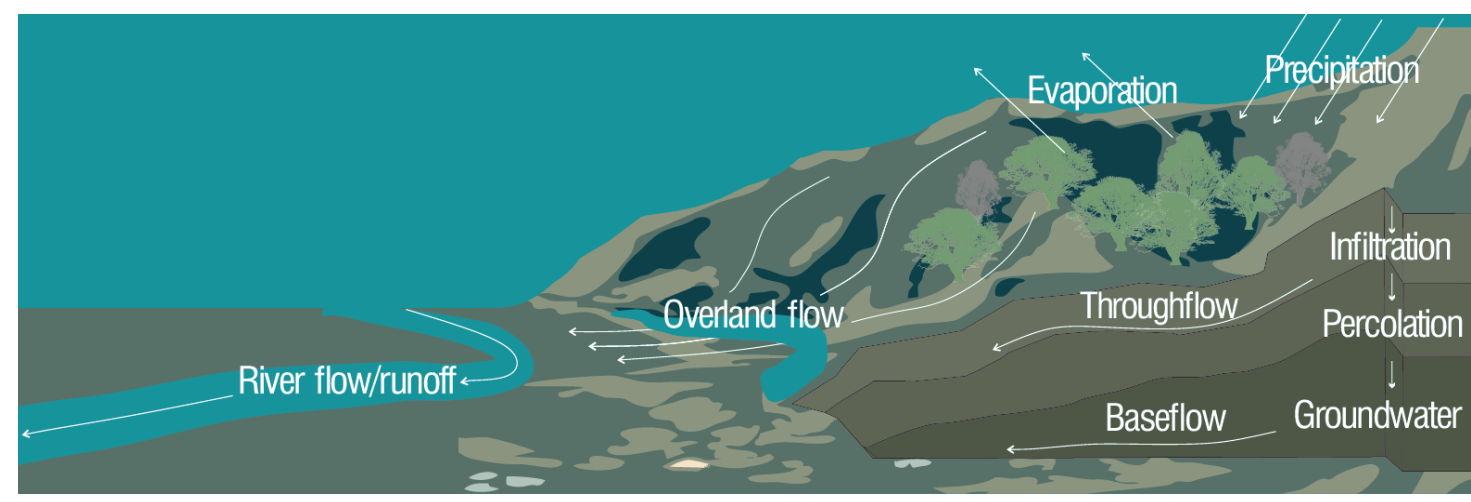

Figure 19: Water cycle with multiple, simplified pathways. 
stream networks which also connect with the ocean. Eventually, water is then evaporated and forms into clouds before precipitating again (Ward \& Robinson, 1990).

Flooding occurs when more water enters the catchment than can exit it within a certain period. This process depends on precipitation input, catchment geology, catchment characteristics, land cover, marine influence, and broader climate change impacts.

\section{Precipitation factors in flooding}

Precipitation defines the quantity of water entering a catchment, occurring though frontal, orographic, or convective systems. These systems vary in rain intensity and duration (Mosley \& Pearson, 1997). Flooding occurs through two processes, excess overland flow and bank-breaching flow. The first is due to infiltration or saturation excess caused by heavy or prolonged rainfall (Abdul \& Gillham, 1984; Ward \& Robinson, 2000). Where ground saturation reaches the surface (water table/field capacity), saturation excess overland flow occurs, highlighting the importance of antecedent conditions. If the precipitated volume is greater than what can penetrate the soil, infiltration excess hortonian overland flow occurs (IEHOF) (Mosley, 1979).

\section{Geology, topography, and soil factors in flooding}

Geology, soils, and topography determine where and how fast water flows through a catchment. Brown et al. (1999) showed the control of bedrock surfaces on flow directionality though on a larger scale the flow is determined by the catchment shape. Catchment shape and connectivity are equally important controls on runoff, with increased bifurcation resulting in flashier hydrograph response. This is exacerbated by storm tracks moving from the catchment headwaters to mouths (Jencso \& McGlynn, 2011; Ward \& Robinson, 1990). Water moving through a system is then dependent on geology and soil type (Anderson \& Burt, 1978). Limestone makes up approximately $40 \%$ of the Marokopa catchment geology and is associated with karst structures which are known for their hydrological complexity (Bakalowicz, 2005; Hartmann et al., 2017; Scarsbrook et al., 2008). Karst hydrogeology is discussed below. Additionally, unconsolidated sands increase drainage and hydraulic conductivity, while clays have many smaller pores 
that "hold on" to water (Heath, 1983). Moreover, sediment transport can exacerbate flooding, causing blockages and destruction downstream (Mosley \& Pearson, 1997).

The relative impact of topography, geology and vegetation on catchment hydrology changes throughout the year. Jencso and McGlynn (2011) found that vegetation and geology had a greater impact on flooding during drier periods and topography during wetter periods. The Marokopa catchment is impacted by both seasonal variation and the limestone-karst systems which have subsequent significant influence on the catchment's hydrological response (Mahler \& Lynch, 1999).

\section{General karst geology and hydrology}

Various karst landforms have formed throughout the Marokopa catchment as carbonate rock has dissolved in reaction to carbonic acid exposure (Scarsbrook et al., 2008). Several levels of landscape features influence the hydrologic response of a karst system. These include whether water enters the karst landscape through autogenic or allogenic means, and the surface (exokarst), near-surface (epikarst) and subterranean (endokarst) landforms it percolates through. Finally, karst hydrology is dependent on three main throughflow mechanisms: shaft flow, throughflow and vadose seepage.

Autogenic hydrological system runoff is due to direct precipitation onto the limestone, and diffuse recharge (Gunn, 1983). In contrast, allogenic system runoff is from nearby non-karst systems and is indicative of point-source infiltration, which passes through the ground in a series of integrated but discrete "pipes" (Ford \& Williams, 2007; Gunn, 1983). Marokopa catchment has extensive karst systems, which are a mixture of autogenic and allogenic systems (Figure 20).

Exokarst features within the Marokopa catchment include depressions, polygonal karsts, solution dolines ("tomo"), sinkholes and cockpits which have the potential to develop concentrated autogenic streams, flaggy limestone and protruding forms (Williams, 2004). Endokarst structures in the area include large caves and crevices. Such structures together impact and are impacted by the hydrology of the area (Chinarro, 2014). Broadly, karst hydrology is not dissimilar to other geological systems, although karst systems tend to be more complex and are usually recharged in two ways, diffuse infiltration through narrow openings 
resulting in slow two-phase flow and rapid concentrated infiltration due to bigger fractures (van Beynen et al., 2011).

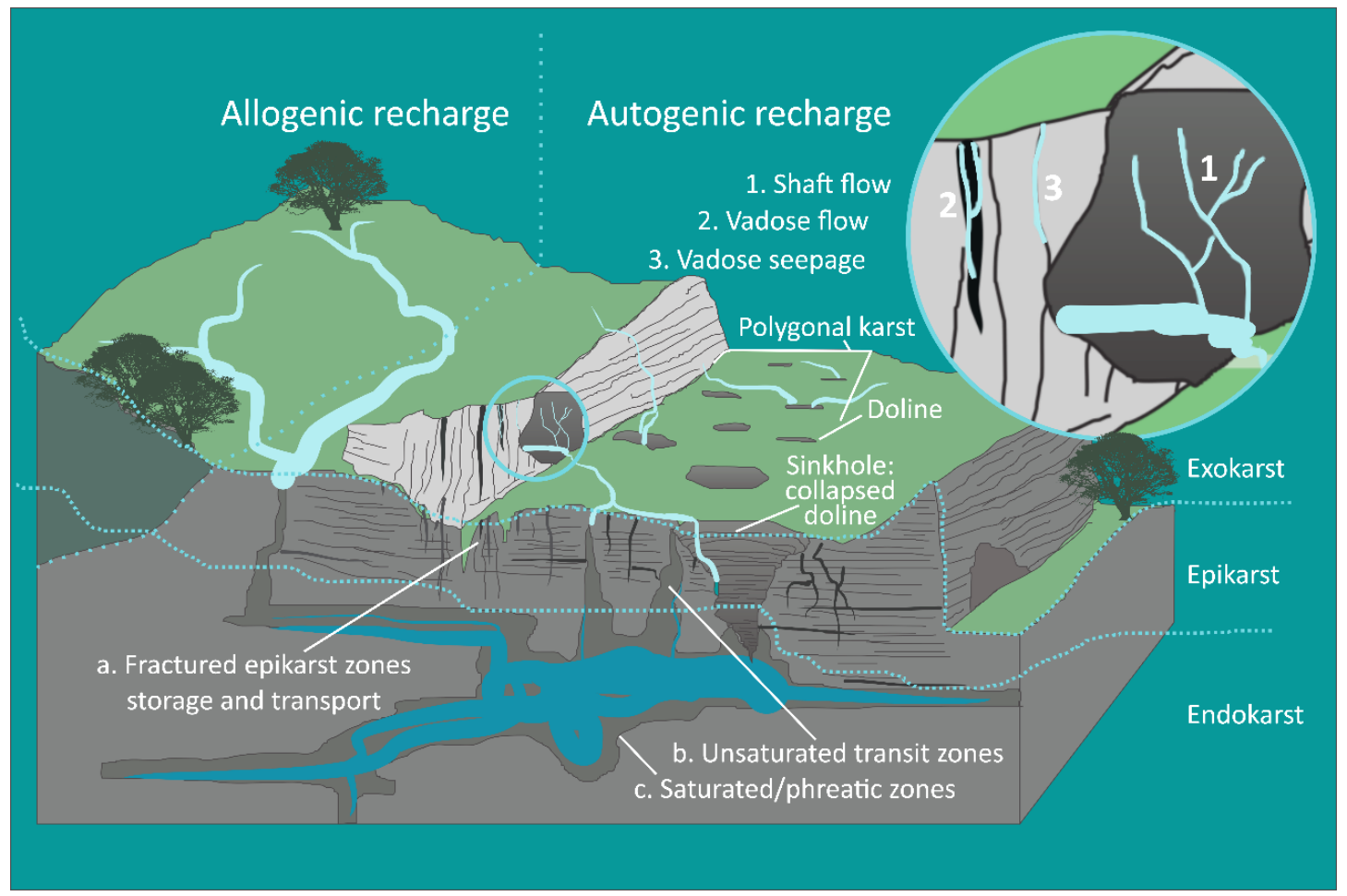

Figure 20: Different scale karst landforms, recharge types and flow paths.

Karst researchers generally acknowledge three throughflow zones (not including the superficial recharge areas). First, the fractured epikarst zone which has significant storage and water transport. Below this, there is typically the unsaturated transit zone which provides rapid vertical infiltration. Underneath this is usually a network of hierarchical saturated/phreatic zones that are filled with water (Chinarro, 2014). This last zone can drain quickly, depending on the reservoir connectivity, but also helps to maintain baseflow storage and flow throughout drier periods (van Beynen et al., 2011).

\section{Marokopa catchment karst geology and hydrology}

The water moving between karst throughflow zones is generally further classified into three types, based on the structures which transport the water (Gunn, 1983). The first is shaft flow, where meteoric water runs down cave walls; this makes up the largest percentage of flow processes in Waitomo (Gunn, 1983). The second throughflow mechanism is vadose flow, which is meteoric water moving vertically through fractures. Thirdly, vadose seepage defines water that moves through smaller joints and makes up the smallest flow output in the MarokopaWaitomo area (Gunn, 1983). 
Karst landscapes significantly impact catchment hydrology (Ford \& Williams, 1989). The Waitomo karst consists of heterogeneous structures and is defined as an interstratal karst, with sandstone and siltstone interbedded with limestone (Edbrooke, 2005). Feeney (1977) suggested that the karst formed with cap rock dissolution. This was followed by landscapes forming depressions where streams flowed preferentially due to an impermeable subsurface (Figure 21) (Hawke, 1982). As the karst system developed, depressions grew, and complexity increased, with further clustered dolines forming due to the dissolution of joints (Gunn, 1978). As dissolution continued, karst systems and valleys grew vertically and laterally until bounded by impermeable surfaces (Hawke, 1982).

Karst hydrology can be defined using many methods. Chemical tracers were used in the upper Marokopa catchment to determine the permeability and resulting flows through the conduit-karst system (Gunn, 1978). Results found that overland flow was insignificant, and that subcutaneous (beneath ground surface) flow was more significant than throughflow for vertical movement. Gunn (1983) describes the system as conduit-dominated, although without allogenic systems. This meant that near/surface water concentration largely impacted underground flow rates.

Comparison of upper catchment hydrographs showed that the rapid discharge of subcutaneous flow and upper-soil throughflow result in flashy 'non-karstic' hydrograph for surface streams (Williams, 1983). In contrast, lags of 2-14 weeks between precipitation and cave percolation rates were found using crosscorrelation. Furthermore, some sites may hold water in network fissures, and therefore not correlate with rainfall events (Williams, 1983). The Waitomo karst system has a staggered-discharge, with fast and lagging outflow mechanisms, resulting in sustained baseflow at some sites. After large floods events, water is held in joints (after percolating down to areas to impermeable areas, and depressions (Williams, 1983). 


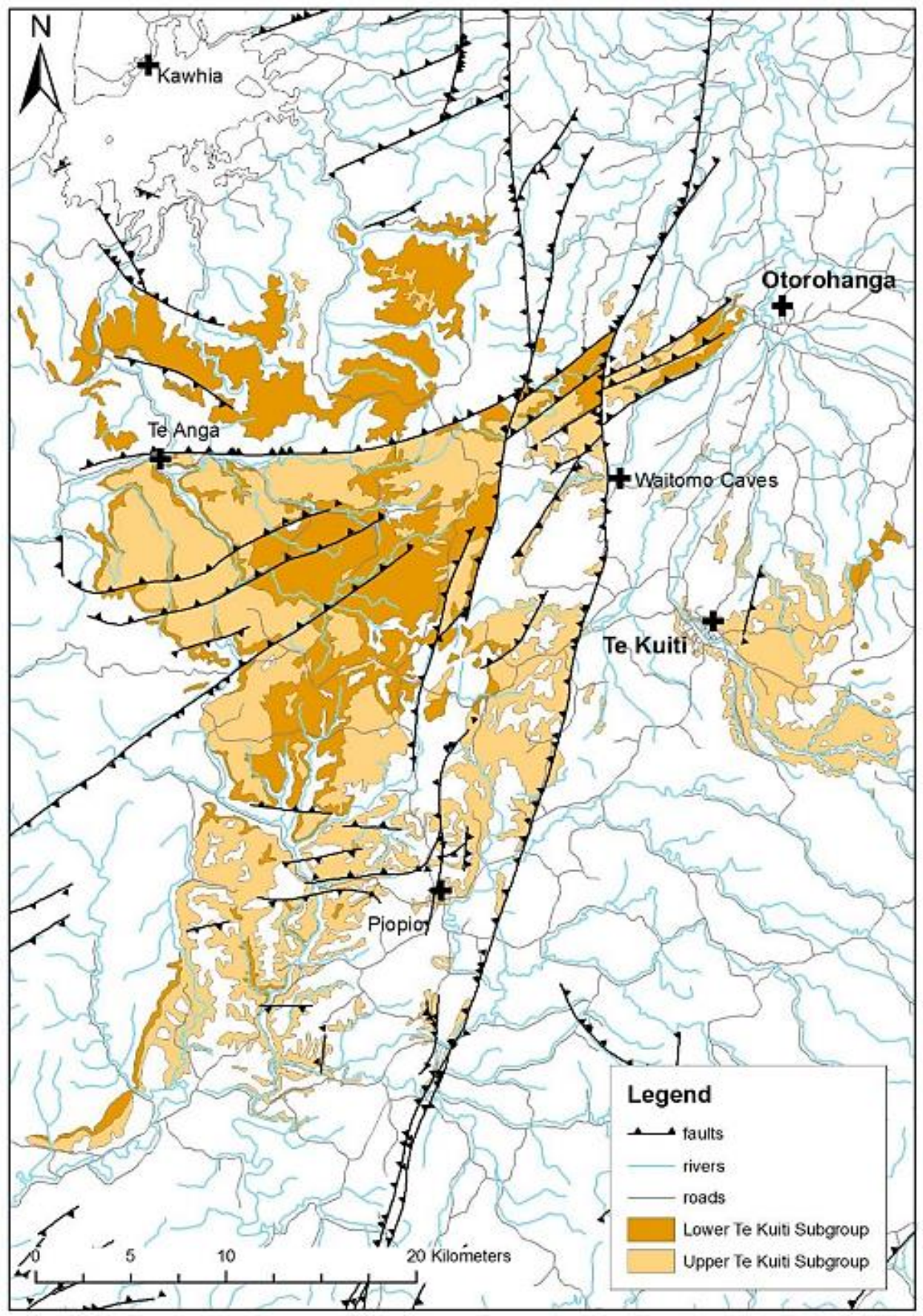

Figure 21: Te Kuiti limestone/karst structures (Zammit, 2008).

\section{Land cover factors in flooding}

The dominant land covers within the Marokopa catchment, forested and pastoral land, impact catchment hydrology in different ways. Vegetation intercepts precipitation (reducing peak flow), connects storage (draining water through root systems) and increases evapotranspiration (Cameron, 1963; Ward \& Robinson, 1990; Watson \& Mardern, 2004). In contrast, exotic agricultural grasses are more susceptible to extreme conditions and compaction, which increases sediment 
transport and decreases vegetation (Marshall et al., 2009; Singleton \& Addison, 2000). As land use significantly influences hydrology and flood potential, so does any change in land use.

\section{Land cover change influences flooding}

Through deforestation, urbanisation, and wetland drainage; land use change impacts catchment hydrology (O'Connell et al., 2007). Deforestation causes higher erosion rates, leading to accretion (sediment accumulation) and subsequent flooding (Gomez et al., 1998; Marden et al., 2005). While not documented in the literature of the area, anthropogenic drainage systems are likely present due to the reclaimed wetland of the farmland closest to the river. Further agricultural development such as channel straightening and restriction, seen in Marokopa, decreases the biodiversity and sustainability of meandering streams while increasing surface runoff (Kozlowski, 2002; O’Connell et al., 2007).

\section{Tidal/Sea Level factors in flooding}

Tides, storm surge, and sea level impact flooding to different degrees; they also influence and intensify each other. Wolf (2009) outlined the effects of semi-diurnal tidal and quasi-periodic storm surge on flooding, including increased coastal water depth, subsequent extremes in wave height, and the overtopping of flood infrastructure. King et al. (2007) used qualitative interviews with local Māori to describe the historical impact of storm surge and tsunami hazards. While accounted for in different regional plans, few structured analyses of tidal flooding within a modern, regional-resolution New Zealand context currently exist, highlighting the disconnection between a holistic socio-political awareness and physical modelling approaches, especially in regards to future environmental changes (Ministry for the Environment, 2017; Waikato Regional Council, n.d.-a).

\section{Climate change factors in flooding}

Climate scientists agree that the impacts of anthropogenic climate change are significant, but vary globally, nationally, and regionally. Using a combination of models, and greenhouse gas scenarios, global average surface temperatures are expected to be $1.5^{\circ} \mathrm{C}$ by 2100 above pre-industrial levels with atmospheric moisture, the driver of weather systems, subsequently set to increase (Intergovernmental Panel on Climate Change, 2018; Pachauri et al., 2014; Warrick 
et al., 2001). New Zealand is projected to have a $+0.7^{\circ} \mathrm{C}$ increase in minimum/mean/maximum temperature by 2040 , which may increase IEHOF through increased soil water repellency (Ministry for the Environment \& Statistics New Zealand, 2016; Müller \& Deurer, 2011). Furthermore, New Zealand extreme precipitation events are also likely to become more frequent (from 1-in-440 to 1-in$100^{3}$ or 1-in-50 year event ${ }^{4}$ by 2100 ) (Intergovernmental Panel on Climate Change, 2018; Royal Society New Zealand, 2016). Increased rainfall is likely to increase both infiltration excess flooding (increased precipitation intensity) and saturated overland flow (increased frequency). Furthermore, ground conditions will likely become more constantly saturated, increasing flood extent and duration (Ministry for the Environment, 2008).

\section{Pacific Climate Oscillations}

Pacific climate oscillations (PCO), namely the El Nino Southern Oscillation (ENSO), Southern Annular Mode (SAM) and Indian Ocean Dipole (IOD), could intensify extreme precipitation and subsequent flooding across New Zealand. However other researchers state that decadal climate systems have little effect on heavy rainfall. For example, Mullan et al. (2008) found that negative SAM and IOD can intensify storm systems over New Zealand. This could increase both extreme precipitation and storm surge events at Marokopa. Furthermore, La Nina (Positive ENSO) are $80 \%$ likely to bring above-average rainfall to the northern half of New Zealand (Mullan et al., 2008). In contrast, Dravitzki and McGregor (2011) showed the seasonal probability of extreme precipitation as independent of PCO. Due to the local-scale impacts of such systems, a comparison of PCO influence across New Zealand is required for future climate modelling/projections to create policies that account for the conditions of today and tomorrow.

\subsubsection{Social factors in flooding}

Flood vulnerability in New Zealand reflects policy decisions made at the local, regional, and national levels. However, problems in governance structures can arise in many ways. Issues include when predictions of climate change are not accurate enough, when community-governance relations are under pressure when there are differences in risk perception, or rigid rather than dynamic planning (Manning et

\footnotetext{
${ }^{3} \mathrm{RCP} 3$, a low $\mathrm{CO}_{2}$.

${ }^{4} \mathrm{RCP} 8.5$, a high $\mathrm{CO}_{2} \mathrm{RCP}$.
} 
al., 2015). Consistent and comparable analysis on larger scales, across diverse regions, including calculations of uncertainty is needed (Ministry for the Environment, 2008). A comparison of European regulatory flood risk management approaches (namely "coercive" and "cooperative") emphasised the importance of tensions between government protection and individual rights, culture, political systems, and traditions (Pottier et al., 2005). Tensions between governing bodies and community groups have also been documented at Marokopa, as well as within the development of co-management strategies (Addenbrooke et al., 2016; Blackett et al., 2010). While ecosystem services research is currently being piloted for certain services (freshwater and estuary) and specific locations within the Waikato Region, Hall et al. (2014), O'Connell et al. (2007) and Wheater and Evans (2009) call for more holistic management and modelling approaches to land use and flood risk, detailed below (Olubode-Awosola, 2017).

\section{Flood risk management - political factors in flooding}

With the impact that climate change is likely to have on extreme events, land management decisions are increasingly becoming hazard mitigation and adaptation decisions. Flood management is a social decision-making process, but it also results in physical structures. Therefore, for this review, flood risk management has been separated from the physical and social factors in flooding.

\section{Historical flood management strategies}

Global hazard management until the 1970s focused on land drainage and flood defence structures such as dams, levees and local protection, due to agricultural and food-production aspirations (Burrel et al., 2007). Through the 1980s hard engineering structural "improvements" of rivers were adopted, regardless of environmental impact and flooding was addressed individually (O'Connell et al., 2007; Tunstall et al., 2004). While "Hard engineering" approaches are necessary in some circumstances, they have globally been found lacking as they resolve only the outcomes of flooding, cause a false sense of security or continuity and often have unknown negative impacts (Ballinger, 2011; Dahm \& Gibberd, 2018; van Ogtrop et al., 2005). Mathematical modelling of flood risk has increasingly become more popular, mirroring environmental and societal values. This societal change introduced "soft engineering" approaches, in contrast to "hard" drainage and flooding control schemes, supplementing or replacing such structures with green 
infrastructure. (Hermans, 2018). "Soft" approaches include wetland restoration and planting. Finally, the 1990s brought a more holistic approach to land-water management, spatially and temporally. Modern approaches build on this, with policies that engage with local communities and focus on working with the changing environment (Kreibich et al., 2015; McEwen et al., 2017; Taylor, 2007; Tunstall et al., 2004).

\section{Current flood management strategies}

Current flood protection strategies range from mitigation to adaptation; structural to non-structural measures; are applied at different temporal or spatial scales; and across economic, social, and environmental themes. These approaches include the protection of property, the adaptation of settlements and managed retreat (Appendix C) (Hart, 2011). Flood management strategies can be categorised into physical approaches to minimise event magnitude, while others focus on flood vulnerability.

Schemes to reduce the flood hazard include source control, reducing runoff through afforestation, recharge or increasing permeability, increasing drainage systems and storage, increasing river capacity, dams, dykes, and flood embankments (Associated Programme on Flood Management, 2016). Strategies to reduce flood vulnerability and exposure include rezoning or redevelopment of land use, policy/housing and building codes, information sharing, and engagement. The World Meteorological Organization (2009) outlines the challenges within different flood mitigation and adaptation strategies, namely community impact, urbanisation, risk perception, climate variability and holistic-environment ecosystem-service approaches.

\section{Summary: Flooding hazard and flood factors}

Flood hazard research is wide-ranging, including hazard description, flooding factors and modelling approaches. Flood factors include precipitation, geology, topography, catchment characteristics, land use, marine impacts, climate change, and the impact of people. Flood hazard research often focuses on catchmentsystems, land use, and flood hazard mitigation. Flood management strategies have changed over time from more independent, agriculturally-focused schemes to holistic models of flood risk that account for environmental sustainability. Methods 
used to mitigate and adapt to flood risk can be categorised by their structure, impact on environmental/social/economic systems, or temporal and spatial resolution. Gaps in flood hazard research exist in determining flood impacts and which factors have the most significant importance spatially and temporally. Such factors also need to be considered when modelling, depending on the different methods used to simulate the flood hazard.

\subsection{Hydrological, hydrodynamic, and ecosystem service models}

Models are used to represent, understand, test, and forecast scenarios and systems for the improvement of management or decision making, such as for flood mitigation and adaptation (Beven, 2012; Ward \& Robinson, 2000). This thesis explores traditional flood modelling approaches and places flow peak and preliminary flood inundation outputs within a holistic ecosystem-service framework. Traditional modelling techniques include empirical, physically-based, deterministic, and stochastic methods at lumped or distributed spatial scales (Teng et al., 2017). Physically-based flow models can be broken down further into hydrological and hydraulic models (Jackson et al., 2013; Lane, 1998; Salvadore et al., 2015; Sharps et al., 2017). In contrast, ecosystem service models look to evaluate the benefits and values of ecosystems including flood mitigation, erosion, sediment delivery agricultural productivity, and water quality. While traditional inundation models outline current and future flooding risks, placing such information within an ecosystem service framework allows for a more holistic, contextualised, and integrated modelling output.

\subsubsection{Flood rainfall-runoff and inundation modelling}

Both hydrological and hydraulic models are needed to outline the flood risk at Marokopa within this thesis, with the methodologies further detailed in Chapter 4. Hydrological models simulate catchment response to rainfall events (Jaafar et al., 2015; Nourani et al., 2009; Wagener et al., 2004). We use this process to compare modelled and observed hydrographs to define flood peak volumes. In contrast, inundation models estimate the resulting runoff by predicting the spread of the rainfall-runoff-determined peak flood volume beyond the normal river channel, using dynamic flow equations (Ballinger, 2011; Benavidez, 2018; Teng et al., 2017). Both hydrological (rainfall-runoff) and hydraulic (inundation) models 
represent water in different ways and can be classified by how they represent space, processes and uncertainty. They must also be calibrated and validated.

\section{Classification of rainfall-runoff models}

\section{Spatial representation}

Models represent space to different degrees, with different models preferred due to the resolution of available data, processing efficiency, and outputs needed. Lumped models represent a characteristic using a single value extrapolated out to a wider catchment and are the most computationally efficient. (Maxwell, 2013; Pechlivanidis et al., 2014; Wagener et al., 2004). Semi-distributed models account for some spatial variation, using averaged values for sub-catchment-scale datasets (Beven, 2006). Fully distributed models aim to represent all spatial changes in the environment. For example, SWAT and Topnet use metre-scale raster data digital elevation models (DEM) to run topographic routing analysis (Davie, 2004). Although classified as "distributed" models, Beven (2012, p. 16) described such models as " lumped conceptual models at the elemental scale." However, the importance of spatial representation is debated. Butts et al. (2004) outline the value of model complexity while Perrin et al. (2001) question the limits of complex modelling on real-world processes. These differences between spatially classified models emphasise that modelling is inherently a human-constructed representation, a culmination of choices made at the highest level, and reflects our perception of catchment hydrology. Modelling is not an independent, indifferent process, but one that is human-constructed.

\section{Process representation}

Many assumptions exist when representing a complex environment with a simplification. These assumptions define model types. Some models calibrate to measured datasets (empirical models), others use fundamental equations to outline model processes (physics-based), while a final group (conceptual models) aim to obtain a middle ground to these approaches.

Empirical models use measured catchment data to derive hydrological catchment relationships, such as the relationship between effective precipitation and runoff (Beven, 2012; Wainwright \& Mulligan, 2013). Furthermore, artificial intelligence can be used to identify relationships between indices that are not 
already known, by training models to identify data correlations with no other user input or expert knowledge (Minns \& Hall, 1996). Extrapolation of empiricallyderived relationships beyond the initial temporal, spatial, and magnitude scales are at risk of being misapplied as they are catchment-specific.

In contrast, Physics-based models mathematically represent all the necessary components of a system and vary significantly in complexity. However, complex models are not inherently "better" (Ballinger, 2011; Jakeman \& Hornberger, 1993). More parameters mean a larger potential for equifinality, where many combinations of parameters give the same output (Lu et al., 2009). This increases the uncertainty in which metrics are genuinely driving the output ( $\mathrm{Lu}$ et al., 2009). Physics-based models require calibration, to compare the current understanding of the catchment with catchment dynamics in real life (Ballinger, 2011; Wainwright \& Mulligan, 2013). An example of these are the MIKE SHE models, designed to model the impact of human development on catchment systems using a grid of surface, groundwater, and unsaturated flow (Wainwright \& Mulligan, 2013; Ward \& Robinson, 2000).

Finally, Conceptual models combine the data-driven nature of empirical models with the theorised hydrology of a catchment. Expert knowledge is needed to structure the model, with calibration required to ensure the right relationships between parameters are in effect (Maxwell, 2013; Wainwright \& Mulligan, 2013). Conceptual models aim to represent simplified physical components, interrelationships, and thresholds of the hydrological cycle and can be used in ungauged settings, or beyond boundary conditions (Pechlivanidis et al., 2011). An example of a conceptual model is TOPMODEL, which uses distributed topographic routing and soil/land cover datasets to define soil moisture deficit, saturation and output runoff (Bandaragoda et al., 2004; Maxwell, 2013; Ward \& Robinson, 2000).

\section{Classification of inundation modelling}

Many flood inundation modelling approaches exist: empirical, hydrodynamic, and conceptual models. However, the flood hydrographs calibrated from rainfallrunoff modelling are needed as input for the final hydrodynamic model. These inundation model classifications are summarised below, to contextualise the methodology of this thesis. 
Empirical modelling is computationally efficient, using direct and independent observations, such as surveys and remote sensing, from rapidly improving technology (Teng et al., 2017). However, is catchment and magnitude-specific, heavily reliant on using the past as a blueprint for the future, incorporates no physical knowledge of the flooding process, and limited by instrumentation and processing uncertainty.

In contrast, physically-based models are founded on hydraulic linkages. These account for changing/extreme precipitation and flow events and produce detailed output maps in solving St. Vernant channel and flow routing equations to different complexities and spatial models (Ballinger et al., 2011; Bates et al., 1992; Teng et al., 2017). These hydraulic models can be categorised into one-dimensional models, such as HEC-RAS, MIKE 11, ONDA and represent overbank flooding (Ballinger et al., 2011). These are suited to catchments with little data and are more efficient than the more complex models. However, such models cannot simulate lateral flow or complex landscapes (Benavidez, 2018). Furthermore, the cross-sectional nature of the models leaves a significant gap in channel representation (Ballinger et al., 2011). Two-dimensional models such as MIKE21, RMA-2, and TELEMAC, and three-dimensional models, such as CFX, FLOW 3D, and TELEMAC-3D, require more input data and time to run. Such models can represent different lateral (2D), and vertical (3D) flows within river channels, showing how flows interact with inriver and floodplain structures (Ballinger et al., 2011; Teng et al., 2017).

Finally, simplified conceptual models use mass conservation and topographic data to estimate water depth at the raster DEM resolution. Though, such models do not perform well at high flow momentum or complex landscapes (McGrath et al., 2018). However, they simulate inundation quickly and can cover large flood extents. Additionally, SCM require relatively little data to run and are computationally efficient (Benavidez, 2018).

\section{Uncertainty representation within hydrological and hydrodynamic} models

Model uncertainty is essential for researcher reporting, decision justification, and public engagement and is incorporated within modelling structures in two ways: deterministically and stochastically (Neale \& Weir, 2015). Deterministic models process one set of input parameters and boundary conditions, resulting in a 
single output. In contrast, stochastic means to have variable input according to a random probability distribution and output a similar range (Beven, 2012). Stochastic modelling allows for uncertainty calculation throughout the modelling process (Ballinger, 2011; Maxwell, 2013). However, the addition of a stochastic probability distribution function to a deterministic model output combines the roles of both uncertainty types (Beven, 2012).

\section{Calibration of hydrological and hydrodynamic models}

Parameter calibration is needed in modelling to make sure that the system is represented realistically and varies in method from parameter optimisation to prior estimation and direct measurement. Many studies use parameter optimisation which involves running a model with slight variations of set parameters until the modelled output is like the observed dataset (Blasone et al., 2007; Feyen et al., 2007; Madsen, 2003). Other methods, including prior estimation and direct measurement, have not been as successful. The first results in a range of outputs while the second is dependent on measuring an environment that is continually changing in time and space, a difficult feat (Beven, 2012). While more complex hydrological models exist, the need for empirical calibration and validation remains, primarily due to equifinality (Minns \& Hall, 1996). Furthermore, hydrological and hydraulic models only characterise flow or flooding hazards but give little information around the best mitigation and adaptation options, which ecosystem service modelling is better placed to outline.

\subsubsection{Ecosystem Services (ES)}

Ecosystem service modelling defines direct and indirect benefits gained from ecosystems, including provisioning, regulating, cultural services, and support services, outlined below (Deng et al., 2016; Millennium Ecosystem Assessment, 2005). ES models simulate these landscape benefits (Table 3) and vary in structure, data input and output (depending on the research focus) and have developed significantly in recent decades, as detailed below. While flood hazard and mitigation are the focus of this thesis, ecosystems are inherently holistic, as shown by the continuing research and investment of regional councils into ecosystem service research (Olubode-Awosola, 2017). Any land use changes which impact flood mitigation are likely to impact other ecosystem services. This highlights the 
importance of identifying what the impacts of different land management choices might be, looking at different trade-offs and synergies within the environment.

\section{Ecosystem service modelling advances}

ES modelling is a novel approach that has a wide range of applications. A review of the global and national use ES modelling is needed to contextualise the use of ES within this project. Early studies of ecosystem services explored the physical and economic benefits and values gained from the environment (Costanza et al., 1998; Daily et al., 1997; Worm et al., 2006). However, modern analysis outlines the importance of holistic models in decision making at the policy level, including cultural services, increasing the diversity of model type, complexity, uncertainty calculations, multiple-service models, and data input (Andrew et al., 2015; Daily et al., 2009; Englund et al., 2017; Power, 2010; Sharps et al., 2017).

Two key ES research gaps are evident. Firstly, that the aesthetic, heritage or spiritual value of ES are often overlooked or misunderstood in scientific literature (Chan et al., 2012; Daniel et al., 2012). Secondly, that ES results are useful in decision models, but analysing several ES services within a landscape to determine where synergies may exist is not modelled within most research (Deng et al., 2016; Jackson et al., 2013). These gaps are further supported when reviewing New Zealand ES modelling.

\section{New Zealand ecosystem service modelling}

This researcher adopted the Millenium Ecosystem Assessment conceptual framework, and critically analysed 30 New Zealand research publications ${ }^{5}$ to outline ecosystem service research and research gaps in New Zealand. Publications were categorised into different ES topics studied (Appendices: Table 10). This determined which topics have the least and most research currently. Articles could be placed in multiple ES topics, due to the interconnectedness of ecosystem service research. ES topics were then aggregated and graphed (Figure 22) where appropriate, for example, where water-related ES services were studied. This included services around flood mitigation, water quality, quantity and freshwater.

\footnotetext{
${ }^{5}$ Chosen using the search term ecosystem services in Google Scholar. Limited number due to time constraints.
} 
Table 3: List of ES, following the typology of Millennium Ecosystem Assessment.

\begin{tabular}{|c|c|c|c|}
\hline Provisioning services & Regulating services & Cultural services & Supporting services \\
\hline \multirow{4}{*}{$\begin{array}{l}\text { Agricultural production } \\
\text { (food, fibre, bioenergy) } \\
\text { Forage/livestock production } \\
\text { Fisheries }\end{array}$} & Air quality regulation & Cultural diversity & Soil formation \\
\hline & Climate regulation & Spiritual values & Photosynthesis \\
\hline & Regulation of atmospheric & Knowledge & Primary production \\
\hline & gases & systems & Nutrient cycling \\
\hline \multirow{3}{*}{$\begin{array}{l}\text { Aquaculture } \\
\text { Wild plant and animal } \\
\text { products }\end{array}$} & Carbon sequestration & Educational values & Water cycling \\
\hline & Carbon storage & Inspiration & \\
\hline & Water flow regulation & Aesthetic values & \\
\hline \multirow{6}{*}{$\begin{array}{l}\text { Timber } \\
\text { Wood fuel } \\
\text { Genetic resources } \\
\text { Pharmaceuticals } \\
\text { Freshwater (consumption, } \\
\text { irrigation, hydropower) }\end{array}$} & Groundwater recharge & Social relations & \\
\hline & Water purification & Sense of place & \\
\hline & Erosion control & Cultural heritage & \\
\hline & Pollination & Recreation and & \\
\hline & Pest control & tourism & \\
\hline & Disease regulation & & \\
\hline \multirow{2}{*}{$\begin{array}{l}\text { Ornamental species } \\
\text { Energy (solar/wind farms) }\end{array}$} & Natural hazard regulation & & \\
\hline & Allergen control & & \\
\hline \multirow{8}{*}{$\begin{array}{l}\text { Transportation } \\
\text { Shade and shelter }\end{array}$} & Soil fertility & & \\
\hline & Habitat provisioning & & \\
\hline & Waste treatment & & \\
\hline & Regulate noise pollution & & \\
\hline & Seed dispersal & & \\
\hline & UV protection & & \\
\hline & Drought mitigation & & \\
\hline & Barrier effect & & \\
\hline
\end{tabular}

\section{Review outcomes}

The four most common aggregated research themes were Land ${ }^{6}$ (24\%), Political $(22.1 \%)$, Water (18.3\%) and Nutrients \& Ecology (15.4\%). Research primarily focused on the implementation of better land management that would provide either environmental, social or economic benefits. Examples of this include the value of soil properties in natural capital stocks (Dominati et al., 2014), using participatory approaches, incorporating Māori values in land use decisions, evaluating the natural environment's role in tourism and quantifying nutrient pathways within New Zealand catchments (Dominati et al., 2014; Lyver et al., 2017; Scott, 2017; Trodahl et al., 2016). Further research is needed including more independent cultural or local perspectives in decision making, applying models in a range of environments, and planning for a climate change-resilient future.

This review highlights the prominence of water management within ES literature and identifies several gaps in current New Zealand ES literature. Firstly, the importance of having a variety of ES modelling locations (showing the significance of including rural townships like Marokopa in analysis). Secondly, undertaking ES modelling under different climate change scenarios, which is a key future recommendation from this project. Finally, the lack of trade-off land

${ }^{6}$ Land (Agriculture, Erosion, Land use, Soil and Vegetation), Political (Decision making, economics and policy) and Water (Flood/flow, Fresh/Water and Water Quantity). 
management decision-support tools, for which the LUCI model has a novel approach

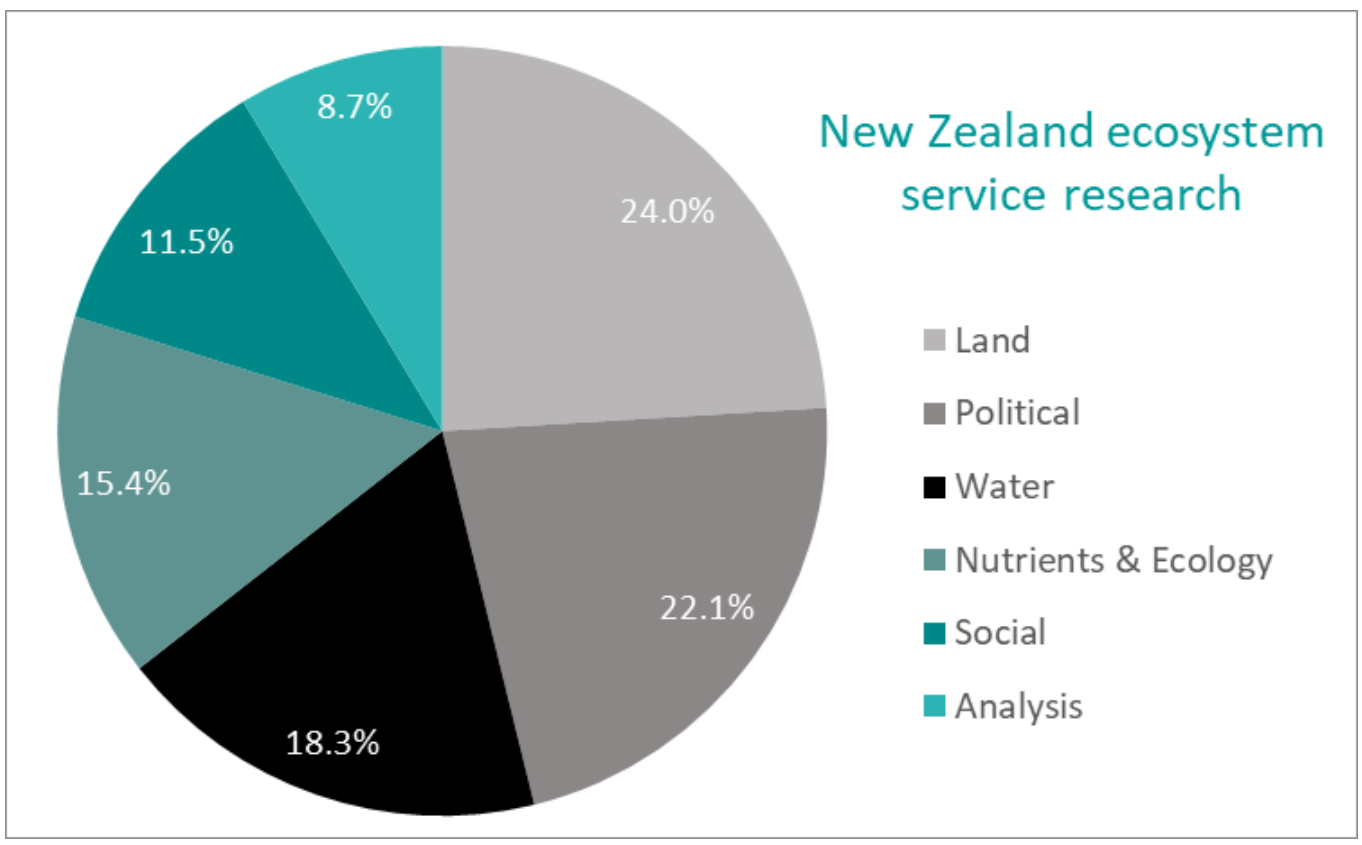

Figure 22: New Zealand ecosystem service research: frequency of topics within modern literature

\section{Summary: flood risk modelling}

Many flood risk models exist, which aim to represent the factors and impacts of flooding in different ways. Hydrological models represent water passing through a catchment and range in complexity, spatial representation, and model process. With empirical, physics-based, or conceptual relationships used to various degree, flood modelling can include simulations of changing flood peaks or flowinundation relationship definition. While the resulting flood risk maps and climatechange adjusted event reoccurrence intervals are useful for high-level flood hazard management, such outputs only outline the problem and do not provide any useful mechanisms for future land management decisions.

In contrast, ES research presents knowledge around current and future services and highlights the importance of valuing the environment as a resource and not a right. Furthermore, recent studies highlight the unique application of ES in both community engagement and land management decisions, especially when considering different scenarios and synergies. The process for how this project defines the current and future flooding risk at Marokopa, including different scenarios and ES synergies, are detailed in the following chapter. 


\section{Conclusions}

- Hazard impact is defined by event magnitude, vulnerability, and exposure.

- Floods are influenced by a diverse range of factors, including climate, geology, topography, soil, land cover, land management, marine conditions, climate change and the local community.

- In order to model the full impact of floods, both the physical conditions and future land management conditions should be considered.

- Inundation modelling outlines areas of flood extent.

- ES models simulate various services for wide-ranging application, including prioritisation of investment or land management changes that complement traditional flood modelling approaches. 


\section{Methods and methodologies}

This chapter discusses the three methods used to evaluate the flooding hazard in Marokopa, New Zealand (Figure 23). Flood modelling methods (interview, rainfall-runoff, and flatwater inundation modelling) and output are outlined before those of ecosystem services, as inundation represents hazard magnitude and ecosystem services represent the potential for land use management in minimising hazard magnitude. Efficient management schemes result when including inundation output within an ecosystem service framework, leading to the same structure being used for the methods section.

\subsection{Land Use and Capability Indicator (LUCI)}

This project uses two LUCI modelling approaches to describe where flooding at Marokopa may occur and where flooding is mitigated by landscape features. The first method (Section 4.2) involves the generation of flood peaks through rainfallrunoff modelling which can then be fed into an inundation model. While initially

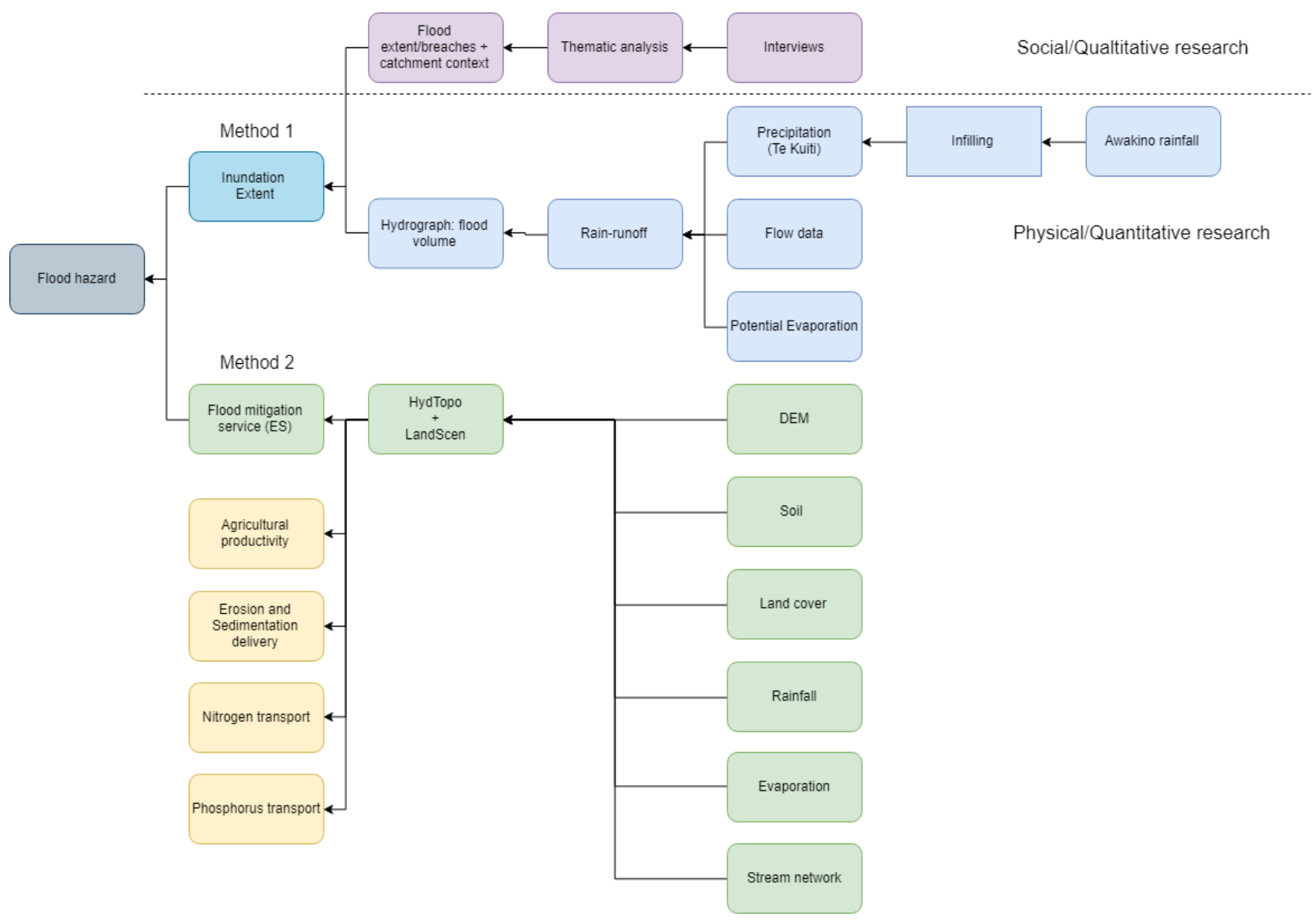

Figure 23: Project methods (flood inundation and ecosystem service modelling), and method components.

this thesis aimed to present flatwater inundation modelled floods under different climate change scenarios, due to the complexity of the rainfall-runoff modelling 
(needed for inundation modelling), as well as time and data constraints, this thesis focuses on gathering the required data and developing an accurate rainfall-runoff model for future inundation modelling. ES modelling (Section 4.3) uses an ArcMap toolbox that requires the input of a digital elevation model (DEM), soil and land cover datasets to quantify the natural landscape in terms of different ecosystem services, including flood mitigation, erosion, agricultural productivity, and nitrogen and phosphorus transport. Inundation modelling will be added into this suite of services in future by the LUCI team.

\subsection{Flood modelling}

Upper catchment rainfall-runoff modelling at Marokopa Falls is needed to provide boundary flow conditions to the lower catchment. Interviews were critical in contextualising the Marokopa hydrology and describing past flood events' extent and timing for future inundation modelling. We present these historical floods, as well as flood analysis using topographic estimates in Section 7.2.

\subsubsection{Interviews}

Ontology: the study of "existence", and the researcher's place within it

As a student of Earth sciences, this researcher sees the world as independent of connected Earth systems on a larger scale. Although people's experiences of such systems vary, this researcher does not think that thoughts themselves impact the physical, real-world, only how we choose to move through it. This "chosen" perspective has defined what method and methodologies have been used, as outlined in the following paragraph (Greener, 2011; Jackson, 2013).

\section{Epistemology: nature knowledge}

According to Jackson (2013, p. 53), the "ontological stance links to [the] epistemological perspective - with the ontological perspective of the reality of the world and the epistemological perspective about knowledge of that world." To understand the Marokopa catchment, different perspectives from the community are needed to disclose the historic flood record and system. However, as a Ngāti Maniapoto member, it is acknowledged that this researcher is connected and accountable to the Marokopa and Mirumiru marae communities. 


\section{Positionality: influence of individuality on research}

This researcher views this project from a constructivist-positivist position; where the physical world can be described (and therefore forecast) in numerical terms. To present the numerical results in a real-world context, a mixed-methods approach is needed to understand the Marokopa catchment and produce useful map output of Marokopa flooding (Williams, 2014).

\section{Ethics approval}

Ethical issues include results potentially identifying areas of flood or erosion risk that coincide with residential properties, therefore potentially impacting housing prices. Ethics was granted under the number [0000026605], by the Victoria University of Wellington Human Ethics Committee.

\section{Interviews}

Over six days, 12 community members from the Marokopa catchment were interviewed (Participants A through L), ranging from Māori to pākeha, people living at the Marokopa village to farmers inland and in the upper catchment. Interviews took place at the Community Hall or the subject's homes and ranged in duration from 1 hour to 3 hours. A semi-structured interview process was used to direct the conversation, without restricting it. The full list of questions is found in Appendix D.

\section{Qualitative data analysis}

A thematic approach was used to gather information relevant to the clusters, (flooding, erosion, land management, ES and karst hydrology), using NVivo 12. From this, information around catchment dynamics was used to contextualise the flood models (Richards \& Morse, 2012; Scott, 2017). Additionally, information around flood extent, timing, and duration were used as input data for inundation modelling.

\subsubsection{Rainfall-runoff model}

Inundation modelling requires knowledge of how flow relates to overbank flooding extent, gained through examples of overtopping stop-banks, floodgates, or remotely sensed/satellite data (Ballinger et al., 2011; Patro et al., 2009). Flow, flood extent, and rainfall data are limited at Marokopa, therefore a specifically-developed 
spatially-lumped conceptual rainfall-runoff model was used to define the relationship between input rainfall and output catchment runoff. This model is an extension of the one applied by Maxwell (2013) and Maxwell et al. (2018). Infilled Te Kuiti precipitation (infilled using Awakino precipitation), Te Kuiti evaporation, humidity, and Marokopa Fall streamflow are used to model stream response to rainfall.

A Monte-Carlo approach was used to select a "best-fitting" set of model parameters defining catchment characteristics (lagtime between rainfall peak and flow peak, infiltration values, drainage, reservoir residence times, and stored volumes (Maxwell, 2013). The rainfall-runoff model then iterates through precipitation values, simulating water passing through an 'infiltration' zone, a 'draining' zone and three reservoirs of different residence times (fastflow, interflow, and baseflow) (Figure 24).

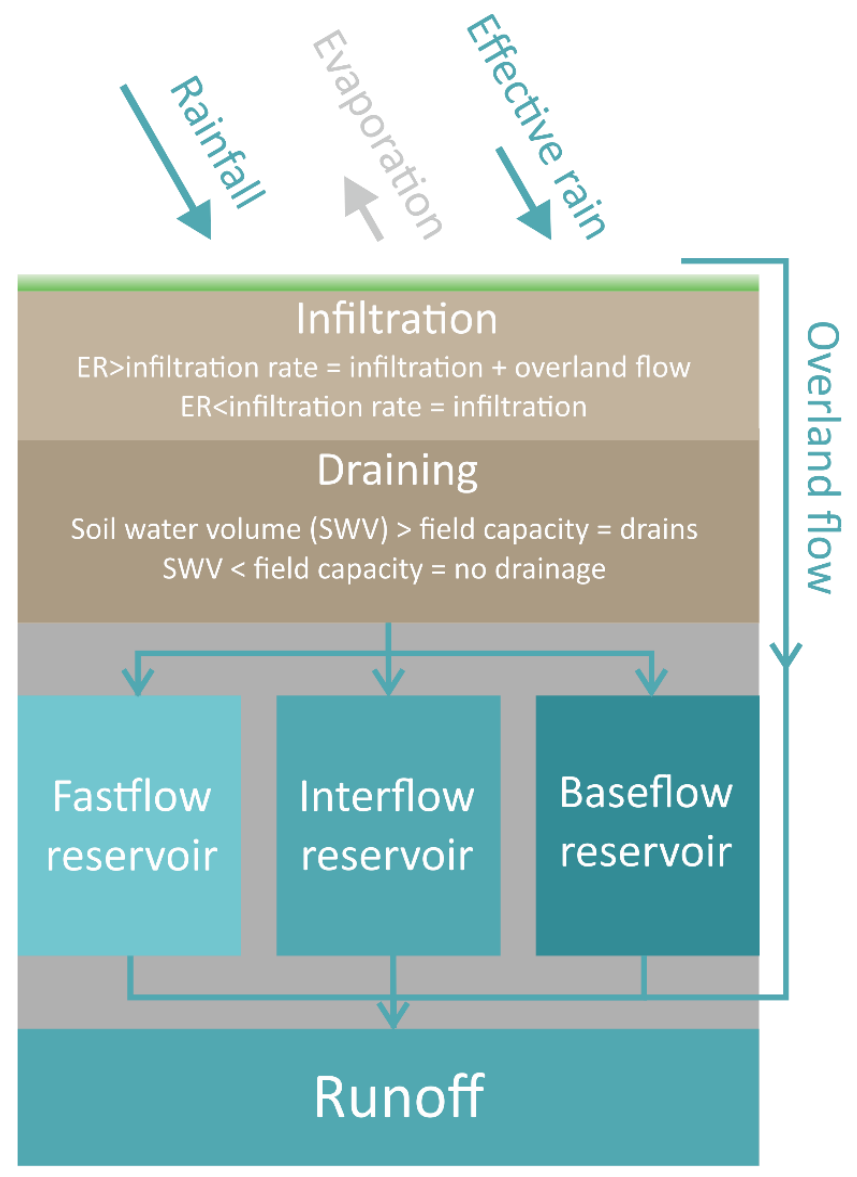

Figure 24: Rainfall-runoff model, adapted from Maxwell (2013).

As the model runs through timesteps of precipitation, water which is not lost to evaporation infiltrates into the soil or passes over the earth's surface as overland 
flow, eventually reaching the stream. Infiltrated water then passes into a secondary draining segment of the model and, finally, passes proportionately into the three reservoirs. According to their respective residence times, water leaves each of the reservoirs as runoff. Modelled flow is then output and compared with observed flow.

Different parameter ranges were used in the modelling process to create a bestfit rainfall-runoff model of the upper Marokopa catchment, with several parameter ranges created to reflect seasonal changes (Appendix E). Moreover, modelling of the entire record and individual flood events were compared. As we are modelling flood events, the parameters which best reflect flood hydrology are significantly different from "normal/mean flow" hydrological conditions. During the infilling process a 26-hour gap within both Te Kuiti and Awakino precipitation records was seen, from the $30^{\text {th }}$ April- $1^{\text {st }}$ May 2008. The total infilled precipitation record being from $4^{\text {th }}$ March 2005 to $1^{\text {st }}$ June 2017.

Before this data gap the data was used for model validation, while the data after this gap was used for model calibration. Model calibration was estimated based on visual best fit of flood period hydrographs and the Nash-Sutcliffe efficiency (NSE) measure of correlation, which normalises the difference between modelled and observed flow (Krause et al., 2005; Nash \& Sutcliffe, 1970). The NSE measure was output both for individual flood event hydrographs and parameter value plots.

Parameter calibration plots displays the NSE value for that parameter set, across each run (Figure 25). The number of runs ranged from 1000 to 100,000 to ensure that large permutations of parameters can be modelled and compared. As the model
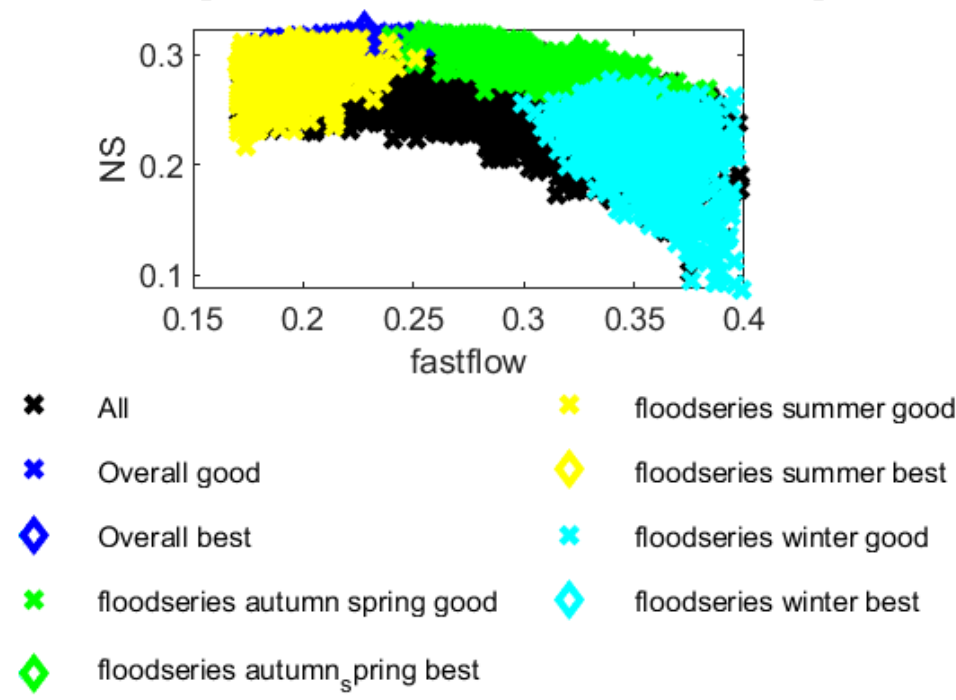

Figure 25: Nash-Sutcliffe fastflow parameter plot for a summer flood. 
aims to represent flood conditions, the parameters are calibrated so that the floods have a better-normalised fit between the modelled and observed flow. As seen in Figure 25, the lowest proportion fastflow (yellow, summer) have the highest NSE values compared to the overall record (black) and winter floods (blue), which has a higher proportion of fastflow (0.35 to 0.4$)$. This indicates that this parameter set produces a better model fit for summer, rather than spring/autumn or winter floods.

\section{Assumptions and boundary conditions}

Several assumptions are made in the selection and use of hydrological models (Ballinger, 2011; Wainwright \& Mulligan, 2013). For the use of rainfall-runoff modelling, baseflow is not accounted for in variations of the hydrologic routing although underground rivers have been identified upstream. Catchment hydrology may be better represented by semi-distributed model, rather than the current lumped one. Scarce precipitation, evapotranspiration, and river flow data availability have meant that data for the Marokopa catchment has been extrapolated and interpolated from different areas.

\subsubsection{Flatwater inundation modelling}

The LUCI flatwater inundation modelling is an example of SCM, which represents a catchment by grid cells with associated elevation and saturation data. While groundwater and flow velocities are not modelled, the LUCI structure allows for detailed, hydraulically-consistent efficient modelling of large, regional-scale areas (Benavidez, 2018; Teng et al., 2017). Output peak flow from the upper Marokopa catchment rainfall-runoff modelling would ideally be used as input for the inundation model. The inundation model defines areas of flooding for different discharges (flood scenarios) (Figure 26). Flood volume scenarios simulate different sized flood events with corresponding runoff volume (cumecs). Users set where flooding occurs ("breaches") by first defining the amount of water to spill, based on the derived river or precipitation input volume and flow (cumecs). Paired breaches on either side of the river, outline where floods spill over bank capacity while associated metadata describes the characteristics such as the overtopping volume $\left(\mathrm{m}^{3}\right)$. This volume is the amount of water that breaches the river banks. Metadata defines paired breaches, where overtopping has occurred on opposing sides of the river. The river polyline approximates the centre of the river, defining the river flow direction. The DEM of the floodplain must be high resolution as this 
determines where the inundation model incrementally floods within the iterative flooding process.

Pre-processing is needed to estimate the flood volumes and bank-breaching flood volumes. Generally, this requires time and extent data for when stopbanks are breached, as these are measured to specific river capacities. Due to a lack of stopbanks, flow, and rainfall data at Marokopa, rainfall-runoff modelling is needed. However, the nearest flow record is at Marokopa falls, $10 \mathrm{~km}$ inland from

Flatwater inundation modelling process
(adapted from Benavidez, 2018)

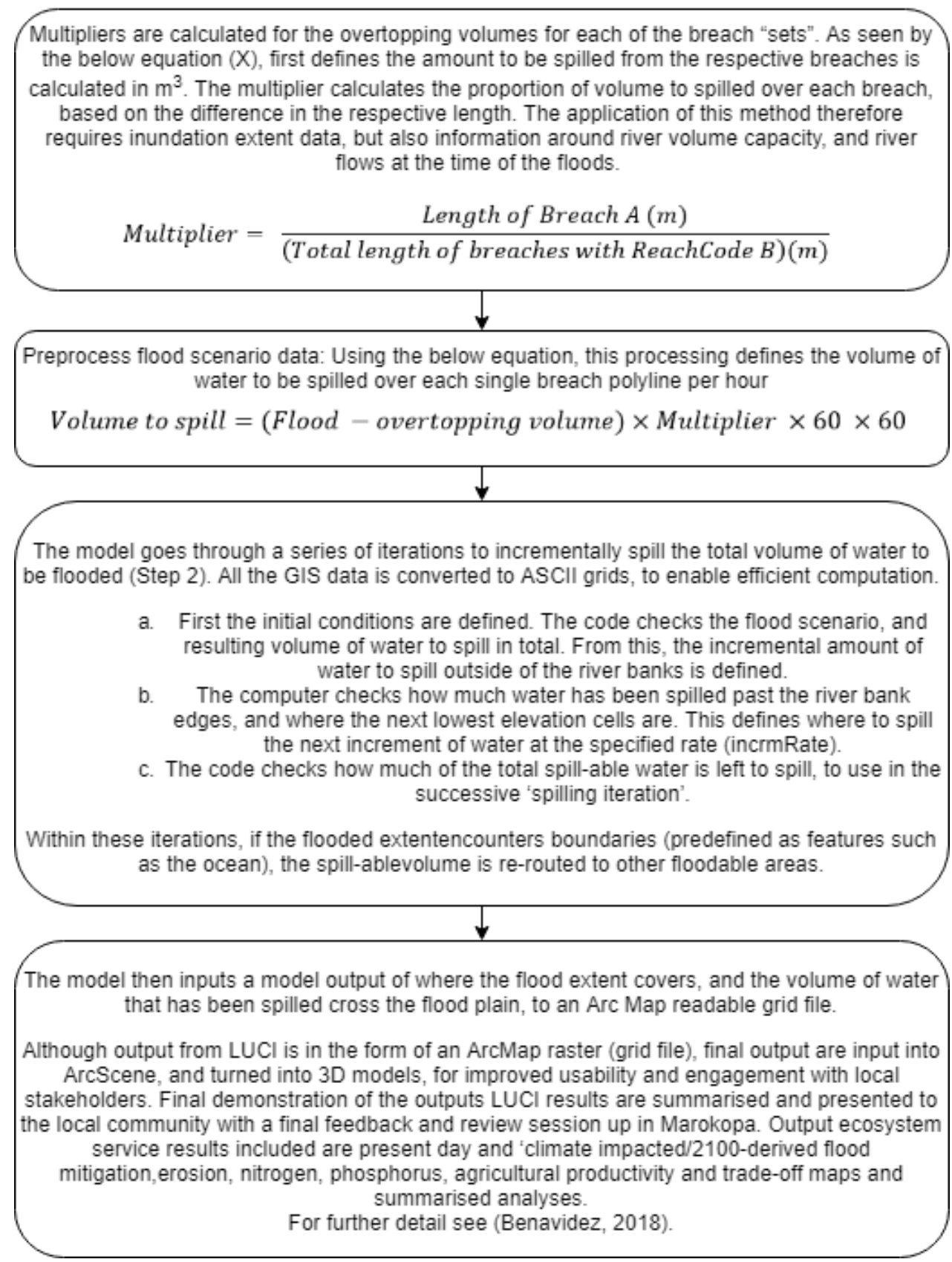

Figure 26: Inundation modelling process (adapted from Benavidez, 2018). 
Marokopa. The upper catchment, to Marokopa Falls, is simulated with a conceptual rainfall-runoff model, which is then used as an analogue to flow and flood inundation extent at Marokopa. The nearest high-resolution rainfall record is at $\mathrm{Te}$ Kuiti and is infilled from Awakino. Continuous rainfall is needed to run a rainfallrunoff model (detailed in Section 5.1).

\section{Model uncertainty}

For this study, rainfall-runoff modelling is required to relate climate conditions to flood inundation. However, this modelling incorporates a large degree of uncertainty as the rainfall and evaporation are extrapolated from Te Kuiti and are therefore unlikely to be directly representative. We assume that the upper and lower Marokopa catchment hydrology are related and that rainfall-runoff modelling can be used to define the Waitomo/Marokopa Falls hydrology. Moreover, uncertainty from the rainfall-runoff modelling would also be incorporated into the inundation modelling. Uncertainty analysis using Monte-Carlo or other approaches could be beneficial to minimise the impact of equifinality (Maxwell, 2013; Maxwell et al., 2018). However, such analysis is beyond the scope of this thesis.

Model limitations include the flatwater model not accounting for energy or momentum exchanges, being founded on mass-conservation, and users must define flood breaches from channels, therefore requiring detailed user or local knowledge (Ballinger et al., 2011). As breach data must be related to river volume, floodgate, and flood bank structures are typically used to inform breach discharge. No flood bank structures are present along the Marokopa river, requiring the extrapolation of flow data from the upper catchment, rainfall-runoff modelling, and local knowledge of historical flood extent (Benavidez, 2018; Teng et al., 2017). Flood extent and catchment hydrology were obtained through 12 resident interviews. The lack of historical flood volume, extent and timing data has limited the return period that can accurately be modelled, thus making this project a scoping study rather than a detailed model of hydrological processes with associated uncertainty.

\subsection{Ecosystem service modelling}

ES models define benefits gained from the landscape, accounting for various land cover, soil, topographic, and hydrological datasets. Hydrological models can predict how a river system changes in response to input precipitation and flow. However, hydrological/hydraulic models do not outline how to manage 
environments for best practice. Forming holistic decisions with better land use synergies is possible using ecosystem service models, which we seek to do using the ES model LUCI.

\section{ES model comparison}

LUCI is a GIS-based application developed by a team at Victoria University of Wellington and is based on the Polyscape framework(Jackson et al., 2013). It is housed within an Arc-toolbox (Figure 27) that requires nationally-available topography, soil, and land cover datasets to run. For more realistic ES results, stream network, precipitation, and evaporation datasets can be used. LUCI modelling quantifies the natural landscape value in terms of ecosystem service provision, with high-resolution datasets used where possible (Jackson et al., 2019; Jackson et al., 2013).
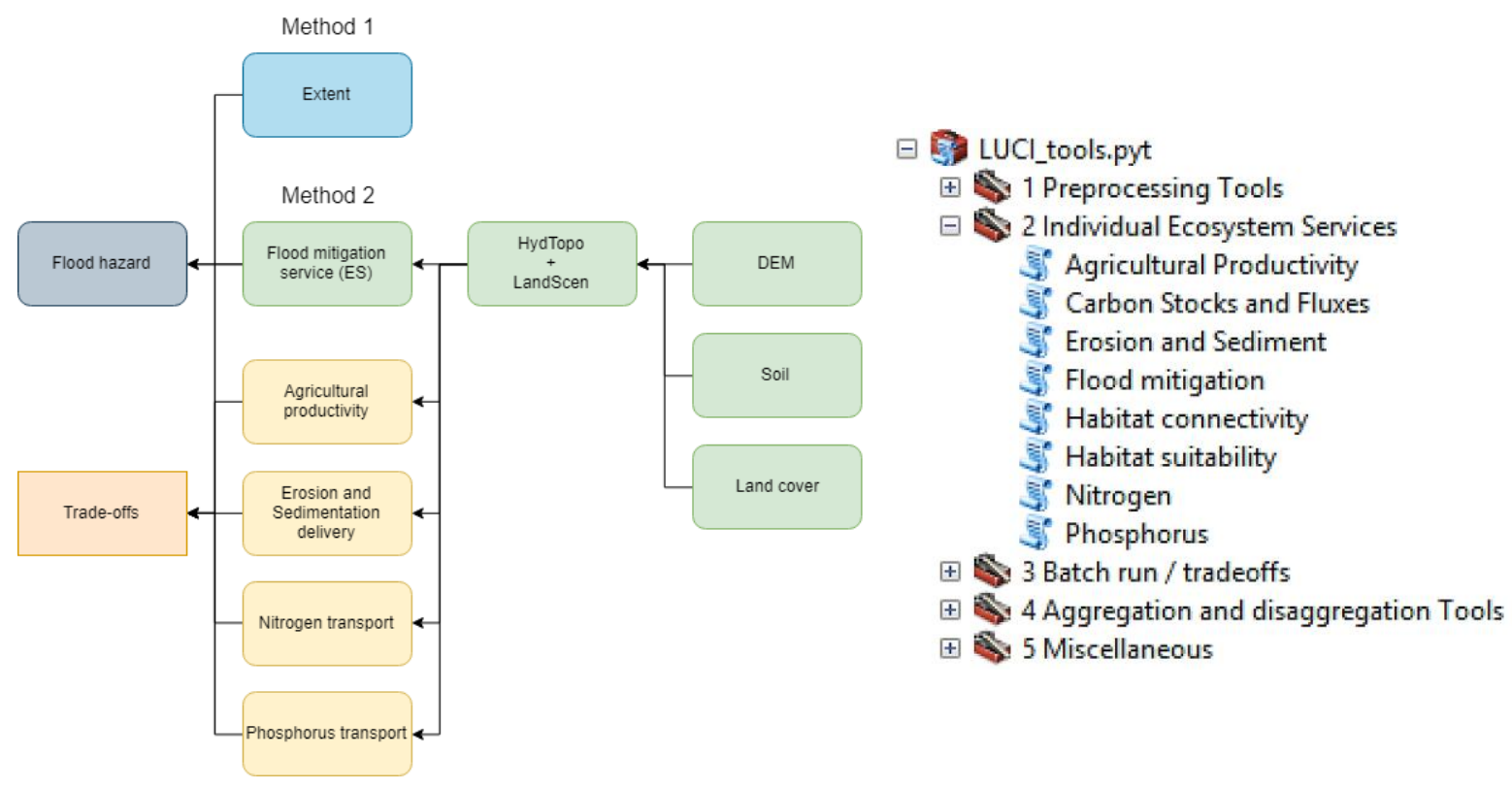

Figure 27: Standard LUCI ecosystem service components and modelling process (left). ArcMap toolbox (right).

The interaction between landscape and runoff results in secondary outputs such as accumulated loads, sediment delivery, and flood-prone areas. Ranked classifications of individual ES services can also be compared, generating trade-off maps for decision making. Individual agricultural productivity, flood mitigation, habitat connectivity, nitrogen and phosphorus transport, carbon stock, and flux services can be calculated while trade-off services analysing co-benefits are also 
possible. However, only select services are analysed within the scope of this project, namely: those that influence flooding (flood mitigation, interception, erosion, sediment delivery); or services that are influential to the community (agricultural productivity, water quality). Soil and land cover datasets are linked with tables that quantify ecosystem service values. These evaluated datasets are then manipulated by simulation of topographically-routed of water and sediment.

\section{ES model comparison}

Several established ES models exist. InVEST maps and evaluates global ES using open source software, while ARIES further simulates the value and management of ES and ES flows at customisable scales (Martínez-López et al., 2019). Finally, developed by a team at Victoria University of Wellington, LUCI maps the current and potential of a range of ES services, while also contrasting how management decisions may impact ES synergies (Bagstad et al., 2013). Both InVEST and LUCI account for input land use, land cover, and biophysical process relationships to evaluate the landscape in biophysical or monetary units (Bagstad et $a l ., 2013)$. In contrast, ARIES creates a customised online platform for ecosystem service evaluation and accounts for uncertainty with potential and actual benefits as well as sources and sinks of services (Sharps et al., 2017). While subsequent runs of the ARIES model are efficient, the customisable set-up requires time and technical knowledge whereas InVEST and LUCI can derive local ecosystem services from largely available national datasets. Furthermore, while LUCI derives its flood-mitigation/water supply service provision from topographically and hydraulically routed accumulation at the regional and local scales, InVEST output is at the sub-catchment-scale.

Finally, LUCI is particularly useful due to the trade-off tool allowing for the step from current landscape evaluation to best-possible future landscape management opportunities. The inclusion of single-service and multiple-service synergies is invaluable for decision makers, individual farm owners, regional councils, and national policy-makers (Herzig et al., 2013; Jackson et al., 2013; Sharps et al., 2017). 


\section{Pre-processing tools: HydTopo and LandScen}

HydTopo reconciles the DEM and stream network information, ensuring that water is routed realistically as datasets may not always be consistent. Topographic data is routinely used for ES modelling (Crossman et al., 2013). For Marokopa preprocessing was needed to "burn in" the stream network to the DEM, making the river network lower than the surrounding raster cells. See Benavidez (2018) and Hellweger (1997) for method and methodology. Under different reconditioning processes, vast differences in output were seen (Table 4, Figure 28). Therefore, reconditioning with a stream file is needed to ensure hydrological consistency.

Table 4: Range of tested HydTopo parameters to increase accuracy.

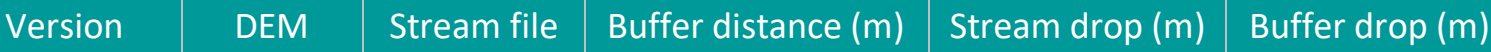

\begin{tabular}{|l|l|l|l|l|l|}
\hline HydTopo01 & $8 \mathrm{~m}$ & No & 75 & 3 & 2 \\
\hline HydTopo02 & $8 \mathrm{~m}$ & Yes & 75 & 3 & 2 \\
\hline HydTopo03 & $8 \mathrm{~m}$ & Yes & 100 & 6 & 4 \\
\hline
\end{tabular}

The LandScen pre-processing tool derives permeability and hydraulic connectivity from correlated soil and land cover tables within LUCI. This information is then used to model catchment response to the spatial distribution of accumulated water and classify ecosystem service values/mitigating features with the individual LUCI services (Jackson et al., 2019).

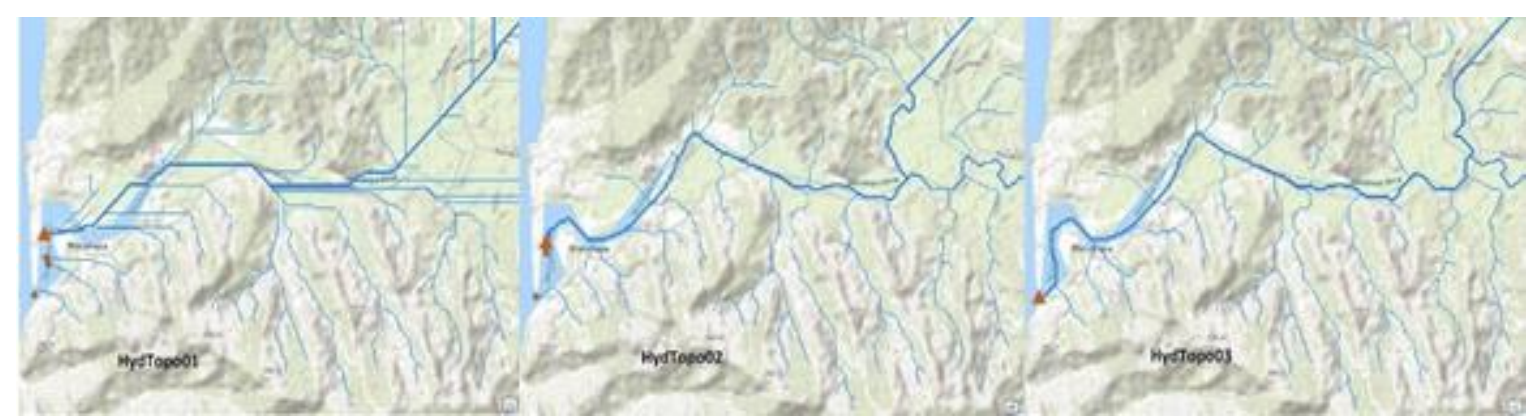

Figure 28: HydTopo modelling process, where floodplains, stream shapefile data and reconditioning were needed. The left image shows HydTopo01, with no stream file used for reconditioning/burning in, the middle image shows the HydTopo02 reconditioning, and the right image shows the HydTopo03 reconditioning with the largest stream drop. HydTopo03 reconditioning produces the most realistic modelled stream profile.

\section{Other individual LUCI tools}

Flood-influencing services such as flood mitigation and erosion, but also, agricultural productivity, nitrogen and phosphorus concentration are modelled. These individual ecosystem service tools function in different ways, detailed in 
Jackson et al. (2013). Individual and multi-service ES parameters are listed within Appendix E. Moreover, individual ES outputs are comparable. This allows for the comparison of different services and how different synergies relating to land management decisions impact overall environmental ES. For any service, the landscape is therefore divided into very high existing service, high existing service, moderate or marginal service, small or degrading service, or very small or rapidly degrading service.

\section{Flood mitigation}

This tool defines where water accumulates or drains within a catchment and produces two outputs: mapped flood mitigation and flood interception (Figure 29). The first, flood mitigation, categorises land cover into areas that store or redistribute water. The second (flood interception) simulates accumulated flow and where it is and is removed due to mitigating features or areas of high storage. Wetlands and indigenous forest provide storage capacity and therefore have "high existing (storage/flood mitigation) value." Areas where flow accumulates, unmitigated, are defined as "priority areas for change (in storage/mitigation)." These hydrologicallyclassified areas are further categorised into "opportunity" areas and "mitigating" areas. The former are where further work can be done to increase landscape connectivity and storage and the latter are features that already have high infiltration or storage capacity (Benavidez, 2018). In addition, a threshold accumulated flow can be defined by the user, indicating which areas have the highest priority for change according to the user's local knowledge (Benavidez, 2018; Jackson et al., 2019).

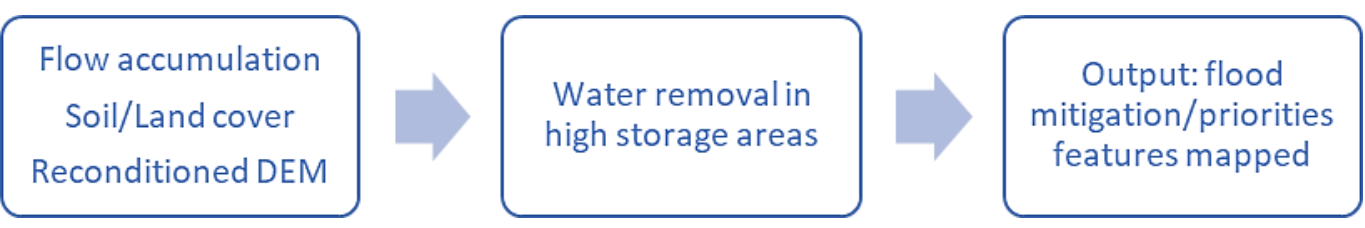

Figure 29: Flow mitigation tool process.

\section{Erosion and sediment delivery}

Erosion and river sedimentation are large components of the Marokopa river system and are correlated with flooding, according to residents (Beschta, 1983; Jones \& Schumm, 1999). Three denudation tools exist within LUCI. First, the 
HydTopo and LandScen sub-tools and their derived topographical and hydrological routing data are used to create a Compound Topographic Index (CTI). CTI accounts for flow magnitude, slope, and concavity. More accurate erosion output result from using threshold information for current landslide scars, although this was not utilised in this study due to time constraints. RUSLE erosion is also applied, which accounts for rainfall, soil, slope, and land cover/vegetation. Moreover, areas with potential sediment loading in water bodies are identified by combining the erosion output with hydrologic connectivity. These outputs can identify areas at risk of erosion and decreased water quality due to suspended sediment

\section{Agricultural productivity}

Agricultural practices account for approximately $40 \%$ of the Marokopa catchment land cover; therefore, farming location and intensity impact flood mitigation potential. This tool maps the agricultural productivity of the landscape, accounting for slope, soil fertility, aspect, drainage, and saturation. DEM and land use/land cover data are needed, through which current agricultural practices can be defined. The user can select weightings and thresholds for slope, fertility, elevation, aspect, and waterlogging. Outputs include maps of current, potential, and relative agricultural productivity, which are highly dependent on user knowledge of the catchment and input datasets.

\section{Nitrogen and Phosphorus transport services}

With agriculture being prevalent within the Marokopa catchment land use, knowing the nutrients lost is essential for optimal land management practices. LUCI tool uses the export coefficient approach routing method (Trodahl et al., 2016). Information from the HydTopo uses effective precipitation to determine flow direction and accumulation and resulting nutrient leaching. Areas, where nutrients have been leached, are highlighted, which is useful for land management planning. For more detailed methodology and methods, see Trodahl et al. (2016).

\section{Trade-offs and Synergies}

While flooding is the focus of this project, effective flood mitigation infrastructure is dependent on the current land use options (Burby et al., 2000). The best land management for different areas must, therefore, compare the different potential ecosystem services for that location (Duguma et al., 2014; Power, 2010). 
LUCI trade-off maps compare the benefits of different ecosystem services across the analysed area. The last step of the single service analyses is to evaluate the current ES function, the trade-off tool then compares the value and potential role of multiple services (Figure 30).

Areas of good service across multiple ES are identified as areas where the landscape should not change. Similarly, areas where poor provision correspond across multiple services are defined as where users should change the landscape. If some services currently function well, while others do not, these could be managed differently for improved ecosystem service value.

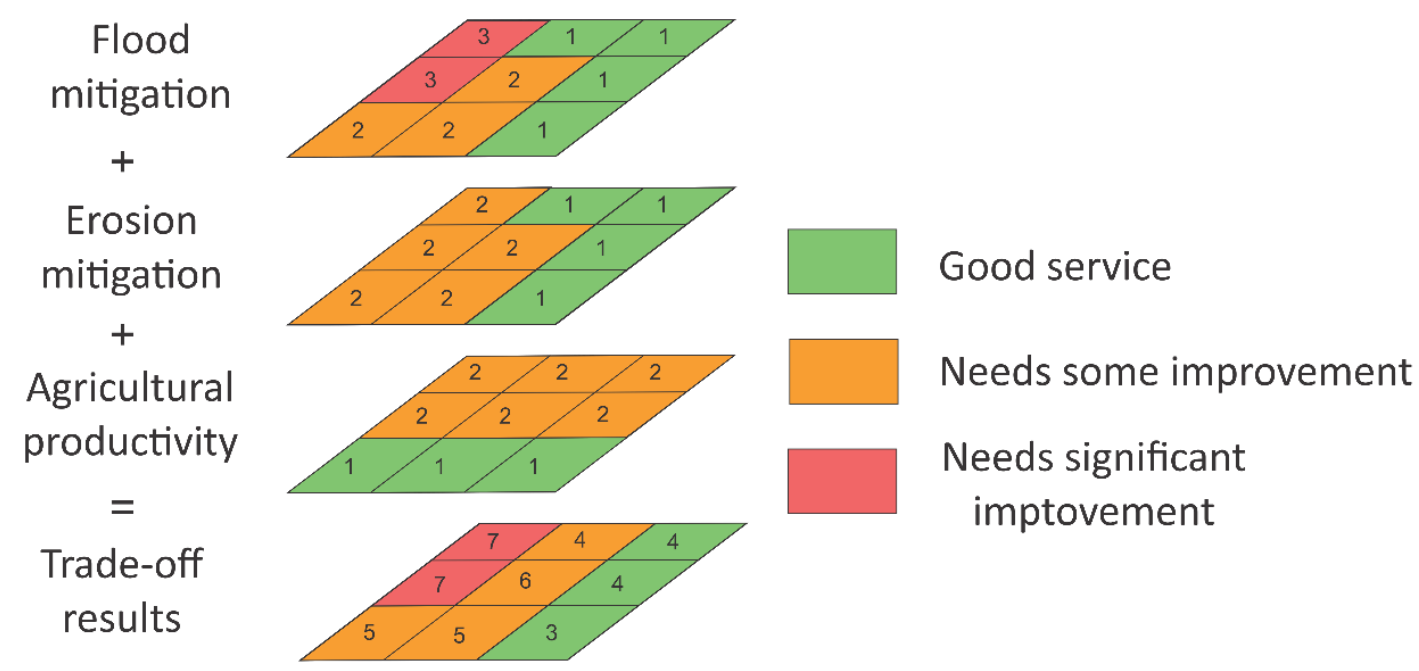

Figure 30: Trade-off ES process.

\section{Assumptions and boundary conditions}

LUCI utilises national datasets, allowing for efficient, low-resolution decision making. However, it is constrained to low-resolution output and cannot model metre-scale changes in ES specifically, unless customised datasets are generated for local utilisation at the farm scale. Furthermore, spatial differences in groundwater are not accounted for in variations of the hydrologic routing, although underground rivers have been identified upstream of the Marokopa catchment. It is recommended that this be a component of development for further LUCI ES development. Smaller-scale features such as farm practices, river bank or localised erosion, fertiliser usage, stocking rate, cropping, and farming intensity are also not modelled, but impact various ES. 


\section{Conclusions}

- Flood risk at Marokopa is outlined using two methods, inundation and ecosystem services.

- Further, interviews were used to identify flood extents and breach locations for inundation model parameterisation.

- Inundation outputs improve or give further context to ecosystem service outputs; this is described first and requires a rainfall-flow-flood extent relationship to be defined.

- Due to the lack of river volume and flow data at Marokopa, upper catchment rainfall-runoff modelling was used to relate upper catchment rainfall and flow to lower catchment breach conditions.

- Ecosystem services provide the opportunity to use nationally-available datasets to determine the flood and erosion mitigation, agricultural productivity, nitrogen and phosphorus services provided by the environment.

- Single and multi-service comparisons can be analysed, allowing for improved, synergistic decision making. 


\section{Data review}

Flood risk is defined within this thesis using traditional inundation and holistic ecosystem service modelling. Inundation modelling begins with running a rainfallrunoff model of the Marokopa upper catchment (highlighted in Figure 31), as there is not enough high-resolution data to do so in the lower catchment. This modelling determines flood peak volumes under current and future climate change scenarios. The flood peak volume is then spread across the river Marokopa floodplain, using a flatwater inundation model and represents current and future flood risk at Marokopa. This processing requires continuous precipitation, potential evaporation and river flow records for validation (Figure 32). Complementary ecosystem service modelling is carried out to outline the best management strategies possible to mitigate flooding and erosion. This requires a digital elevation model (DEM), land cover polygons, soil polygons, precipitation and evaporation raster grids and polyline stream network. For more detail see Chapter 4.

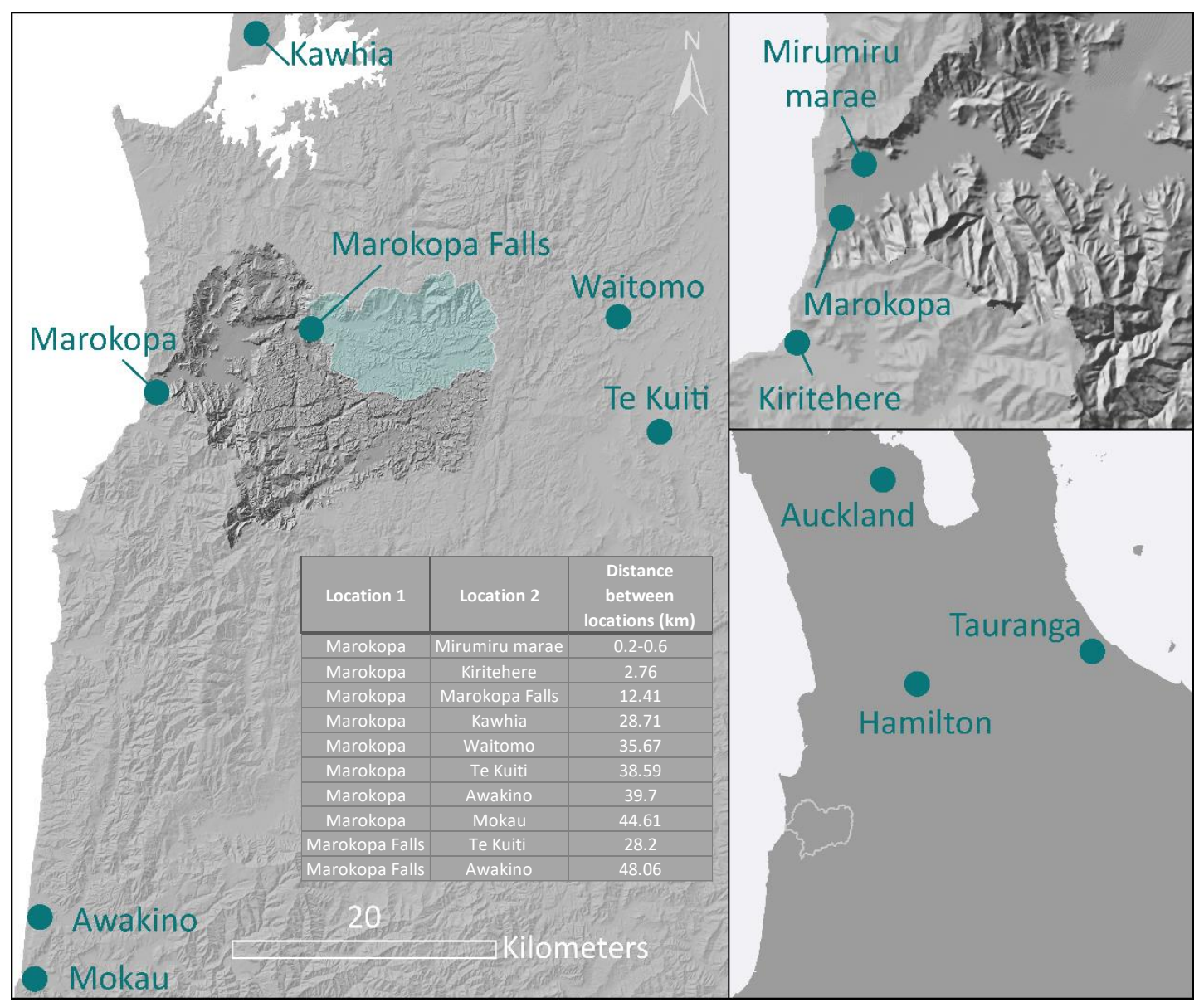

Figure 31: Marokopa and locations where surrounding data was recorded, with a table of distances between each township. 


\section{Data duration}

Several datasets are used through the rainfall-runoff, inundation modelling and ES modelling. These are outlined below.

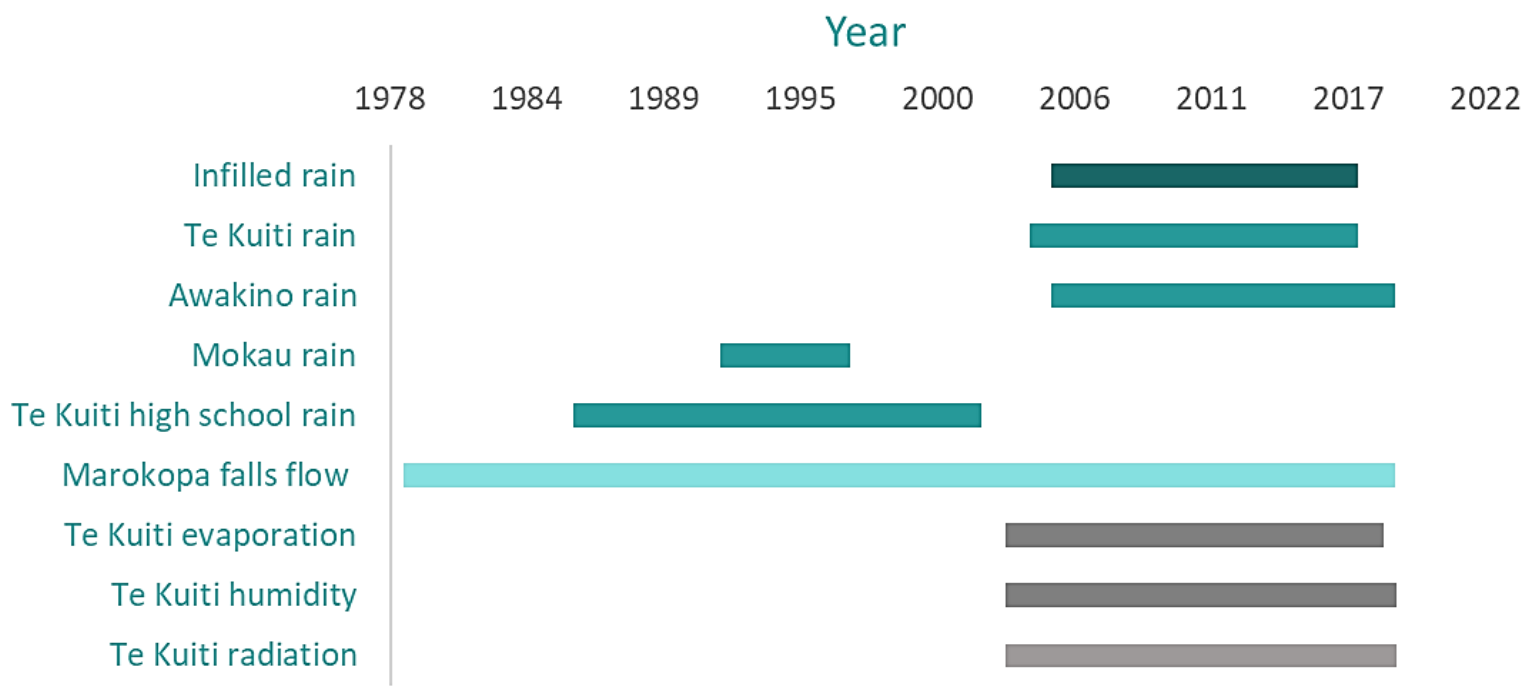

Figure 32: Dataset duration of parameters used within the modelling of this thesis.

\subsection{Precipitation}

Precipitation data is needed for both the inundation (rainfall-runoff) and ecosystem service modelling. For rainfall-runoff estimation, high-resolution data is needed - both spatially and temporally. Ideally, this would present as a continuous, 10-minute (or higher) record for Marokopa. While over 20 climate stations occur within $25 \mathrm{~km}$ of Marokopa, those stations as well as Marokopa village itself only have daily resolution precipitation. Precipitation rain rate data for Awakino, Te Kuiti (Figure 33) are used for rainfall-runoff modelling. Mokau and Te Kuiti High School data, pictured below are not used but are recommended for future work in the area as they could create a longer rainfall-record. The precipitation data was resolved to hourly resolution and correlated across different stations before infilling methods were used to construct a near-continuous record. In future, a Monte-Carlo approach or others could be used to find the times of the year where the highest correlations occur as seasonality significantly impacts model fit. 
Hourly Awakino Rainfall
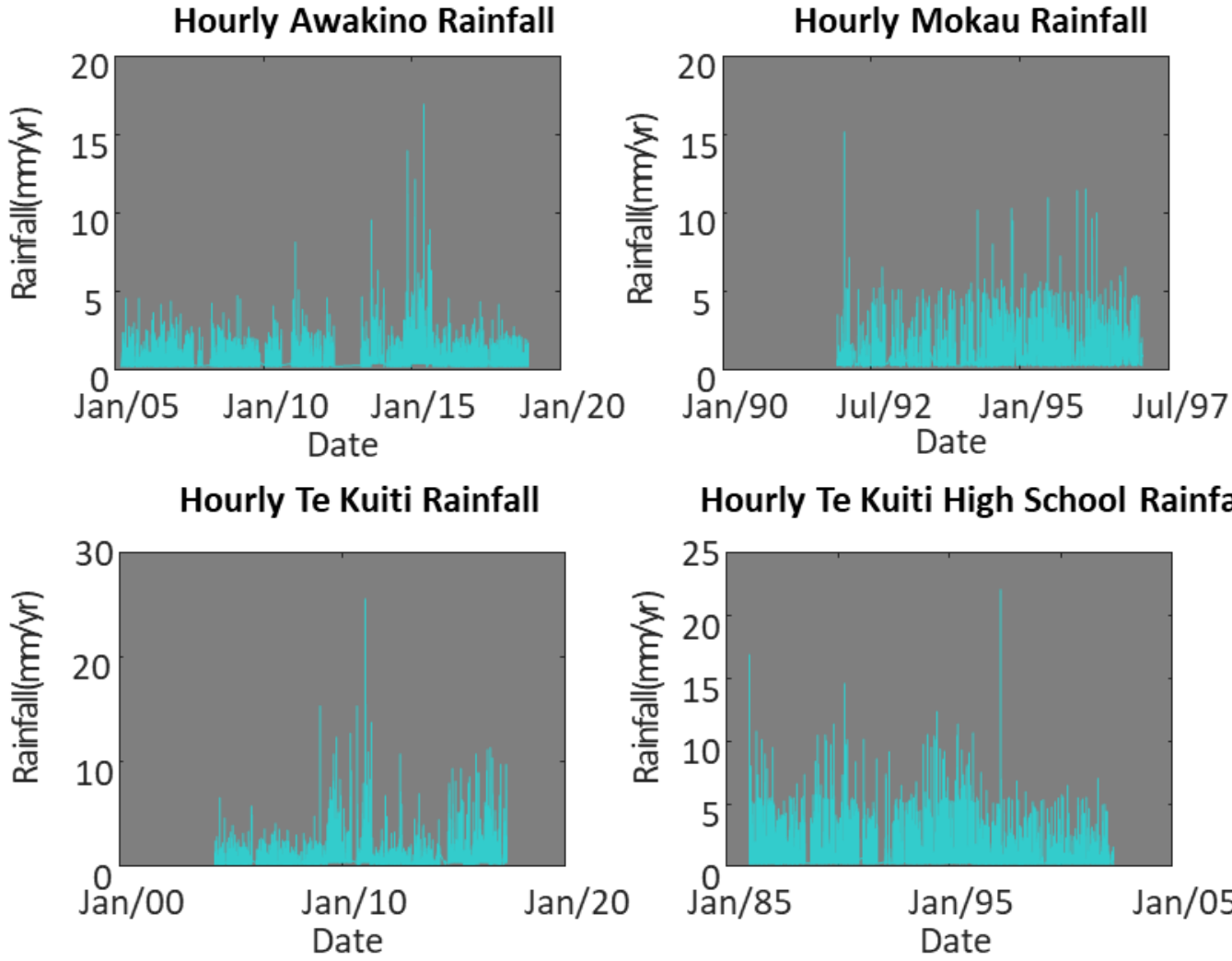

Hourly Te Kuiti High School Rainfall

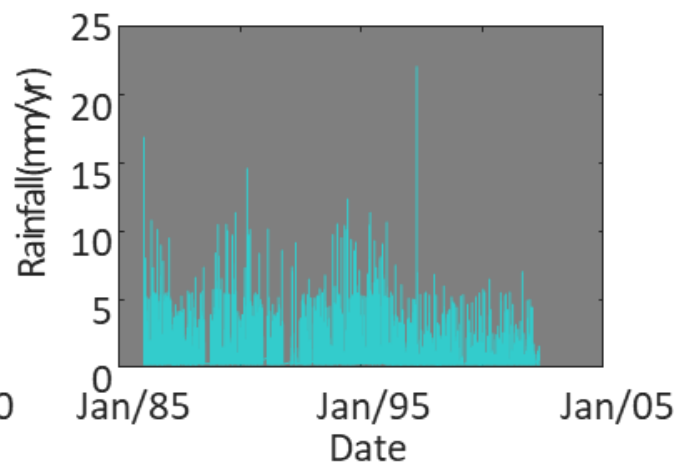

Figure 33: Hourly rainfall records for Awakino, Mokau, Te Kuiti and Te Kuiti High School (data source: NIWA).

\section{Infilling data}

Infilling data is needed for precipitation because a rainfall-runoff model runs on continuous data. Missing data can be attributed to extreme rainfall, human error or instrumental malfunction (Sattari et al., 2017). The Awakino rainfall record was chosen to infill gaps in the Te Kuiti rainfall record, as the closest, high-resolution rainfall record to Marokopa/Waitomo. For further studies, Te Kuiti High School data could be used as another input rainfall, as it is also from Te Kuiti, but it cannot be used here as an infilling record as it is from a different period (Figure 32). As discussed below, infilling methods differ based on distance, areal and average methods, namely the station average and normal ratio (Bárdossy \& Pegram, 2014; Maxwell, 2013; Sattari et al., 2017).

\section{Overview of infilling methods}

The arithmetic average method calculates missing precipitation values by dividing the infilling station values by the infilling station number. As the simplest process, this method generally generates values round the station averages, does not 
account for distance and is most useful when stations are evenly distributed across the catchment.

The inverse distance weighting method is the most prevalent method for infilling missing data values. This process generates values by dividing the reciprocal of the infilling value divide by the distance between the infilled and infilling-stations and does account for distance (Sattari et al., 2017).

The normal-ratio method is used when annual average precipitation of the known gauge is more than $10 \%$ of the missing-data station and does not account for distance. However, it assumes regional-scale climate predictably impacts localscale precipitation. The missing gauge values are generated by multiplying known stations gauge values by calculated weightings. These weightings are based on the correlations between the infilled and known station, as detailed in Sattari et al. (2017).

Due to the lack of spatially representative and high-resolution datasets, the normal-ratio method was used to infill the precipitation record. While correlations were used to define the rainfall pattern similarities between different stations, the infilling method, and datasets used were chosen due to limited overlap between datasets. This resulted in an infilled record (Figure 34), where the later record was used for model calibration, and prior for model validation.

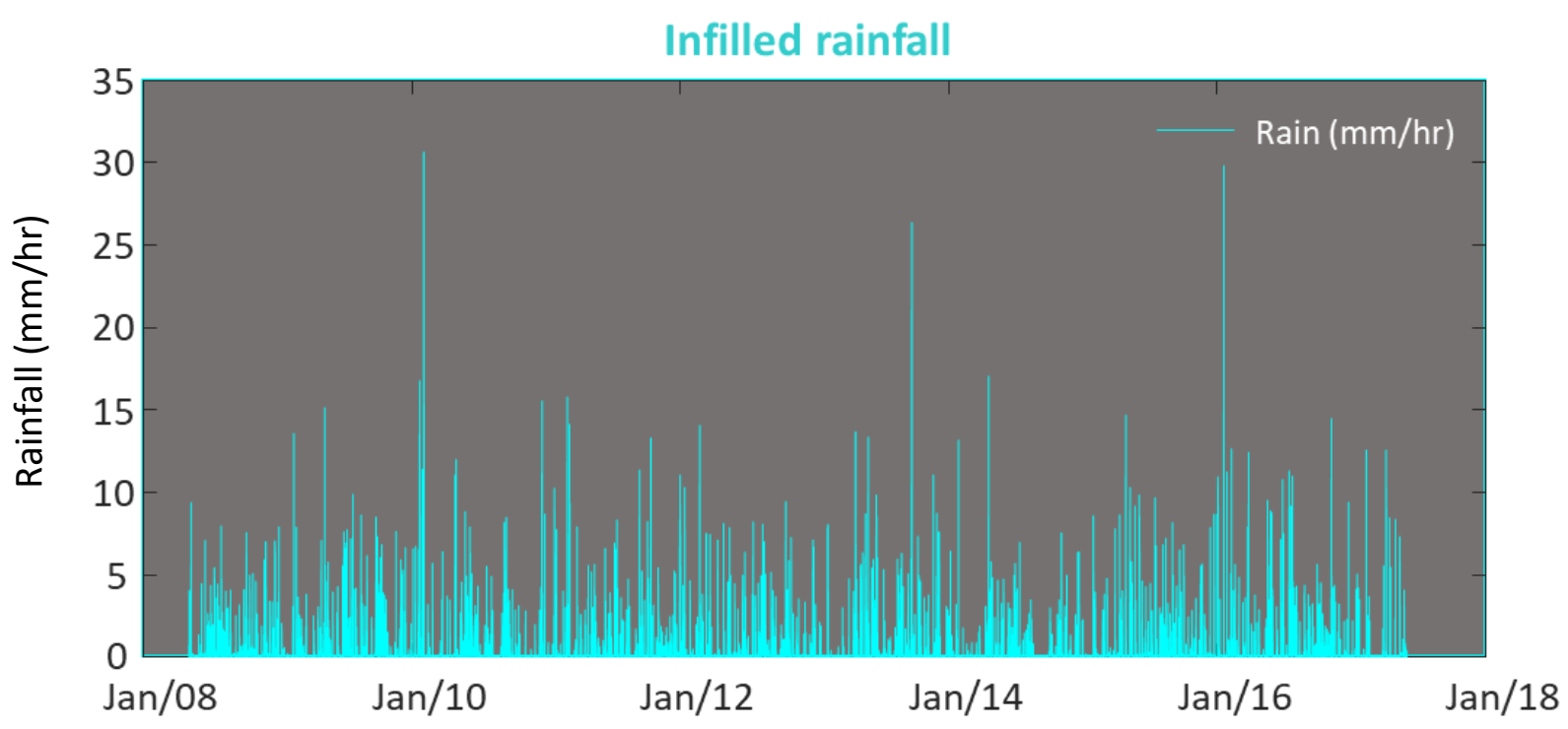

Figure 34: Infilled Te Kuiti hourly rainfall record. 


\subsection{Evaporation}

Evaporation data is needed for rainfall-runoff modelling, to determine effective precipitation and requires at least hourly Marokopa evaporation data. The diurnal signal of the Te Kuiti High School PET was extracted from daily PET and further resolved to hourly resolution using a sinusoidal function. Evaporation data was corrected for hourly radiation, and humidity to represent actual evaporation (Maxwell, 2013).

\subsection{Flow}

While six river flow gauges are within 30kim of Marokopa, no flow data is recorded within the Marokopa catchment apart from Marokopa Falls (Waikato Regional Council, n.d.-b). Marokopa Falls 15-minute river flow was re-sampled to hourly resolution and used for model calibration and validation in the rainfall-runoff modelling of the upper catchment (Figure 35). Flow generated within the upper catchment can then use as boundary conditions for future inundation modelling. Preliminary flood extents, outlined during interviews, are presented in Section 7.2.

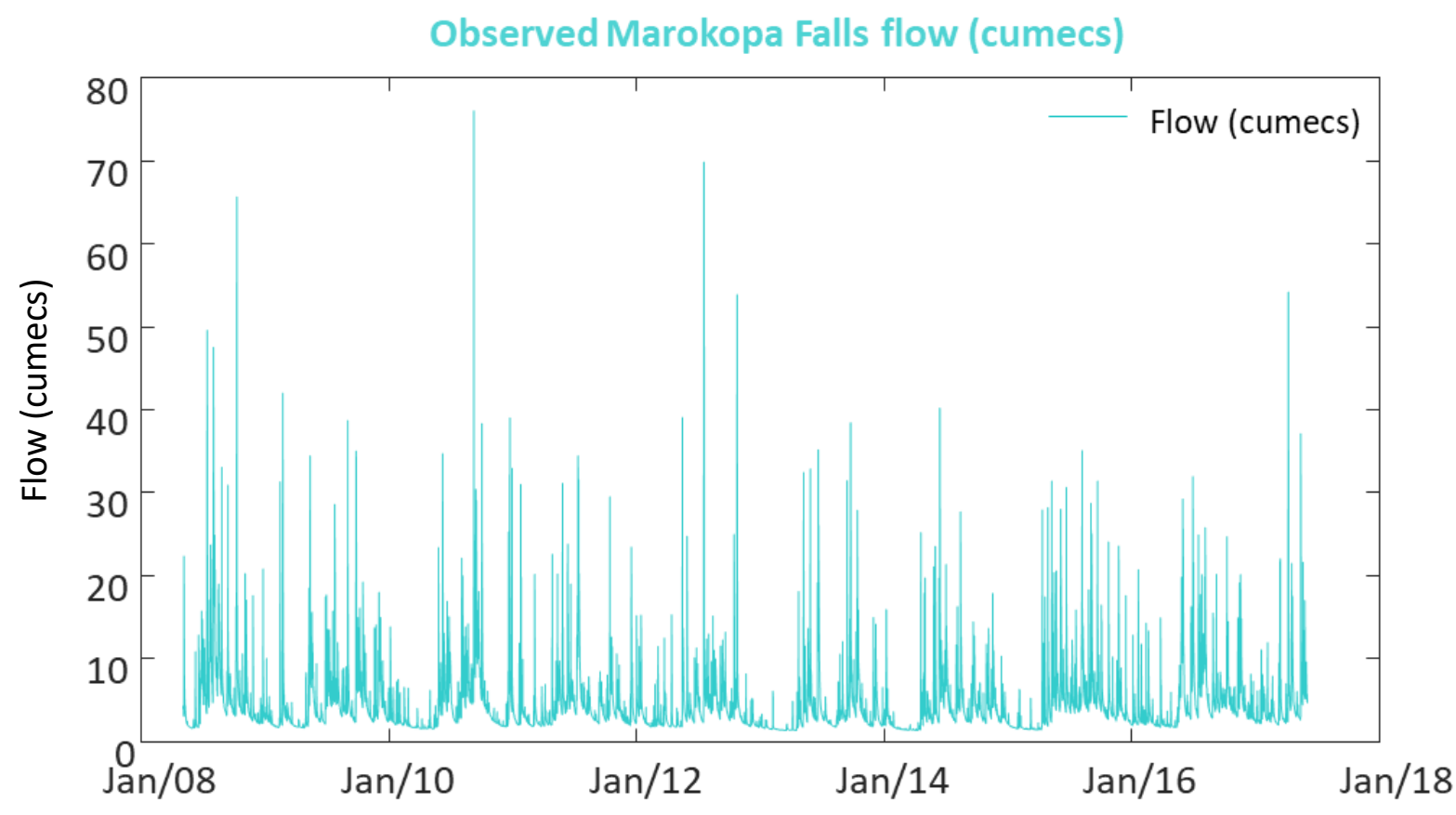

Figure 35: Marokopa falls flow data (data source: NIWA).

Flow calculation within ES modelling

LUCI can use rainfall, temperature and evaporation datasets to simulate climatic response within various ES. For further detail on the LUCI ES method, see Section 4.3. Modelled flow outputs are dependent on low-resolution raster input 
precipitation, temperature and evaporation rates. Annual New Zealand precipitation (Figure 36), monthly temperature (Figure 37), and actual annual evaporation (Figure 38) from NIWA.

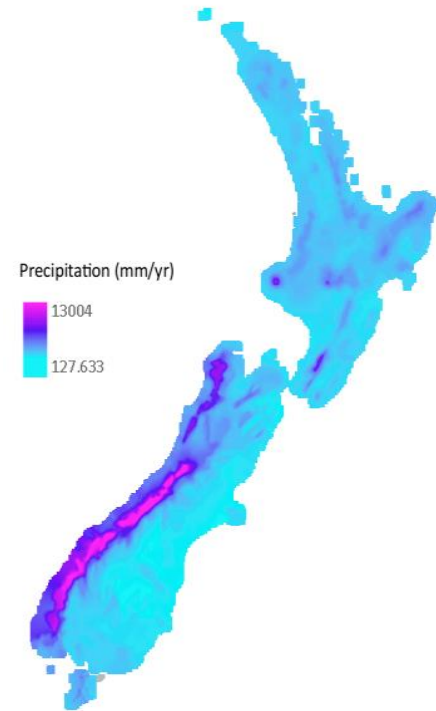

Figure 36: Annual New Zealand precipitation (data source: NIWA).

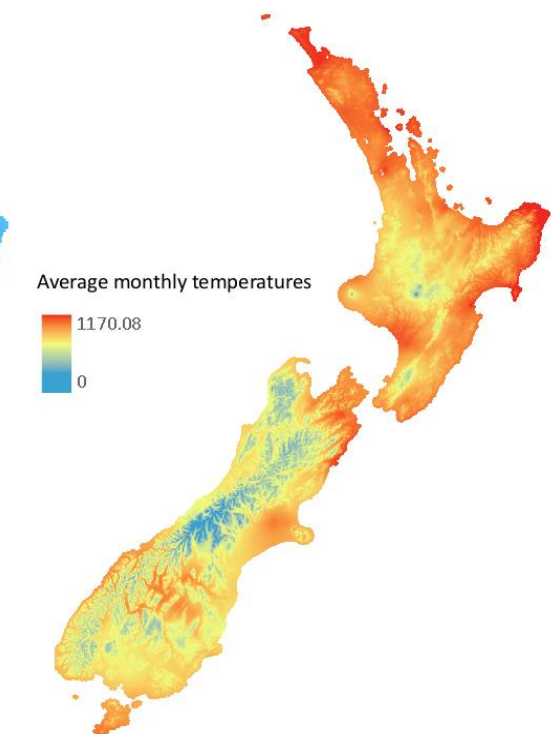

Figure 37: Average New Zealand monthly temperatures (data source: NIWA).
Average annual actual evaporation

1103.61

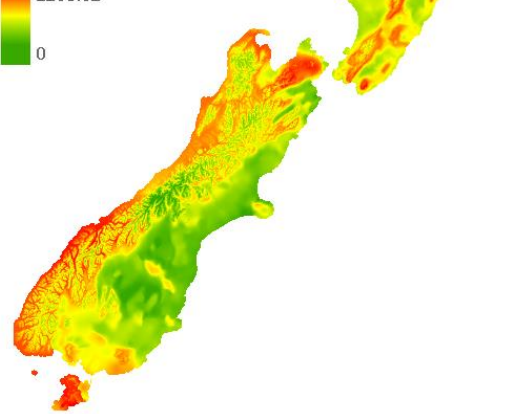

Figure 38: Annual average New Zealand evaporation (data source: NIWA).

\subsection{Landscape}

Digital elevation model (Figure 39), land cover (Figure 40) and soil data (Figure 41) are needed to run the LUCI ES modelling. These datasets come from LINZ. Two DEMs are needed to complete the modelling of this thesis. For the inundation modelling, high-resolution topographic data is needed. Although not completed within this project a $1 \mathrm{~m}$ LiDAR (Light Detection and Ranging) would have been used, as the extent of this covered the entire Marokopa floodplain. Inundation modelling of the Marokopa floodplains, outlined in Section 7.2 would therefore likely have been possible. A second, $8 \mathrm{~m}$ DEM from LINZ was used for ES modelling. Although described as for visualisation only, comparison of ES results with the eight- and $15 \mathrm{~m}$ DEM (also from LINZ) yielded little to no observable differences. Pre-processing using the "burning in" method had a larger impact, as shown by Figure 28 and detailed in Section 4.3. Land cover database (LCDB v4) data is from the summer 2012/2013 period and contains 33 "mainland classes". For better readability, these have been simplified in the below map legends as not all classes are present. The soil data used in ES modelling was the 
Fundamental Soil Layer from LRIS. Although 16 attributes are contained within this dataset, only the Soil Order was used for ES analysis.

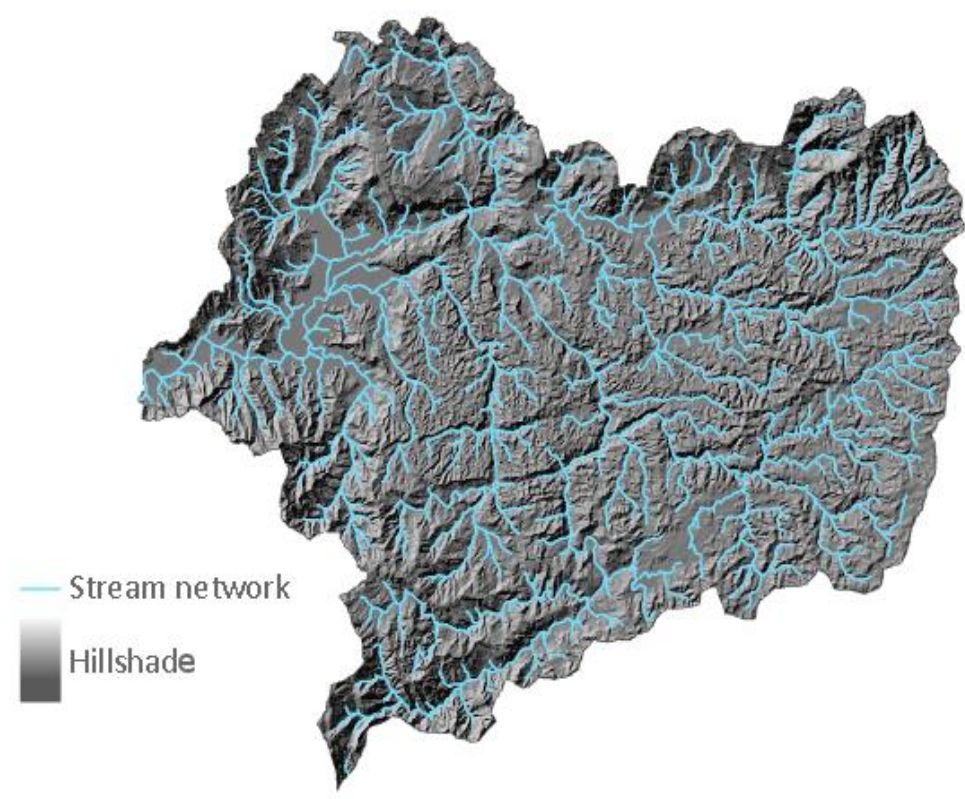

Figure 39: Marokopa catchment stream network (data source: NIWA)
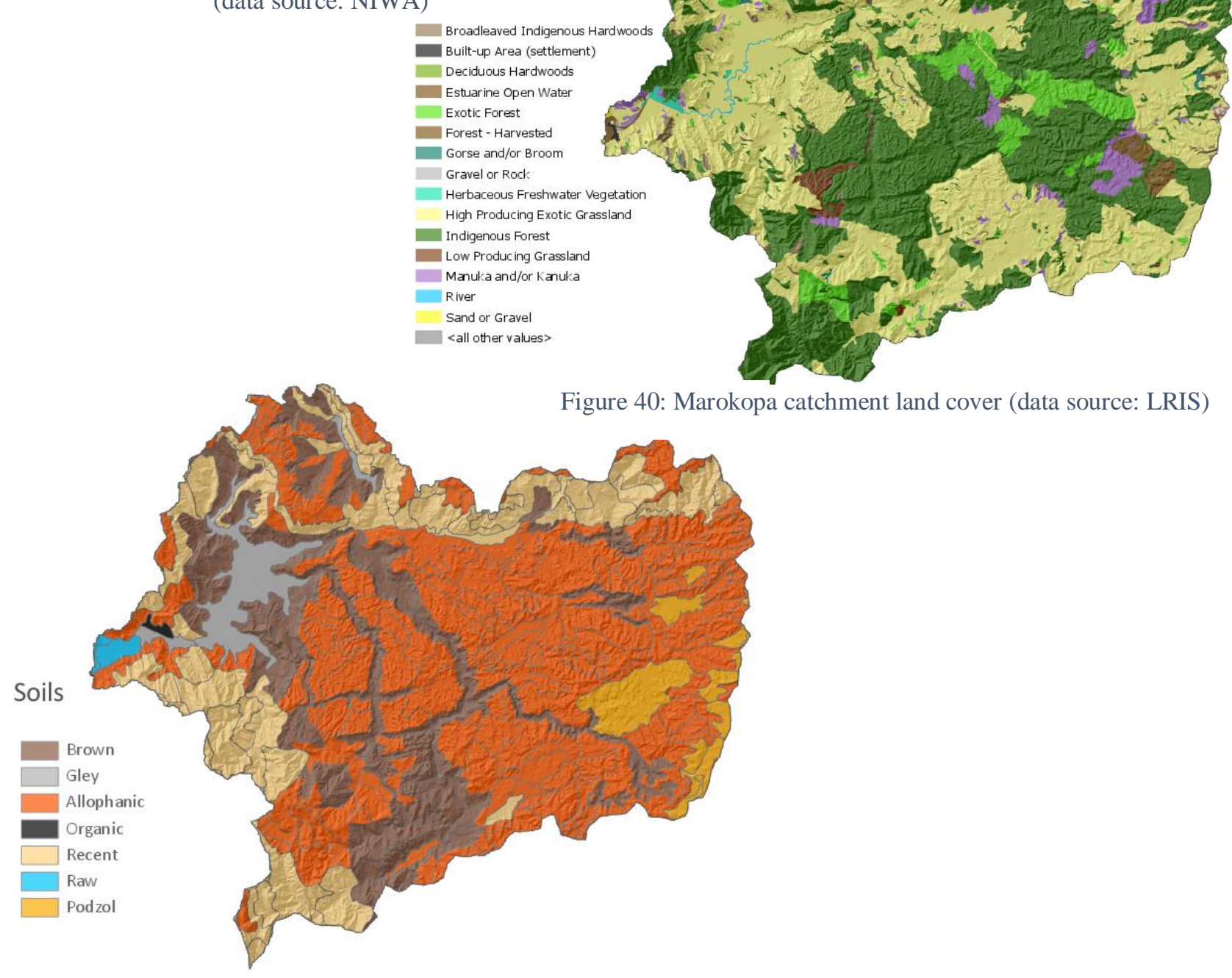

Figure 40: Marokopa catchment land cover (data source: LRIS)

Figure 41: Marokopa catchment soils (data source: FSL, LRIS). 


\subsection{Ocean}

The ocean plays a large part in flood and erosion risk within the Marokopa catchment, as detailed in Chapter (Setting). Figure 42 shows the tidal record for the nearest tidal gauge location in Kawhia, over $\sim 70$ years. While extremely significant for Marokopa flooding, ocean dynamics analyses are excluded from this project's methodology as neither inundation or ecosystem service modelling account specifically for marine datasets and are beyond the time constraints of this project. Such analyses are recommended for future research in the topic of flooding, Marokopa flooding modelling and ES modelling.

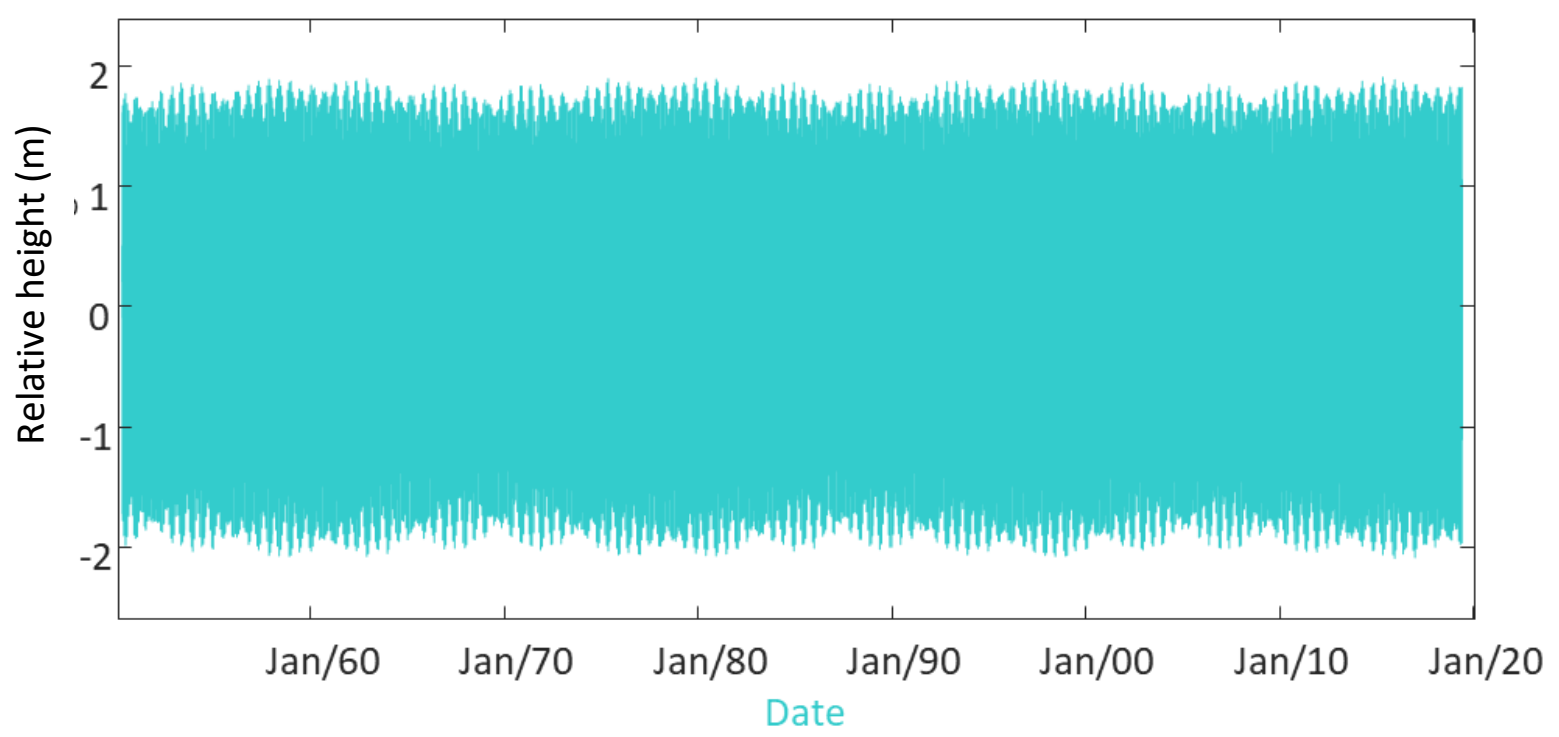

Figure 42: Tidal data from Kawhia (data source: Waikato Regional Council).

\section{Conclusions}

- Neither high-resolution (10-minute) rainfall nor flow are measured at Marokopa. Distal records are instead used within the context of this project. The next closest gauges include Marokopa Falls (flow) and Te Kuiti (rainfall).

- As rainfall-runoff modelling requires a continuous record of rainfall, Awakino rainfall was used to infill Te Kuiti rainfall.

- Evaporation is needed for rainfall-runoff modelling and required the passing of a sinusoidal function in its application.

- Topographic data is required for ES and inundation estimation; the first used an $8 \mathrm{~m}$ DEM while the second used a $1 \mathrm{~m}$ LiDAR dataset. 
- National-scale precipitation, evaporation, temperature, land cover and soil were used for ES modelling. 


\section{Marokopa interview results}

This chapter discusses the qualitative data, which is used to describe Marokopa's flooding history and characterise the erosion and flooding hazards in the area. This data was obtained through interviewing 12 participants, referred to here as Participants A through L. Participants included people who live at Marokopa village, iwi [tribal] members, and farmers from throughout the catchment. Qualitative data were necessary for the rainfall-runoff modelling and inundation modelling, to inform flood, erosion and rainfall-flow relationships within the Marokopa catchment. Analysis of the interviews resulted in themes (Figure 43). These themes were influenced by the line of questions asked (Appendix D) and the participants' descriptions of council-community engagement, land management practices, karst hydrology, and the impact these had on hazards in the Marokopa catchment.

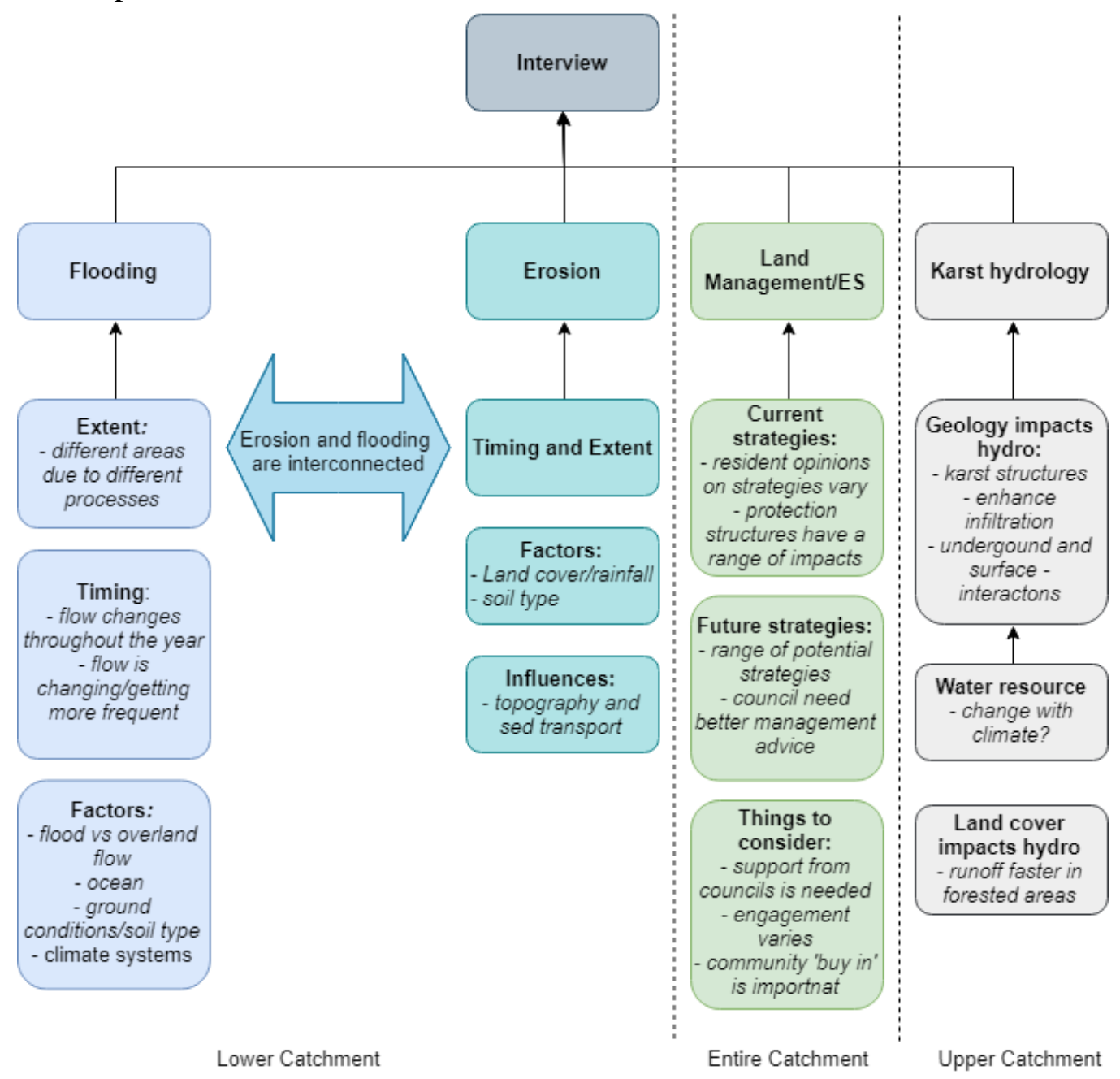

Figure 43: Themes taken from interviews, including what parts of the Marokopa catchment they relate to. 


\section{Lower catchment: Erosion and flooding}

Erosion and flooding impact at Marokopa vary in timing and locale due to different factors. These factors include rainfall, land cover types, soil, and marine conditions which subsequently impact landscape evolution. Furthermore, the interconnectedness of flooding was a common theme amongst participants.

\section{Throughout catchment: Land management}

Participants gave varied responses when asked about current erosion and flood mitigation and adaptation strategies. Many were more interested in future land management decisions. Finally, others emphasised the more indirect strategies of social, political, and economic investment.

\section{Upper catchment: Karst hydrology and ecological values}

The upper Marokopa catchment landscape is significantly different from the lower catchment but has a significant influence on the lower catchment hydrology. One participant outlined the impact geology and land cover have had on the hydrology of the upper catchment, while also discussing different land management strategies around conservation.

\subsection{Flooding at Marokopa: where, when, what, how}

\section{Flood Extent and Timing}

Marokopa flood events vary in location and size due to different driving processes, as outlined in Section 3.2. Participants described the largest flood extents as having covered sections of the main road entering the Marokopa village and majority of the farm plains $\sim 5 \mathrm{~km}$ inland. Both floods were likely caused by bankbreaching flooding. However, due to the significant extent of the farm-flooding, rainwater pooling (overland flow) was also a possible factor. Flooding and rough river conditions impact transport to and from Mirumiru marae and, therefore, the ability of the local iwi to gather for different hui (meetings) and events. Road flooding meant that participants were neither able to leave Marokopa, nor could others come in from "Town” (Otorohanga/Te Kuiti).

\footnotetext{
Participant E: "Well we had a big flood [around 1950], it flooded from there [inland near Participant E's land] right down here to Marokopa....
} 
...We couldn't get out; we were there for days.

There was water everywhere...

...Flooded all the way.

Yeah on the flats [Pictured, Section 7.2]."

Participant I: "Just by the road. Some of the road gets covered, but mostly all the flats out"'[August-September 2017]

Participant L: "Oh, what year was that we had a flood here. We had a big flight right from Te Anga there. The post office got flooded at the junction there." "'[August-September 2017]

Closer to Marokopa village, one participant described the road and strip of farmland nearest the river as more consistently flooded, which is likely due to its reclaimed nature, and waterlogged soils.

Participant K: "Well, sometimes [in the last couple of years] a flood coupled with a high tide, which I talked about. That will put the road as you come into [Marokopa] here [into floodwaters]."

Historically, flooding was mostly a problem in two locations: approximately 5 $\mathrm{km}$ inland, on the flat farmlands; and then just inland from Marokopa village. As flooding is caused by extreme rainfall and high tides climate change is likely to exacerbate both processes.

The speed and height of the river change on seasonal timescales and are impacted by several factors. The tidal Marokopa river form is a combination of water entering the catchment, and marine water "blocking" fluvial water from exiting the catchment. One participant described the river flow itself as significantly lower in summer than winter, as follows.

Participant K: "I'd say that, at normal, you get low periods in the winter if you don't get rain for a couple of weeks. It [the river volume] soon drops back. But in the summertime, when the flow's low, you can walk across in 300, 600 mils of water"... 'I'd say just probably low summer flow compared to normal winter flow. The river's probably only got half the volume of water in it in the summer."

While river flow is significantly lower in summer, floods still occur during this season. Marokopa summer rainfall has historically included drier and wetter periods, with recorded temperatures normally moderate to high. Significant rainfall 
is therefore needed to cause flooding and overcome low summer flows. Participants have different opinions on flood events timing, likely a result of people being in different places when and where they occur. One participant described the increase in flood frequency when asked about how climate change will impact Marokopa as:

\section{Participant H: "Well, I think it's impacted already, you know, in that we're getting more, well, more floods, I guess. I mean, over 50 years, nobody had seen a flood, and then over ten years, there's a flood, and then ten years, there's a flood."}

Climate change may therefore increase extreme summer storms and summer flooding, rather than simply reducing summer rainfall and flow in the catchment.

\section{Factors of flooding}

"Flooding" can be caused by excess water pooling on the land surface, or from water that breaches riverbanks. When describing flooded areas, Participant $\mathrm{F}$ outlined the process of overland flow:

\section{Participant F: "That particular flood, there wasn't a great deal of flood water in the river" ... "But there was just a lot that washed off the land, and yeah the roads were blocked."}

The participant described flooding that was not due to river inundation but instead, overland flow. Water pooling on the ground surface can occur due to intense rainfall, resulting in infiltration excess overland flow or saturated ground conditions (likely due to long-duration rainfall events) can also cause water to pool on the ground surface. This description emphasises the importance of ES modelling, as overland "flooding" rather than bank-breaching flooding (modelled by more traditional hydrodynamic inundation models) is a significant hazard.

Participant $\mathrm{G}$ described the relationships between climate, oceanic setting, and sedimentation with flooding. These processes include the transport of sediment along the river but also the evolution and change of the river channel depth over time.

Participant G: "Our flooding is sheer volume of water on a given area of land, and the ocean can't take it" ..." If the going out water, which will tear out a channel, the coming in [water] will only bring in so much sand" ..." But big floods have huge amounts of water. It's like coming down at high tide for four days. Coming down at high tide level for four 
days. It's still coming down, even when the tide's out. It's still pouring out of the valley."

This quote emphasises the impact of the tide on flooding where water is delayed from leaving the system. Secondly, the participant describes the competing incoming and outgoing flows of water and sediment and states that while both processes occur during floods, the outgoing water and sediment exceeds that of the incoming mass. Sea level rise and projected precipitation changes will likely exacerbate flooding because of increased antecedent saturation.

Ground conditions can increase or buffer flooding occurrence. If soil storage is already full, water must flow as saturation excess overland flow. This was described by a participant from the upper catchment:

Participant C: "It's already almost saturated that soil, when water comes down, it doesn't have the ability to just absorb it and hold it there. It would tend to just run off a lot faster."

As extreme rainfall events are likely to increase in the Marokopa area (Chapter 2) antecedent conditions are likely to play a large part in overland flow. This is similarly true if increased average temperatures increase drought conditions:

Participant C: "We've had a lot of rain just recently, but the stream hasn't gone up because the ground's dry."

As groundwater level is lower in dry periods, increased precipitation may be more readily stored rather than transported through the system as overland flow. Overland flow may increase or decrease depending on the season. Both extreme temperatures and rainfall are projected to increase due to climate change (Chapter 2).

The duration of floodwater is dependent on soil type and ground conditions. Floodwater duration is also related to the permeability and porosity of the ground surface, as identified by the same participant who noticed the change in the subsurface from sand to dirt and the resulting differences in soil water storage capacity:

Participant K: "So you do get times, and we're worse because we're on the sand. If you're down round the camping ground part of the village, and it is a bit sort of bit more dirt. And the lawns don't dry up the same. Which is an advantage in the summer, but they get pretty muddy in the winter." 
Soils have significant flood mitigation capability, as they have the potential to store water. If water can infiltrate into the soil, then infiltration excess overland flooding does not occur. However, with prolonged rainfall, saturation excess overland flow may still occur, as even well-draining soils become fully saturated.

Furthermore, flooding is exacerbated by low-pressure systems and storms. Another participant detailed the impact that the tides have on flooding at Marokopa, especially with low atmospheric pressures, and stated that both systems are needed to get great inundation at Marokopa.

\section{Participant K: "Well, the water sort of goes over there occasionally when you get, usually a really big tide won't do it, you need a flood as well."... "No, generally it won't be a flood by itself. It's usually gotta be a flood and a tide work [ing] together to do it."}

This quote indicates the holistic nature of the earth-hydrology-climate systems, which are dependent not only on the water and sediment volume coming down from the catchment headwaters but also on the water coming in from the ocean and the dynamic channel morphology that results from big storm events. One participant described such events as large and powerful in the following way:

\section{Participant G: "So to me, that's just... We've had huge seas, huge seas come in, big storms, and they've got a power as they wash in, and they're all they've done."}

The ocean is a crucial factor in flooding at Marokopa. While flooding is a hazard, large ocean swells block fluvial floodwaters from leaving the catchment and have the capacity to erode flood protection infrastructure. This marine influence has been seen in action by participants but is also evident when viewing the weathering of the homemade and council-constructed erosion protection structures.

\subsection{Rainfall, erosion and flood dynamics are interconnected}

While flooding was initially identified as the primary hazard in Marokopa, erosion was raised as a significant hazard at several meetings that took place at Marokopa. Participants gave a mixed response when asked about whether flooding or erosion was a more important hazard in Marokopa.

Participant K: "Flooding and erosion? I'm not worried about flooding. A little bit concerned about erosion." 
Participant H: "Well, I think it's the erosion and I suppose, they go together, the flooding causes the erosion."

Participant J: “Flood.”

Participant I: "Flood".

Participant I: "Only time it [flooding] affects the village is when they get the rough seas."

This range in opinions shows that both hazards should be evaluated as either individually or combined, flooding and erosion impact the Marokopa community on different spatial and temporal scales.

Eroded hillslope material is transported to the floodplain during heavy rainfall, collected and then redistributed by the river. Participants described the swollen, brown, sediment-suspended river which eventually left debris behind on the river banks:

Participant H: "So with the result of all that mud coming down, well it ends up in the river and then it comes down here. And those sands, the sand was just brown like the mud flats there all the way down, right the way down."

This response was echoed by an inland participant who had identified the impact of land use on erosion and described the combined impact of heavy rainfall and land use (cropping):

Participant C: "He said, "Well, they cropped it and then there was some rain and all the topsoil just went straight down the side of the hill and it half covered their fence. We're talking like a serious quantity, tons of topsoil we're talking about, and that was just one episode."

This response highlights the importance of managing and using land in a fitfor-purpose way. The participant identified flat land as more suitable for more intensive farming, like how the ecosystem service tool characterises the Marokopa catchment. They further supported what other participants described that erosion occurred randomly throughout the catchment, affecting isolated areas.

\subsection{Erosion at Marokopa; where, when, what, how}

Erosion at Marokopa is tied in with many different systems including the hydrology, the soil, land cover, and the social systems within the Marokopa catchment. Erosion experienced by Marokopa residents and property owners ranges 
from viewing large land scars on the steep hillsides through to the direct effects of landslides blocking roads and the erosion of property.

\section{Erosion extent and timing}

Erosion is a large control on Marokopa topography and sediment transport, especially due to the large magnitude of erosion events. Two participants described the wider region as having similar or larger erosion events. This is likely because of the similar topography and land cover that cover the wider region (Section 2.2)

\section{Participant I: "Not so much here on this ... But it happened there [over the hill to the north of Marokopa], where we lived. Yeah, you would see the slips down there, though. They were huge."}

Most participants lived in different areas throughout their lives (some inland, others further north or south along the coast) however all have lived in the Marokopa catchment for some part of their life. These descriptions show that slope failure and erosion are significant hazards for communities along the entirety of the Marokopa coast.

Temporally, erosion at Marokopa village is seen by the participants as a more direct and constant threat than flooding. In contrast, vast hillslides occur infrequently near the village. More frequent landslides occur inland on steeper hills, although they are still rare events.

\section{Participant K: "We've been here 26 years, and it's always been something you remark about is how well the hills hold. They don't get big slips and erosion and they're steep."}

While the participant explained that significant erosion events at Marokopa are rare, this description differs to my own experiences of Marokopa. Participants may underestimate the hazard of erosion within the Marokopa catchment as such events are a part of their daily lives.

\section{Factors of erosion}

Land cover and heavy rainfall impact erosion, with erosion prevalent in areas of HPEG when combined by intense rainfall. Examples include landslides and increased precipitation washing out waterfalls on two participant's property. One participant outlined the following event: 
Participant K: "'Cause recently we had that bit of very heavy rain went through last, must've been in middle of last summer. That caused most of these recent slips up the valley "... "And normally the bush doesn't slip, but it did with that one."

The participants recognise the ability of forestry to stabilise the hillside and prevent erosion. This is consistent with global studies and the existing parameterisation of the RUSLE algorithm used within the ecosystem service modelling (Section 7.3) (Yang et al., 2003).

Dominant land transport processes are more likely to be slow-state creep rather than mass failure, according to Resident K's description of erosion at Marokopa. The stability of the hillslopes is higher than initially thought which could be due to a consistent network of shallow-rooted grasses, the dip direction of the geological strata (resisting erosion), low stock numbers, or more stable soils. However, with intense rainfall, the friction of the mass is overcome due to the lubrication of soil particles. Several participants remembered events where they could not leave the area due to landslides, although this occurred less frequently than annually. Soil type influences erosion magnitude. One participant explained that sand was more erodible than the hardened silt bank, landward from the river and ocean.

Participant K: "Erosion is occurring up here [at Marokopa] now. It certainly would've washed certainly some of that [the Marokopa spit] away if they hadn't been there, yeah. Because it's quite sandy there [near Marokopa village], like up here a bit, there's [closer towards the hillside] a bit more of a hard bank, but here [near Marokopa village], it's quite sandy where they are."

Marokopa property owners, notably opposite the Marokopa spit, identified erosion as the process which is likely to cause the most, and near-future impact, with erosion described as a risk to property.

\subsection{Land Management/Ecosystem services:}

Several participants outlined different methods on protection, adaptation, or mitigation to ameliorate erosion and flooding, both in the lower and high elevations within the Marokopa catchment. However, participant opinions on mitigation and adaptation structures varied. When asked what could be done to prevent flooding, one described the power of the ocean, saying that nothing could be done: 


\section{Participant L: "I don't think you can do much down there, the water's got power."}

This citation aligns with the managed retreat process that the Waitomo District Council currently has in place. Another participant outlined the competing interests of individual and government/council parties.

\section{Participant G: "And my experience is that sometimes the authorities are a barrier to doing it [protecting residences]. They've got some purist idea that you can't try and stop the sea. And it's their money. Even when [people] are willing to spend their own money to protect their property, they've gotta overcome bureaucracy to be even allowed to."}

This response emphasises hazards as a social, economic, environmental, and political issue. Long-term plans involve managed retreat which accepts nature's role in changing the landscape and designing townships around such changes. However, this does little for property owners who have invested money into beachfront properties and have lived in such areas for decades. Erosion mitigation structures have been used to protect various properties at Marokopa village. One resident put in a foundation wall in front of their property but when asked, another of the participants highlighted a problem for such structures:

\section{Participant K: "They're okay. Their weakness is their foundation, and if they get eroded underneath, well then they collapse."}

Erosion protection structures have been used in the past at Marokopa village, however, due to recent district plans, they are less likely to be implemented. At a Waitomo District Council meeting in August, consultants outlined the different adaptation strategies, including rezoning, managed retreat, and hard structures, including the advantages and disadvantages for each strategy. One strategy discussed was a sea-wall which replaced a homemade structure made by a participant. Another participant explained that sea walls appeared to divert water across the river, potentially causing secondary flooding or erosion. This was especially important as participants described marine waves that travelled around the entire village point (below). Furthermore, across the river at the marae, the fence-line has been moved further inland several times as erosion occurs (pictured below). Participants described the estuary as a dynamic area, further supported by a comparison of the changing estuary morphology from the WDC and consulting group. Their image below contrasted the 1944 river boundary to the 2017 river 
boundary, indicating where erosion and where sedimentation occurred. The river has changed dramatically over time (Figure 44).
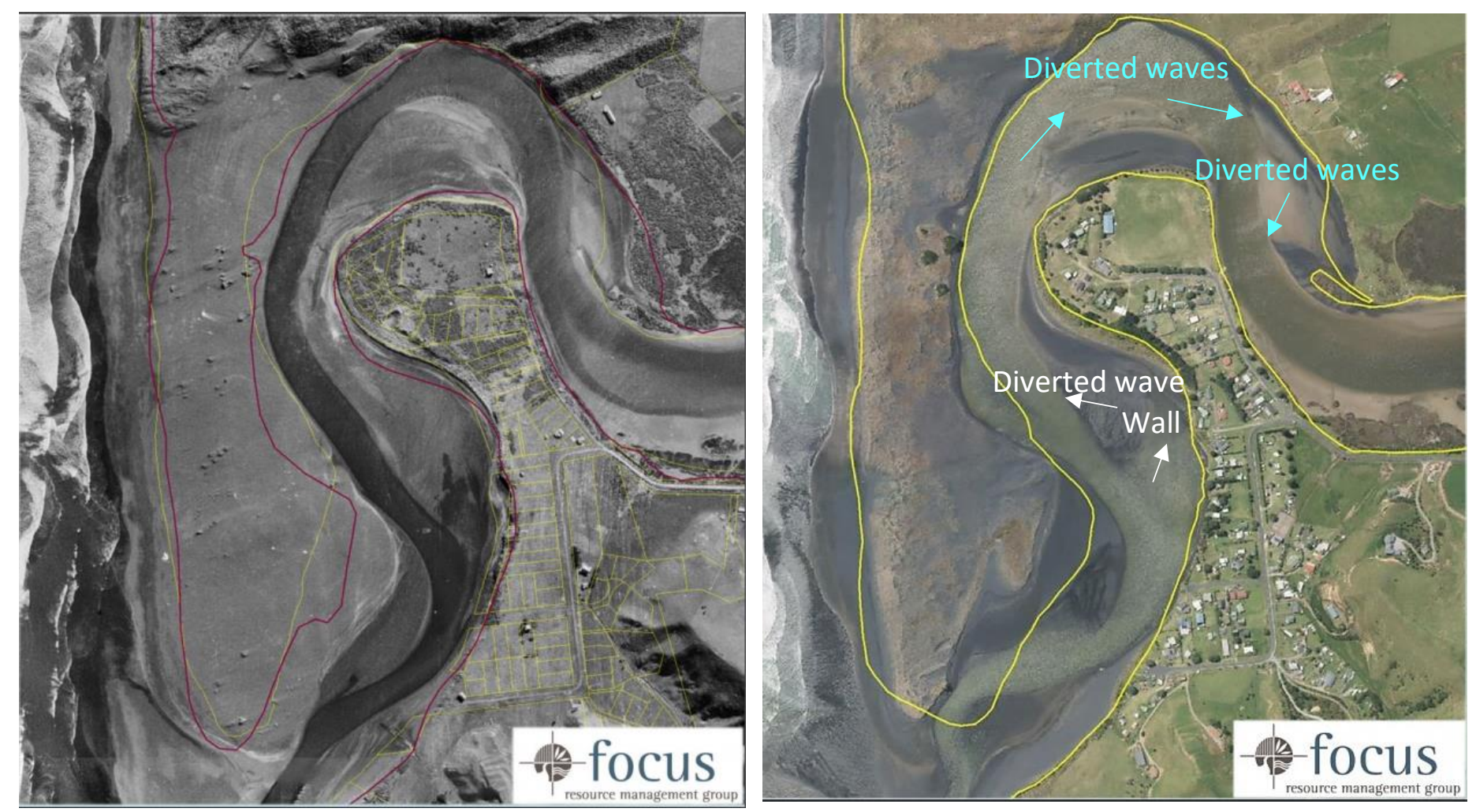

Figure 44: Comparison of Marokopa water level and wave diversion from 1945 (left) to 2017(right) (Focus, 2018). Natural diversion (light blue), structures and structural diversion (white).

Land management advice is needed to protect the holistic values of the landscape and best inform future land management strategies. Farmers face complex problems around conservation and maintaining farming practices, often relying on the advice of district or regional councils. The question being asked more frequently is whether economic benefits should still outweigh environmental ones and, if this is not the case, what next steps are needed, as one participant outlined.

\section{Participant C: "Any waterways above ground would need to be fenced. Any wetlands would need to be identified and probably dealt with appropriately, like what we've done, we've just used single wire electric fences."}

The participant also emphasised the importance of balanced district council advice, as it has not always led to good outcomes. The participant mentioned that pine trees planted under council advice were previously not accessible for removal, resulting in eventual slope destabilisation. This results in economic and environmental losses from an initiative that farmers were told would benefit the environment. This poorly thought out advice is a problem not only for one 
generation but often for many, as farmland is often held for generations. Farmers often have legacies to maintain and build on.

Participant C: "You know, I mean, you know, my family, they've identified these things and they don't want them touched. They want them to be appreciated. They want them to be maintained and this was the best way forward."

Intergenerational conservation is often referenced within Māori culture; however, the above quote shows that such ideals exist within New Zealand's farming community too.

Dune or river bank planting is an option to prevent erosion, made especially viable when funded by local councils. When asked about erosion adaptation measures, participants described the support local council gave when undertaking planting on their family land:

Participant H: "Environment Waikato, it used to be. They supplied all the plants to plant right around. The council provided the materials, the wire and the posts, and we put it up."

This quote highlights the potential for planting at Marokopa, where ES output maps can further prioritise areas for investment. However, as LUCI is a land rather than estuarine or marine ES model processes such as scouring may not be fully realised. This is especially important when making decisions about the land near the marae, with one participant describing the following:

Participant G. "From here down, I think you need to reclaim the edges of the river, and strategically put plots and establish some [ground] that's strong and can't be washed away" ... "It's just taking too much [land] away from behind."

Participants acknowledge that erosion is a hazard for the Marokopa land and are interested in putting in adaptation and mitigation structures to prevent further land being lost.

Management is also needed to protect ecologically and environmentally valuable areas, such as restricting the drainage of wetlands. This process was highlighted by a participant farmer, who describes the draining process undertaken by owners who did not know or acknowledge the environmental or ecological value of wetlands during the 1970s. 
Participant C: "They had swamps across the road [at Te Anga]. They don't have swamps anymore because they've drained them and buried them" ... "But instead of preserving that they've destroyed it. She's gone. Gone, gone. There's no habitat there anymore" ... "It's not their fault. It's the fault of probably, in some ways it will be the regional council or the district council, for not having anything in place to monitor how people deal with their land. If it's not their fault, it's the fault of our people not informing them that this is how we want our areas to be dealt with, and if we don't we're all to blame. Ignorance ain't an excuse anymore is it, you know."

Participant C: "I think that really, we've got to put the money aside and start to look a little bit wider and think a little bit further ahead, because at the end of the day, I reckon that this is probably our last shot to get it right because I don't think farmers generally will be able to afford to get it wrong."

These citations highlight the importance of communication between regional/district councils and individual landowners and the lasting impact poor management decisions and policy can have on future generations. Risk management modelling is often confusing to access, understand, and transform into farm-scale applications, something that councils and scientists need to become more aware of and actively focus on. Ecosystem service maps such as LUCI output can increase engagement between two such parties and communicate holistic land management for increased ecosystem benefits.

Guidance for future sustainable farming practices, around stocking classes and cropping are needed to prevent erosion, sedimentation, and improve water quality. Participant $\mathrm{C}$ explained that having heavier stock on steep terrain is likely to lead to erosion. While the Waikato Regional Council provides a stocking rate calculator, farm stocking rates are not regulated and council rely on farmers prioritising the environment over potential economic gain when making land management decisions.

Participant C: "So, you got your sheep [they] don't cause a lot of damage to your soil structure, but a bull does. If you've got bulls on steep country over the winter and it's raining, she's all on."

Farmers see and manage their land through varying land and climatic conditions and are therefore the best source of information on such practices. This emphasises the benefits of engaging with different communities to improve land 
management strategies. Cropping is the process of planting crops on arable farmland when it isn't being used for grazing. Crops range widely from feed to economic crops and have associated positive and negative impacts (Millner et al., 2013).

Participant C: "I think that probably with cropping, it should be a consentable process, just the same as like you get a consent for chopping down trees" ... "with cropping, the guidelines might be there, but there ain't any rules really around it at this point."

While separate guidelines exist around best management practices, no regulatory process is in place for something which has a significant impact on the environment, especially when loose soil is impacted by heavy rainfall (Glassey et al., 2009). Ecosystem service mapping would help farmers identify not only ideal stocking classes and cropping locations (agricultural productivity) but also the best nutrient leaching areas for buffering vegetation. Participant $\mathrm{C}$ identified the offsetting of potentially problematic land use (stocking, cropping) with riparian buffer/vegetation zones and their multiple benefits: such as ecological value; habitat connectivity; and economic potential. Furthermore, the need for distributed land management practices based on topography, geology, and soil type was stated:

\section{Participant C: "Farmers also, once they've identified those things, they need to come up with strategies that will work for their geology, because the geology changes on the way out to the coast."}

Many district policies are generalised to cover a broad variety of landforms, land uses, and land covers. However, this means that no practice specifically fits that of any farm or community. Farmers need better land management advice from councils. As the number of stakeholders and areas that district and regional councils cover are vast, policies that governing bodies draw up must cover a wide variety of settings and communities. However, this has resulted in regulations and guidance that are too general, as described below by the participant $\mathrm{C}$ :

Participant C: "We're not ignorant to it, but we can't expect every farmer in the region to be an expert. This is the thing that really disturbs me a little about the approach. I mean the regional council, they've got some of the experts, but they can't be expected to do everything."

Better management strategies require investment, council and most importantly, community engagement. The cost of better management is substantial 
with communities and farmers needing support from local councils. With new guidelines and ecological/land management expectations from the government and the wider community, farmers are under pressure to make extremely vast and expensive changes to their land within small timeframes:

\section{Participant C: "The plain reality there is that a lot of farmers are going to really, really struggle to do what we've done in how ... nearly 40 years it's taken us to do this and we're been asked to do it in five. So, this is going to be the problem."}

The participant reiterated that conservation was worth investing in, as water was a shared resource not only passed down to those further down the catchment but also through generations:

\section{Participant C: "That's the difference, we're talking about the water on our farm here, but it's not my water. It's everybody's water"}

Community and council engagement are important, however are also historically overlooked by both the local district council and community of the Marokopa. Several participants described the recent scouring that properties near the river mouth experienced, yet the demographics of people attending local district council meetings are not diverse.

Participant H: "Well, you know, I would think that they should be [here]. But we had a council and environment meeting in August. Not many of them [bach-owners] came."

Blackett and Hume (2006) described historical council-community engagement, outlining the significance of the Marokopa spit and Tupuna burial grounds to individuals and the community alike. In working together, the issue of erosion was co-managed when the council's resources and local energy were invested. This quote highlights the difference in trust and response by the community, with some staunch advocates and some less involved parties. Additionally, the council has a responsibility to engage with all types of stakeholders. Furthermore, community "buy-in" is needed to make good environment management practices permanent:

Participant C: "I actually think that that's probably the one thing I've learned. You can't make people do things, they've got to actually want to jump on board. That's why I think, like I'll be talking to our catchment group that goes down to Marokopa, about things that I think are 
important. But, until the right person comes along and voices their view, I don't believe that I'll be heard. But if the right person comes along, they will be heard. That's the thing, is having that person, and I believe it's got to be coming from a representative of probably one of the Marae and probably down at Marokopa. “..."That's where the voices have got to come from, I think."

Change does not occur without investment by different stakeholder groups. Better land management is the result of historical observation, community-district council engagement with diverse groups, and good policy.

\subsection{Karst hydrology, factors and sources}

The upper catchment of Marokopa is an important area as it captures a large amount of rainfall that impacts downstream areas and because future modelling for the lower Marokopa catchment is based on the outputs from modelling of the upper Marokopa catchment. Water movement is affected by the karst geology and resulting structures. Several other hydrological and ecological studies have taken place on the same farm of a participant in the upper Marokopa catchment (Gunn, 1978; Gunn, 1983). These studies looked at the rate of infiltration and drainage through to an on-site cave system:

Participant C: "He [Gunn] knew how fast that related to moving through the soil and the rock, and to the waterways and out again. Yeah, so he got some good information there, I think."

Water that travels through the upper Marokopa catchment system, underneath the reserve, is unlikely to have been open to surface conditions, until draining from caves further downstream. The participant also went on to explain the use of tracer dyes, which were used to define the location and timing of waterways throughout the research area.

Participant C: "It'd be measuring flow and the same here."..."So he'd put dye in and he checked where it came out. And so he'd defined like all of these little tributaries above ground, he defined where they went and where they came out at the bottom. And then he'd started a study and it makes you realize just how, just how complex it is really, it's like all these little veins draining back."

As the landowner described, the underlying karst geology can be expressed at the surface as a series of depressions: 
Participant C: "Under both areas [farmed and forested] is polygonal karst which is an unusual formation of karst where it almost looks like, sort of like an egg carton. It's sort of got lots of depressions, all these depressions. They're all called dolines and so they form like a sink basically, and the water will drain through the base of these things, down into water systems and because the karst is sort of semi-porous, it will drain out into the water course."

This citation highlights the difference in landscape drainage as water collects in depressions and then drains down to the epikarst and endokarst structures underneath. The participant also outlined where two main Marokopa tributaries drain off his property, one of which goes underground for approximately $900 \mathrm{~m}$. Outside of the participant's property, water has therefore drained through natural forests and cave systems.

\section{Participant C: "It [water] flows faster through a crack, and it actually can flow right out the bottom of the limestone."}

Karst systems can increase infiltration at large and small scales, as shown by the comparison of disappearing streams and micro-fissures. Many mechanisms of throughflow are documented within karst hydrology research, which, as indicated by Participant $\mathrm{C}$, can result in water exiting the system more quickly.

\section{Land cover and soil saturation influences hydrology at Te Anga}

Runoff is faster in forested areas with sparse understory, as explained by Participant $\mathrm{C}$, who suggested that faster runoff occurs in forested areas due to ground being saturated because of a shaded, sparsely vegetated understory:

Participant C: "And so, so you imagine a forested area that's really shaded, that soil is already damp underneath though because it doesn't get dried out the same way as the stuff with just a little bit of grass on top of this. And I suspect that, that has something to do with it because it's already almost saturated that soil, when water comes down, it doesn't have the ability to just absorb it and hold it there."

As a resource, water will be impacted by climate change and is a complicated system. While extreme runoff volumes and resulting floods are the focus of this thesis, problems can arise due to lack a of water too. This is especially relevant for reticulated water and keeping animals hydrated, a problem that farmers currently face, and is likely to increase due to increases of temperature with climate change. 
Participant C: "One of the real scary things up here and, and it should have been scary for the rest of the country too, is when we have these dry spells, and I see the water drying up on our farm. It makes you realize just the mortality of us, we're just animals and if the water dries up, it doesn't take long before everybody's in trouble."

Fortunately, the participant's farm has "true water sources" that have never dried up.

Participant C: "This is where we started identifying the true water sources on our farm. This one was good as gold. This one was, this one was a strong, a strong, never dried up, never really slowed down."

This quote highlights the potential problems and benefits that farming communities are likely to experience in future decades. With a complex subsurface, land management is often reliant on landscape features that are not well understood. Sustainable land management must therefore account for karst geological processes, as they have significant impact on surface hydrology.

\subsection{Summary of qualitative results and findings}

\section{Lower catchment findings}

- Marokopa flooding extent, timing, and impacting processes were described. Flood events were categorised into inland flooding and estuary flooding.

- These occurred on different timescales and occurred due to different processes including rainfall, soil type, antecedent soil saturation and marine conditions.

- While opinions vary on the frequency of flood events on the decadal scale, both seasonal and tidal variations have a significant impact on river volumes. Other factors include storm system type and land management strategies.

- Participants outlined that erosion is a significant Marokopa hazard that occurs on both the hillslopes and beach-front edges of properties.

- Rainfall, land cover types and soil impact erosion, with landslides following large rainfall events.

- When comparing erosion and flood hazards, participant responses varied as to which presented a higher risk. The interconnectedness of the hazards was outlined by the fact that erosion increases the impact of flooding and that flooding can also cause further erosion. 


\section{Throughout the catchment findings}

- While participants' opinions vary on current management strategies, they agree that more can be done for the future to protect the landscape against flooding and erosion.

- Potential land management strategies include planting, preventing land drainage and increasing regulations around farm cropping and stocking rates. Aside from these strategies, concepts such as acknowledging land management change costs and engagement by council and community were also highlighted as important.

\section{Upper catchment findings}

- While the karst geology lends the upper catchment to different hydrology and geomorphic landforms, the impact of forestry and farming are like those experienced in the lower regions.

- The karst hydrology was described as having a significant impact on the hydrology of the area, potentially increasing infiltration with the underground and surface stream networks likely to impact each other.

- Water was also highlighted as a resource that increases in importance but decreases in quantity with climate change thus increasing the need for support and investment by the farming and governing communities.

- Erosion and ecological value loss are significant issues within the upper catchment.

- The call for better management strategies, and bringing different voices to the table, farming, governing, and participants. 


\section{Flood modelling results}

This chapter presents the flood modelling results, which are divided into three sections. Section 7.1 discusses the factors that impact the rainfall-runoff modelling and presents rainfall-runoff model output hydrographs for eleven floods. Section 7.2 outlines the preliminary inundation results, including historical flood extents and topographic inundation analysis. While it was the intention to undertake flood inundation modelling, due to data scarcity, the complexity of the rainfall-runoff modelling (needed for inundation modelling), as well as time and data constraints, this chapter instead examines datasets for future inundation modelling. The third section (Section 7.3) presents the flood ES output, namely the flood mitigation, interception results and denudation as water and sediment dynamics are interlinked.

\subsection{Rainfall-runoff results}

Rainfall-runoff model fit is impacted by four components: the accuracy of the input conditions; the model structure; model parameterisation throughout time; and missing data. This section discusses these four components before presenting the modelled results.

\section{Input climate conditions}

Rainfall-runoff modelling simulates flow from calibrated relationships of input rainfall and flow paths. Input rainfall patterns, and how they relate to observed flows, are the foundation for such modelling. These relationships are examined below for the 12 floods modelled: this model aims to represent extreme peak flow, rather than the rainfall-runoff conditions under 'normal' conditions (Figure 45).

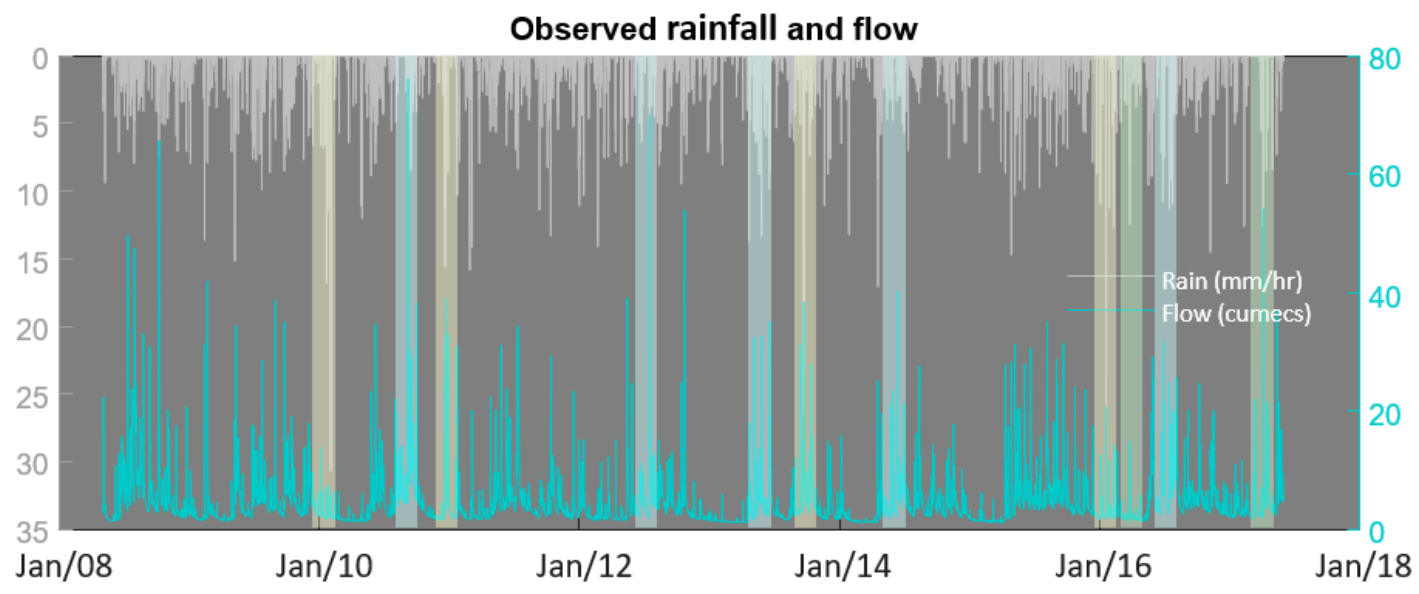

Figure 45: Marokopa Falls flow with 12 modelled flood periods indicated, colours indicate summer (yellow), winter (blue) and interview-described floods (green). 
Concerning the earlier flow duration curve (Figure 14), we aim to represent the highest flows at approximately 5 cumecs or higher, as these are likely to result in flooding. These only make up less than 5\% of the flow record at Marokopa Falls.

\section{Flood event characterisation (observed rainfall and flow)}

Floods and high flows can occur at any time during the year, as shown by residents' accounts, resident footage of flood events, and correlative flow records at Marokopa Falls. Each precipitation event and flow response is independent and unique. However, flows are generally lower in summer and higher in winter. Significant differences throughout the year include changes in precipitation patterns, with summer rainfall usually short but intense. In contrast, spring, autumn, and winter rainfall events can last days, occurring more frequently. The flow response to these events varies seasonally, with summer flows dominated by baseflow sources, while winter flows have higher proportions of fastflow sources. Furthermore, water generally leaves the catchment more quickly during the winter months. High flow event ( "floods") rainfall-runoff characteristics are described, before the analysis of modelled flow results to contextualise events.

Ten floods were visually identified through the flow record while two further flood dates were identified by interview participants. One participant-recognised flood coincided with an already-chosen flood period, resulting in the analysis of eleven floods, which are numbered by the date that they occurred. For this analysis, seasonality plays a large part in determining rainfall-runoff relationships. Therefore, the floods have been re-categorised into 'summer' floods, 'winter' floods, and 'spring-autumn' floods with associated letters. The summer events include floods one, three, six and eight, while the spring/autumn floods consist of floods two, five and eleven. The winter floods are made up floods four, seven, nine and ten. Furthermore, each flood was modelled using a parameter type-specific to it's season.

\section{Summer floods}

Flood 1 is driven by three short, but relatively intense rainfall events, followed by two significantly larger rainfall events (Figure 46). The first recorded over a day and peaking at $\sim 17 \mathrm{~mm} / \mathrm{hr}$, with the final rainfall event reaching over $30 \mathrm{~mm} / \mathrm{yr}$. In contrast, the overall flow at Marokopa Falls is low. Five small responses to flow 
are seen, however none are proportional to the rainfall intensity; high rainfall at $\mathrm{Te}$ Kuiti does not necessarily result in higher flows at Marokopa Falls, nor does low rainfall at Te Kuiti always result in low Marokopa Falls flow.

Summer floods
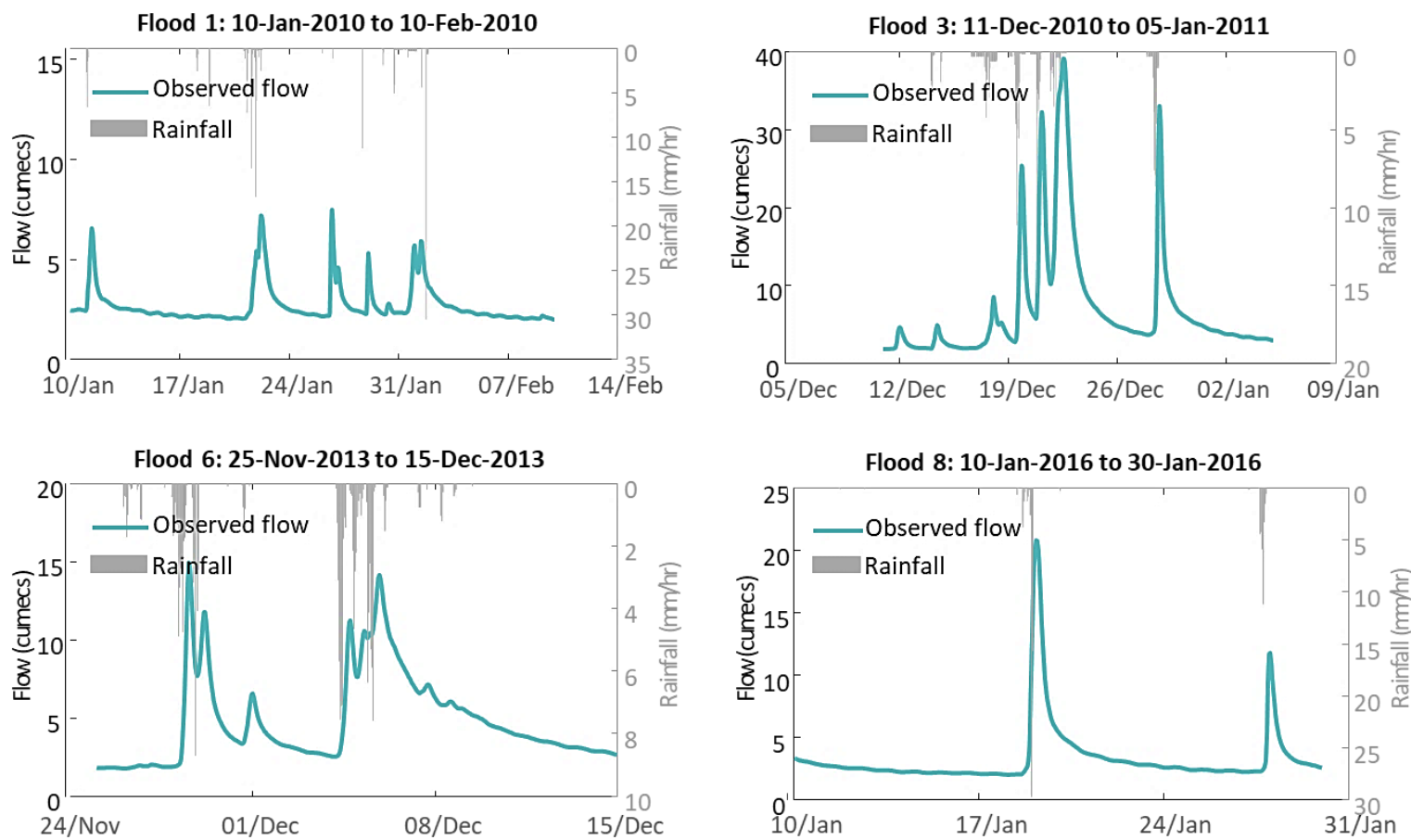

Figure 46: Observed summer flood flow and rainfall.

Flood 3 shows a cluster of moderate-large rainfall events with a week of dry conditions on either side (Figure 46). The four rainfall events, starting from $\sim 19$ th Dec, occur every two days and peak intensities of $\sim 4 \mathrm{~mm} / \mathrm{hr}, 11 \mathrm{~mm} / \mathrm{hr}, 15 \mathrm{~mm} / \mathrm{hr}$ and $4 \mathrm{~mm} / \mathrm{hr}$. A final $\sim 9 \mathrm{~mm} / \mathrm{hr}$ occurs eight days later. Significant flow response correpsond with each peak with 28, 32 and 39 cumecs. The residence time of the water is greater than what can exit the system between the four rainfall events, as shown by the increasing baseflow proportion.

Flood 6 has three major rainfall events, the first is an extremely short duration event, that peaks at $\sim 11 \mathrm{~mm} / \mathrm{hr}$ (Figure 46). Following this are two rainfall events with two-three-day duration, and intensity of $9 \mathrm{~mm} / \mathrm{hr}$ and $8 \mathrm{~mm} / \mathrm{hr}$ respectively. Preceding each event is approximately a week of dry conditions. Regional dry conditions likely reduce flow during rainfall events, as the groundwater storage is depleted meaning that more water can be stored rather than leave the catchment. This process is shown by the small flow responses (15, 12 and 14 cumecs). 
Flood 8 comprises two high-intensity rainfall events $(30 \mathrm{~mm} / \mathrm{hr}$ and $12 \mathrm{~mm} / \mathrm{hr}$ peaks), separated by nine days of no rain (Figure 46). Moderate responses are seen within each event, with peaks of 22 and 13 cumecs. Like flood six, reduced flow peak is likely caused by low groundwater conditions.

\section{Spring/Autumn floods}

Flood 2 shows the different response flow can have to rainfall (Figure 47). Three rainfall events have peaks of $4 \mathrm{~mm} / \mathrm{hr}, \sim 8 \mathrm{~mm} / \mathrm{hr}$ and $5 \mathrm{~mm} / \mathrm{hr}$. However, the rainfall response does not have the same pattern. The flow responses peak with the first rain event at 78 cumecs $\left(\sim 7^{\text {th }}\right.$ Sept $)$, followed by 15 cumecs $\left(10^{\text {th }}\right.$ Sept $)$ and 30 cumecs $\left(13^{\text {th }}\right.$ Sept $)$. While the first rainfall event's duration is longest, this pattern also likely shows the impact data extrapolation has on rainfall-runoff modelling. As Te Kuiti is $28 \mathrm{~km}$ from Marokopa Falls, rainfall that occurs in Te Kuiti may not indicate rain at Marokopa Falls and therefore cause a unique low response.

Flood 5 is another example of a high rainfall resulting in an unusually low flow response (Figure 47). Two rainfall events are seen with peaks of $\sim 7 \mathrm{~mm} / \mathrm{hr}\left(20^{\text {th }}\right.$ Sept) and $27 \mathrm{~mm} / \mathrm{hr}\left(22^{\text {nd }} \mathrm{Sept}\right)$. In response, a smaller, initial flow peak (17 cumecs) is followed by a second flow peak of 39 cumecs.

\section{Spring/Autumn floods}
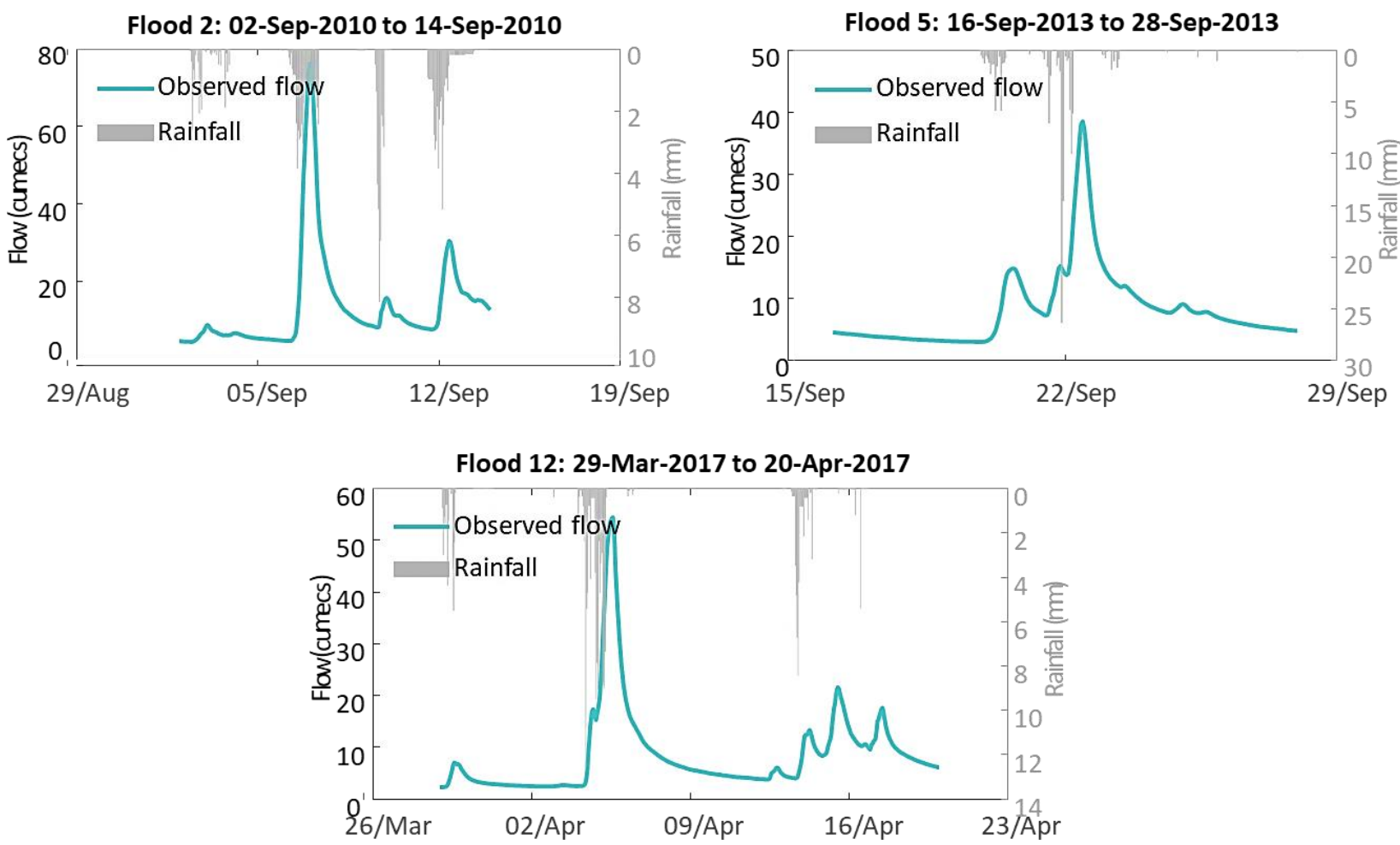

Figure 47: Observed autumn/spring flood flow and rainfall. 
Flood 12 has three major rainfall events, with three distinct flow responses (Figure 47). The rainfall events are separated by $\sim$ seven and eight days, with the first peaking at $\sim 6 \mathrm{~mm} / \mathrm{hr}$, $\left(29^{\text {th }}\right.$ March), the second at $\sim 13 \mathrm{~mm} / \mathrm{hr}\left(4^{\text {th }}\right.$ April) and the final at $\sim 9 \mathrm{~mm} / \mathrm{hr}\left(\sim 14^{\text {th }}\right.$ April). The flow had a small response to the first event ( 8 cumecs), a large second response (55 cumecs) and another more dispersed final response with a peak (20 cumecs).

\section{Winter floods}

Flood 4 is characterised by five days of medium-heavy rainfall, followed by a large rainfall peak rate of $8 \mathrm{~mm} / \mathrm{hr}$ (Figure 48). The initial event's flow peak precedes the rainfall peak, indicating that low intensity but long-duration rainfall can result in higher flows (70 cumecs). Another three-day rainfall event with a 3.8 $\mathrm{mm} / \mathrm{hr}$ peak follows the first event over a week later. The second rainfall event has a smaller flow response (11 cumecs), three days after the rainfall's peak.

Flood 7 has the highest flow rate of the year 2014, although it is half that of other years, indicating that flow rate changes on seasonal but also annual scales (Figure 48). The main rainfall event occurs just over 24 hours, with four peaks in rainfall ( $\sim 3 \mathrm{~mm} / \mathrm{hr}$ each) that occur in the latter half of the rainfall event. The peaks are spaced approximately five hours apart. The flow response can be divided into four separate peaks, with the first responding to the first few hours of rainfall, and the last three flow peaks to the four rainfall peaks. Interestingly, the last flow peak (40 cumecs) looks to be the combined response of the last two rainfall sub-events, indicating that the residence times were longer than for the previous rainfall peaks.

Flood 9 is a long-duration events, with rainfall occurring nearly every day from the $\sim 11^{\text {th }}$ May till the $7^{\text {th }}$ June (27 days) (Figure 48). Rainfall event peaks occur every two-three days, averaging $\sim 3 \mathrm{~mm} / \mathrm{hr}$ in intensity, although three of the largest intensities on the $17^{\text {th }}, 29^{\text {th }}$ May and $5^{\text {th }}$ June measure over $9 \mathrm{~mm} / \mathrm{hr}$. The flow response is more consistent, as seen by the apparent baseflow increase. Two flow peaks are seen, correlating with the last two rainfall peaks on the $25^{\text {th }}$ May (20 cumecs) and $29^{\text {th }}$ June (30 cumecs).

Flood 10's rainfall consists of three events, spread over $\sim 7$ days (Figure 48). These have a peak intensity of $7 \mathrm{~mm} / \mathrm{hr}$ ( $\left.23^{\text {rd }} \mathrm{June}\right), 11 \mathrm{~mm} / \mathrm{hr}\left(29^{\text {th }} \mathrm{June}\right), 7 \mathrm{mmhr}$ ( $1^{\text {st }} \mathrm{July}$ ). Flow generally responds to each rainfall event, although the response size 
varies based on the frequency of rainfall. For example, the largest rainfall does not coincide with the largest flow, as the preceding two-three days show dry conditions. This indicates that extreme winter flows may be more impacted by rainfall duration or frequency rather than intensity.
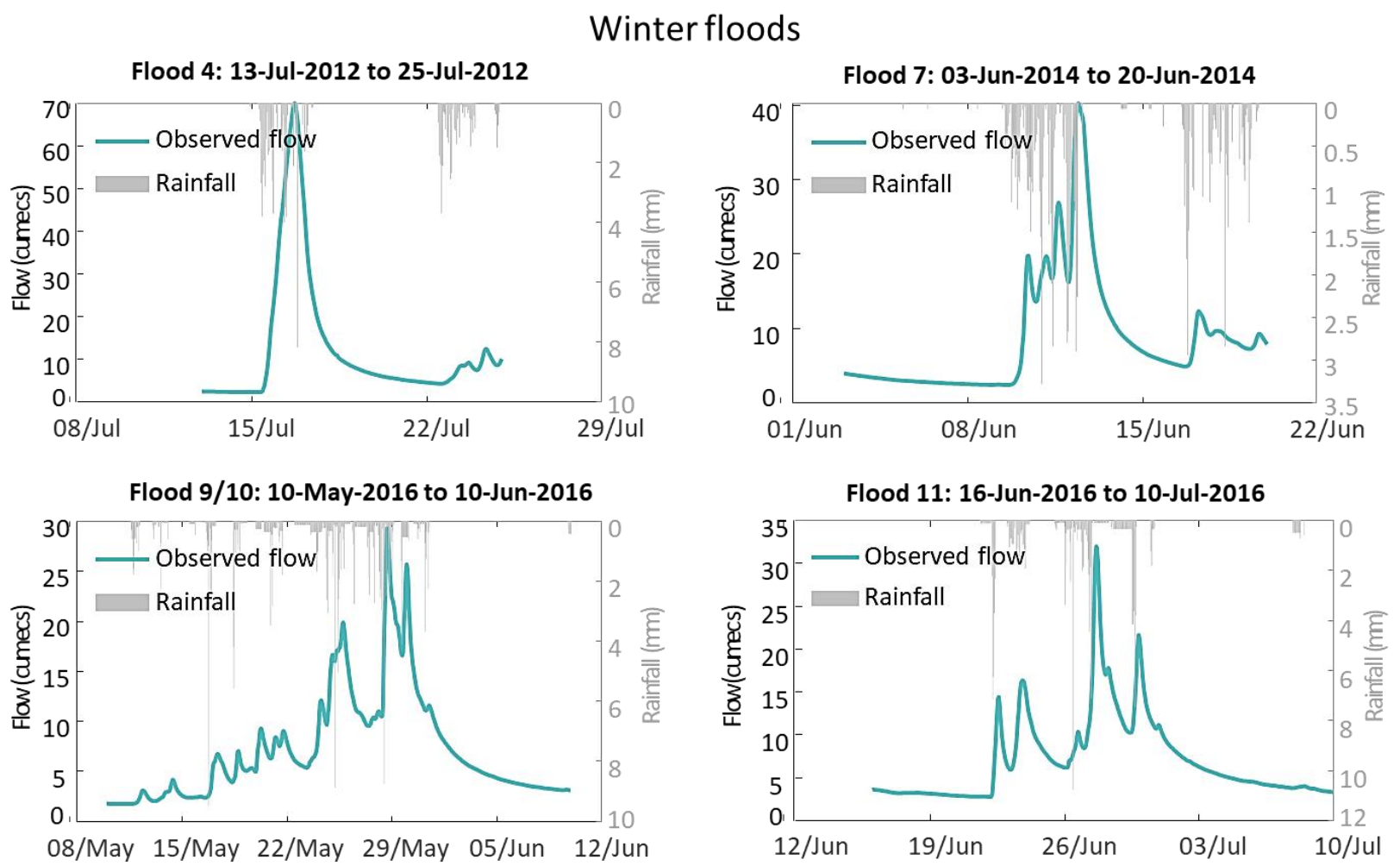

Figure 48: Observed winter floods flow and rainfall.

\section{Model structure}

The rainfall-runoff model (detailed in Chapter 4) influences the modelled flow timing and amount. This includes the structure of the conceptual model and the ranges of parameters used. The structure comprises of a series of reservoirs that water moves through. These are effectively the infiltration and saturation of a soil component, which drains parallel to three reservoirs; water that drains from the reservoirs becomes runoff. Therefore, throughout modelled flood events water is entering, filling, and exiting these various water cycle components.

The inclusion of the infiltration zone means that the water can realistically simulate overland flow, in the event of high-intensity rainfall. Overland flow is rarely seen in modelled output, largely reflecting the high infiltration rates of the karst environment (Figure 49). 

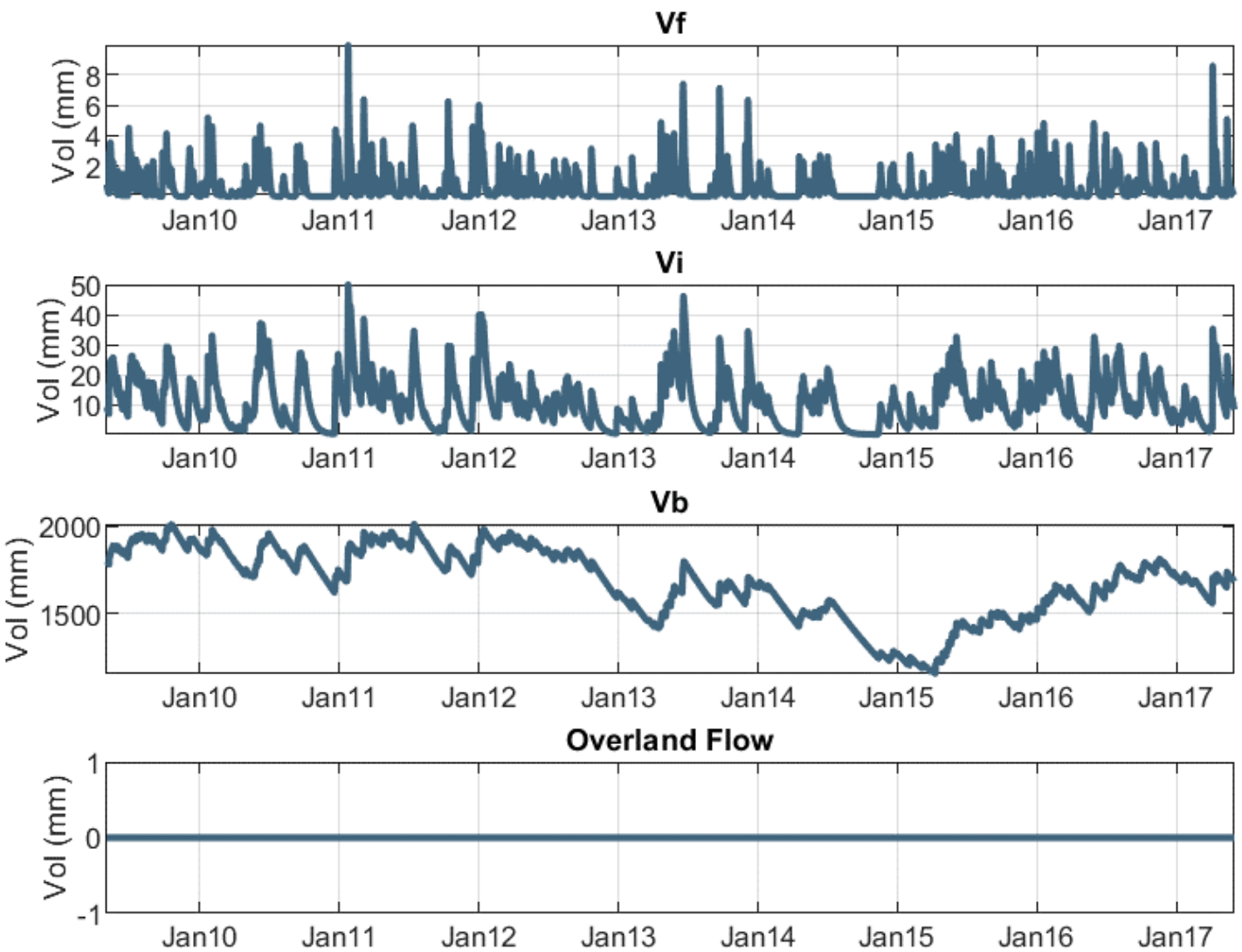

Figure 49: Reservoir volumes, showing the change in reservoir volume over $\sim$ seven years. Below this, overland flow is modelled. The lack of overland flow suggests a highly permeable upper catchment, or lack of extremely high rainfall.

The draining component of the model aims to represent ground saturation. Where field capacity is met, water drains to the three reservoirs. This includes saturation overland flow and sustained flows in drier months. This is important in the Marokopa setting as floods frequently occur year-round, with antecedent soil conditions likely to influence flood occurrence, like long duration or high-intensity rainfall. This is observed when flow is exacerbated by smaller secondary rainfall events (Figure 50).

The reservoirs represent the different types of pathways water can take once it has entered the groundwater system; namely fast paths, medium paths and slow/baseflow paths. These paths largely reflect the permeability and porosity of the catchment, which is influenced by the land cover, soil type and geology of the area. The structure of 'in-parallel' reservoirs means that each reservoir has a proportion of the draining water from the soil. 


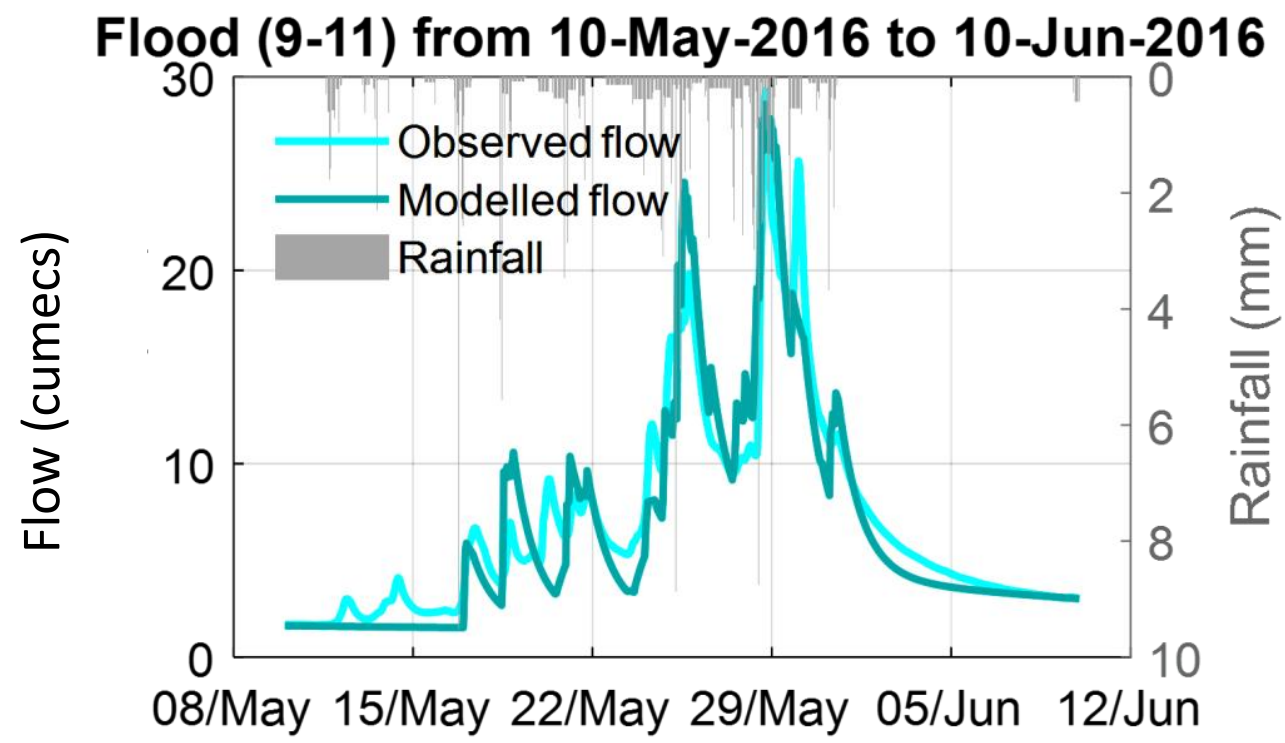

Figure 50: Differences in rainfall event impact: May flood event where secondary flows (24-29th May) cause significantly higher runoff response than primary rainfall events (15-21th May).

There is a counter balance between the proportions of reservoirs and the residence times (RT) of reservoirs (how timely water leaves the system and becomes runoff, or modelled flow). Shorter RT means that water leaves the system quicker, therefore acting more like fastflow reservoirs (depending on the timesscales used). This means that interflow reservoirs (or any reservoir) can act as a fastflow reservoir if the RT are extremely short, or as a baseflow reservoir if the RT are much longer, introducing equifinality as a potential influence on model fit.

\section{Parameters}

The rainfall-runoff model has the following parameters: the rain multiplier, infiltration capacity, field capacity, saturation capacity, draining rate (soil to reservoirs), fast, interflow and baseflow reservoir proportions and residence times, and lag-time (between precipitation event and flood peak). Two flood events modelled for this project were identified through interviews, while the rest were selected looking at the observed flow across seven years. Three 'season-based' parameter sets were used to best represent the catchment hydrological response throughout the year (Appendix F). Finally, a warmup period of 365 days was used within the modelling process. 


\section{Seasonality}

The rain multiplier approximates the total rainfall captured within the Marokopa Falls catchment, which eventually leaves the system as runoff. This correction is needed because the Te Kuiti rain station only samples one area, whereas many regions contribute to the Marokopa Falls flow. In winter, the rain multiplier that produces the best fit is higher than summer flows. This indicates that more waterways are 'activated' during winter time, resulting in larger winter flows than summer flows (Figure 51).
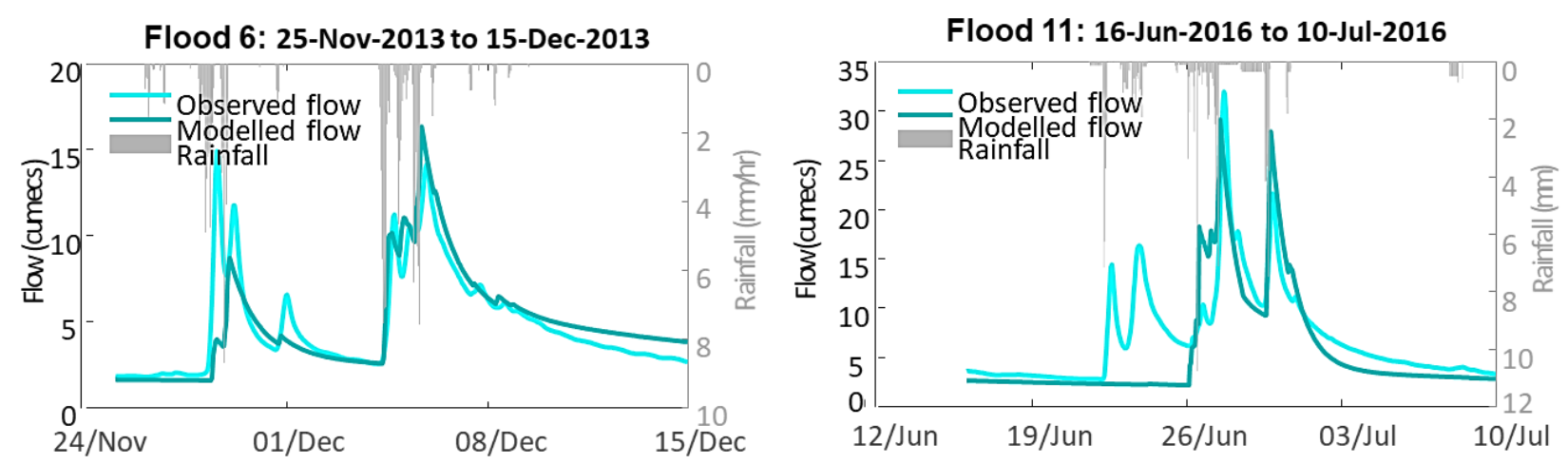

Figure 51: Comparison of flows between seasonal flows with summer (left) and winter (right).

Best fit maximum infiltration ranges between 200 and 250mm; field capacity between 300 and $350 \mathrm{~mm}$; saturation capacity between 100 and $200 \mathrm{~mm}$ in addition to field capacity and draining rate between 100 and $200 \mathrm{~mm}$.

Summer flow is dominated by baseflow, while winter flows are influenced more by the fastflow reservoir. Decreased rainfall in the summer likely reduces the fastflow and interflow reservoirs, therefore deeper sources of water make up the largest proportion of summer flows. In contrast, more water bodies are activated during the winter: with increased rainfall, these conditions result in flows that are dominated by fastflow hydrology.

\section{Localised processes}

Poor model fit was not always the result of model structure or parameterisation, but something outside of the modelling process entirely: the availability of representative, high-resolution, and three-dimensional input data. As the Te Kuiti 
rainfall and Marokopa Falls stations are used to reflect the entire rainfall-runoff relationship for the Marokopa Falls catchment, this is not representative. Although Te Kuiti present the nearest high-resolution rainfall record, the modelled flow shows that some high flow events are still underestimated by the model, as no associated rainfall is seen (Figure 52). This happens when localised rainfall occurs at either location, resulting in poorly correlating flows. Furthermore, due to the karstic nature of the region, distributed subsurface storage could also delay rainfallrunoff response, resulting in poor model fit.

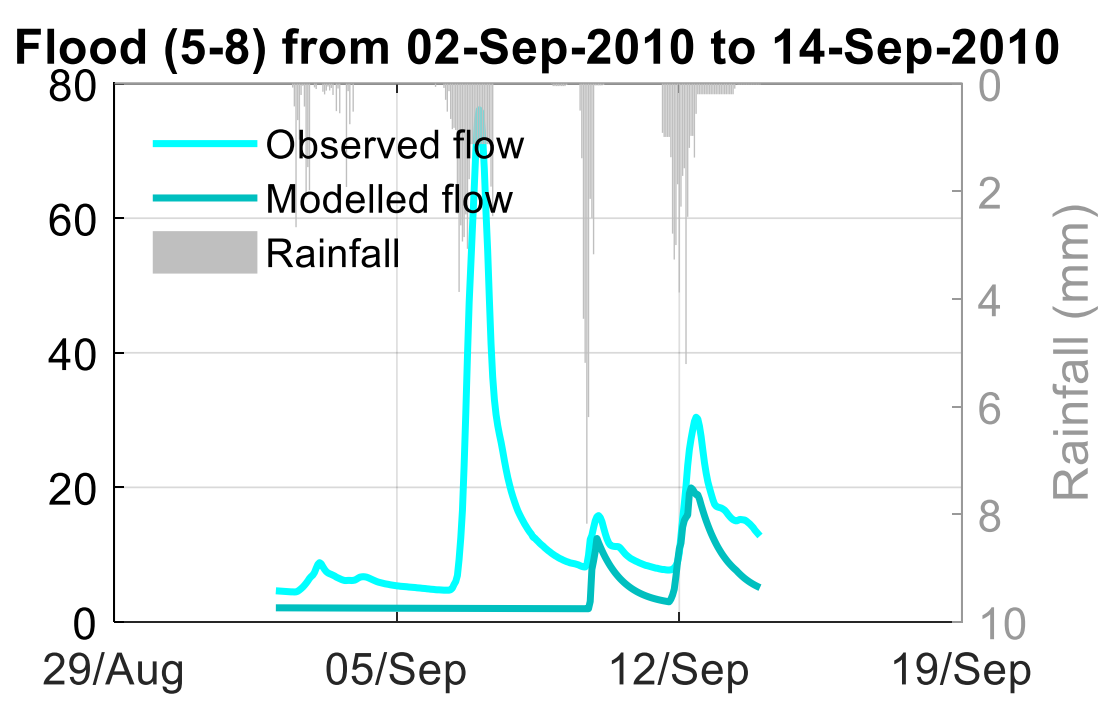

Figure 52: Modelled flood event where the input rainfall was not captured by Te Kuiti rainfall stations.

\section{Comparison of observed and modelled flood hydrographs}

Three parameters (summer, spring/autumn, and winter) sets are used within this model to account for seasonal variations in rainfall and flow. Like the 'Flood event characterisation (observed rainfall and flow)', the rainfall-runoff results will be discussed in these seasonal-groups, rather than chronologically. In future works, it is suggested that parameters vary between ranges based on the time of year of the flood period. Model results are presented by season (Table 5) and have associated NSE values (Table 6). 
Table 5: Flood with order by season shown, as results are presented by season, not chronologically.

\begin{tabular}{|c|c|c|c|}
\hline Flood & Start flood & End flood & Flood by season \\
\hline \hline 1 & 10-Jan-10 & 10-Feb-10 & summer 1 \\
\hline 2 & 2-Sep-10 & 14-Sep-10 & spring-autumn 1 \\
\hline 3 & $11-$-Dec-10 & 5-Jan-11 & summer 2 \\
\hline 4 & $13-J u l-12$ & $25-J u l-12$ & winter 1 \\
\hline 5 & $16-S e p-13$ & $28-S e p-13$ & spring-autumn 2 \\
\hline 6 & $25-$ Nov-13 & 15-Dec-13 & summer 3 \\
\hline 7 & 3-Jun-14 & 20-Jun-14 & winter 2 \\
\hline 8 & 10-Jan-16 & 30-Jan-16 & summer 4 \\
\hline 9 & 10-May-16 & 10-Jun-16 & winter 3 \\
\hline 10 & 16-Jun-16 & 10-Jul-16 & winter 3 \\
\hline 11 & 8-May-16 & 30-May-16 & winter 4 \\
\hline 12 & 29-Mar-17 & 20-Apr-17 & spring-autumn 3 \\
\hline
\end{tabular}

Table 6: Floods with associated NSE values. Each model run uses parameters for a specific season but creates plots for all seasons. Highlighted values show NSE for respective periods. Bolded values show modelled flood periods using their correlative seasonal parameter set.

\begin{tabular}{|c|c|c|c|c|}
\multirow{2}{*}{$\begin{array}{c}\text { Floods in } \\
\text { order of } \\
\text { season }\end{array}$} & \multicolumn{4}{|c|}{ NSE } \\
\cline { 2 - 5 } & Spring/autumn & Summer & Winter & Flood \\
\hline \hline 1 & -17.0729 & $\mathbf{- 8 . 0 8 6 7}$ & -52.9419 & 1 \\
\hline 5 & $-\mathbf{0 . 4 7 8 6 1}$ & -0.60845 & -0.42474 & 2 \\
\hline 2 & 0.62668 & $\mathbf{0 . 3 4 0 6 2}$ & 0.74402 & 3 \\
\hline 8 & 0.064039 & -0.15431 & $\mathbf{0 . 3 0 7 4}$ & 4 \\
\hline 6 & $\mathbf{0 . 7 7 5 7 9}$ & 0.63977 & 0.26798 & 5 \\
\hline 3 & 0.56297 & $\mathbf{0 . 7 3 7 8 3}$ & -3.2412 & 6 \\
\hline 9 & 0.071751 & -0.31308 & $\mathbf{0 . 4 2 1 6 9}$ & 7 \\
\hline 4 & 0.082141 & $\mathbf{0 . 6 4 2 7 9}$ & -3.5026 & 8 \\
\hline 10 & 0.79111 & 0.53284 & $\mathbf{0 . 8 9 4 4 4}$ & 9 \\
\hline 12 & 0.45002 & 0.11779 & $\mathbf{0 . 5 1 6 8 4}$ & 10 \\
\hline 11 & 0.49707 & 0.25106 & $\mathbf{0 . 3 9 8 1 4}$ & 11 \\
\hline 7 & $\mathbf{0 . 8 1 7 3 3}$ & 0.67263 & 0.74291 & 12 \\
\hline
\end{tabular}

\section{Summer floods}

During rainfall-runoff modelling, the initial results normally produce high errors, because the reservoirs and residence times have not yet fully warmed up to represent the full hydrological state, resulting in an $\mathrm{NSE}^{7}$ value of -8.1 . This is likely the case with floods one and five (Figure 53). Flood 1's flow response is twice that

\footnotetext{
${ }^{7}$ Nash-Sutcliffe efficiency value is measured from $-\infty$ to 1 , for further detail see Section 4.2.2.
} 
of the observed flow, with a large reaction to peak rainfall of $15 \mathrm{~mm} / \mathrm{hr}\left(22^{\text {nd }} \mathrm{Jan}\right)$ and $30 \mathrm{~mm} / \mathrm{hr}\left(3^{\text {rd }} \mathrm{Feb}\right)$ with 16 and 15 cumecs each. While this is an overreaction when compared with the observed values, the fact that the observed flow records such a low flow response indicates that localised rainfall may have occurred at $\mathrm{Te}$ Kuiti. Therefore, the model has overestimated the flow response likely because of both the proximity to warm up, but also "errors" from input data.

Flood 3 also presents flood modelling results with high flow error, as the modelled flow is underestimated, with an NSE of 0.34. However, this "summer" set of parameters produces the best fit for the other summer events. This event may be impacted by non-seasonal factors. This could be queried through a more in-depth look at the regional climate and flow surrounding the Marokopa catchment. Major differences include no modelled flow response between the $12^{\text {th }}$ and $20^{\text {th }} \mathrm{Dec}$, and an underestimate of the last three flow peaks at values of 10,9 and 12 cumecs compared to the observed 32,38 and 34 cumecs $\left(21^{\text {st }}, 23^{\text {rd }}\right.$ and $\left.28^{\text {th }} \mathrm{Dec}\right)$. This is likely also an example of missing rainfall at Te Kuiti or localised rainfall at Marokopa Falls, given the high flow response to small 3-7 mm/hr rainfall events.

The modelled flood 6 flow response matches the general pattern of the observed flow, resulting in an NSE of 0.74 However, there are significant scale differences. The initial modelled flow peak ( $\sim 8$ cumecs) was underestimated by $\sim 6$ cumecs, while the second flood peak was more accurately modelled (16 cumecs compared to an observed 14 cumecs). As the corresponding peak rainfall events are $\sim 5 \mathrm{~mm} / \mathrm{yr}$ and $\sim 7 \mathrm{~mm} / \mathrm{hr}$, the observed flow looks to have a disproportionately low flow response to the initial rainfall event. Therefore, modelled flow is underestimated for this event.

Flood 8 is a simple event, and therefore the pattern is more easily modelled. The initial flow peak (17 cumecs) is underestimated by four cumecs. The second flow peak is more accurately modelled, only underestimated by 1.5 cumecs. However, the modelled baseflow is consistently $\sim 2$ cumecs higher than the observed flow. The NSE is moderate (0.64), and likely indicative of the consistent underestimation of the model. 

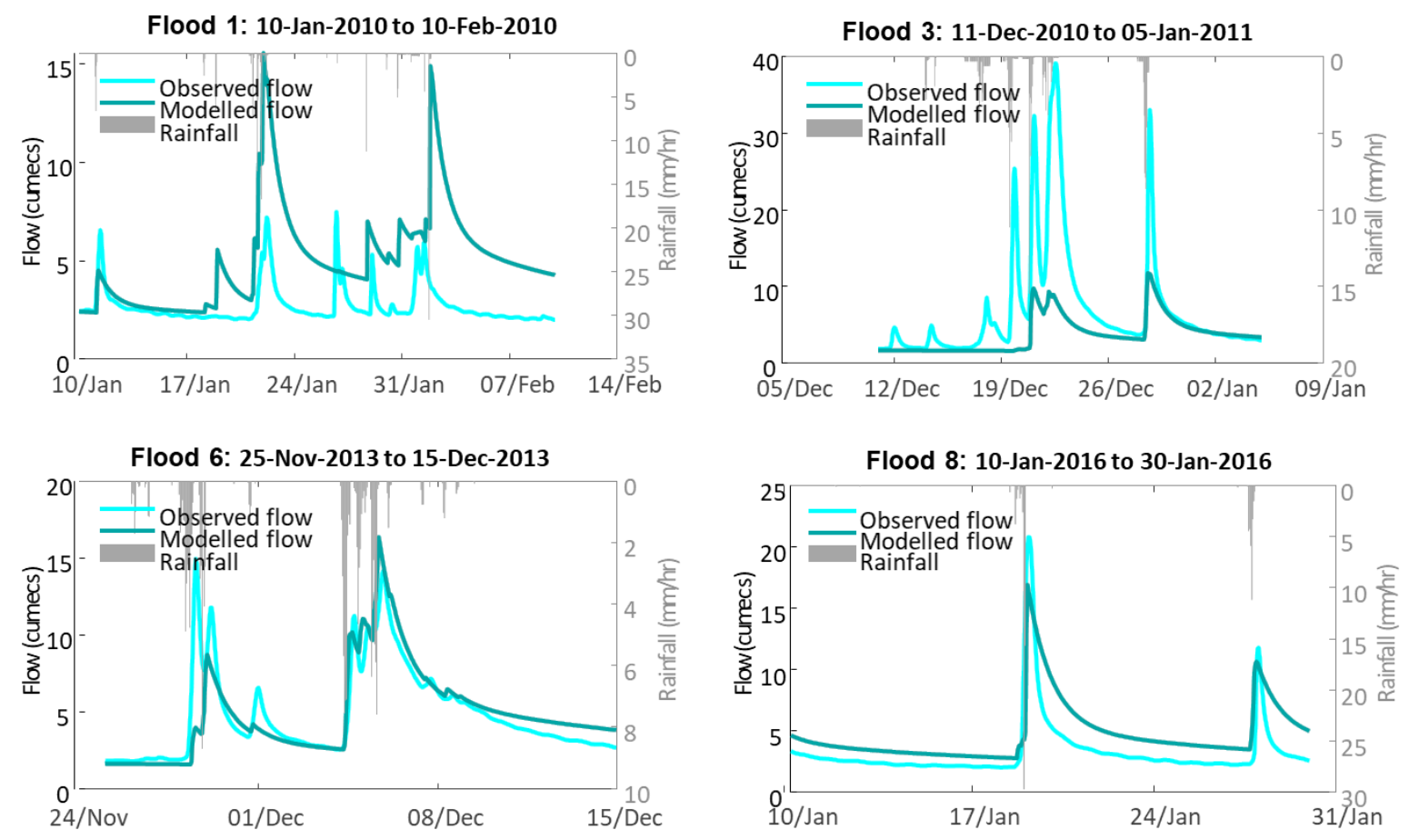

Figure 53: Modelled, observed summer flood with associated rainfall.

\section{Autumn/spring floods}

Two of the autumn/spring floods are poorly modelled, and underestimated, while another two provide a good approximation of flow (Figure 54). This inconsistent modelling is likely due to localised rainfall occurring within either the Marokopa Falls catchment or Te Kuiti.

Flood 2 is an example of poor modelling, which may be due to the proximity of this flood period to the warmup period. Specifically, these errors include no flow response to two days of 2-4 $\mathrm{mm} / \mathrm{hr}$ rainfall, compared to an observed flow response peak of 78 cumecs. Model results during the first two years of this record are therefore not representative of the full model potential, as demonstrated by the low NSE of -0.48 . 
Flood 5 shows a good visual fit to the observed flow record, which is supported by an NSE value of 0.78 . However, the modelled flow underestimates the smaller, initial flow value by five cumecs, and the primary peak is overestimated by nine cumecs.

\section{Spring/Autumn floods}
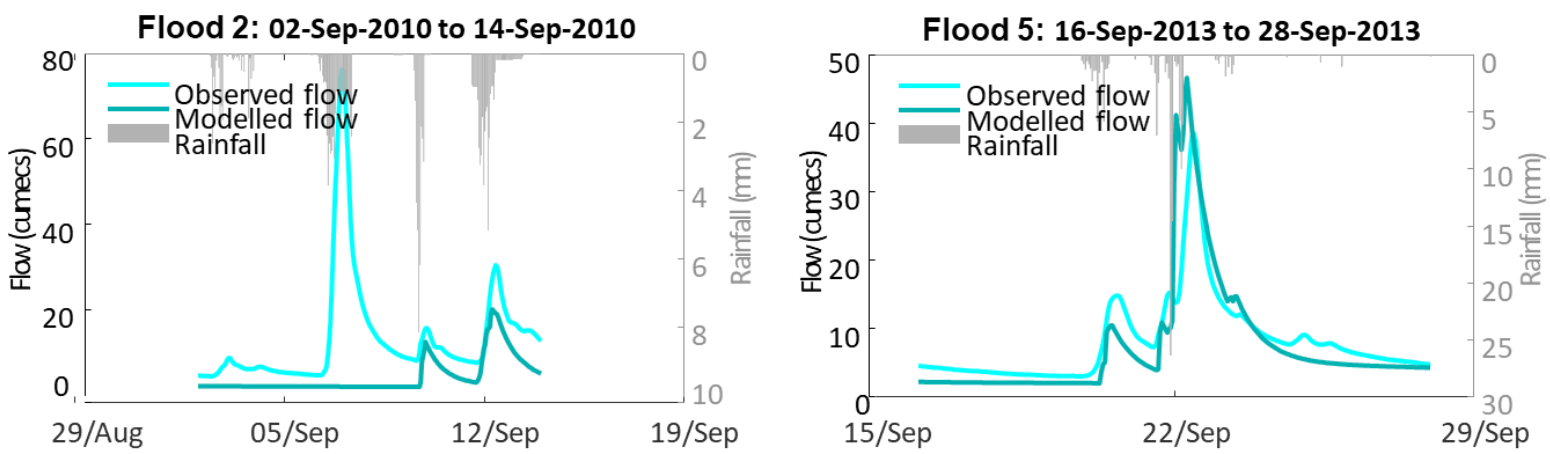

Flood 12: 29-Mar-2017 to 20-Apr-2017

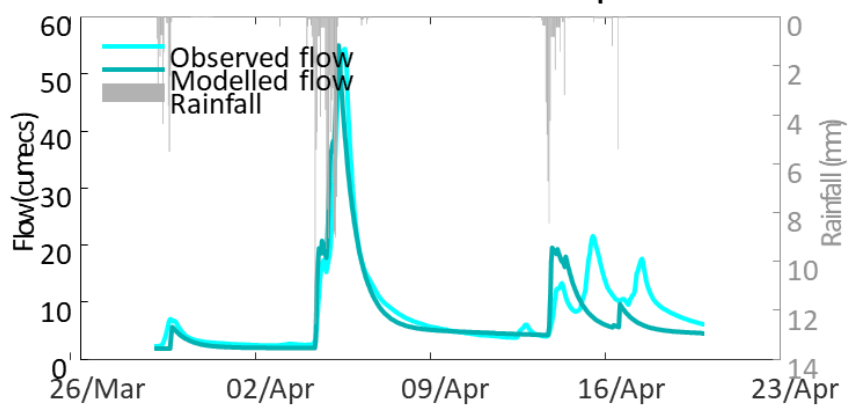

Figure 54: Observed autumn/spring flood with associated rainfall.

Flood 12's modelled flow presents little error, fitting both the scale and pattern of the observed flow and resulting in a high NSE of 0.82. The first flow peak is underestimated by two cumecs. The second peak has a slightly smaller flow-lag to the $8 \mathrm{~mm} / \mathrm{hr}$ rainfall and overestimates the flow by one cumec. The largest flow errors are seen over the five days from $14^{\text {th }}$ till the $19^{\text {th }}$ of April. Firstly, overestimating $8 \mathrm{~mm} / \mathrm{hr}$ rainfall $\left(14^{\text {th }}\right.$ April) and secondly underestimating the last two flow peaks ( $15^{\text {th }}$ and $19^{\text {th }}$ April). These last two observed flow peaks have a longer two-day lag, compared to the earlier flow peak.

\section{Winter floods}

While the general pattern of the winter flood modelled flow, fits that of the observed flow, the scale is incorrect (Figure 55). This is also seen by the low NSE (0.29). In response to a $\sim 9 \mathrm{~mm} / \mathrm{hr}$ rainfall event, the modelled flow is underestimated by a large $\sim 20$ cumecs. This is indicative of further localised rainfall 
within the Marokopa Falls catchment. While this could be corrected by parameter changes, this set fits best with the other winter flood events.

Flood 7 generally fits the observed flow pattern with staggered primary and secondary floods as shown by the NSE of 0.41 . However, the modelled flow is a consistently 4 cumecs lower than the observed flow, although the flows for the other two winter flood months have had a lower error. This indicates that June 2014 had had abnormally high rainfall. The largest model error occurs at the peak flow, with a difference of 18 cumecs. Modelled flow before and after the flow peak is noticeably lower than observed values, indicating that lower intensity rainfall is not modelled effectively, and residence times may be too short. The observed flow has four peaks, while the modelled rainfall has three. The first observed flow peak is almost completely "missed" by the model, again showing that the flow response to low-intensity rainfall is underestimated. Finally, the observed flow peaks occur a few hours after the rainfall peaks, while the modelled flow has a much shorter lag time.

The modelled flow for flood 9 and 10 (same event) also fits the generally observed flow pattern, with three of the $\sim$ seven flow peaks having very little error. This flood has both an NSE value of 0.89 and a good visual fit. Furthermore, most of the low-points during this flood are well-modelled except for one which corresponds with a period of no rain. This indicates that the interflow residence time may be too low. As previously mentioned, the flow response to initial low-intensity rainfall appears underestimated $\left(15^{\text {th }}\right.$ May). Furthermore, the second highest observed flow point $\left(\sim 1^{\text {st }}\right.$ June $)$ is also under-modelled. While the receding flows after the peak flow are modelled well, this "missed" peak indicates that flow reservoir storage has been overestimated or residence times underestimated.

Interestingly, flood 11 has divided model results. While the first flood peaks are poorly modelled, the large, final flows have a much better model fit, the combination resulting in a low NSE value of 0.39 . While the initial $8 \mathrm{~mm} / \mathrm{hr}$ rainfall event is completely missed, both final rainfall events $(11 \mathrm{~mm} / \mathrm{hr}$ and $\sim 4 \mathrm{~mm} / \mathrm{hr}$ ), result in observed flow peaks of 32 and 21 cumecs. However, the modelled peaks are 29 and 27 cumecs, with the main peak underestimated, and the last peak overestimated. This opposing response to rainfall may be due to overestimated residence times, or localised rainfall experienced at Te Kuiti, but not within the Marokopa Falls catchment. 

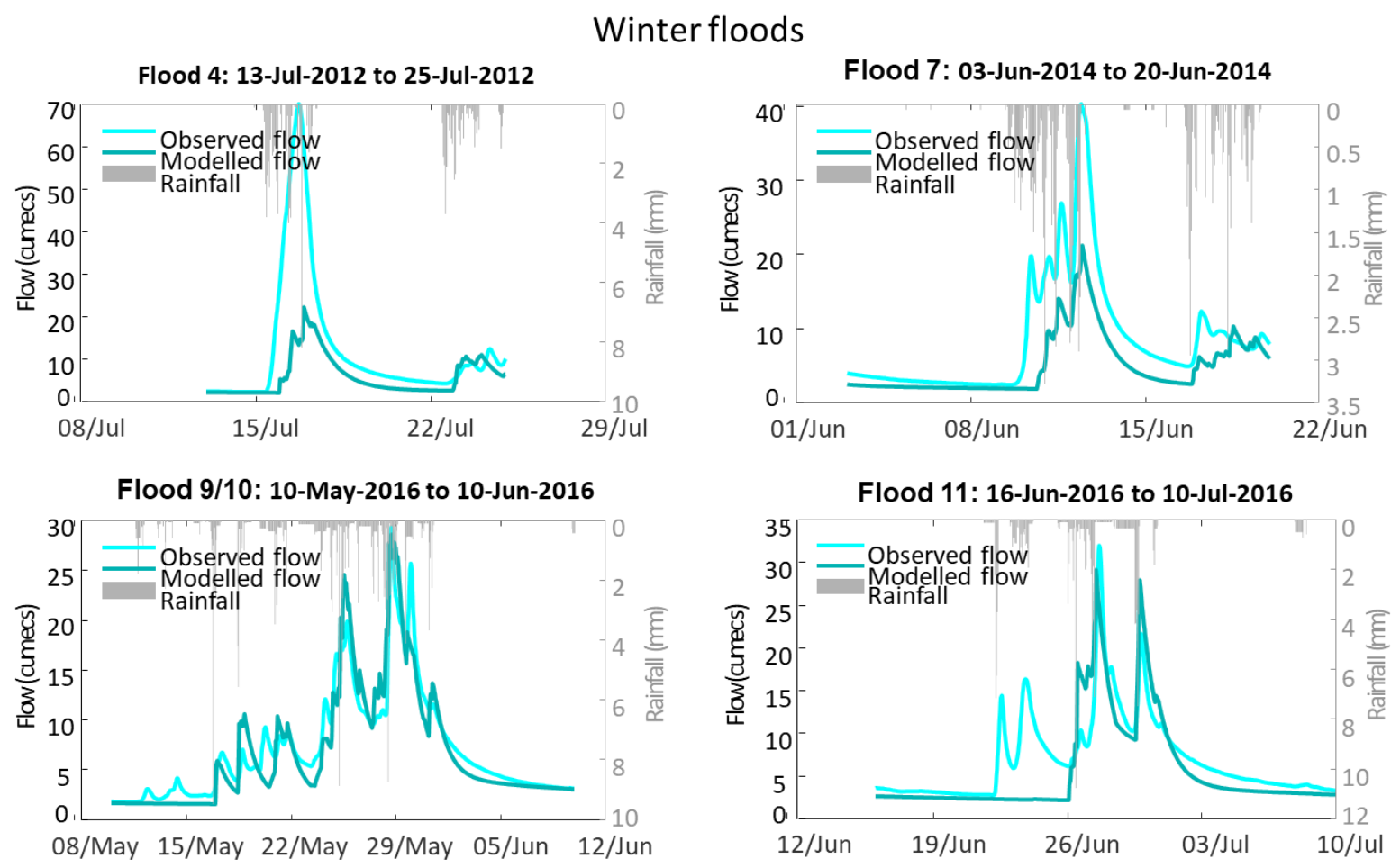

Figure 55: Observed winter flood with associated rainfall.

\section{Comparison of modelled and observed flow}

Model error was compared by subtracting the observed flow from the modelled flow. Positive values indicate that the model results were higher than the observed flow. Negative values are caused by the model underestimating flow. Different parameter ranges were used when modelling summer, autumn/spring and winter floods, therefore each seasonal output has different model-error (Figure 56). Generally, larger errors coincided with peak flow, occurred throughout the year, and resulted in both significant under, and over-estimations. Summer parameter ranges resulted in modelled flows that were too low, both in comparison to the observed record and to the model results when other seasonal parameter ranges were used. These anomalously large errors occurred within the record. In contrast, winter floods largely overestimated flow however also had the largest positive errors as well. However, comparisons of model performance across the entire record ignores the fact that the modelled parameter ranges targetted specific times of the year to improve model fit. 
Difference between modelled and observed flow (cumecs)

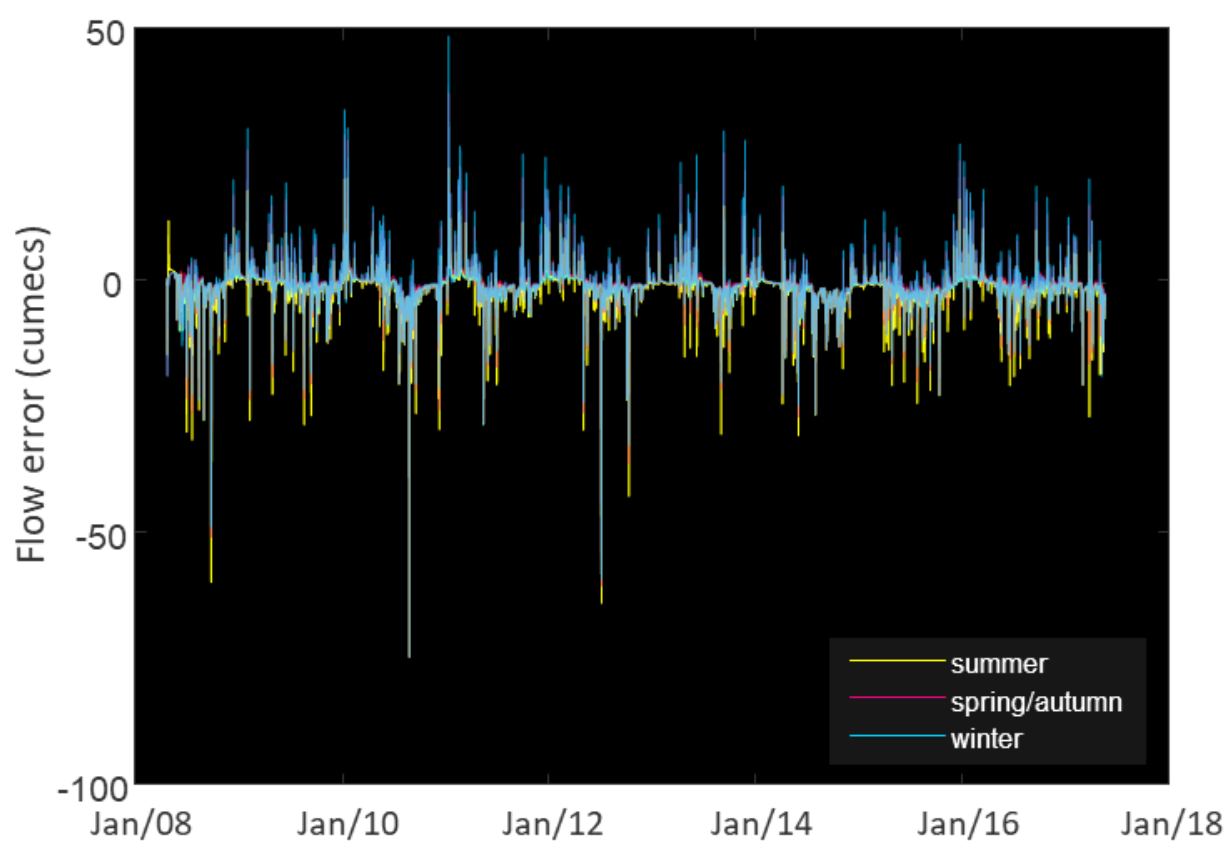

Figure 56: Model error for modelled period May 2008 through to June 2017.

Figure 57 shows model fit for the three-parameter sets over one year (Jan 2013 to Jan 2014), in comparison to observed flow. During the summer months, the summer parameters have a smaller error, however significantly underestimate flow during the May-June and September periods. This is because summer flows are comparatively lower to winter flows, which are what this parameter set is designed to calibrate towards. Interestingly, the spring/autumn parameter set produces the lowest error during the winter months "non-flood" flows, however, produces the second largest error during winter flood peaks. While it produces the best fit during Sep-Nov months, for which it was designed, generally all models perform well during the autumn months. Finally, the winter parameter set performs poorly during Jan 2013 through to late April, and from Nov through to Jan 2014. Generally, the winter parameter set fits non-flood peak flows well, as well as the Sep-Nov period. Interestingly, winter (April-July) flow peaks are largely overestimated, even when the summer and spring/autumn parameter sets underestimate the peak flows. Generally, parameter sets designed for certain seasons perform best, compared with the performance of other parameters sets during the same period. Further analysis of localised rainfall at Te Kuiti or Marokopa Falls could provide insight into the 
significant error during some flow peaks, and improve further Marokopa catchment rainfall-runoff modelling.

Model error for the year Jan 2013 to Jan 2014

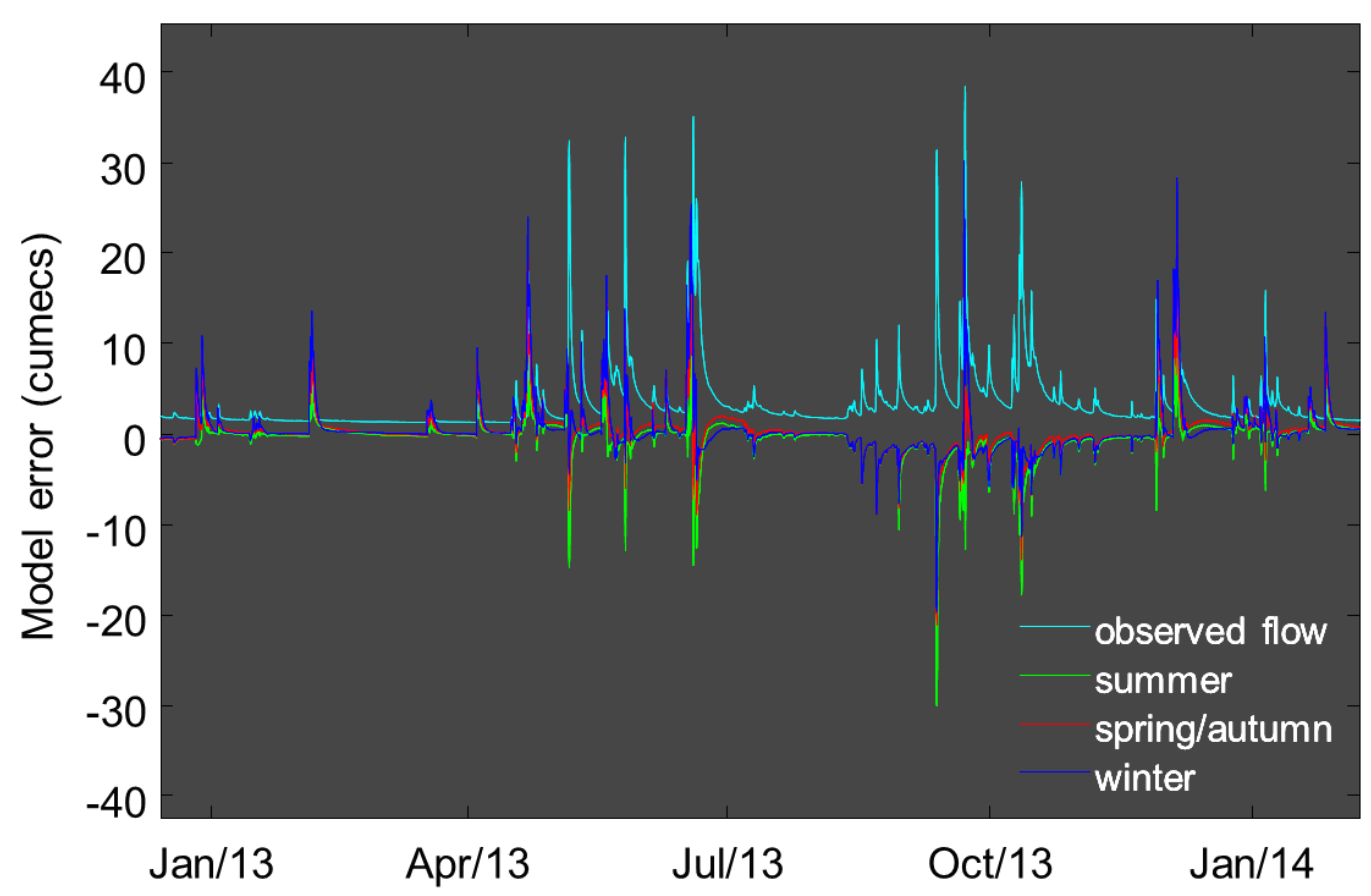

Figure 57: Model error for year period: comparison of the summer, spring/autumn and winter parameter set impact on model error, with observed flow for the one-year period starting Jan 2013.

\section{Conclusions}

- Both the model structure and parameter ranges represent the local context.

- No overland flow is modelled, indicating high permeability due to karstic conditions.

- Seasonality has a significant influence on the amount of water entering the system.

- During summer, modelled flow is dominated and sustained by baseflow.

- During winter, modelled flow is dominated by fastflow.

- Missing data or localised rainfall causes significant model errors, which is likely due to the distance between the rainfall and flow gauges.

- High-intensity, short-duration events are more accurately modelled than low intensity, long-duration rainfall events.

- Throughout the year, NSE values vary consistently, from extremely low ($50)$ to high values $(0.8)$, indicating that either model produces inconsistent results, or that local rainfall and missing data occurs throughout the year.

- Model error is decreased when using season-dependent parameter ranges. 


\subsection{Preliminary inundation model results and data}

Due to the complexity of the rainfall-runoff modelling (needed as input for inundation modelling), this thesis has instead focused on developing the rainfallrunoff model. Having poor inputs could render the inundation model next to useless. This chapter compares the input datasets needed vs what is available at Marokopa for inundation modelling. Inundation is estimated based on elevation datasets, historical flooding and future climate change.

Both historical flood breaches and flow rate are required for flatwater inundation. However, neither dataset was available at Marokopa; this data needed to be gathered. Historical flood extents were gained during participant interviews (Figure 58). Flow volumes were estimated from observed Marokopa Falls flow. As both interviews and the rainfall-runoff modelling processes were time expensive, inundation modelling could not be completed. Instead, we present the data gathered for future inundation modelling, including analysis of historical floods, associated maximum flows and topographic-derived flood risk. Six historical floods (HF) were described by participants (Table 7), which outline flood behaviour and flood processes.

Table 7: Historical floods, identified by interview participants, with associated dates and estimated maximum flow (measured at Marokopa Falls).

\begin{tabular}{|c|c|c|}
\hline $\begin{array}{c}\text { Historical } \\
\text { Flood (HF) }\end{array}$ & Flood date & Maximum flow (cumecs) \\
\hline \hline 1 & 5-Jan-18 & 11.7 \\
\hline 2 & Aug-Sept 2017 & 47.9 \\
\hline 3 & 2017 (est. April) & 54.3 \\
\hline 4 & Apr-16 & 29.3 \\
\hline 5 & Feb-04 & 103.4 \\
\hline 6 & Jul-86 & 115.6 \\
\hline
\end{tabular}

HF 1 has the smallest extent $\left(\sim 100 \mathrm{~m}^{2}\right)$ and occurred the most recently $\left(5^{\text {th }} \mathrm{Jan}\right.$ 2018). This was not a localised event, with flooding also experienced as far as the Firth of Thames (Waikato Regional Council, 2018). Footage (video and photographs) show river water inundating the Marokopa campgrounds and field, with water depth at the campground estimated as $30 \mathrm{~cm}$. During this time, people were unable to enter or leave Marokopa, as reflected by several participants. Both the campground and flooded field appear to be between 2 and $2.5 \mathrm{~m}$ above sea level. As the land across the river is also within this elevation, future work could look to 
discern whether this area was inundated. According to participants and the Waikato Regional Council (2018), this flood was exacerbated by king tide conditions, and therefore indicate that with future sea level rise, similar conditions are likely to be experienced more frequently. Furthermore, river flow at Marokopa Falls is comparatively low (11.7 cumecs), indicating that this event was caused more by coastal inundation than river flow. Floods caused by both marine level and river flow extremes are therefore likely to result in larger and longer events.

HF 2 (Aug-Sept 2017) occurred at the opposite end of the Marokopa floodplains, where the narrow, steep-sided valley opens. At elevations between 5 and $10 \mathrm{~m}$, this flood covers an area of $\sim 300 \mathrm{~m}^{2}$. Furthermore, with an associated flow of 47.9 cumecs compared to 11.7 (HF 1) it is very likely caused primarily by river inundation rather than tidal influences.

HF 3 occurred during 2017 and had a significant extent of approximately $3 \mathrm{~km}^{2}$ towards the north-eastern edge of the Marokopa floodplains. Three wide-extent floods (HF 3, 4 and 6), were identified, as described by Participant E:

"We couldn't get out, we were there for days."

"There was water everywhere...

While participants floods were outlined during the interview, the observed and actual extent may differ as people do not have a satellite view of the area, but an oblique one. Furthermore, due to the width of the floodplains, inundation on this scale may be indicative of both river-bank breaching and overland flow "flooding" occurring. Uncertainty increases with increasing distance from the observer, such as at the flood edges. For HF 3, elevations between 2 and $5 \mathrm{~m}$ are inundated, with the flood boundaries often occurring at the 5-6 m mark. While the flow rate is 7 cumecs more than HF 2, the change in flood extent is significantly larger, which may reflect other external conditions or antecedent conditions. 


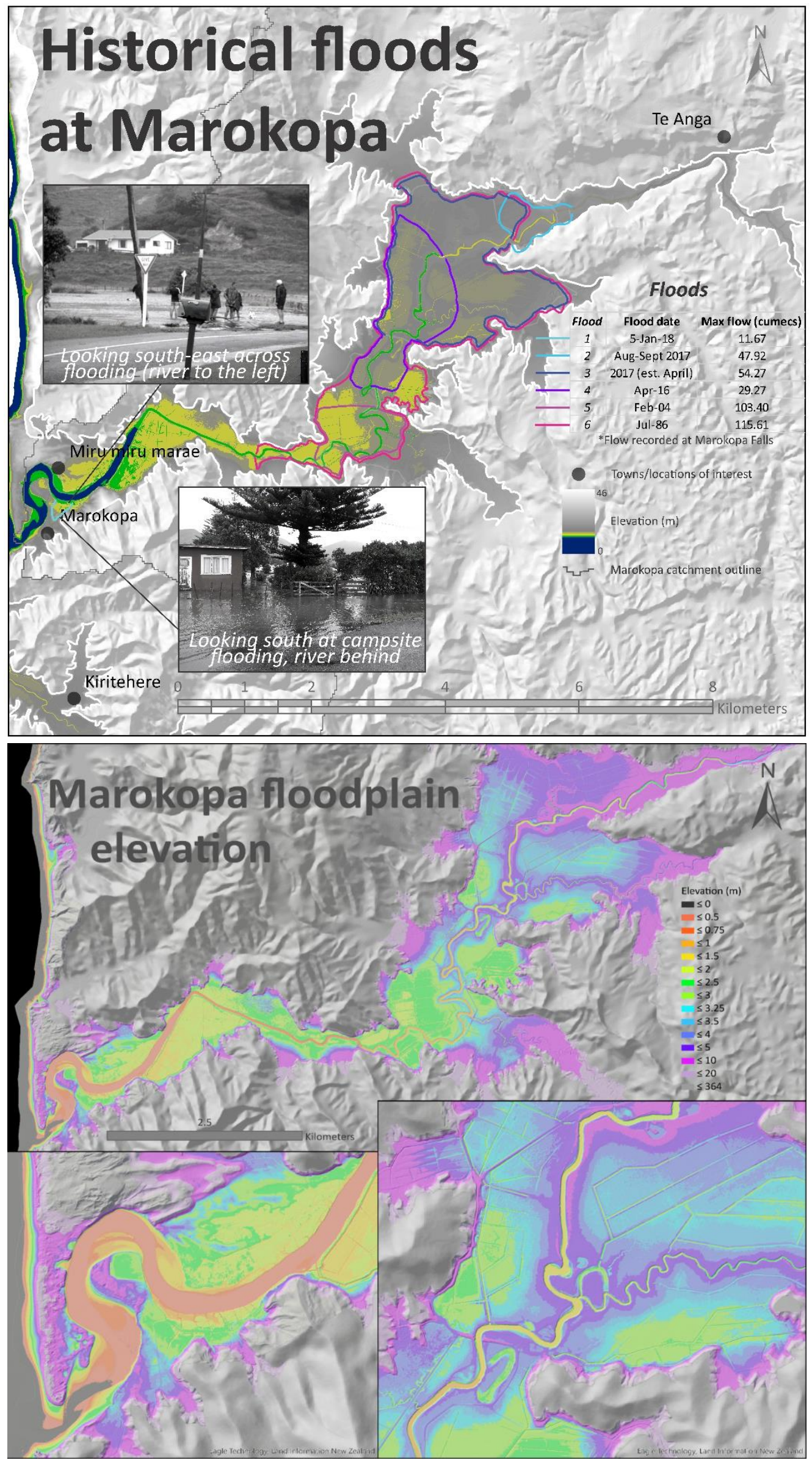

Figure 58: Historical flood extents and photographs of Flood 1 (top), and Marokopa floodplain elevation. 
HF 4 has a comparatively small flow rate (29.3 cumecs), compared with the other river inundation floods and covers a moderate extent of $\sim 1.5 \mathrm{~km}^{2}$. While inundating elevations between 2.5 and $5 \mathrm{~m}$, the pattern of area flooded is interesting. The Marokopa floodplains can be divided into two sections, with a rise in elevation approximately $6 \mathrm{~km}$ north-east away from Marokopa (town location). This area changes from 3 to $3.5 \mathrm{~m}$, while the river is bounded by areas of 3.5-4 m, two pockets of 2.5-3 m elevation are seen. Interestingly, HF 4 extends over this rise, joining two slightly distinct areas, and then follows and floods to the west of the river.

HF 5 covers a small-moderate area of $\sim 1.2 \mathrm{~km}^{2}$ and inundates elevations between 2 and $3.25 \mathrm{~m}$. Seemingly bounded by the $3.5 \mathrm{~m}$ elevations, this flood has the second-largest maximum flow of the HF identified (103.4 cumecs, 50 cumecs higher than the next flow rate). However, it has a comparatively small inundated area: flow maximum ratio, when compared with the other floods. This may be indicative of localised rainfall, antecedent conditions or marine influence. This flood likely inundated other areas that were not remembered by other participants.

HF 6 has the highest flow and largest extent flood identified by any participant. This unsurprisingly indicates that larger floods have the most personal impact and are, therefore, the most memorable. With an extent of $\sim 3.2 \mathrm{~km}^{2}$, this flood inundated over half of the Marokopa floodplains from $2 \mathrm{~m}$ up to $10 \mathrm{~m}$. While this flood may have flooded other areas of the catchment, the high observed flow (115.6 cumecs) indicates that this was likely an inundation event.

In the future, with both sea level rise, and increases in extreme rainfall, coastal, bank-breaching and overland flow "inundation" or flooding is likely to increase in both magnitude and duration throughout the Marokopa area.

\section{Conclusions}

- Historical floods vary widely in extent, date and maximum flow (measured at Marokopa falls).

- Area and flow generally co-vary, except for HF 3.

- Although it appears that floods are decreasing in size, this is likely only because only the largest floods are remembered.

- All floods apart from HF 1 are likely due to bank-breaching river flow; HF 1 is more likely the result of coastal inundation. 


\subsection{Ecosystem service modelling results}

ES modelling provides a quantitative analysis of landscape benefits, and account for water, nutrient and sediment flows. Such analysis provides a holistic view of the landscape, as ES can be modelled individually, or comparatively for improved decision making.

\section{Flood mitigation classification}

Figure 59 represents the ability of land cover and soil types to mitigate flooding. Mitigated areas $(51.6 \%)$ have land cover or soil that can remove water from the land surface. Uphill areas and where resulting flow passes through mitigating areas are mitigated flood-prone areas $(8.8 \%)$, and all other areas without mitigation are flood prone (37.6\%) (Jackson et al., 2019). Marokopa catchment is divided into farming and indigenous forest (Chapter 2). Non-mitigated areas correspond with the agricultural HPEG dominating the north-west areas and floodplain as well as the southern and eastern boundaries of the catchment. Figure 59 shows that farmed land cannot mitigate flooding, likely due to land development, drainage systems and ground compaction (Ballinger, 2011; Howe \& White, 2003). Agricultural grasses are shallow-rooted exotic species which are less resilient to drought and flooding (Marshall et al., 2009). Over-grazed paddocks are further impacted due to the high volumes of animals that pass through, compacting the soil ("pugging") and destroying the grasses - resulting in loose sediment/topsoil (Drewry \& Paton, 2000; Singleton \& Addison, 2000). Few riparian belts bound the river (observed). Furthermore, farmed land is found on high-sloping areas.

Mitigating forested areas are where indigenous trees, ponds, permeable soils or other "flow sinks" exist, and make up most of the mountainous inland area (Figure 8)(Dunning, 1998). Forested areas re-route incoming precipitation via interception and absorption. Deeply rooted tree species such as kanuka (Kunzia ericoides) and podocarp can also store or absorb water nearer to the water table (Cameron, 1963; Phillips, 2005; Watson \& Mardern, 2004). Forested areas, unlike pastured ones, can retain the water within soils during drought, reducing hydrophobic characteristics that increase overland flow (Nedkov \& Burkhard, 2012). 


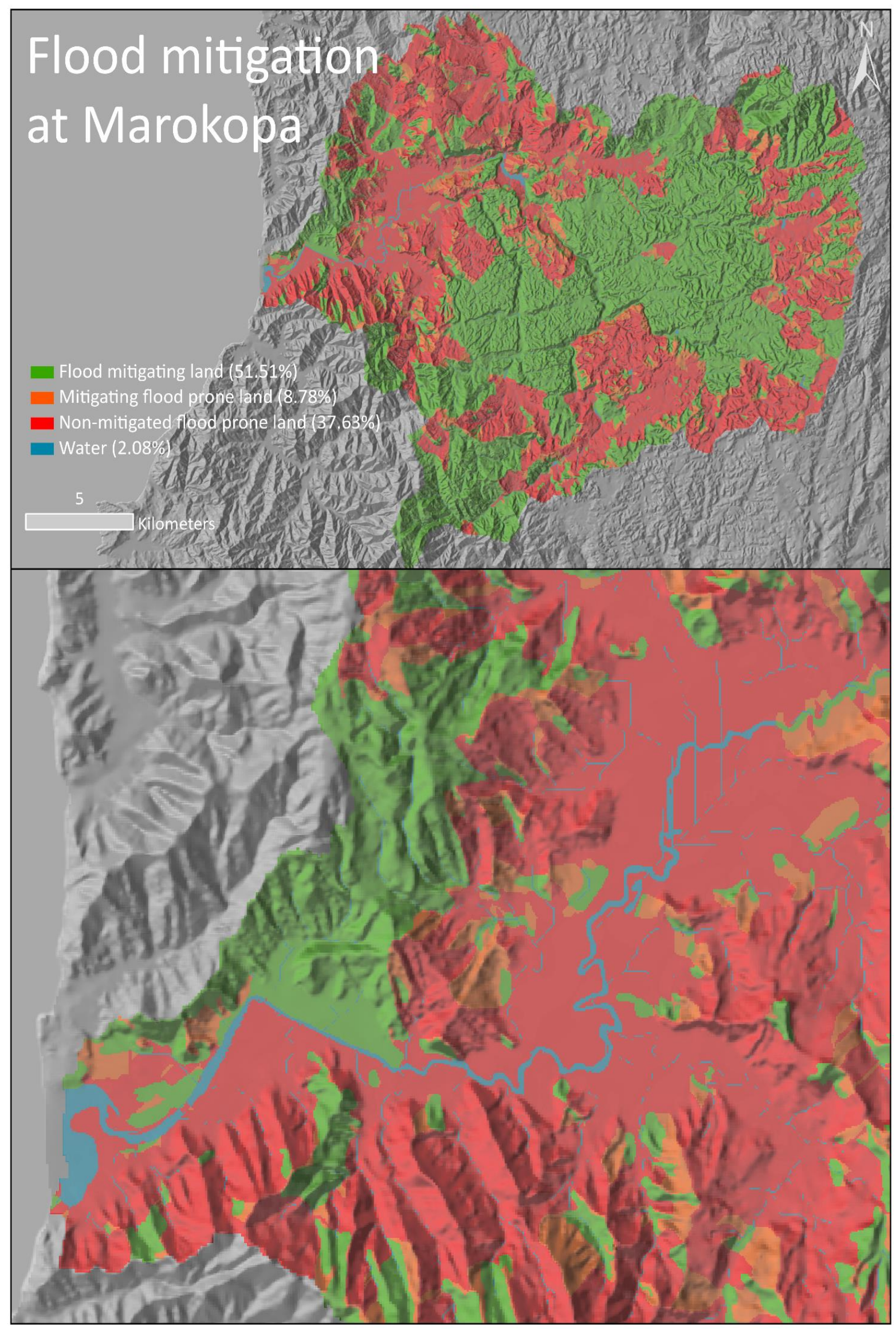

Figure 59: Flood mitigation within the Marokopa catchment. 
Flood interception classification:

Using flow accumulation information, LUCI classifies areas of mitigation within the landscape (Figure 59). Interception refers to where areas of flow overlap (are intercepted) with mitigating features. As in the previous figure, the contrast between forested areas and agricultural land is clear (Figure 60). Areas in red

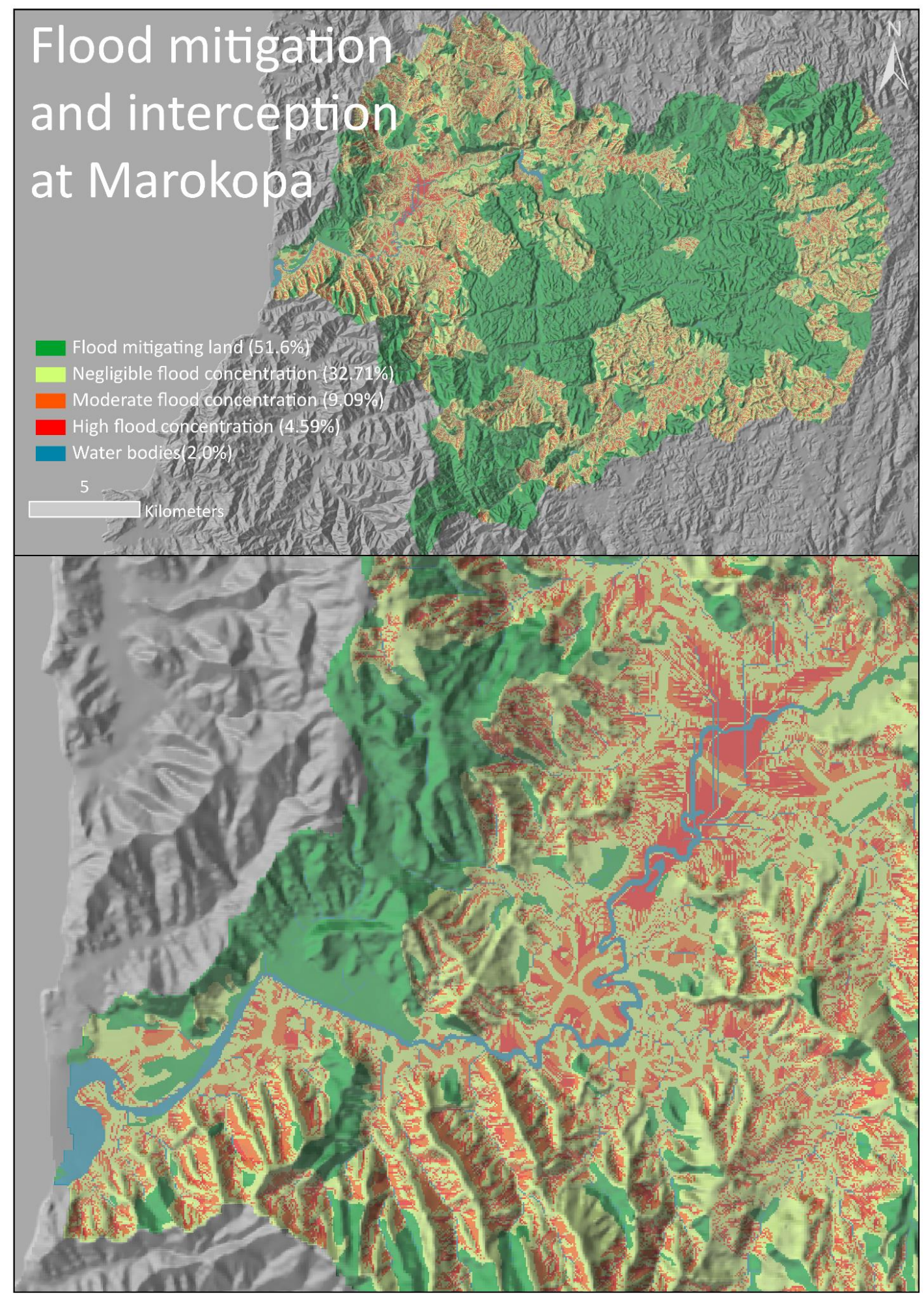

Figure 60: Flood interception within the Marokopa catchment. 
(4.8\%) represent where unmitigated land accumulates flow within the landscape, highlighting where flood mitigation/adaptation structures could be implemented to improve infiltration or storage capacity (Jackson et al., 2019). Such areas are concentrated in the north-eastern, south-eastern and western HPEG floodplains. These areas occur where mountainous regions give way to slightly flatter areas, generating larger flows and accumulating more runoff which can be drained or stored.

\section{Erosion vulnerability and sediment delivery}

Three outputs describe Marokopa catchment denudation: CTI erosion vulnerability (Figure 61), RUSLE erosion (Figure 62) and sediment delivery (Figure 63), each accounting for different factors. The CTI erosion vulnerability describes where land is at risk of gully erosion (not mass wasting) and accounts for slope and concavity, but not land cover or soil type. RUSLE combines rainfall erosivity (R-factor), soil erodibility ( $\mathrm{K}$ factor), slope length and steepness (LSfactor) and land cover/vegetation (C-factor $)^{8}$. Sediment delivery outlines where sediment is transported within the catchment, accounting for land cover type and stream connectivity. Erosion output is not directly comparable with different units. However, significant patterns in denudation processes are clear: CTI erosion outputs (Figure 61 ) show that most of the catchment, $85.2 \%$, has negligible erosion, with dispersed, high-slope areas identified as moderate erosion risk (11.4\%). Few areas of high erosion risk exist within the catchment (1.3\%). RUSLE and sediment delivery have significantly different results to CTI, clearly reflecting the importance of land use. Negligible erosion correlates with forested areas: however, this is not accounted for within the CTI process, as seen by comparing the white-outlined areas across the three denudation outputs. The CTI method does not account for vegetation and therefore overestimates stability. Areas of steep forested slopes minimise sediment delivery as the rooting systems hold the soil more readily than shallow-rooted pastoral landscapes, resulting in lower sediment transport values. As slope is accounted for across all tools, this is reflected in erosion output. All high erosion areas are high sloping across all three tools, although RUSLE areas have anomalously significantly higher erosion rates in low sloping areas.

\footnotetext{
${ }^{8}$ For information on this method and application, see Benavidez (2018), Benavidez et al. (2018) and Klik et al. (2015).
} 


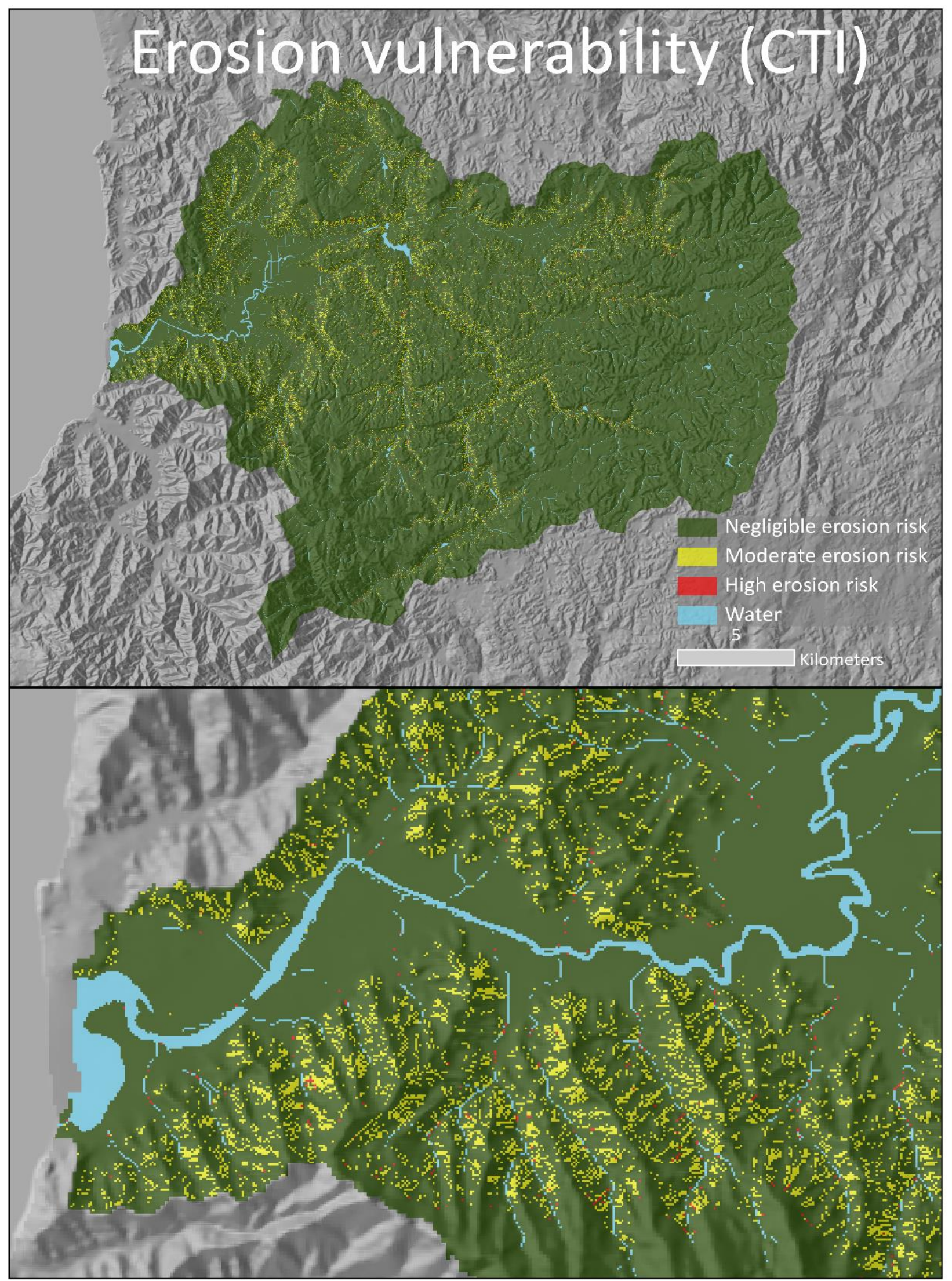

Figure 61: CTI-calculated erosion vulnerability within the Marokopa catchment. 


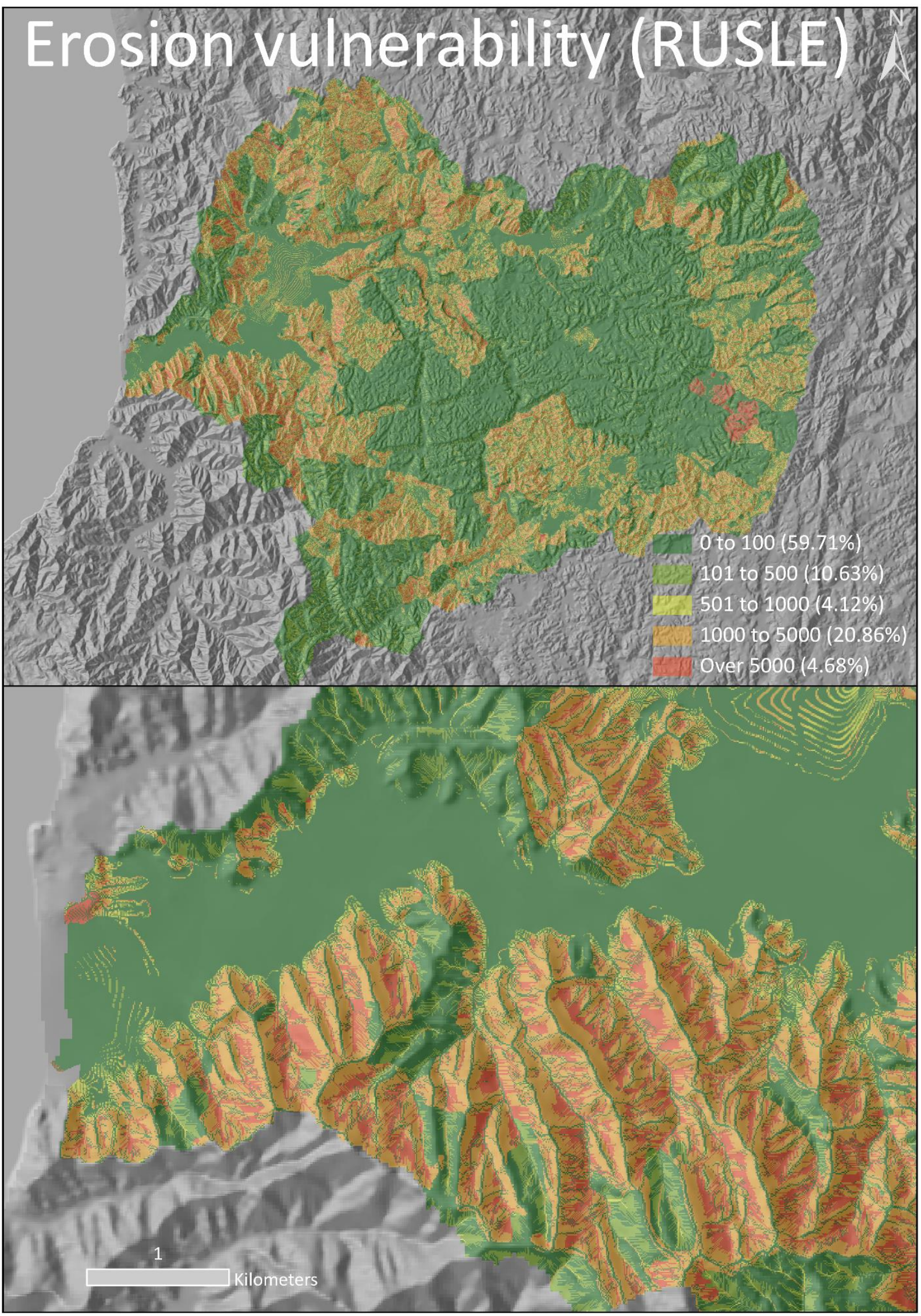

Figure 62: RUSLE-calculated erosion vulnerability within the Marokopa catchment. 


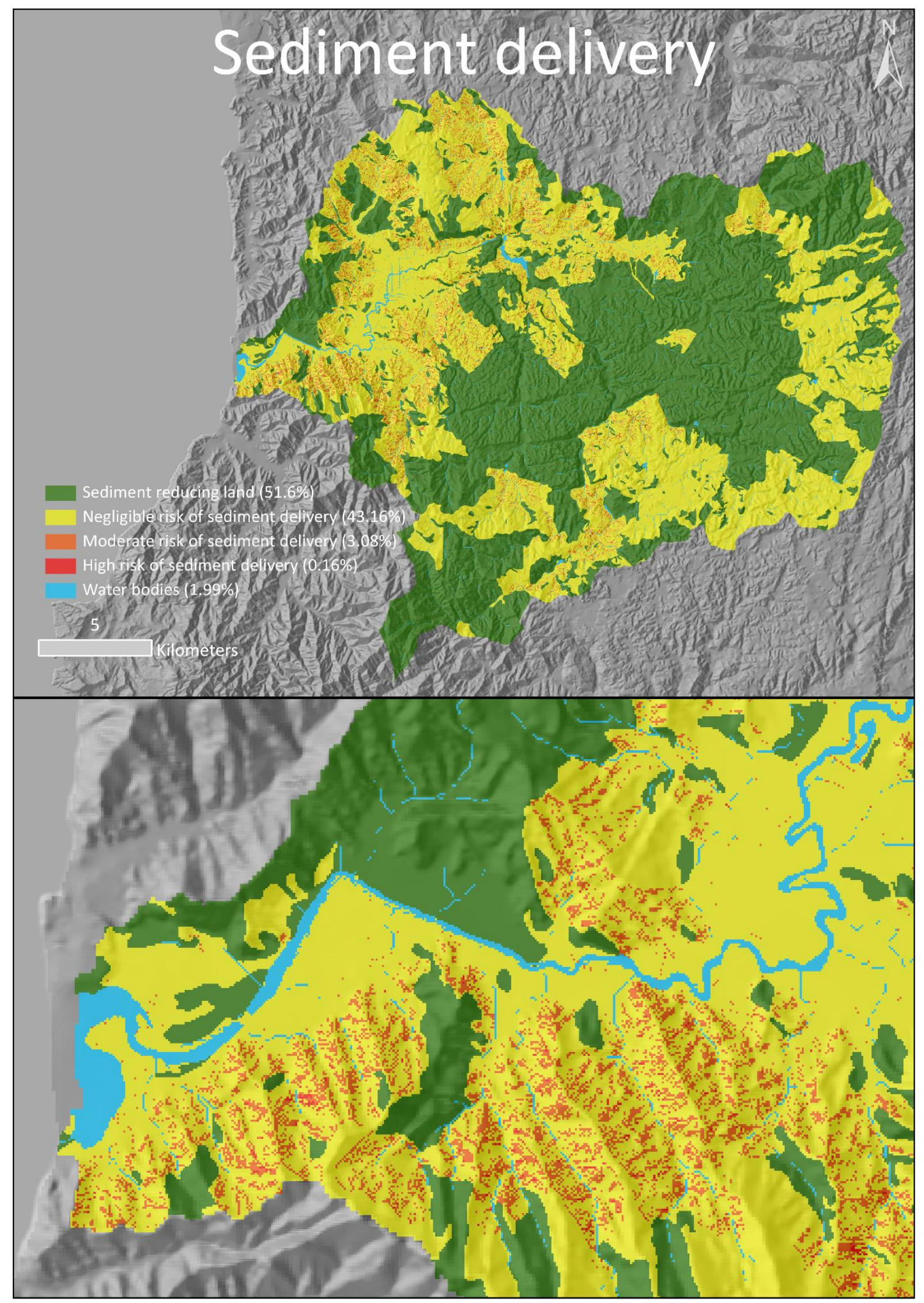

Figure 63: ES Sediment delivery within the Marokopa catchment. 


\section{Conclusions}

- Flood mitigation results show that the forestry land cover site corresponds with poor modelled flood mitigation.

- Flood interception results show that the areas of highest unmitigated flow accumulation occur on high slopes and the central floodplain.

- Highest erosion and sediment delivery are seen on steep slopes. 


\section{Agricultural activity, water quality, and trade-off results}

\section{Agriculture}

Figure 64 shows the difference between the current and optimal land cover utilisation across the catchment. Most (42.6\%) of land use intensity fits the landscape slope and soil type. Some areas $(2.4 \%)$ within forested regions appear to be under-utilised, often sections of indigenous forest on low slopes. Over-utilised areas (26.1\%), appear where agriculture occurs on steeply dipping terrain. Agriculture is prevalent within the Waikato/Marokopa area (Kingi, 2014). However, much of the steeper coastal areas are over-utilised while low-sloping, high elevation areas in the 'back-country' are under-utilised and potentially could be converted for agricultural use (Figure 64). In future, questions around the increasing intensification and the conversion of sheep, beef, and forestry blocks to dairy farms and stocking rates will require knowledge of where to intensify land use and where other uses are more valuable (Cameron et al., 2009). At optimal

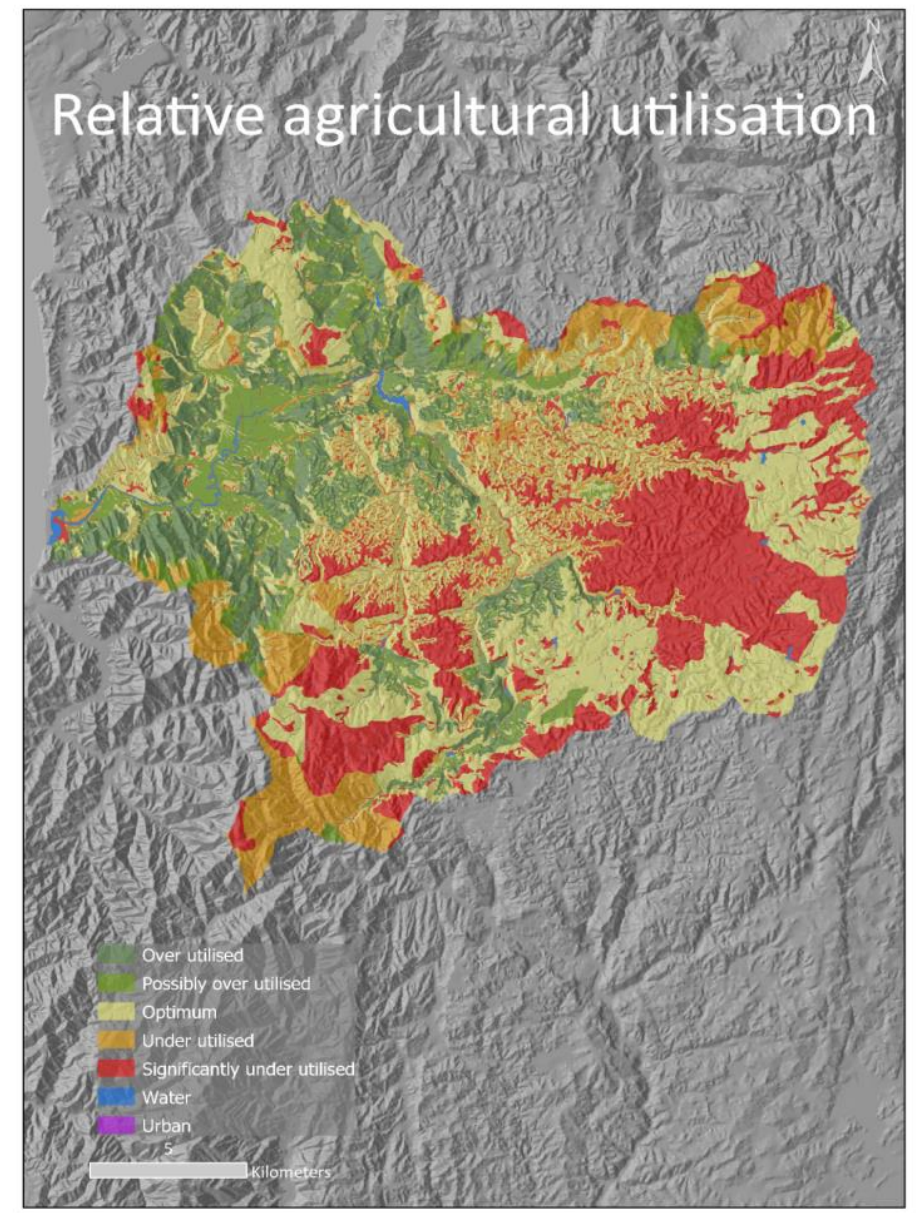

Figure 64: Relative agricultural utilisation within the Marokopa catchment. 
locations, sustainable agricultural practices can be utilised, resulting in economic and environmental best-practice land use across the catchment (Niggli et al., 2009).

\section{Water-quality: nitrogen and phosphorus}

Based on land cover and soil type, LUCI generates landscape classifications of nitrogen and phosphorus. Landscape nutrient concentrations are converted to stream concentrations through a particulate versus dissolved nutrient ratio and delivery to streams. Areas with associated agricultural land uses have high nitrogen or phosphorus concentrations when compared with regional and national datasets (Figure 65, Figure 66) (Ministry for the Environment, 2007; Ministry for the Environment \& Statistics New Zealand, 2015). Although the ES results show that future investment into this research area is valuable, current Marokopa catchment water quality has only been considered for trade-off synergies. No further analysis of these water quality outputs will occur within the scope of this thesis (Keeler et al., 2012; Sweeney et al., 2004; Trodahl et al., 2016).

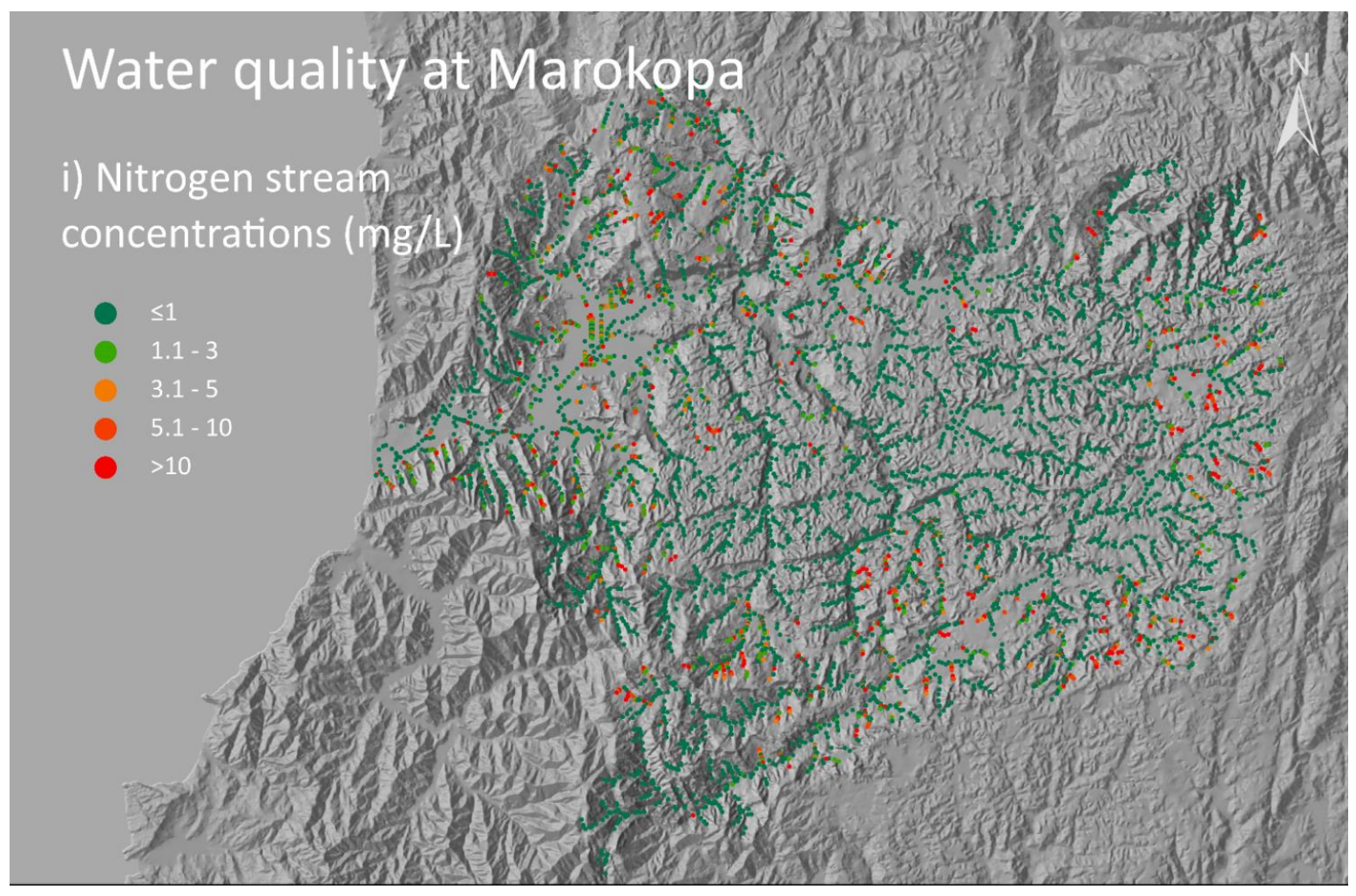

Figure 65: Nitrogen stream concentrations within the Marokopa catchment. 


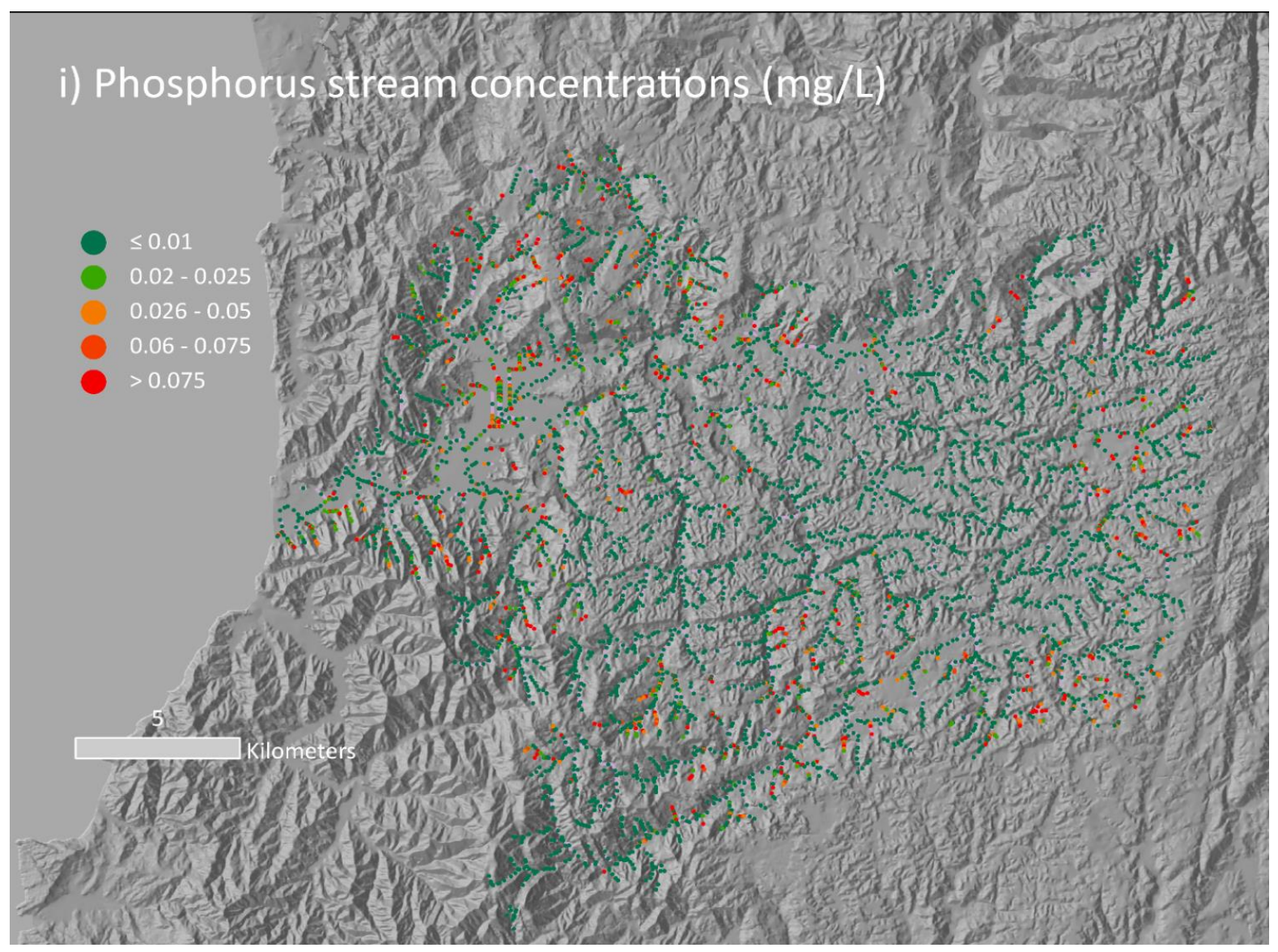

Figure 66: Phosphorus stream concentrations within the Marokopa catchment.

\subsection{Ecosystem service trade-off results}

Trade-off maps compare the value and potential role of multiple services within the Marokopa catchment. Areas of good individual service are correlated and identified as areas where the landscape should not change. Similarly, areas of current poor service are correlated across the services and are defined as locations where users should change the landscape for overall ecosystem benefits. ES can also be weighted within the trade-off modelling if certain services are prioritised over the rest of the analysed services as detailed in Section 3.3.2. Weighted tradeoff maps are created by assigning values to each of the ES being compared (Appendix E). Prioritised services are given a higher value, which means that tradeoff maps will appear like the individual ES maps of the prioritised service.

\section{Erosion/sediment delivery vs flood mitigation}

Erosion and flooding are dominant hazards in the Marokopa region, as described by residents in the area. However, no areas within the existing catchment 
mitigate both flooding and erosion to an "excellent" standard, only "significant" provision $(50.1 \%$ ) (Figure 67). Orange areas show where there is still opportunity to improve both services, generally on steeper HPEG slopes of the upper catchment or floodplains. Erosion and flooding factors and impacts are interconnected. However, as the community has identified both hazards, Figure 67 describes where efforts should be focused to mitigate either hazard, i.e. where to "get the most bang for your buck", which are largely in steeply sloping and floodplain areas currently used for agriculture.

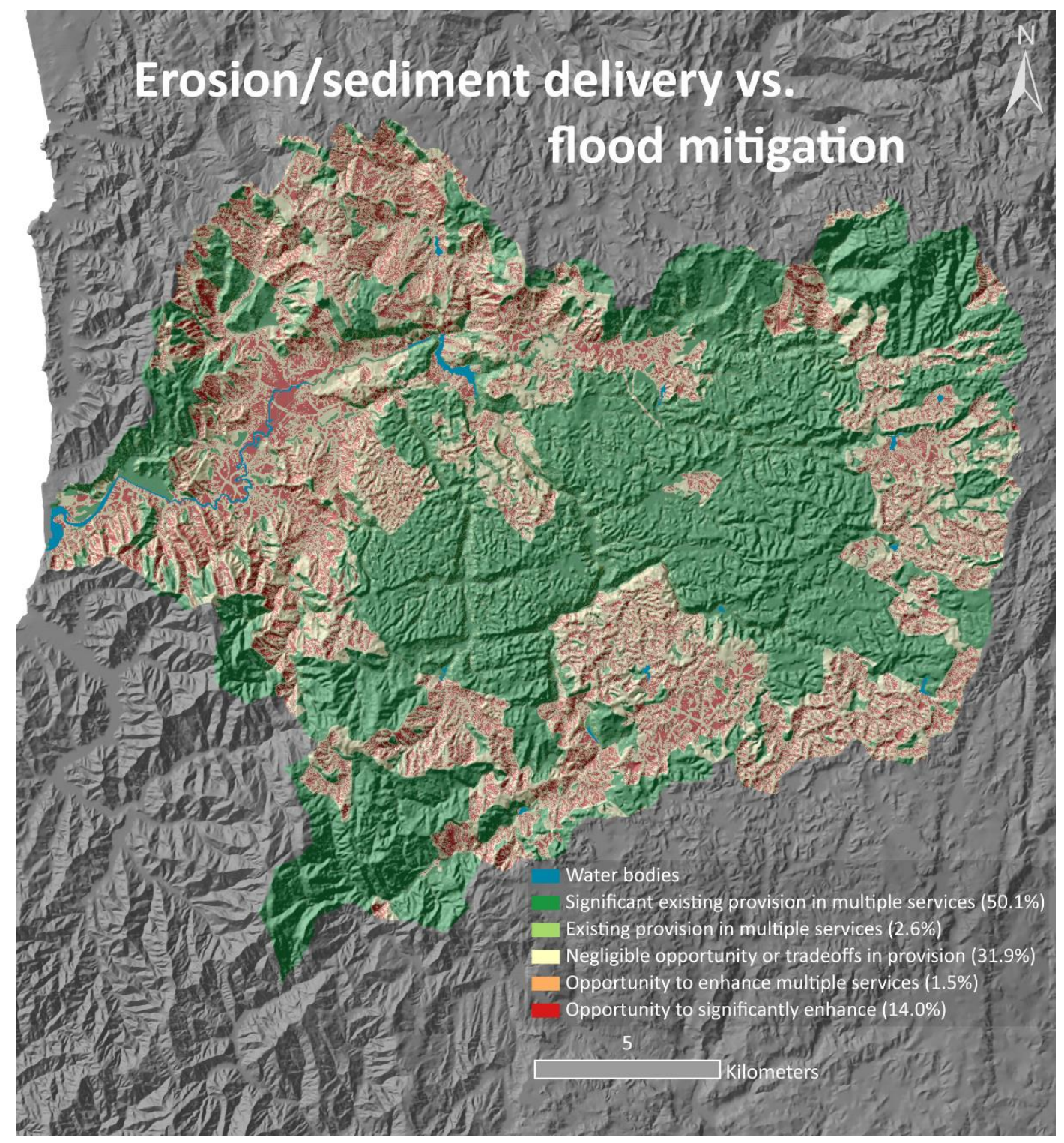

Figure 67: ES trade-off output: erosion and flooding services considered within the Marokopa catchment. 
Flood mitigation vs erosion vs agricultural productivity vs nitrogen vs phosphorus transport (equal weighting)

The most valuable ES services have been categorised as flood mitigation, erosion, and agricultural productivity, as identified by the local community. Research should be undertaken into nitrogen and phosphorus transport, as well as carbon flux and habitat suitability, although these have not been analysed here. Trade-off results of the first three individual services, compared with trade-offs of all services are interestingly similar. Trade-off maps can be weighted, as shown by comparing Figure 68 and Figure 69. Figure 68 has no ES service preferentially weighted against the other services, while Figure 69 preferentially weights flood risk against the rest of the considered ES using a 3 to 1 weighting.

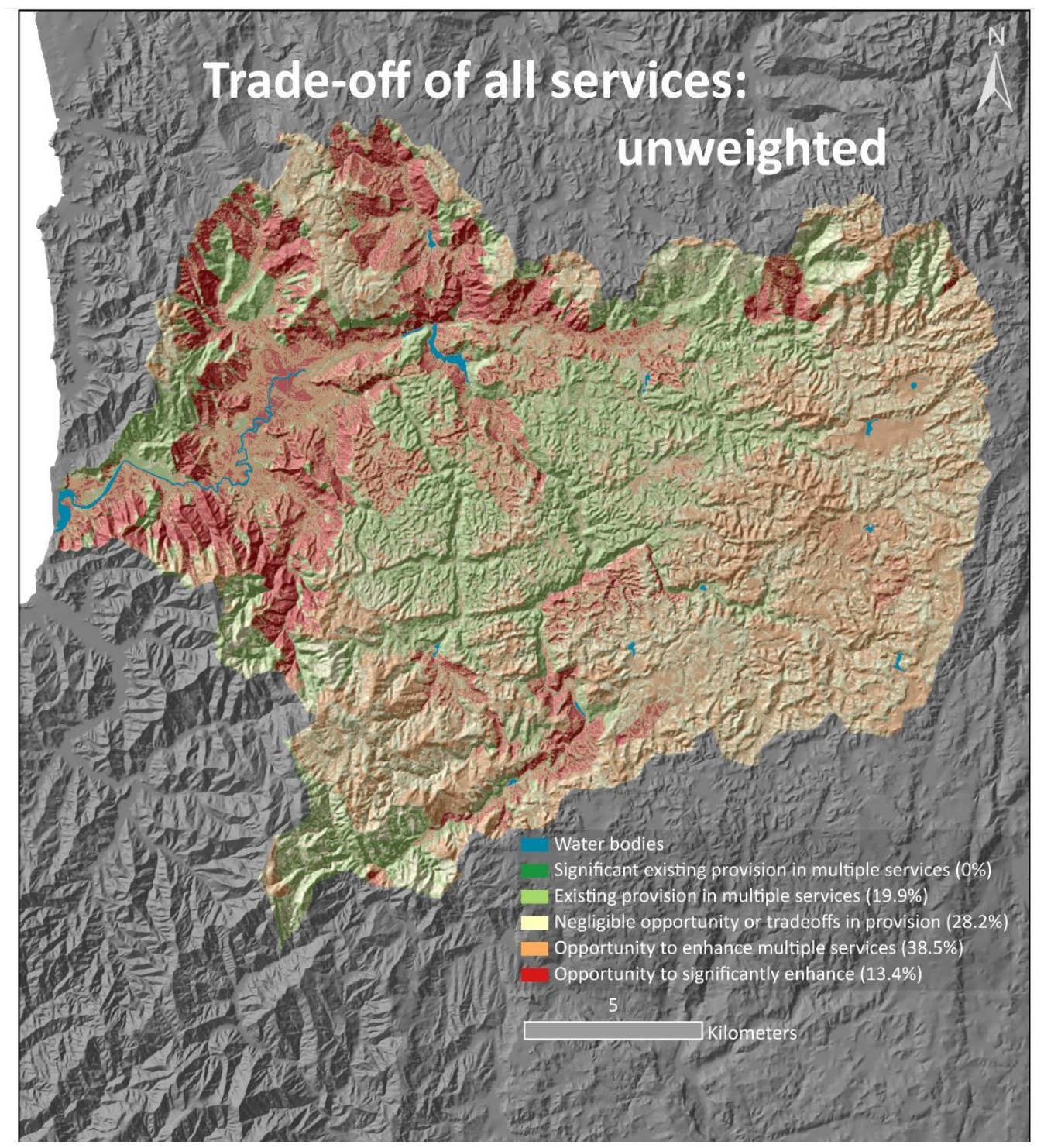

Figure 68: Non-weighted trade-off map. 
While no areas across the catchment give "excellent service provision", almost half the catchment is identified as having "moderate" service provision (this corresponds with forested locations) (Figure 68). Improvements across all services can be made when landscapes that have been categorised as having high slopes $\left(21^{\circ}+\right)$, recent or brown soils and HPEG have a change in land use.

Flood mitigation vs erosion vs agricultural productivity vs nitrogen vs phosphorus transport (flood mitigation preferentially ranked)

In contrast, Figure 69 represents areas of opportunity when flood mitigation is weighted more than the other ES services, rather than equally. Generally, the same patterns exist, with HPEG land having the most opportunity to improve ES services across the board. Floodplains represent an excellent opportunity to synergistically improve services. However, areas of high elevation and slope increase the opportunity to improve service ( $18.0 \%$ to $24.7 \%)$.

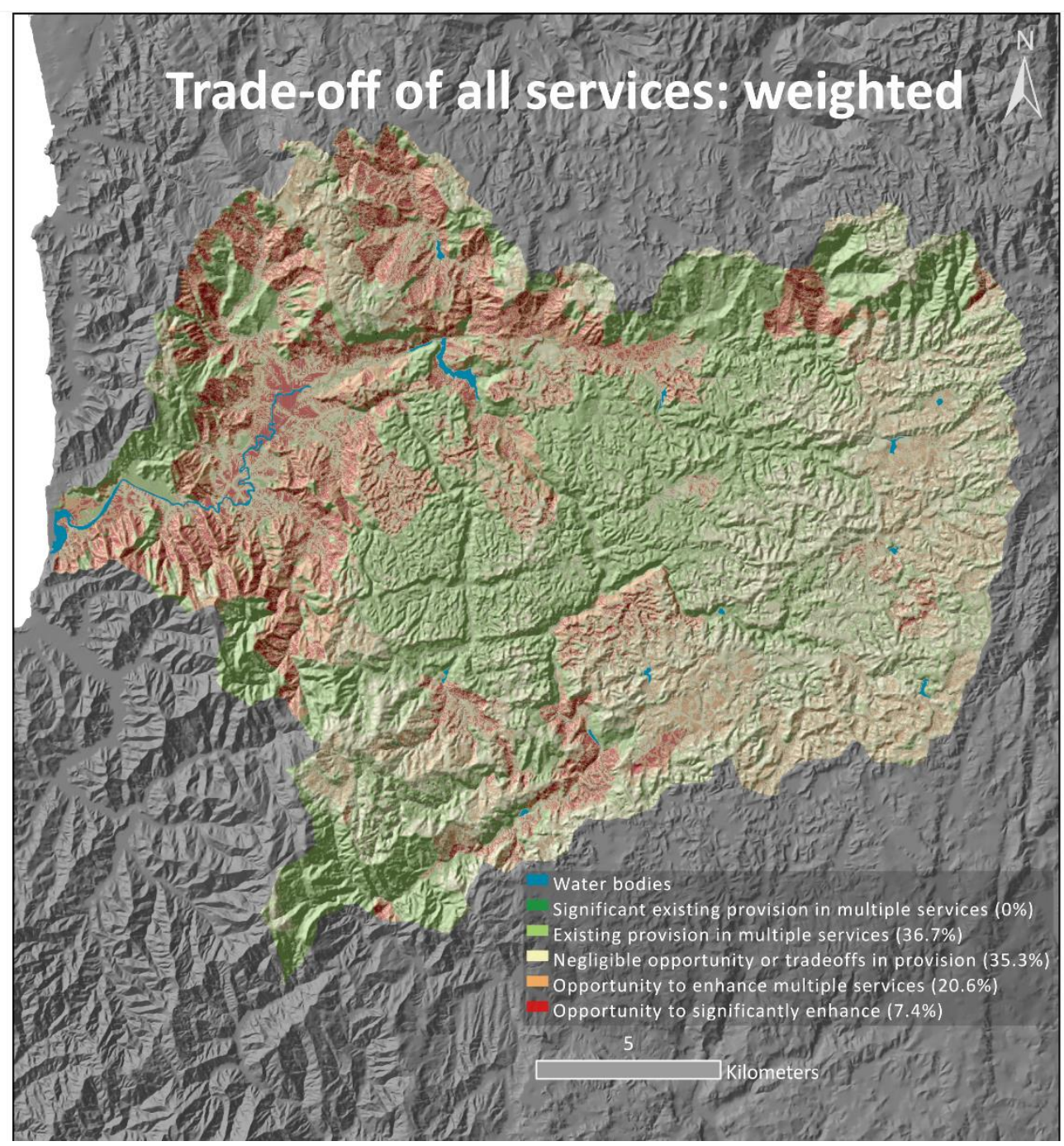

Figure 69: Weighted trade-off map 


\subsection{Other ES service/trade-off land management discussion.}

\section{Relative agricultural utilisation}

With a $125 \%$ increase in dairying within the Waitomo region predicted, holistic management of agriculture is important for a sustainable future at Marokopa and in the wider region (Kingi, 2014). Economically, agriculture contributes an average of $24 \%$ to the Waikato GDP ${ }^{9}$. However, economic success is dependent on the physical and economic climate, with large changes in milk price and drought contributing to changes in production and income (Statistics New Zealand, 2018). Sustainable land management practices can minimise the impacts of climate change, as they also make the New Zealand economy resilient to such impacts. Sustainability defines processes that meet and maximise the health, food, and ES needs of current and future generations (Tilman et al., 2002). Several reviews outline the needs, methods, frameworks, and roles within and of sustainable agricultural farming (Darnhofer et al., 2010a; Darnhofer et al., 2010b; Niggli et al., 2009; Wezel et al., 2014). Tilman et al. (2002) and Zhang et al. (2007) outline that while sustainable agricultural practices are needed, recognising that agricultural practices influence surrounding ES is an often overlooked issue. Valuing these services and developing management plans that build on, rather than detract from, these synergies inform sustainable land management not just agriculture. Trade-off outputs (Figure 67, Figure $69 \&$ Figure 68) demonstrate where best to change land management to benefit a combination of erosion/sedimentation, agricultural utilisation, and flood mitigation.

\section{Trade-offs in ecosystem service output}

The Marokopa catchment has a modelled opportunity to increase overall ES services through the conversion of steep-terrain HPEG to another land cover such as forestry. When services are equally ES services are improved by prioritising land management changes on the slopes of the agricultural floodplains (Figure 68). However, when flood mitigation is preferentially weighted, areas of water accumulation are found to improve all ES instead. ES cannot prescribe a single best land cover scenario, as any solution is dependent on the needs of current and future

9 From Stats NZ (https://www.stats.govt.nz/information-releases/regional-gross-domesticproduct-year-ended-march-2017\#waikato), accounting from 2000 to 2016, with a minimum of $14.92 \%$ and a maximum of $32.03 \%$. 
generations (Tilman et al., 2002). Councils and communities must determine whether ES modelling should aim for minor overall multi-ES improvement or whether the prioritisation of certain services would result in more valuable benefits (Viglizzo et al., 2012). Moreover, practical application and engagement with ES output in decision making requires clear and concise communication of the science involved (Burkhard et al., 2013).

\section{Conclusions}

- Modelling results suggest agriculture is over utilised in the steep hillslopes bounding the Marokopa floodplains and underutilised in the flatter locations to the south and east of the Marokopa catchment.

- High nitrogen and phosphorus concentrations are seen on the edges of the Marokopa catchment and in farming areas.

- Considering flood mitigation, erosion, sediment delivery, agricultural productivity, and water quality, the Marokopa floodplain and surrounding hillslopes are priority areas to change land management or land use. 


\section{Discussion}

This chapter discusses the results presented throughout this thesis and relates them to the research aims (Chapter 1). Figure 70 shows how the objectives for each method interviews, rainfall-runoff modelling, inundation and ES modelling relate to each aim. The contributions from each method to each thesis aim are discussed and compared with relevant literature. This analysis will be related to the importance of hazard analysis in rural locations such as Marokopa. Finally, limitations and suggestions for future work are outlined.

\section{How methods relate to thesis aims}

Various interconnected methods were used to analyse these research aims, namely interviews with Marokopa catchment residents, rainfall-runoff and ecosystem service (ES) modelling. As discussed, inundation modelling was planned to delineate flood risk: however, due to constraints detailed in Chapter 5, this was not possible. Figure 70 outlines how these methods relate to each research aim.

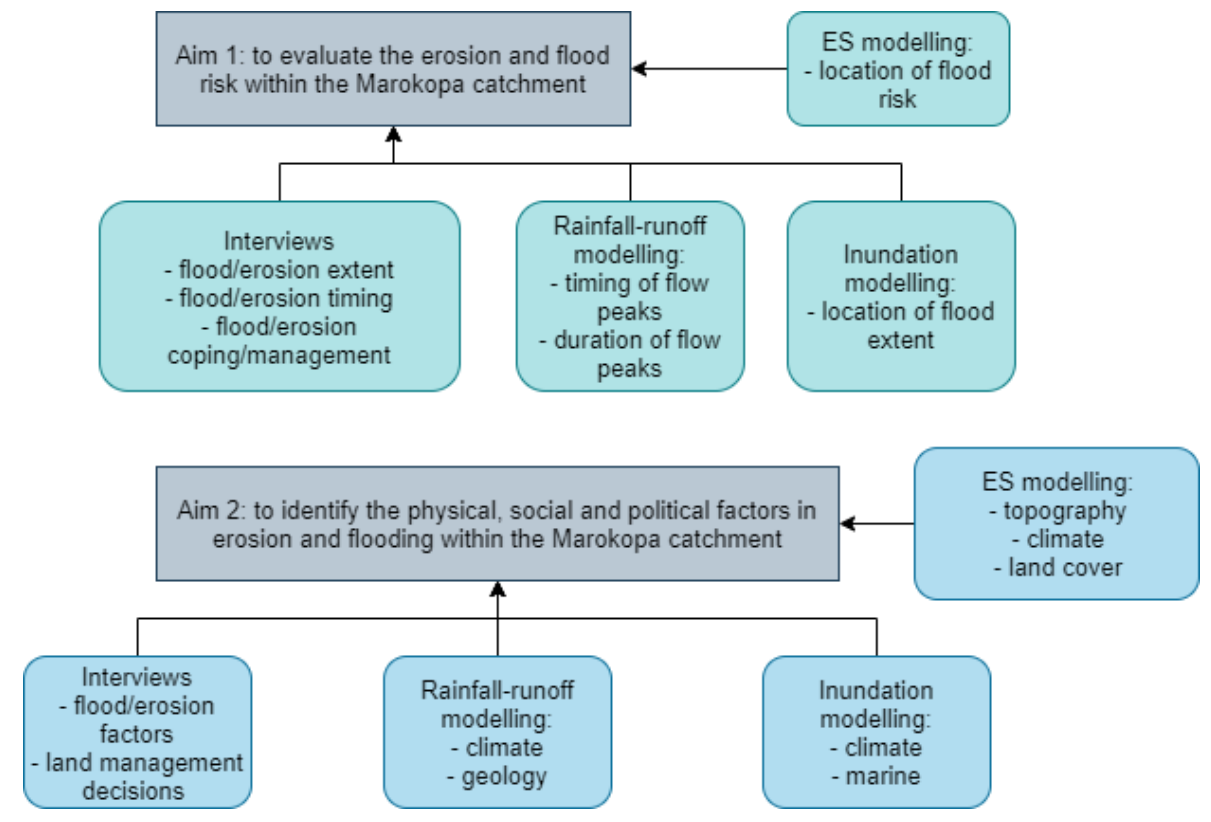

Figure 70: Relationship between thesis aims and methods.

\subsection{Aim 1: identify Marokopa flood and erosion risk}

Hazard risk, as previously stated, is a combination of event magnitude, vulnerability and exposure, and is therefore influenced by physical and sociopolitical factors. Both qualitative and quantitative results are useful in evaluating 
the flood and erosion risk. Both participant descriptions and modelling (inundation and ES) evaluate the extent and magnitude of Marokopa flooding and erosion.

\section{Lessons from the locals (qualitative analysis)}

Academic hazard definitions must correspond with local definitions, as local communities understand and experience the hazards as they occur. Participants described historical flooding as occurring at Marokopa campgrounds, but also across the floodplains $\sim 5 \mathrm{~km}$ inland. While this is likely the result of river inundation, further inland 'flooding' may be overland flow. Water surplus due to over saturated soils, or infiltration excess, is more likely than bank breaching flooding, due to the distance of the flooding to the water body. Intense or long duration rainfall causes overland flow (Abdul \& Gillham, 1984; Ward \& Robinson, 2000). Mosley (1979) suggests that such processes are most common on arable farmland, such as at Marokopa. The need for both inundation and overland flow modelling emphasises the importance of local input in defining flood hazards (Fuchs et al., 2017). As overland flow is not currently simulated within inundation models, future traditional and ES flood modelling should include overland flow estimations.

Furthermore, flood impact can depend on flood duration. Only interviews described this aspect of flooding. Future modelling work could involve simulating not only maximum flood depth and extent but also draining capacity and duration.

Flood risk is a human construct. Participants were also able to relate physical processes to human impacts, such as identifying road flooding. While this is not a large area, it is vital and more critical than when other, less utilised areas flood. Flooding is not problematic unless livelihoods are affected: risk not only outlines the physical process, but social vulnerability too (Fuchs et al., 2017; Kron, 2005).

While flooding was initially the focus of this thesis, community members highlighted erosion as an equal, if not more important, local hazard. Erosion occurs both on the steep hillslopes and due to scouring from marine waves. Participants described hillslope erosion as less frequent in indigenous-forested areas, rather than grassland areas. Erosion and high rainfall or, high flow, are connected as rainfall mechanically erodes soil particles and flows transport, further eroding or redistributing river sediments. 


\section{Rainfall-runoff results}

Rather than flooding extent, rainfall-runoff modelling describes the timing and processes that cause upper catchment flow peaks. Model results highlight increased permeability due to subsurface karst systems, thereby increasing infiltration and decreasing overland flow (Gunn, 1978). Subsurface flows are subsequently divided into diffusive and rapid infiltration, the later shown by the dominance of fastflow reservoirs in winter floods (van Beynen et al., 2011). With more streams activated in wintertime, the rain multiplier parameter was also significantly higher in winter than summer. Across all seasons however, the model performed inconsistently, indicating that either localised rainfall or subsurface conditions resulted in unaccounted rainfall or subsurface network storage (Williams, 1983).

\section{Preliminary inundation results}

While flatwater inundation modelling was not completed, the topographic analysis provides a simple, preliminary indicator of flood risk: as floods are more likely to occur at lower elevations. Mapped Marokopa township flood areas coincide with participant descriptions; with lower elevations around the Marokopa campsite identified as flood-prone. Furthermore, floods with high Marokopa Fall's flow generally result in large flood extent. However, floods with low Marokopa Fall's flow can also result in large township flooding, due to extreme tidal conditions such as king tides. A simple flatwater inundation model would underestimate excess water: marine processes, overland flow and flow resulting from other water bodies which influence Marokopa flooding. Future work in the Marokopa area should include both inundation and overland flow to estimate full excess water.

\section{Ecosystem service modelling results}

The LUCI ES flood modelling produces two outputs: flood mitigation opportunities and flood concentration areas. While the former categorises the landscape into areas with flood mitigation potential, the latter simulates the areas of potential flood risk. Flood interception results support the general qualitative pattern of flood risk: the floodplains $5 \mathrm{~km}$ inland. The LUCI ES toolbox simulates where water accumulates, which is more comparable to overland flow than inundation modelling. However, it does not highlight the camping area near 
Marokopa township as being at risk. This difference is likely because marine conditions are not yet accounted for yet within the LUCI ES flood risk model ${ }^{10}$, according to participants, it is a significant flooding factor. Coastal inundation ES is therefore recommended for future works in the area.

Three LUCI methods (CTI erosion, RUSLE erosion and sediment delivery) were used to simulate denudation within the Marokopa catchment. These ES results agree with qualitative results that erosion occurs on the steep-sided hillslopes. Furthermore, the RUSLE and Sediment delivery methods also agree with participant descriptions that erosion occurs more on farmland than forested areas. This significantly changes the locations and extent of erosion in the Marokopa area. Modelled erosion varies in intensity: however, it mainly simulates hillslopes as a high-risk site of erosion. In contrast, residents describe the hillside erosion as a rare occurrence. Further differences include ES modelling not accounting for marine scouring, which was identified by the local community as a significant hazard.

\subsection{Aim 2: identify Marokopa erosion and flood factors}

Several factors influence both flooding and erosion. These factors include climate, geology, topography, soil, land cover, marine conditions, and social factors, such as land/flood management strategies. These factors are derived from participant conversations, flood process literature, or otherwise included within the rainfall-runoff, inundation or ES modelling.

Table 8: Flood and erosion factors $(\checkmark$ and $\mathrm{O}$ ) presented within the interview, rainfall-runoff, inundation and ecosystem service results.

\begin{tabular}{|c|c|c|c|c|}
\hline \multirow[b]{2}{*}{ Factor } & \multicolumn{4}{|c|}{ Method } \\
\hline & Interviews & $\begin{array}{l}\text { Rainfall- } \\
\text { runoff }\end{array}$ & Inundation & Ecosystem service \\
\hline Climate & $\checkmark 0$ & $\checkmark$ & $\checkmark$ & $\checkmark 0$ \\
\hline Geology & $\checkmark$ & $\checkmark$ & & \\
\hline Topography & vo & & $\checkmark$ & $\checkmark 0$ \\
\hline Soil & $\checkmark$ & $\checkmark$ & & $\sqrt{ } 0$ \\
\hline Land Cover & vo & & & vo \\
\hline Land management & Vo & & & \\
\hline Marine & Vo & & & \\
\hline Climate change & $\checkmark 0$ & & & \\
\hline Community & $\checkmark 0$ & & & \\
\hline
\end{tabular}

${ }^{10}$ LUCI coastal inundation is available for other modelling, however is not yet within the ES toolbox. 


\section{Climate/rainfall/seasons}

Both flooding and erosion are influenced by climate. One participant stated that flows were lower during the drier summer months and that antecedent conditions had a large impact on flood occurrence, while another noted that large landslides coincided with heavy rainfall. Rainfall-runoff results support the observations of participants that seasonal changes in climate correspond with changes in flows rate. Evidence of this includes better model performance when the rain-multiplier is higher for summer rather than winter months. In summer, the karst system results in a sustained baseflow, as shown by the baseflow dominance in modelled rainfallrunoff response. Interestingly, the modelled results vary in the error produced, indicating either a change in rainfall event type (possibly entering from different directions) or the impact of extrapolated rainfall being used in a rainfall-runoff model. Localised rainfall at either the rainfall or flow measured location will result in disproportionate flow response.

\section{Geology}

The geology of the upper catchment significantly impacts the hydrology of the area, further demonstrated by rainfall-runoff modelling. One participant described previous studies by Gunn (1978); Gunn (1983), outlining the different flow paths karstic systems have to areas with non-karstic geology. These differences, including drainage through polygonal karst and fractures, increase infiltration. Furthermore, rainfall-runoff model performance improves when the karstic nature of the area is represented within the model parameters and structure, as supported by Ford and Williams (1989). Karst geology results in distributed flow peaks, as the flow is dispersed through slower and faster paths. Furthermore, the lack of overland flow can be attributed to water infiltrating quickly into the soils due to micro and macro karst fissures (Williams, 1983).

\section{Topography}

All methods, except the rainfall-runoff modelling, which was spatially lumped in this thesis, account for topography. As previously mentioned, when identifying flood-prone areas, participants outlined low-lying areas. Erosion-prone areas 
identified included steep, hillslopes, but also low elevations where erosion was due to marine erosion.

Both the topographic and flatwater inundation estimate floodwater extent and depth based on rainfall input flow volume and elevation. The first assigns a specific height as 'inundated', classified as the inundated area. The second (the flatwater inundation model) instead uses hydrologic concepts such as iterative topographic routing (Benavidez, 2018; Teng et al., 2017). Finally, topography is a significant input for ES modelling and is widely used to map a variety of services (Crossman et al., 2013). Input topography is here used to identify different flow paths throughout the catchment (Section 4.3).

\section{Soils}

Participants also related differences in soils to drainage and water storage capacity. Marokopa area was divided by participants into areas with more 'dirt' or sand. The sandy areas resulted in well-drained soils during winter but dry lawns in summer (Hewitt, 1998a). Within rainfall-runoff modelling, soil is conceptually modelled, relaying water through a soil water model component before percolating into groundwater reservoirs. This rate is dependent on the soils of the area, and, in the case of the karstic system, the geology. This results in high infiltration rates, and no observed overland flow. While not accounted for within the inundation model, ES modelling derives soil permeability and connectivity from correlated soil and land cover tables within LUCI, creating the LandScen output. This information is then used to simulate flows of water for the individual LUCI services (Jackson et al., 2019).

\section{Land cover and land management}

Participants described land cover and land management as having a significant impact on erosion. Management strategies include planting to reduce erosion, having stocking and cropping regulations. Land use and land use changes have a significant impact on flooding. These environmental changes can also alter the sensitivity of catchments towards their climate and climate change (Macklin \& Lewin, 2003). Whether it be deforestation, afforestation, or some other change, this affects not only the hydrology of the area but also the nutrient/sediment cycle. LUCI accounts for input land cover and biophysical process relationships to evaluate the landscape (Bagstad et al., 2013) 


\section{Marine}

Nearly all participants acknowledged the role that tides and marine impacts had, and would likely continue to have on either causing or exacerbating Marokopa flooding. Several quantitative studies support the fact that flooding is impacted by events such as tides, storm surge and sea level rise (Ezer \& Atkinson, 2014; Wolf, 2009) While rare, qualitative studies on ocean-flooding relations can identify physical factors and provide opportunities to engage with local indigenous knowledge (King et al., 2007). However, none of the quantitative methods of flood and erosion modelling currently account for marine conditions.

\section{Community}

Finally, a strength of qualitative analysis is an increased understanding and value of people's place in the world, which lies outside of the scope of modelling. Several participants identified the importance of community engagement with local, regional, and national councils, and the role these governing bodies have in setting the scene for flood mitigation and adaptation. However, while councils aim to support rural communities, climate change adaptation plans aim to prevent risk rather than protect resident assets. Plans may include rezoning, which is controversial when dealing with peoples' homes and livelihoods.

In contrast, participants have outlined that councils also play a significant part in supporting local planting to prevent erosion. Financial and local knowledge are both important resources that councils can provide to help stakeholders plan for climate change. The most critical resource, however, is engagement. Adaptation and mitigation strategies require investment, from both governing and local communities. Therefore, better community engagement and communication are essential for enabling future minimisation of vulnerability and hazard risk. 


\section{Conclusions}

Marokopa is a low-population township, located on the west coast of the Waikato region, that is exposed to both high magnitude flooding and erosion. Positioned at the opening of a $364 \mathrm{~km}^{2}$ catchment that covers a range of land cover, soil, and geology types, this area is the link between the rising oceans and dynamic geomorphology of the west coast. The upper catchment karst geology inland, paired with the lack of high-resolution rainfall and flow makes hydrological modelling complex but also lends itself to a more holistic analysis of hazard analysis. Qualitative experiences of past and current residents are used to inform historical flooding and erosion, while ecosystem services allow for future improvement of synergistic land management decisions. This thesis aims to evaluate the magnitude and influencing factors of flooding and erosion at Marokopa, using a combination of qualitative data, rainfall-runoff, inundation and ecosystem service modelling. The specific aims being:

- To evaluate the erosion and flood risk within the Marokopa catchment.

- To identify the physical, social and political factors in erosion and flooding within Marokopa.

This thesis makes several contributions to the local, rainfall-runoff, inundation and ecosystem services modelling communities. These are:

- Community engagement: this project uniquely involves residents of the Marokopa community throughout the scientific process, ensuring academic accountability. Engagement includes preliminary communication at the project's inception; several meetings involving different community members; and a final report to communicate local findings for the local people.

- Novel utilisation of a mixed-method approach to flood and erosion analysis: the integration of participant experiences and quantitative rainfall-runoff, as well as inundation and ecosystem service, results in both temporal and spatial outlining of flood and erosion extent at macro and 
catchment-scales. Furthermore, local knowledge and experiences were utilised in the traditionally quantitatively-dominated field of flood modelling and significantly improved evaluating the interconnectedness of the system, and contributing factors to local flooding and erosion.

- Development of a bespoke rainfall-runoff model accounting for the complex karst-environment within a data-sparse environment. The predictive capability of this model, although dependent on extrapolated rainfall (28.3 km away), had low modelled-observed flow error, unless due to local rainfall processes. Highly-resolved rainfall at Marokopa Falls would likely improve such errors. Through model development, calibration, and validation of the model; rainfall intensity, duration, and geological influences on infiltration were identified as having a significant impact on model fit.

- Flood and erosion mitigation ecosystem services were modelled. Modelling incorporated flood and erosion factors such as climate, topography, soil and land type to identify areas most at risk of flood and erosion. Priority areas for future land management and hazard mitigation investment were outlined, with synergistic comparative comparisons also analysed. 


\subsection{Future Work}

\section{Overall}

- Future research should include ground-truthing of topography/elevation, soils, land cover and geology, flow, and rainfall as all models are the sum of their inputs.

\section{Interviews}

- Flooding impact is dependent on socio-political structures. Therefore, interviews with local/regional council around local hazards and mitigation/adaptation opportunities would provide a more holistic view of the problems and opportunities in this area.

\section{Rainfall-runoff modelling}

- Use of Mokau and Te Kuiti High School rainfall data for rainfall-runoff modelling would increase the length of the rainfall-runoff modelling period.

- Using a variety of rainfall sources and creating a rainfall that is more representative by weighting it by area could reduce errors caused by local rainfall.

- A seasonally-varying rain multiplier parameter is suggested to reduce model error.

\section{Inundation modelling}

- Due to time constraints, properly analysed and calibrated inundation modelling was not conducted within this research project but is heavily recommended for future work.

- Optical, radar and infrared images could be utilised for identification of river-channel breaches and flood extent or duration and subsequent inundation modelling

- Quantification of overland flow at Marokopa floodplain is needed to discern flood inundation from the more rain-dependent process.

- Ocean dynamics such as tides, storm surges, tsunami and sea level rise have a significant impact on flooding at Marokopa, and therefore should be analysed further, either through inundation or ES modelling. 


\section{Ecosystem service modelling}

- Farm practices such as cropping and stocking rates offer the opportunity to represent how changes in specific land management practices influence various ES within LUCI.

- Marine erosion is not yet included within LUCI modelling but is extremely important for the mitigation and adaptation of future coastal communities.

- ES modelling under different climate change and land cover change/land management scenarios would be beneficial for future ES assessment.

- Cultural services included in LUCI ES modelling could improve targeted areas for flood or erosion mitigation.

\subsection{Final Conclusions}

This thesis provides a successful scoping study of flood and erosion risk within the Marokopa catchment. Community engagement allowed for grounded, meaningful local discussion of flood risk, flood risk factors and future opportunities. These discussions outlined that both physical factors and social factors like Marokopa community and Mirumiru marae have a role in deciding Marokopa's future. Rainfall-runoff modelling was applied at a unique and hydrologically-complex location, with positive results. Localised rainfall, seasonality and the karstic systems were identified as significant influences on runoff. Hydrological model results combined with the gathered historical flood extents provide a foundation for future flood inundation modelling. Finally, ecosystem service modelling outlines the Marokopa floodplain and surrounding hillslopes as areas for prioritised flood and erosion mitigation. Integration of quantitative and qualitative methods outlines current flood risk extent and evaluates factors which contributes to flooding, providing a thorough knowledge base for future flood modelling within the Marokopa catchment. 


\section{Appendices}

\section{A. Definitions, abbreviations, acronyms}

Table 9: Definitions of commonly used thesis terms.

\begin{tabular}{|c|c|}
\hline Term & Definition \\
\hline Base flow & $\begin{array}{l}\text { Sustained groundwater/subsurface flow, that has deeper } \\
\text { sources than interflow or fastflow reservoirs. Has the } \\
\text { longest residence time. }\end{array}$ \\
\hline Calibration & $\begin{array}{l}\text { Testing accuracy by comparing modelled values with } \\
\text { observed values }\end{array}$ \\
\hline Catchment/watershed & Area of land where all water gathers at a single water body. \\
\hline Cumecs & Measure of flow, one cubic meter per second. \\
\hline DEM & Digital elevation model, map of elevation \\
\hline CTI & Compound Topographic Index, measure of erodibility \\
\hline Evaporation & $\begin{array}{l}\text { The process of water turning to gas due to input } \\
\text { energy/heat. }\end{array}$ \\
\hline HydTopo & $\begin{array}{l}\text { ArcMap tool that defines areas and direction of flow } \\
\text { accumulation }\end{array}$ \\
\hline Iwi & $\begin{array}{l}\text { Group of indigenous New Zealanders (Māori), with links } \\
\text { to a particular region. }\end{array}$ \\
\hline Land Cover & $\begin{array}{l}\text { Dataset that describes the types of vegetation, structures or } \\
\text { other physical features of an area. }\end{array}$ \\
\hline Land Use & $\begin{array}{l}\text { Dataset that describes how physical features are used } \\
\text { (development, conservation etc.) }\end{array}$ \\
\hline LiDAR & $\begin{array}{l}\text { Light Detection and Ranging, method used to determine } \\
\text { elevation through remote sensing from an airborne device } \\
\text { or satellite. }\end{array}$ \\
\hline LUCI & $\begin{array}{l}\text { Land Use and Capability Indicator, GIS program that } \\
\text { evaluates current and potential ecosystem services. }\end{array}$ \\
\hline PAW & Plant available water \\
\hline NZ & New Zealand (Aotearoa) \\
\hline P/ot Evap & $\begin{array}{l}\text { Potential evaporation, measure of evaporation possible due } \\
\text { to the energy and wind of an area }\end{array}$ \\
\hline RUSLE & $\begin{array}{l}\text { Revised Universal Soil Loss Equation, Soil erosion } \\
\text { equation (rainfall erosivity, soil erodibility, slope, crop } \\
\text { management) }\end{array}$ \\
\hline Ecosystem service/s & Services that the environment provides \\
\hline Falling limb & $\begin{array}{l}\text { The period after the flow peak, where flow decreases back } \\
\text { to 'normal' flow. }\end{array}$ \\
\hline Fastflow & $\begin{array}{l}\text { Quickflow. Event-response flow that is essentially made of } \\
\text { the extra volume of water added to a catchment by a } \\
\text { rainfall event. Has the shortest residence time. }\end{array}$ \\
\hline Flood & $\begin{array}{l}\text { Excess of water, within this thesis this process is the same } \\
\text { as inundation, or where water exceeds the bounds of a } \\
\text { waterway }\end{array}$ \\
\hline
\end{tabular}




\begin{tabular}{|c|c|}
\hline GIS & Geographic Information System \\
\hline Hydrograph & $\begin{array}{l}\text { Figure representing the change in flow rate over a period of } \\
\text { time. }\end{array}$ \\
\hline Hydrological Cycle & $\begin{array}{l}\text { Water cycle, including precipitation, evaporation, } \\
\text { interception by vegetation, accumulation and infiltration } \\
\text { into the ground, and eventual runoff }\end{array}$ \\
\hline Intensity & For rainfall, the amount of mm that fall within an hour \\
\hline Interflow & $\begin{array}{l}\text { Reservoir representative of faster residence times than } \\
\text { baseflow, but slower than fastflow reservoirs. }\end{array}$ \\
\hline Inundation & $\begin{array}{l}\text { Like flooding, where water exceeds the bounds of a } \\
\text { natural/ water course }\end{array}$ \\
\hline Karst/karstic & $\begin{array}{l}\text { Type of geological landscape where rock dissolution has } \\
\text { resulted in increased permeability and drainage landforms }\end{array}$ \\
\hline Land management & $\begin{array}{l}\text { How landscapes vegetation or structures are developed or } \\
\text { protected }\end{array}$ \\
\hline Model & $\begin{array}{l}\text { A simplification of reality, which can be used to predict the } \\
\text { response of catchment to external factors. }\end{array}$ \\
\hline NSE & $\begin{array}{l}\text { Nash-Sutcliffe Efficiency evaluates the variance between } \\
\text { modelled and observed values }\end{array}$ \\
\hline Output & Results \\
\hline $\begin{array}{l}\text { Overland flow } \\
\text { (infiltration and } \\
\text { saturation) }\end{array}$ & $\begin{array}{l}\text { Excess water, due to rainfall exceeding the amount that can } \\
\text { infiltrate, or where the soil is fully saturated. }\end{array}$ \\
\hline Participant/resident & $\begin{array}{l}\text { Person interviewed throughout this thesis, with past or } \\
\text { current connections to the Marokopa catchment }\end{array}$ \\
\hline Qualitative & $\begin{array}{l}\text { Research that seeks to understand the rationale or } \\
\text { experiences, rather than assigning numbers. }\end{array}$ \\
\hline Council & $\begin{array}{l}\text { A tier of regional government that looks to provide } \\
\text { regional services }\end{array}$ \\
\hline $\mathrm{RCP}$ & $\begin{array}{l}\text { Representative Concentration Pathway describes various } \\
\text { greenhouse gas emissions scenarios for future climate } \\
\text { modelling, to determine how current decisions impact } \\
\text { future climate. }\end{array}$ \\
\hline Residence time & $\begin{array}{l}\text { The amount of time water takes to leave a particular } \\
\text { reservoir }\end{array}$ \\
\hline Rising limb & The period before a flow peak \\
\hline Synergy & $\begin{array}{l}\text { Where two or more processes have a combined impact } \\
\text { greater than their individual value. }\end{array}$ \\
\hline Trade-off & $\begin{array}{l}\text { Where different ecosystem services are combined to } \\
\text { identify areas of best investment, or current good service. }\end{array}$ \\
\hline Validation & Checking the accuracy of something \\
\hline
\end{tabular}




\section{B. New Zealand Ecosystem Service Review}

The below three figures/tables show the literature used in the New Zealand ES services review, how literature was coded under different services, and finally the aggregated results. Aggregated results are grouped ES services, showing broadly, which ES services feature most prominently in the literature.

\section{Table 10: List of literature used within the ES research review.}

New Zealand ecosystem service review references

1 (Ausseil et al., 2013)

2 (Dominati et al., 2014)

3 (Simmons, 2013)

4 (Trodahl et al., 2016)

$5 \quad$ (Baskaran et al., 2009)

6 (Rieb et al., 2017)

7 (Langdale et al., 2012)

8 (Easton, 2015)

$9 \quad$ (Ballinger, 2011)

10 (Benavidez, 2018)

11 (Scott, 2017)

12 (Chick \& Laurence, 2016)

13 (Anderson et al., 2008)

14 (Trodahl et al., 2017)

15 (Coleman, 2009)

16 (Olubode-Awosola, 2017)

17 (Van den Belt et al., 2012)

18 (Lyver et al., 2017)

19 (Clough, 2013)

20 (Creagh, 2010)

21 (Cullen et al., 2004)

22 (Kampen, 2014)

23 (Moller, 2012)

24 (MacLeod \& Moller, 2013)

25 (Marapara, 2016)

26 (Greenhalgh \& Hart, 2015)

27 (Royal Society of New Zealand, 2011)

28 (Kaval \& Van den Belt, 2017)

29 (Scion, 2017)

30 (Dymond et al., 2012)

31 (Grêt-Regamey et al., 2008)

32 (Nelson et al., 2009)

33 (Norris, 2012)

34 (Roberts et al., 2015) 


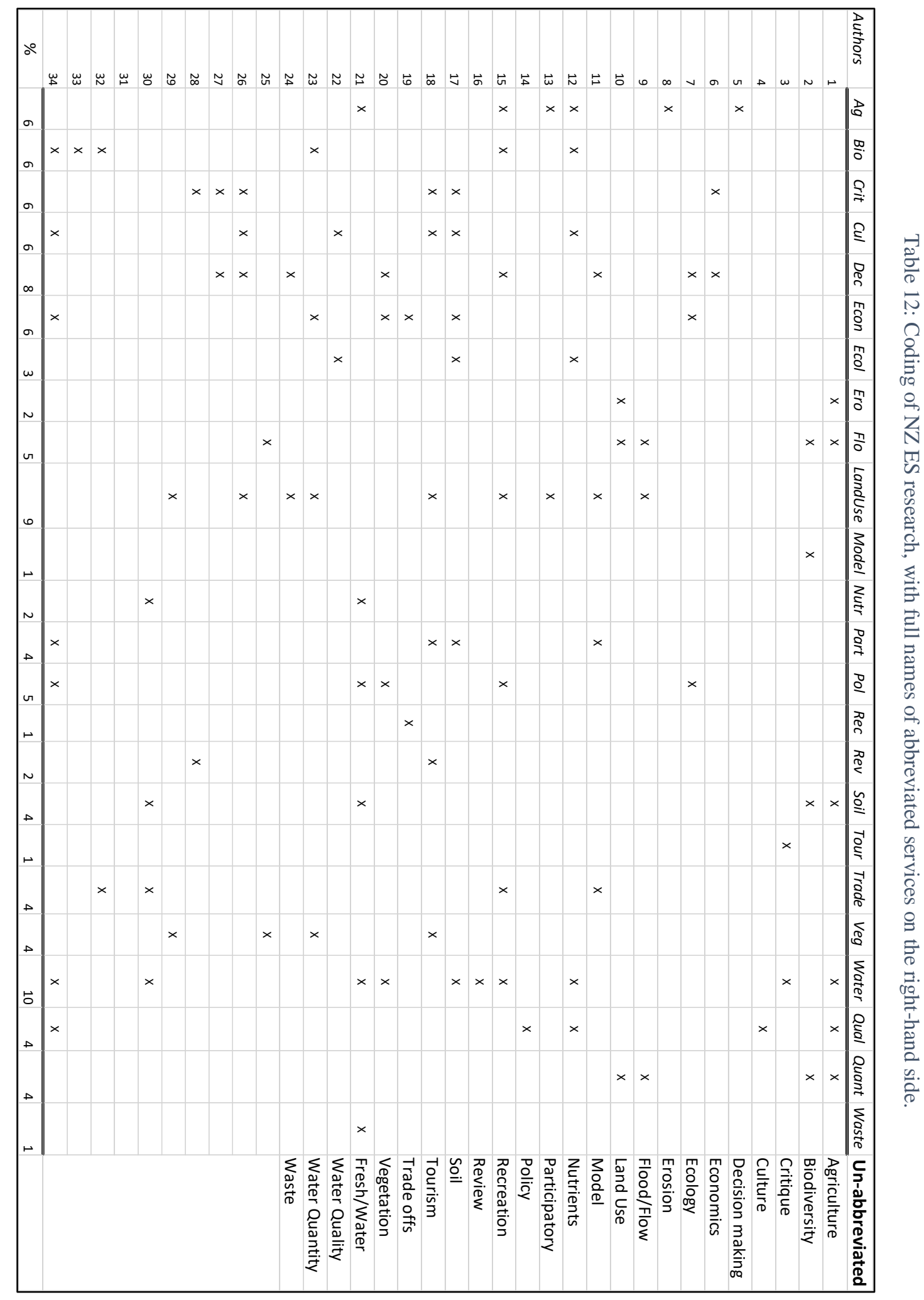

Table 11: Aggregated NZ ES services

\begin{tabular}{|c|c|c|c|c|c|}
\hline Land & Political & Water & Nutrients \& Ecology & Social & Analysis \\
\hline 24.04 & 22.12 & 18.27 & 15.38 & 11.54 & 8.65 \\
\hline Agriculture & Decision making & Flood/Flow & Biodiversity & Culture & Critique \\
\hline Erosion & Economics & Fresh/Water & Ecology & Participatory & Model \\
\hline Land Use & Policy & Water Quantity & Nutrients & Recreation & Review \\
\hline Soil & & & Water Quality & Tourism & \\
\hline Vegetation & & & & & \\
\hline $24.0 \%$ & $22.1 \%$ & $18.3 \%$ & $15.4 \%$ & $11.5 \%$ & $8.7 \%$ \\
\hline
\end{tabular}




\section{Flood management examples}

Adapted from Associated Programme on Flood Management (2016):

Table 13: Flood management strategies.

\begin{tabular}{|c|c|}
\hline \multicolumn{2}{|c|}{ Reduce vulnerability } \\
\hline \multirow{8}{*}{$\begin{array}{l}\text { Protect/secure livelihoods, } \\
\text { strengthen community's base of } \\
\text { natural resources }\end{array}$} & - Skill development/training \\
\hline & - Encourage livelihood diversity \\
\hline & - Promote access to information \\
\hline & - Link to markets \\
\hline & - Community participation, offer flood insurance \\
\hline & - Enact policies to protect natural resources \\
\hline & - Introduce automatic flood warning capabilities \\
\hline & - Create awareness of flooding risks \\
\hline \multirow{6}{*}{$\begin{array}{l}\text { Provide elaborate flood emergency } \\
\text { plan and post-flood recovery } \\
\text { commitments }\end{array}$} & - Provide reliable emergency rescue and support \\
\hline & (shelters, food, water, medicine supplies) and \\
\hline & postdisaster recovery operations \\
\hline & - Use floodplain digital mapping \\
\hline & - Use remote sensing and geographic information \\
\hline & system (GIS) \\
\hline Improve prevention & - Watersheds and river basin models \\
\hline \multirow{5}{*}{ Structural measures } & - Embankments \\
\hline & - Dams/reservoirs \\
\hline & - Flood proofing \\
\hline & - Floodplain mapping \\
\hline & - Land use regulations \\
\hline \multirow{6}{*}{ Non-structural measures } & $\begin{array}{l}\text { - Improve infrastructure/transport } \\
\text { /communication }\end{array}$ \\
\hline & $\begin{array}{l}\text { - Enforcing building codes and restricting new } \\
\text { developments }\end{array}$ \\
\hline & $\begin{array}{l}\text { - Setting sewage treatment plants in high flood risk } \\
\text { areas }\end{array}$ \\
\hline & - Improve drainage \\
\hline & - Protect wetlands and natural ponds \\
\hline & - Monitor river corridors \\
\hline \multicolumn{2}{|c|}{ Integrate cutting-edge techniques to predict contaminant passage and environmental } \\
\hline \multirow{6}{*}{$\begin{array}{l}\text { Forensic fingerprinting (chemical, } \\
\text { isotopical, mineralogical, tree-ring } \\
\text { and DNA fingerprinting) as well as } \\
\text { fate and transport evaluations }\end{array}$} & $\begin{array}{l}\text { - Assess pre- and post-flooding damage due to the } \\
\text { spread and dislocation of environmental } \\
\text { contaminants }\end{array}$ \\
\hline & $\begin{array}{l}\text { - Recover costs from responsible parties and help } \\
\text { rehabilitate the environment and sensitive } \\
\text { floodplain ecosystems }\end{array}$ \\
\hline & $\begin{array}{l}\text { - Promote local mitigation/containment (such as } \\
\text { tlands, reforestation, sewage/waste treatment } \\
\text { plants) }\end{array}$ \\
\hline & $\begin{array}{l}\text { - Synthesize missing historic hydrologic (floods, } \\
\text { droughts) data }\end{array}$ \\
\hline & $\begin{array}{l}\text { - Understand interaction between components of } \\
\text { hydrologic cycle }\end{array}$ \\
\hline & $\begin{array}{l}\text { - Identify potential groundwater recharge areas } \\
\text { and reduce runoff }\end{array}$ \\
\hline
\end{tabular}




\begin{tabular}{|c|c|}
\hline \multicolumn{2}{|c|}{ Integrate sustainable measures/green technologies } \\
\hline \multirow{2}{*}{ Implement conservation strategies } & - Reduce soil erosion, mudslides/landslides \\
\hline & - Promote forest management \\
\hline $\begin{array}{l}\text { Use of sustainable resources to } \\
\text { reduce impact from floods }\end{array}$ & $\begin{array}{l}\text { - Plant trees to stabilize slopes and reduce flood } \\
\text { water runoff }\end{array}$ \\
\hline \multirow{2}{*}{$\begin{array}{c}\text { Research, develop, and integrate } \\
\text { innovative solutions }\end{array}$} & - Use sustainable barriers \\
\hline & - Use local resources/labor/materials \\
\hline \multicolumn{2}{|c|}{ Combine defensive and preventing approaches } \\
\hline Restrain water passage & $\begin{array}{l}\text { - Use floodwalls, watertight barriers, elevated } \\
\text { buildings }\end{array}$ \\
\hline $\begin{array}{l}\text { Plan ahead for failure of } \\
\text { restraining systems }\end{array}$ & $\begin{array}{l}\text { - Watertight storage facilities for food and potable } \\
\text { water, protect power lines }\end{array}$ \\
\hline \multicolumn{2}{|c|}{ Inter-dependence with national and international policies } \\
\hline \multirow{5}{*}{$\begin{array}{l}\text { Integrate local/community, } \\
\text { regional, nationalflood } \\
\text { management groups/ } \\
\text { stakeholders with international } \\
\text { conventions/treaties within legal } \\
\text { context Delegation of } \\
\text { responsibilities }\end{array}$} & $\begin{array}{l}\text { - Enact national policies respectful of international } \\
\text { laws and agreements }\end{array}$ \\
\hline & $\begin{array}{l}\text { - Joint multinational monitoring, research and } \\
\text { assessment, forums, workshops, and information }\end{array}$ \\
\hline & $\begin{array}{l}\text { - Equitable compensation and use of shared } \\
\text { watershed/river basins }\end{array}$ \\
\hline & $\begin{array}{l}\text { - Amicable dispute resolution through negotiation, } \\
\text { nongovernmental organizations (NGOs), and } \\
\text { arbitration provision }\end{array}$ \\
\hline & - Environmental impact assessment (EIA) \\
\hline \multicolumn{2}{|r|}{ Balance costs and benefits } \\
\hline \multirow{4}{*}{ specific risk and cost-benefit assessn } & - Risk assessment evaluations \\
\hline & - Cost-benefit analyses (CBA) \\
\hline & - Multi-criteria analyses (MCA) \\
\hline & $\begin{array}{l}\text { - Economic analyses to prioritize options and } \\
\text { strategies }\end{array}$ \\
\hline \multicolumn{2}{|c|}{ Address postrecovery issues } \\
\hline & $\begin{array}{l}\text { - Move vulnerable activities away from flood- } \\
\text { prone areas, revisit building permits criteria }\end{array}$ \\
\hline & $\begin{array}{l}\text { - Restore water supply, power, hospital } \\
\text { communication, sewage, schools, and other } \\
\text { essential services }\end{array}$ \\
\hline & - Provide financial/material help to the needy \\
\hline Document lessons-learnt & - Learn from past flooding events \\
\hline \multicolumn{2}{|r|}{ Learning and evolving } \\
\hline & $\begin{array}{l}\text { - Document successes and failures of rescue } \\
\text { operations }\end{array}$ \\
\hline & $\begin{array}{l}\text { - Document extents of flooded area, depth, and } \\
\text { damages, and update hazard index maps }\end{array}$ \\
\hline
\end{tabular}




\section{Interview questions}

\section{Cluster 1: Introduction (6 Questions)}

1. What is your Name?

2. Is Marokopa where you grew up?

3. Where would you describe "Marokopa" as being?

4. What is your favourite thing about, (or place at) Marokopa?

5. How old are you, or if you prefer: which age group do you belong to? (18-25, 26-40, 41-55, 56-70, 71-95, 95+)

6. How long have you and/or your whānau lived in Marokopa?

\section{Cluster 2: Basic (3 Questions)}

7. What hazards do you think Marokopa is most susceptible to?

8. How would you describe flooding in Marokopa? (is it a hazard?)

9. How would you describe erosion in Marokopa? (is it a hazard?)

\section{Cluster 3: Earlier events (4 Questions)}

Flooding:

10. Can you remember any family stories about floods before you were born/moved here?

11. Please describe the first big flood that you experienced in Marokopa?

- When did the flooding occur?

- Please draw an outline of the flood on this map. (Did it reach the Marae/houses/the field/other infrastructure?)

- $\quad$ How long did the flooding last?

- $\quad$ Do you have any footage/photos of these events? (If Yes - would you give consent to provide or allow the researchers to make copies of your items for reference in the project?)

12. What other flood events can you remember?

- When did the flooding occur?

- $\quad$ Please draw an outline of the flood on this map. (Did it reach the Marae/houses/the field/other infrastructure?)

- $\quad$ How long did the flooding last?

- $\quad$ Do you have any footage/photos of these events? (If Yes - would you give consent to provide or allow the researchers to make copies of your items for reference in the project?)

\section{Erosion:}

13. Please describe the first landslide blockage that you experienced in Marokopa?

- $\quad$ Do you have any footage/photos of these events? (If Yes - would you give consent to provide or allow the researchers to make copies of your items for reference in the project?) 


\section{Cluster 4: Recent events (4 Questions) \\ Flooding}

14. Please describe the last big flood that you experienced in Marokopa?

- When did the flooding occur?

- Could you please draw the flood's outline on this map? (Did it reach the Marae/houses/the field/other infrastructure?)

- How long did the flooding last?

- Do you have any footage/photos of these events? (If Yes - would you give consent to provide or allow the researchers to make copies of your items for reference in the project?)

Erosion:

15. Do the roads get blocked by landslides?

Please describe this last (most recent) event?

- Were the landslides in the same place as previously?

- $\quad$ Please provide an example of when this last happened?

- $\quad$ Do you have any footage/photos of these events? (If Yes - would you give consent to provide or allow the researchers to make copies of your items for reference in the project?)

\section{Weather:}

16. Please describe the local weather and how it impacts flooding?

- Is the rainfall really intense, but only lasts a few hours at a time? Or gentle but lasts days?

- $\quad$ How does the rainfall in summer compare to winter?

- How would you describe the local weather and how it impacts erosion?

\section{Cluster 5: Marae connection (5 Questions)}

17. Please describe your interactions with the Marokopa marae and Ngāti Maniapoto iwi?

- What are your experiences of flooding near the marae?

- Please draw the flood's outline on this map?

- What are your experiences of erosion near the marae?

- Please draw it's outline on this provided map?

- How worried are you about the marae, in terms of flooding and erosion, on a scale of 1 (not worried) to 10 (very worried)

- What are your thoughts on what could be done to protect the marae? (Mitigate or adapt to flooding?)

\section{Cluster 6: Climate change (4 Questions)}

18. What is your understanding of climate change?

- How do you think climate change will affect Marokopa?

- Have you recognized any of these changes yourself?

- Or have others close to you?

\section{Cluster 7: Other (1 Question)}

19. Is there anything else you would like to share? 


\section{E. Ecosystem Service model parameters}

Table 14: Ecosystem service modelling parameters.

\begin{tabular}{|c|c|c|c|c|}
\hline \multicolumn{5}{|c|}{ Tradeoffs 05 weighted } \\
\hline Agricultural Productivity Services & $\begin{array}{c}\text { Erosion Mitigation } \\
\text { Services }\end{array}$ & $\begin{array}{c}\text { Flood Mitigation } \\
\text { Services }\end{array}$ & $\begin{array}{l}\text { Nitrogen } \\
\text { Services }\end{array}$ & $\begin{array}{c}\text { Phosphorus } \\
\text { Services }\end{array}$ \\
\hline 1 & 1 & 3 & 1 & 1 \\
\hline Weighted arithmetic & & & & \\
\hline Weighting & & & & \\
\hline \multicolumn{5}{|c|}{ RUSLE } \\
\hline$R$-factor: a constant & 0.026 & & & \\
\hline$R$-factor: $b$ constant & 1.536 & & & \\
\hline LS-factor: Cutoff slope angle (degrees) & 26.6 & & & \\
\hline \multicolumn{5}{|c|}{ Agricultral productivity } \\
\hline Slope threshold for very productive land & 5 & & & \\
\hline Slope threshold for somewhat productive land & 15 & & & \\
\hline Elevation threshold metres for improved agriculture & 350 & & & \\
\hline AgProd Elevation threshold metres for all agriculture & 3000 & & & \\
\hline $\begin{array}{l}\text { AgProd Fertility relative to national standard ( } 1 \\
\text { (standard) } 3 \text { (low fertility)) }\end{array}$ & 3 & & & \\
\hline Consider slope & TRUE & & & \\
\hline Consider slope elevation & TRUE & & & \\
\hline Consider slope waterlogging & TRUE & & & \\
\hline Consider slope soil fertility & TRUE & & & \\
\hline Consider slope aspect in overall valuation & TRUE & & & \\
\hline \multicolumn{5}{|c|}{ Erosion and Sediment delivery } \\
\hline EroSed CTI threshold for moderate erosion risk & 50 & & & \\
\hline EroSed CTI threshold for high erosion risk & 1000 & & & \\
\hline \multicolumn{5}{|l|}{ Flood mitigation } \\
\hline $\begin{array}{l}\text { FloodMit lower threshold for flood mitigation } \\
\text { opportunity relative upstream area caught }\end{array}$ & 5 & & & \\
\hline $\begin{array}{l}\text { FloodMit lower threshold for very high flood } \\
\text { mitigation opportunity relative upstream area caught }\end{array}$ & 20 & & & \\
\hline \multicolumn{5}{|c|}{ Nitrogen } \\
\hline Nitrogen Proportion dissolved vs particulate & $0.8 \mathrm{mg} / \mathrm{l}$ & & & \\
\hline Nitrogen $N$ concentration threshold $1 \mathrm{mg} / \mathrm{l}$ & $1 \mathrm{mg} / \mathrm{l}$ & 5 & & \\
\hline Nitrogen $N$ concentration threshold $2 \mathrm{mg} / \mathrm{l}$ & $2 \mathrm{~kg} / \mathrm{yr}$ & 10 & & \\
\hline Nitrogen $N$ critical load threshold $1 \mathrm{~kg} / \mathrm{yr}$ & $1 \mathrm{~kg} / \mathrm{yr}$ & 0.1 & & \\
\hline Nitrogen $N$ critical load threshold $2 \mathrm{~kg} / \mathrm{yr}$ & $2 \mathrm{~kg} / \mathrm{yr}$ & 1 & & \\
\hline Nitrogen N Root zone to stream attenuation & 0.5 & & & \\
\hline Nitrogen N In-stream attenuation factor & 0.5 & & & \\
\hline \multicolumn{5}{|c|}{ Phosphorus } \\
\hline Phosphorus Proportion dissolved vs particulate & 0.3 & & & \\
\hline Phosphorus P critical accumulation threshold $1 \mathrm{mg} / \mathrm{l}$ & 0.025 & 1 & & \\
\hline Phosphorus P critical accumulation threshold $2 \mathrm{mg} / \mathrm{l}$ & 0.075 & 2 & & \\
\hline Phosphorus $P$ critical load threshold $1 \mathrm{~kg} / \mathrm{yr}$ & 0.01 & 1 & & \\
\hline Phosphorus P critical load threshold $2 \mathrm{~kg} / \mathrm{yr}$ & 0.1 & 2 & & \\
\hline Phosphorus $P$ Root zone to stream attenuation factor & 1 & 1 & & \\
\hline Phosphorus $P$ In-stream attenuation factor & 0.3 & 0.3 & & \\
\hline
\end{tabular}




\section{F. Rainfall-runoff parameter seasonal parameter sets}

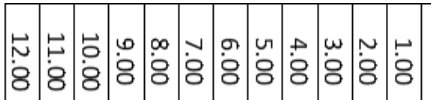

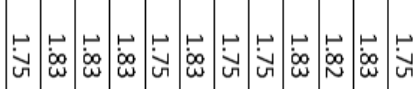

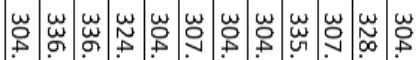

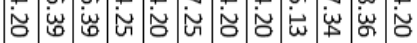

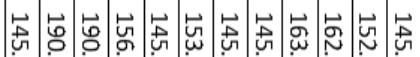

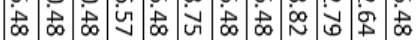

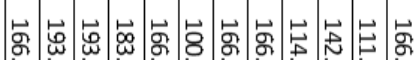

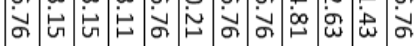

然

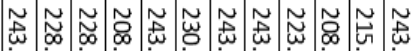

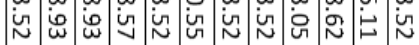

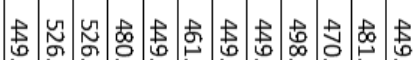

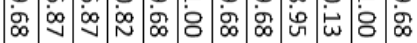

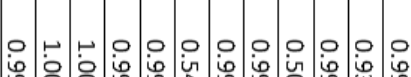
형

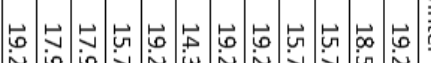
$\tilde{\infty}$

น్h

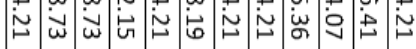

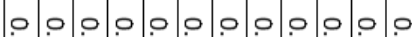

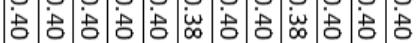

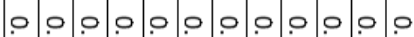

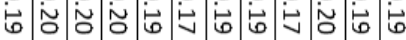

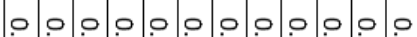

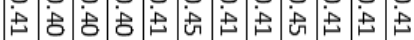

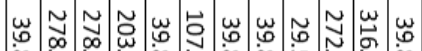

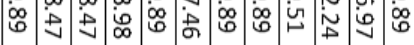

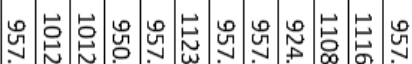

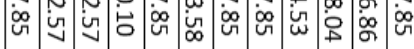

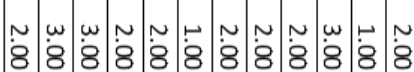

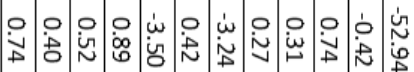

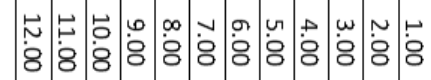

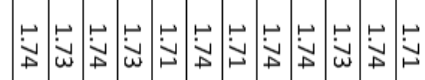

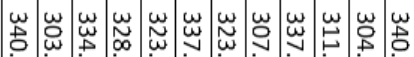

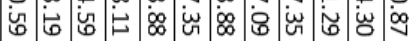

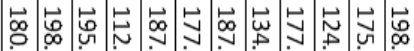

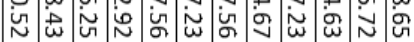

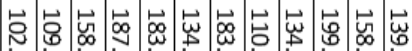

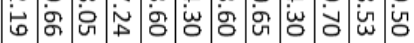

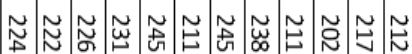

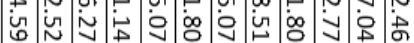

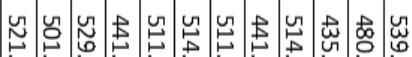

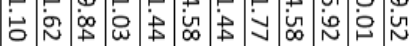

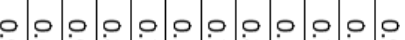

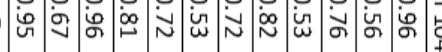

.

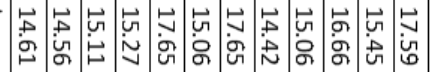

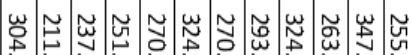

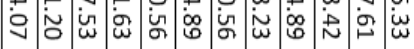

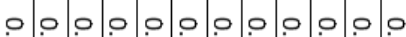

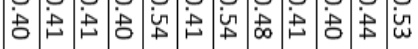

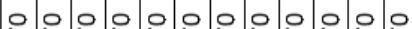

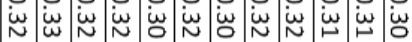

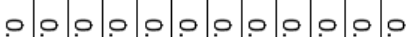

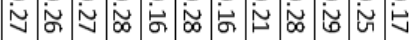

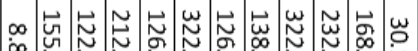

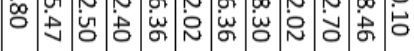

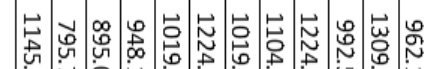

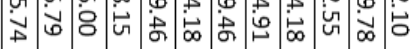

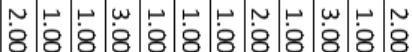

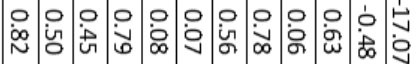

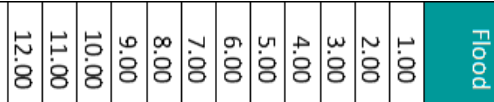

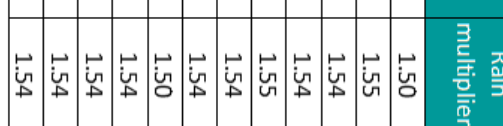

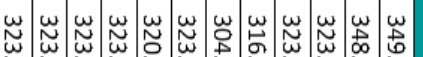

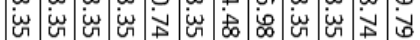

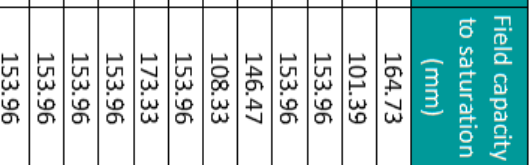

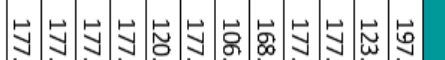

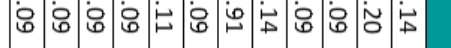

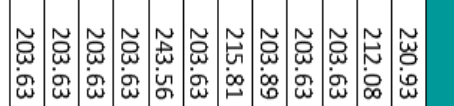

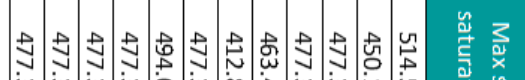

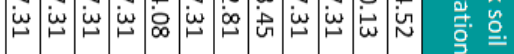
\%ो 家

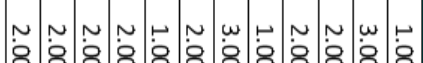

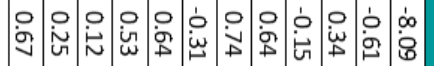

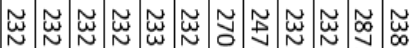

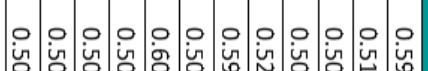

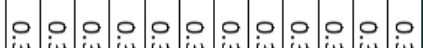

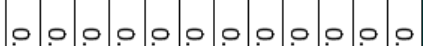

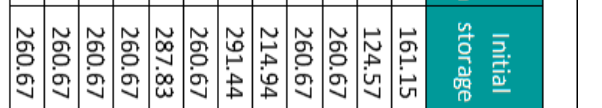




\section{References}

Abdul, A. S., \& Gillham, R. W. (1984). Laboratory studies of the effects of the capillary fringe on streamflow generation. Water Resources Research, 20(6), 691-698. https://doi.org/10.1029/WR020i006p00691.

Addenbrooke, J., McKenzie, A., \& Lawrence, L. (2016). West Coast Zone Plan: Te Mahere o te Rohe Taihauāuru. Retrieved from https://www.waikatoregion.govt.nz.

Anderson, M., Barnes, A.-M., \& Wratten, S. D. (2008). Ecosystem Services in Productive Landscapes: New Zealand's emerging agricultural pattern and land-use change. Retrieved from http://researcharchive.lincoln.ac.nz.

Anderson, M. G., \& Burt, T. P. (1978). The role of topography in controlling throughflow generation. Earth Surface Processes, 3(4), 331-344. https://doi.org/10.1002/esp.3290030402.

Andrew, M. E., Wulder, M. A., Nelson, T. A., \& Coops, N. C. (2015). Spatial data, analysis approaches, and information needs for spatial ecosystem service assessments: a review. GIScience Remote Sensing, 52(3), 344-373. https://doi.org/10.1080/15481603.2015.1033809.

Arnell, N. W., \& Gosling, S. N. (2016). The impacts of climate change on river flood risk at the global scale. Climatic Change, 134(3), 387-401. https://doi.org/10.1007/s10584-014-1084-5.

Associated Programme on Flood Management. (2016). The Role of Land-Use Planning in Flood Management. Retrieved from https://www.floodmanagement.info.

Atkin, E., \& Mead, S. (2017). Surf breaks of regional significance in the Waikato region. Retrieved from https://www.waikatoregion.govt.nz.

Ausseil, A. G., Dymond, J. R., Kirschbaum, M. U. F., Andrew, R. M., \& Parfitt, R. L. (2013). Assessment of multiple ecosystem services in New Zealand at the catchment scale. Environmental modelling \& software, 43, 37-48. https://doi.org/10.1016/j.envsoft.2013.01.006.

Bagstad, K. J., Semmens, D. J., Waage, S., \& Winthrop, R. (2013). A comparative assessment of decision-support tools for ecosystem services quantification and valuation. Ecosystem Services, 5, 27-39. https://doi.org/10.1016/j.ecoser.2013.07.004.

Bakalowicz, M. (2005). Karst groundwater: a challenge for new resources. Hydrogeology Journal(1), 148-160. https://doi.org/10.1007/s10040-0040402-9.

Ballinger, J. (2011). Natural buffer placement and downstream flood mitigation in rural Hawkes Bay, New Zealand. (Master of Science), Victoria University of Wellington, New Zealand. Retrieved from http://hdl.handle.net/10063/1960 
Ballinger, J., Jackson, B., Pechlivanidis, I., \& Ries, W. (2011). Potential flooding and inundation on the Hutt River. Retrieved from Wellington, New Zealand: https://www.victoria.ac.nz.

Bandaragoda, C., Tarboton, D. G., \& Woods, R. (2004). Application of TOPNET in the distributed model intercomparison project. Journal of Hydrology, 298(1-4), 178-201. https://doi.org/10.1016/j.jhydrol.2004.03.038.

Bárdossy, A., \& Pegram, G. (2014). Infilling missing precipitation records-A comparison of a new copula-based method with other techniques. Journal of Hydrology, 519(27), 1162-1170. https://doi.org/10.1016/j.jhydrol.2014.08.025.

Barredo, J. I. (2007). Major flood disasters in Europe: 1950-2005. Natural Hazards, 42(1), 125-148. https://doi.org/10.1007/s11069-006-9065-2.

Baskaran, R., Cullen, R., \& Takatsuka, Y. (2009). Estimating the value of agricultural ecosystem services: a case study of New Zealand pastoral farming. Australasian Journal of Environmental Management, 16(2), 103112. https://doi.org/10.1080/14486563.2009.9725224.

Bates, P. D., Anderson, M. G., Baird, L., Walling, D. E., \& Simm, D. (1992). Modelling floodplain flows using a two-dimensional finite element model. Earth Surface Processes and Landforms, 17(6), 575-588. https://doi.org/10.1002/esp.3290170604.

Bayley, P. B. (1991). The flood pulse advantage and the restoration of riverfloodplain systems. Regulated Rivers: Research Management, 6(2), 75-86. https://doi.org/10.1002/rrr.3450060203.

Benavidez, R. (2018). Understanding the effect of changing land use on floods and soil erosion in the Cagayan de Oro catchment. (Doctor of Philosophy), Victoria University of Wellington, New Zealand. Retrieved from http://hdl.handle.net/10063/7948

Benavidez, R., Jackson, B., Maxwell, D., \& Norton, K. (2018). A review of the (Revised) Universal Soil Loss Equation ((R) USLE): with a view to increasing its global applicability and improving soil loss estimates. Hydrology and Earth System Sciences, 22(11), 6059-6086. https://doi.org/10.5194/hess-22-6059-2018.

Beschta, R. L. (1983). Channel changes following storm-induced hillslope erosion in the Upper Kowai Basin, Torlesse Range, New Zealand. Journal of Hydrology, 22(2), 93-111. Retrieved from https://www.jstor.org

Beven, K. J. (2006). Rainfall-runoff modeling: Introduction. In Encyclopedia of Hydrological Sciences. https://doi.org/10.1002/0470848944.hsa130.

Beven, K. J. (2012). Rainfall-runoff modelling: the primer (2nd ed.). Chichester, England: John Wiley \& Sons, Ltd. https://doi.org/10.1002/9781119951001. 
Bhatt, C. M., Rao, G. S., Diwakar, P. G., Dadhwal, V. K., \& Risk. (2017). Development of flood inundation extent libraries over a range of potential flood levels: a practical framework for quick flood response. Geomatics, Natural Hazards and Risk, 8(2), 384-401. https://doi.org/10.1080/19475705.2016.1220025.

Blackett, P., \& Hume, T. (2006). Community involvement in coastal hazard mitigation: An initial scoping of process and pitfalls (NIWA Client Report, prepared for GNS Science No. Ham2006-083). Retrieved from Hamilton, New Zealand: https://www.niwa.co.nz.

Blackett, P., Smith, E., Rouse, H., Hume, T., Rickard, D., Hume, A., Bell, R., Ramsey, D., Dahm, J., \& Wishart, P. (2010). How can we engage with coastal communities over adaptation to climate change?: A case study in Whitianga on the Coromandel Peninsula. Paper presented at the New Zealand Planning Institute Conference: Planning Pathways to the Future, Christchurch, New Zealand.

Blasone, R.-S., Madsen, H., \& Rosbjerg, D. (2007). Parameter estimation in distributed hydrological modelling: comparison of global and local optimisation techniques. Hydrology Research, 38(4-5), 451-476. https://doi.org/10.2166/nh.2007.024.

Brown, V. A., McDonnell, J. J., Burns, D. A., \& Kendall, C. (1999). The role of event water, a rapid shallow flow component, and catchment size in summer stormflow. Journal of Hydrology, 217(3-4), 171-190. https://doi.org/10.1016/S0022-1694(98)00247-9.

Burby, R. J., Deyle, R. E., Godschalk, D. R., \& Olshansky, R. B. (2000). Creating hazard resilient communities through land-use planning. Natural Hazards Review, 1(2), 99-106. https://doi.org/10.1061/(ASCE)15276988(2000)1:2(99).

Burkhard, B., Crossman, N. D., Nedkov, S., Petz, K., \& Alkemade, R. (2013). Mapping and modelling ecosystem services for science, policy and practice. Ecosystem Services, 4, 1-3. https://doi.org/10.1016/j.ecoser.2013.04.005.

Burrel, B. C., Davar, K., \& Hughes, R. (2007). A review of flood management considering the impacts of climate change. Water International, 32(3), 342-359. https://doi.org/10.1080/02508060708692215.

Butts, M. B., Payne, J. T., Kristensen, M., \& Madsen, H. (2004). An evaluation of the impact of model structure on hydrological modelling uncertainty for streamflow simulation. Journal of Hydrology, 298(1-4), 242-266. https://doi.org/10.1007/10.1016/j.jhydrol.2004.03.042.

Cameron, M., Barrett, P., Cochrane, B., \& McNeill, K. (2009). Implications of Agricultural Change in the Waikato Region: Current Trends and Future Scenarios Retrieved from http://www.waikatoregion.govt.nz. 
Cameron, R. J. (1963). A study of the rooting habits of rimu and tawa in pumice soils. New Zealand Journal of Forestry, 8, 771-785. Retrieved from http://www.nzjf.org.nz

Carrivick, J. L., \& Tweed, F. S. (2016). A global assessment of the societal impacts of glacier outburst floods. Global Planetary Change, 144, 1-16. https://doi.org/10.1016/j.gloplacha.2016.07.001.

Chan, K. M. A., Satterfield, T., \& Goldstein, J. H. (2012). Rethinking ecosystem services to better address and navigate cultural values. Ecological Economics, 74, 8-18. https://doi.org/10.1016/j.ecolecon.2011.11.011.

Chappell, P. R. (2014). The climate and weather of Waikato. Retrieved from https://www.niwa.co.nz.

Chick, A., \& Laurence, R. (2016). Mapping the Services and Benefits of Indigenous Biodiversity and Historic Heritage in New Zealand: An Exploration of Spatial Datasets. (0478150687). Wellington, New Zealand: Department of Conservation. Retrieved from https://www.doc.govt.nz

Chinarro, D. (2014). System Engineering Applied to Fuenmayor Karst Aquifer (San Julián de Banzo, Huesca) and Collins Glacier (King George Island, Antarctica) Springer International Publishing https://doi.org/10.1007/9783-319-08858-7.

Clough, P. (2013). The value of ecosystem services for recreation. In D. J.R. (Ed.), Ecosystem services in New Zealand - conditions and trends. , . Lincoln, New Zealand: Manaaki Whenua-Landcare Research New Zealand https://www.landcareresearch.co.nz.

Coleman, D. (2009). Whangarei District Ecosystem Services Background Report. Retrieved from http://www.wdc.govt.nz.

Costanza, R., d'Arge, R., De Groot, R., Farber, S., Grasso, M., Hannon, B., Limburg, K., Naeem, S., O'neill, R. V., \& Paruelo, J. (1998). The value of the world's ecosystem services and natural capital. Ecological Economics, 25(1), 3-15. https://doi.org/10.1016/S0921-8009(98)00020-2.

Creagh, K. K. (2010). Value and price: a transdisciplinary approach to ecologically sustainable urban water management. (Doctor of Philosophy), University of Auckland, Retrieved from https://researchspace.auckland.ac.nz/

Crossman, N. D., Burkhard, B., Nedkov, S., Willemen, L., Petz, K., Palomo, I., Drakou, E. G., Martín-Lopez, B., McPhearson, T., \& Boyanova, K. (2013). A blueprint for mapping and modelling ecosystem services. Ecosystem services, 4, 4-14. https://doi.org/10.1016/j.ecoser.2013.02.001.

Cullen, R., Takatsuka, Y., Wilson, M., \& Wratten, S. D. (2004). Ecosystem services on New Zealand arable farms. Blenheim, New Zealand. https://researcharchive.lincoln.ac.nz. 
Dahm, J., \& Gibberd, B. (2018). Marokopa Coastal Hazards. Focus Resource Management Group, Retrieved from http://www.waitomo.govt.nz/Documents/Documents/Community\%20Mee ting\%20Presentation \%20-\%20Coastal\%20Hazards\%20\%20Marokopa\%20August\%202018\%20(A405910).pdf

Daily, G., Alexander, S., Ehrlich, P. R., Goulder, L., Lubchenco, J., Matson, P. A., Mooney, H. A., Postel, S., Schneider, S. H., Tilman, D., \& Woodwel, G. M. (1997). Ecosystem Services: Benefits Supplied to Human Societies by Natural Ecosystems. Issues in Ecology, 2(2), 1-18. Retrieved from https://www.esa.org

Daily, G. C., Polasky, S., Goldstein, J. H., Kareiva, P. M., Mooney, H. A., Pejchar, L., Ricketts, T. H., Salzman, J., \& Shallenberger, R. (2009). Ecosystem services in decision making: time to deliver. Frontiers in Ecology and the Environment, 7(1), 21-28. https://doi.org/10.1890/080025.

Daniel, T. C., Muhar, A., Arnberger, A., Aznar, O., Boyd, J. W., Chan, K. M. A., Costanza, R., Elmqvist, T., Flint, C. G., Gobster, P. H., Grêt-Regamey, A., Lave, R., Muhar, S., Penker, M., Ribe, R. G., Schauppenlehner, T., Sikor, T., Soloviy, I., Spierenburg, M., Taczanowska, K., Tam, J., \& Von der Dunk, A. (2012). Contributions of cultural services to the ecosystem services agenda. Proceedings of the National Academy of Sciences, 109(23), 8812-8819. https://doi.org/10.1073/pnas.1114773109.

Darnhofer, I., Bellon, S., Dedieu, B., \& Milestad, R. (2010a). Adaptiveness to enhance the sustainability of farming systems. A review. Agronomy for sustainable development, 30(3), 545-555.

https://doi.org/10.1051/agro/2009053.

Darnhofer, I., Fairweather, J., \& Moller, H. (2010b). Assessing a farm's sustainability: insights from resilience thinking. International journal of agricultural sustainability, 8(3), 186-198. https://doi.org/10.3763/ijas.2010.0480.

Davie, T. (2004). Review of different hydrological modelling frameworks for usage in the Motueka Integrated Catchment Management programme of research. Retrieved from https://icm.landcareresearch.co.nz.

Deng, X., Li, Z., \& Gibson, J. (2016). A review on trade-off analysis of ecosystem services for sustainable land-use management. Journal of Geographical Sciences, 26(7), 953-968. https://doi.org/10.1007/s11442-016-1309-9.

Dominati, E., Mackay, A., Green, S., \& Patterson, M. (2014). A soil change-based methodology for the quantification and valuation of ecosystem services from agro-ecosystems: A case study of pastoral agriculture in New Zealand. Ecological Economics, 100, 119-129. https://doi.org/10.1016/j.ecolecon.2014.02.008.

Dons, A. (1987). Hydrology and sediment regime of a pasture, native forest, and pine forest catchment in the central North Island, New Zealand. New 
Zealand Journal of Forestry Science, 17(2/3), 161-178. Retrieved from https://nzjforestryscience.nz

Dravitzki, S., \& McGregor, J. (2011). Extreme precipitation of the Waikato region, New Zealand. International Journal of Climatology, 31(12), 18031812. https://doi.org/10.1002/joc.2189.

Drewry, J. J., \& Paton, R. J. (2000). Effects of cattle treading and natural amelioration on soil physical properties and pasture under dairy farming in Southland, New Zealand. New Zealand Journal of Agricultural Research, 43(3), 377-386. https://doi.org/10.1080/00288233.2000.9513438.

Duguma, L. A., Minang, P. A., \& van Noordwijk, M. (2014). Climate change mitigation and adaptation in the land use sector: from complementarity to synergy. Environmental Management, 54(3), 420-432. https://doi.org/10.1007/s00267-014-0331-x.

Dunning, K. J. (1998). Effects of exotic forestry on stream macroinvertebrates: the influence of scale in North Island, New Zealand streams. (Master of Science), Massey University, Palmerston North, New Zealand. Retrieved from http://hdl.handle.net/10179/8552

Dymond, J. R., Ausseil, A.-G. E., Ekanayake, J. C., \& Kirschbaum, M. U. F. (2012). Tradeoffs between soil, water, and carbon-a national scale analysis from New Zealand. Journal of Environmental Management, 95(1), 124-131. https://doi.org/10.1016/j.jenvman.2011.09.019.

Easton, S. (2015). Irrigation and Ecosystem Services: development of an irrigation model for the LUCI ecosystem services framework. (Master of Geographic Information Science), Victoria University of Wellington, Wellington, New Zealand. Retrieved from http://hdl.handle.net/10063/5067

Edbrooke, S. W. (2005). Geology of the Waikato area (Vol. 1). Lower Hutt, New Zealand: Institute of Geological \& Nuclear Sciences Ltd.

Englund, O., Berndes, G., \& Cederberg, C. (2017). How to analyse ecosystem services in landscapes-A systematic review. Ecological Indicators, 73, 492-504. https://doi.org/10.1016/j.ecolind.2016.10.009.

Ezer, T., \& Atkinson, L. P. (2014). Accelerated flooding along the US East Coast: on the impact of sea-level rise, tides, storms, the Gulf Stream, and the North Atlantic oscillations. Earth's Future, 2(8), 362-382. https://doi.org/10.1002/2014EF000252.

Feeney, C. M. (1977). The karstification of drainage: a morphometric approach. Master of Science. University of Auckland. New Zealand.

Feyen, L., Vrugt, J. A., Nualláin, B. Ó., Van der Knijff, J. M., \& De Roo, A. P. J. (2007). Parameter optimisation and uncertainty assessment for large-scale streamflow simulation with the LISFLOOD model. Journal of Hydrology, 332(3-4), 276-289. https://doi.org/10.1016/j.jhydrol.2006.07.004. 
Flick, R. E., Chadwick, D. B., Briscoe, J., \& Harper, K. C. (2012). Flooding "versus" inundation. Eos, Transactions, American Geophysical Union, 93(38), 365-366. https://doi.org/10.1029/2012E0380009.

Ford, D. C., \& Williams, P. D. (2007). Karst hydrogeology and geomorphology (Vol. 576). Chichester: John Wiley \& Sons Ltd. https://doi.org/10.1002/9781118684986.

Ford, D. C., \& Williams, P. W. (1989). Karst geomorphology and hydrology (Vol. 576). Chichester: John Wiley \& Sons. https://doi.org/10.1002/9781118684986.

Frame, D., Rosier, S., Carey-Smith, T., Harrington, L., Dean, S., \& Noy, I. (2018). Estimating financial costs of climate change in New Zealand: An estimate of climate change-related weather event costs. Retrieved from https://treasury.govt.nz.

Fuchs, S., Karagiorgos, K., Kitikidou, K., Maris, F., Paparrizos, S., \& Thaler, T. (2017). Flood risk perception and adaptation capacity: A contribution to the socio-hydrology debate. Hydrology and Earth System Sciences, 21(6), 3183-3198. https://doi.org/10.5194/hess-21-3183-2017.

Glassey, C., Kaufler, G., Parker, M., Pearson, A., Williams, I., \& Johnstone, P. (2009). Best Management Practices for Growing Maize on Dairy Farms. Retrieved from https://www.waikatoregion.govt.nz.

Gomez, B., Eden, D. N., Peacock, D. H., \& Pinkney, E. J. (1998). Floodplain construction by recent, rapid vertical accretion: Waipaoa River, New Zealand. Earth Surface Processes Landforms, 23(5), 405-413. https://doi.org/10.1002/(SICI)1096-9837(199805)23:5<405::AIDESP854>3.0.CO;2-X.

Greener, I. (2011). Designing social research: A guide for the bewildered. London, England: SAGE Publications. https://dx.doi.org/10.4135/9781446287934.

Greenhalgh, S., \& Hart, G. (2015). Mainstreaming ecosystem services into policy and decision-making: lessons from New Zealand's journey. International Journal of Biodiversity Science, Ecosystem Services \& Management, 11(3), 205-215. https://doi.org/10.1080/21513732.2015.1042523.

Greer, D., Atkin, E., Mead, S., Haggitt, T., \& O’Neill, S. (2016). Mapping residence times in west coast estuaries of the Waikato region (8997234). Retrieved from https://www.waikatoregion.govt.nz.

Grêt-Regamey, A., Bebi, P., Bishop, I. D., \& Schmid, W. A. (2008). Linking GISbased models to value ecosystem services in an Alpine region. Journal of Environmental Management, 89(3), 197-208. https://doi.org/10.1016/j.jenvman.2007.05.019.

Gunn, J. (1978). Karst hydrology and solution in the Waitomo district, New Zealand. University of Auckland. 
Gunn, J. (1983). Point-recharge of limestone aquifers - a model from New Zealand karst. Journal of Hydrology, 61(1-3), 19-29.

https://doi.org/10.1016/0022-1694(83)90232-9.

Hall, J., Arheimer, B., Borga, M., Brázdil, R., Claps, P., Kiss, A., Kjeldsen, T. R., Kriauciuniene, J., Kundzewicz, Z. W., \& Lang, M. (2014). Understanding flood regime changes in Europe: A state of the art assessment. Hydrology Earth System Sciences, 18(7), 2735-2772. https://doi.org/10.5194/hess-182735-2014.

Hart, G. (2011). Vulnerability and adaptation to sea-level rise in Auckland, New Zealand (NZCCRI-2011-08). Retrieved from Wellington, New Zealand: https://www.victoria.ac.nz.

Hartmann, A., Barberá, J. A., \& Andreo, B. (2017). On the value of water quality data and informative flow states in karst modelling. Hydrology Earth System Sciences, 21(12), 5971-5985. https://doi.org/10.5194/hess-215971-2017.

Hawke, D. V. (1982). Fluvial processes in the upper Waitomo catchment: a study in applied karst hydrology and geomorphology. (Doctor of Philosophy), University of Auckland, Auckland.

Heath, R. C. (1983). Basic ground-water hydrology (Vol. 2220): US Geological Survey. https://doi.org/10.3133/wsp2220.

Hellweger, F. (1997). AGREE-DEM Surface Reconditioning System. Retrieved January 28 from http://www.ce.utexas.edu.

Hermans, O. F. (2018). Flood Management in New Zealand: Exploring Management and Practice in Otago and the Manawatu. (Master of Planning), University of Otago, Retrieved from http://hdl.handle.net/10523/8172

Herzig, A., Ausseil, A. E., \& Dymond, J. R. (2013). Spatial optimisation of ecosystem services Retrieved from Lincoln, New Zealand: https://www.landcareresearch.co.nz.

Hewitt, A. (1998a). The New Zealand soil classification: Manaaki WhenuaLandcare Research New Zealand.

Hewitt, A. E. (1993). New Zealand soil classification. Lincoln, New Zealand: Manaaki Whenua-Landcare Research New Zealand. http://doi.org/10.7931/DL1-LRSS-1-2010.

Hewitt, A. E. (1998b). New Zealand soil classification. Lincoln, New Zealand: Manaaki Whenua-Landcare Research New Zealand. http://doi.org/10.7931/DL1-LRSS-1-1998.

Houlbrooke, D. J., \& Monaghan, R. M. (2009). The influence of soil drainage characteristics on contaminant leakage risk associated with the land application of farm dairy effluent. Retrieved from http://envirolink.govt.nz. 
Howe, J., \& White, I. (2003). Flooding, pollution and agriculture. International Journal of Environmental Studies, 60(1), 19-27. https://doi.org/10.1080/00207230304746.

Hudson, P., Wouter Botzen, W. J., Poussin, J., \& Aerts, J. C. J. H. (2019). Impacts of flooding and flood preparedness on subjective well-being: A monetisation of the tangible and intangible impacts. Journal of Happiness Studies, 20(2), 665-682. https://doi.org/10.1007/s10902-017-9916-4.

Hughes, M. W., Quigley, M. C., Van Ballegooy, S., Deam, B. L., Bradley, B. A., \& Hart, D. E. (2015). The sinking city: Earthquakes increase flood hazard in Christchurch, New Zealand. GSA Today, 25(3).

https://doi.org/10.1130/gsatg221a.1.

Humphreys, G. S., \& Wilkinson, M. T. (2007). The soil production function: a brief history and its rediscovery. Geoderma, 139(1), 73-78. https://doi.org/10.1016/j.geoderma.2007.01.004.

Intergovernmental Panel on Climate Change. (2018). Summary for Policymakers. Retrieved from https://www.ipcc.ch/site/assets/uploads/sites/2/2019/05/SR15_SPM_versio $\underline{n}$ report LR.pdf.

Irrigation New Zealand. (n.d.). Soil texture and water. Retrieved from https://www.irrigationnz.co.nz/news-resources/irrigation-resources/soiltexture-water/Attachment?Action=Download\&Attachment $\mathrm{id}=103$.

Jaafar, K., Ismail, N., Tajjudin, M., Adnan, R., \& Rahiman, M. H. F. (2015). A review on flood modelling and rainfall-runoff relationships. Paper presented at the Control and System Graduate Research Colloquium Shah Alam, Malaysia.

Jackson, B., Astbury, S., Cooper, D., Craythorne, M., Maxwell, D., Reuland, O., Thomas, A., \& Trodahl, M. (2019). LUCI Help Documentation Retrieved from https://www.lucitools.org/assets/Uploads/LUCI-Documentation-asof-April-2019.pdf.

Jackson, B., Pagella, T., Sinclair, F., Orellana, B., Henshaw, A., Reynolds, B., Mcintyre, N., Wheater, H., \& Eycott, A. (2013). Polyscape: A GIS mapping framework providing efficient and spatially explicit landscapescale valuation of multiple ecosystem services. Landscape and Urban Planning, 112, 74-88. https://doi.org/10.1016/j.landurbplan.2012.12.014.

Jackson, E. (2013). Choosing a methodology: Philosophical underpinning. Practitioner Research in Higher Education, 7(1), 49-62. https://ojs.cumbria.ac.uk.

Jakeman, A. J., \& Hornberger, G. M. (1993). How much complexity is warranted in a rainfall-runoff model? Water Resources Research, 29(8), 2637-2649. https://doi.org/10.1029/93WR00877.

Jencso, K. G., \& McGlynn, B. L. (2011). Hierarchical controls on runoff generation: Topographically driven hydrologic connectivity, geology, and 
vegetation. Water Resources Research, 47(11).

https://doi.org/10.1029/2011WR010666.

Jevrejeva, S., Jackson, L. P., Grinsted, A., Lincke, D., \& Marzeion, B. (2018).

Flood damage costs under the sea level rise with warming of $1.5^{\circ} \mathrm{C}$ and $2^{\circ}$

C. Environmental Research Letters, 13(7), 074014.

https://doi.org/10.1088/1748-9326/aacc76.

Jones, L. S., \& Schumm, S. A. (1999). Causes of avulsion: an overview. In N. D. Smith \& J. Rogers (Eds.), Fluvial Sedimentology VI (Vol. 28, pp. 171178): International Association of Sedimentologists. https://doi.org/10.1002/9781444304213.ch13.

Junk, W. J., Bayley, P. B., \& Sparks, R. E. (1989). The flood pulse concept in river-floodplain systems. Canadian Special Publication of Fisheries Aquatic Sciences, 106(1), 110-127. https://doi.org/10.1016/S00221694(98)00287-X.

Kampen, P. (2014). Potential Benefits of Transplanting Kütai to Restore the Mauri of Ōkahu Bay: Developing Baseline Measures of Subtidal Macrobenthos, Sediment Environment and Larval Dispersal (4577093). Retrieved from http://www.maramatanga.co.nz.

Kaval, P., \& Van den Belt, M. (2017). The Organizing Framework of Ecosystem Services and its use in River Management (22/17). Retrieved from Hamilton, New Zealand: http://tools.envirolink.govt.nz.

Keeler, B. L., Polasky, S., Brauman, K. A., Johnson, K. A., Finlay, J. C., O’Neill, A., Kovacs, K., \& Dalzell, B. (2012). Linking water quality and wellbeing for improved assessment and valuation of ecosystem services. Proceedings of the National Academy of Sciences, 109(45), 18619-18624. https://doi.org/10.1073/pnas.1215991109.

Kellens, W., Terpstra, T., \& De Maeyer, P. (2013). Perception and communication of flood risks: a systematic review of empirical research. Risk Analysis, 33(1), 24-49. https://doi.org/10.1111/j.15396924.2012.01844.x.

King, A. B., Cousins, W. J., Heron, D. W., Matcham, I., Pringle, R., Bell, R., Reese, S., Schmidt, J., \& Henderson, R. (2008). Regional RiskScape: a multi-hazard loss modelling tool. Paper presented at the 4th International i-Rec Conference 2008 Building resilience: achieving effective postdisaster reconstruction, Christchurch, New Zealand.

King, D. N. T., Goff, J., \& Skipper, A. (2007). Māori environmental knowledge and natural hazards in Aotearoa-New Zealand. Journal of the Royal Society of New Zealand, 37(2), 59-73. https://doi.org/10.1080/03014220709510536.

Kingi, T. (2014). Agricultural Development in the Maniapoto Rohe Report prepared for the Maniapoto Māori Trust Board. Retrieved from http://www.maniapoto.iwi.nz. 
Klik, A., Haas, K., Dvorackova, A., \& Fuller, I. C. (2015). Spatial and temporal distribution of rainfall erosivity in New Zealand. Soil Research, 53(7), 815-825. https://doi.org/10.1071/SR14363.

Kozlowski, T. T. (2002). Physiological-ecological impacts of flooding on riparian forest ecosystems. Wetlands, 22(3), 550-561. Retrieved from https://bioone.org

Krause, P., Boyle, D. P., \& Bäse, F. (2005). Comparison of different efficiency criteria for hydrological model assessment. Advances in Geosciences, 5, 89-97. https://doi.org/10.5194/adgeo-5-89-2005.

Kreibich, H., Bubeck, P., Van Vliet, M., \& De Moel, H. (2015). A review of damage-reducing measures to manage fluvial flood risks in a changing climate. Mitigation adaptation strategies for global change, 20(6), 967989. https://doi.org/10.1007/s11027-014-9629-5.

Kron, W. (2005). Flood risk= hazard• values• vulnerability. Water International, 30(1), 58-68. https://doi.org/10.1080/02508060508691837.

Land, Air, Water, Aotearoa. (2019). Environmental monitoring data for Marokopa River. Retrieved 2019, Feb 2 from https://www.lawa.org.nz/exploredata/waikato-region/river-quality/marokopa-river/.

Land Information New Zealand. (2018, 2019, April 3). NZ Topo Map. Retrieved 2019, February 27 from https://www.topomap.co.nz/.

Land Resource Information Systems. (2015). Land Cover Database version 4.1, Mainland New Zealand. Retrieved 2018, August 7 from https://lris.scinfo.org.nz/layer/48423-lcdb-v41-land-cover-databaseversion-41-mainland-new-zealand/.

Lane, S. N. (1998). Hydraulic modelling in hydrology and geomorphology: a review of high resolution approaches. Hydrological Processes, 12(8), 1131-1150. https://doi.org/10.1002/(SICI)1099$\underline{1085(19980630) 12: 8<1131:: A I D-H Y P 611>3.0 . C O ; 2-K . ~}$

Langdale, G., Greenhalgh, S., \& Stancu , C. (2012). Ecosystem Services: Global \& NZ Perspectives. Manaaki Whenua-Landcare Research New Zealand. Retrieved from https://www.landcareresearch.co.nz

Lu, L., Jun, X., Chong-Yu, X., Jianjing, C., \& Rui, W. (2009). Analysis of the sources of equifinality in hydrological models using GLUE methodology. Paper presented at the Hydroinformatics in Hydrology, Hydrogeology and Water Resources Hyderabad, India.

Lyver, P. O., Timoti, P., Gormley, A. M., Jones, C. J., Richardson, S. J., Tahi, B. L., \& Greenhalgh, S. (2017). Key Māori values strengthen the mapping of forest ecosystem services. Ecosystem Services, 27, 92-102.

https://doi.org/10.1016/j.ecoser.2017.08.009. 
Macklin, M. G., \& Lewin, J. (2003). River sediments, great floods and centennialscale Holocene climate change. Journal of Quaternary Science, 18(2), 101-105. https://doi.org/10.1002/jqs.751.

MacLeod, C. J., \& Moller, H. (2013). Environmental monitoring for sustainable land mnagement in New Zealand's production landscapes. Retrieved from http://www.nzdashboard.org.nz.

Madsen, H. (2003). Parameter estimation in distributed hydrological catchment modelling using automatic calibration with multiple objectives. Advances in Water Resources, 26(2), 205-216. https://doi.org/10.1016/S03091708(02)00092-1.

Mahler, B. J., \& Lynch, F. L. (1999). Muddy waters: temporal variation in sediment discharging from a karst spring. Journal of Hydrology, 214(1-4), 165-178. https://doi.org/10.1016/S0022-1694(98)00287-X.

Manning, M., Lawrence, J., King, D. N., \& Chapman, R. (2015). Dealing with changing risks: a New Zealand perspective on climate change adaptation. Regional Environmental Change, 15(4), 581-594. https://doi.org/10.1007/s10113-014-0673-1.

Māori Maps. (n.d). Marokopa (Mirumiru). Retrieved 2019, April 11 from https://maorimaps.com/marae/marokopa-mirumiru.

Marapara, T. (2016). Eco-hydrology interactions between trees, soil and water in terrestrial and wetland areas: The effect of tree planting on water flow dynamics in Wairarapa Wetlands, New Zealand. (Doctor of Philosophy), Victoria University of Wellington in, Wellington, New Zealand. Retrieved from http://hdl.handle.net/10063/5031

Marden, M., Arnold, G., Gomez, B., \& Rowan, D. (2005). Pre-and postreforestation gully development in Mangatu Forest, East Coast, North Island, New Zealand. River Research and Applications, 21(7), 757-771. https://doi.org/10.1002/rra.882.

Marshall, M. R., Francis, O. J., Frogbrook, Z. L., Jackson, B. M., McIntyre, N., Reynolds, B., Solloway, I., Wheater, H. S., \& Chell, J. (2009). The impact of upland land management on flooding: results from an improved pasture hillslope. Hydrological Processes, 23(3), 464-475. https://doi.org/10.1002/hyp.7157.

Martínez-López, J., Bagstad, K. J., Balbi, S., Magrach, A., Voigt, B., Athanasiadis, I., Pascual, M., Willcock, S., \& Villa, F. (2019). Towards globally customizable ecosystem service models. Science of the Total Environment, 650, 2325-2336. https://doi.org/10.1016/j.scitotenv.2018.09.371.

Maxwell, D. (2013). A rainfall-runoff model for the highly regulated Lake Taupo catchment, using a constrained Ensemble Kalman Filter to improve the accuracy and reliability of model output. (Doctor of Philosophy), Victoria University of Wellington, New Zealand. Retrieved from http://hdl.handle.net/10063/2703 
Maxwell, D. H., Jackson, B. M., \& McGregor, J. (2018). Constraining the ensemble Kalman filter for improved streamflow forecasting. Journal of Hydrology, 560, 127-140. https://doi.org/10.1016/j.jhydrol.2018.03.015.

McEwen, L., Garde-Hansen, J., Holmes, A., Jones, O., \& Krause, F. (2017). Sustainable flood memories, lay knowledges and the development of community resilience to future flood risk. Transactions of the Institute of British Geographers, 42(1), 14-28. https://doi.org/10.1111/tran.12149.

McGrath, H., Bourgon, J., Proulx-Bourque, J. S., Nastev, M., \& El Ezz, A. A. (2018). A comparison of simplified conceptual models for rapid webbased flood inundation mapping. Natural Hazards, 93(2), 905-920. https://doi.org/10.1007/s11069-018-3331-y.

McKergow, L. A., Pritchard, M., Elliott, A. H., Duncan, M. J., \& Senior, A. K. (2010). Storm fine sediment flux from catchment to estuary, WaitetunaRaglan Harbour, New Zealand. New Zealand Journal of Marine Freshwater Research, 44(1), 53-76. https://doi.org/10.1080/00288331003721471.

Millennium Ecosystem Assessment. (2005). Ecosystems and Human Well-being: Synthesis (1569735972). Retrieved from Washington, United Stated of America: https://www.millenniumassessment.org.

Millner, J. P., Roskruge, N. R., \& Dymond, J. R. (2013). The New Zealand arable industry. Retrieved from https://www.landcareresearch.co.nz.

Ministry for the Environment. (2007). Environment New Zealand 2007. (ME 847). Wellington, New Zealand: Ministry for the Environment. Retrieved from http://www.mfe.govt.nz

Ministry for the Environment. (2008). Meeting the challenges of future flooding in New Zealand. Wellington, New Zealand: Ministry for the Environment. Retrieved from http://www.mfe.govt.nz

Ministry for the Environment. (2017). Preparing for coastal change: a summary of coastal hazards and climate change guidance for local government. Wellington, New Zealand: Ministry for the Environment. Retrieved from http://www.mfe.govt.nz

Ministry for the Environment \& Statistics New Zealand. (2015). Environment Aotearoa 2015. Ministry for the Environment \& Statistics New Zealand. Retrieved from http://www.mfe.govt.nz \& http://www.stats.govt.nz

Ministry for the Environment \& Statistics New Zealand. (2016). New Zealand's Environmental Reporting Series: Our marine environment 2016. (ME 1272). Ministry for the Environment \& Statistics New Zealand. Retrieved from http://www.mfe.govt.nz

Ministry of Civil Defence \& Emergency Management. (2010). Part B: Floods. Ministry of Civil Defence \& Emergency Management. Retrieved from https://www.civildefence.govt.nz 
Minns, A. W., \& Hall, M. J. (1996). Artificial neural networks as rainfall-runoff models. Hydrological Sciences Journal, 41(3), 399-417. https://doi.org/10.1080/02626669609491511.

Mohammad, A. G., \& Adam, M. A. (2010). The impact of vegetative cover type on runoff and soil erosion under different land uses. Catena, 81(2), 97103. https://doi.org/10.1016/j.catena.2010.01.008.

Moller, S. I. (2012). The economic value of environmental amenities and restoration for rural land in New Zealand (2012/02). Retrieved from Dunedin, New Zealand: https://www.ecosystemsconsultants.co.nz.

Mosley, M. P. (1979). Streamflow generation in a forested watershed, New Zealand. Water Resources Research, 15(4), 795-806. https://doi.org/10.1029/WR015i004p00795.

Mosley, M. P., \& Pearson, C. P. (1997). Floods and droughts: The New Zealand experience (M. P. Mosley \& C. P. Pearson Eds.). Wellington, New Zealand: New Zealand Hydrological Society.

Mullan, B., Wratt, D., Dean, S., Hollis, M., Allan, S., Williams, T., Kenny, G. J., \& Ministry for the Environment. (2008). Climate change effects and impacts assessment: A Guidance Manual for Local Government in New Zealand. (ME 870). Wellington, New Zealand: Ministry for the Environment. Retrieved from https://www.mfe.govt.nz

Müller, K., \& Deurer, M. (2011). Review of the remediation strategies for soil water repellency. Agriculture, Ecosystems \& Environment, 144(1), 208221. https://doi.org/10.1016/j.agee.2011.08.008.

Nash, J. E., \& Sutcliffe, J. V. (1970). River flow forecasting through conceptual models part I-A discussion of principles. Journal of Hydrology, 10(3), 282-290. https://doi.org/10.1016/0022-1694(70)90255-6.

National Institute of Water \& Atmospheric Research. (2019). CliFlo: NIWA's National Climate Database on the Web Retrieved from http://cliflo.niwa.co.nz/. Retrieved 2019, February 27 http://cliflo.niwa.co.nz/

National Institute of Water and Atmospheric Science. (2017). High Intensity Rainfall Design System V4. Retrieved 2019, June 15 from https://hirds.niwa.co.nz/.

National Institute of Water and Atmospheric Science. (n.d.). Kawhia. Retrieved 2018, August 3 from https://www.niwa.co.nz.

Neale, T., \& Weir, J. K. (2015). Navigating scientific uncertainty in wildfire and flood risk mitigation: A qualitative review. International Journal of Disaster Risk Reduction, 13, 255-265. https://doi.org/10.1016/j.ijdrr.2015.06.010.

Nedkov, S., \& Burkhard, B. (2012). Flood regulating ecosystem servicesMapping supply and demand, in the Etropole municipality, Bulgaria. 
Ecological Indicators, 21, 67-79.

https://doi.org/10.1016/j.ecolind.2011.06.022.

Nelson, E., Mendoza, G., Regetz, J., Polasky, S., Tallis, H., Cameron, R., Chan, K. M. A., Daily, G. C., Goldstein, J., \& Kareiva, P. M. (2009). Modeling multiple ecosystem services, biodiversity conservation, commodity production, and tradeoffs at landscape scales. Frontiers in Ecology and the Environment, 7(1), 4-11. https://doi.org/10.1890/080023.

Newsome, P. F. J., Wilde, R. H., \& Willoughby, E. J. (2008). Land resource information system spatial data layers: data dictionary: Manaaki WhenuaLandcare Research New Zealand. http://doi.org/10.7931/DL1V88.

Niggli, U., Fließbach, A., Hepperly, P., \& Scialabba, N. (2009). Low Greenhouse Gas Agriculture: Mitigation and Adaptation Potential of Sustainable Farming Systems. Ökologie \& Landbau 141, 32-33. Retrieved from https://www.oekom.de

Norris, K. (2012). Biodiversity in the context of ecosystem services: the applied need for systems approaches. Philosophical Transactions of the Royal Society B: Biological Sciences, 367(1586), 191-199. https://doi.org/10.1098/rstb.2011.0176.

Nourani, V., Singh, V. P., \& Delafrouz, H. (2009). Three geomorphological rainfall-runoff models based on the linear reservoir concept. Catena, 76(3), 206-214. https://doi.org/10.1016/j.catena.2008.11.008.

O'Leary, B. E. (2010). Soil Carbon Sequestration Potential and Linkages with General Flooding and Erosion Issues, Gisborne/East-Cape Region, North Island, New Zealand. (Master of Science), Victoria University of Wellington, Wellington. Retrieved from http://hdl.handle.net/10063/4499

O’Connell, P. E., Ewen, J., O’Donnell, G., \& Quinn, P. (2007). Is there a link between agricultural land-use management and flooding? Hydrology Earth System Sciences, 11(1), 96-107. https://doi.org/10.5194/hess-11-96-2007.

Olubode-Awosola, F. (2017). Project summary report - Fresh water Ecosystem Services Project - Phase 1 (6112444). Retrieved from http://www.waikatoregion.govt.nz.

Osborne, R. (2002). Cave breakdown by vadose weathering. International Journal of Speleology, 31(1), 37-53. https://doi.org/10.5038/1827806X.31.1.3.

Pachauri, R. K., Allen, M. R., Barros, V. R., Broome, J., Cramer, W., Christ, R., Church, J. A., Clarke, L., Dahe, Q., \& Dasgupta, P. (2014). Climate change 2014: synthesis report. Contribution of Working Groups I, II and III to the fifth assessment report of the Intergovernmental Panel on Climate Change (9291691437). Retrieved from Geneva, Switzerland: https://www.ipcc.ch/report/ar5/syr/.

Paget, D. (2009, January 31). Keep off! Waikato Times. Retrieved from http://www.stuff.co.nz/waikato-times/news/236285/Keep-off 
Patro, S., Chatterjee, C., Mohanty, S., Singh, R., \& Raghuwanshi, N. S. (2009). Flood inundation modeling using MIKE FLOOD and remote sensing data. Journal of the Indian Society of Remote Sensing, 37(1), 107-118. https://doi.org/10.1007/s12524-009-0002-1.

Pechlivanidis, I., Jackson, B., Mcintyre, N., \& Wheater, H. (2011). Catchment scale hydrological modelling: A review of model types, calibration approaches and uncertainty analysis methods in the context of recent developments in technology and applications. Global NEST Journal 13(3), 193-214. https://doi.org/10.30955/gnj.000778.

Pechlivanidis, I. G., Jackson, B., McMillan, H., \& Gupta, H. (2014). Use of an entropy-based metric in multiobjective calibration to improve model performance. Water Resources Research, 50(10), 8066-8083. https://doi.org/10.1002/2013WR014537.

Penman, H. L. (1948). Natural evaporation from open water, bare soil and grass. Proceedings of the Royal Society of London. Series A. Mathematical and Physical Sciences, 193(1032), 120-145. https://doi.org/10.1098/rspa.1948.0037.

Perrin, C., Michel, C., \& Andréassian, V. (2001). Does a large number of parameters enhance model performance? Comparative assessment of common catchment model structures on 429 catchments. Journal of Hydrology, 242(3-4), 275-301. https://doi.org/10.1016/S00221694(00)00393-0.

Phillips, C. (2005). Erosion and sediment control using New Zealand native plants - What do we know. Paper presented at the Protecting the environment as an asset conference, Palmerston North. https://icm.landcareresearch.co.nz.

Phillips, D. J., \& Mead, S. T. (2009). Investigation of a Large Sandbar at Raglan, New Zealand: Project Overview and Preliminary Results. REEF Journal, 1(1), 267-278. Retrieved from http://www.thereefjournal.com

Pottier, N., Penning-Rowsell, E., Tunstall, S., \& Hubert, G. (2005). Land use and flood protection: contrasting approaches and outcomes in France and in England and Wales. Applied Geography, 25(1), 1-27. https://doi.org/10.1016/j.apgeog.2004.11.003.

Power, A. G. (2010). Ecosystem services and agriculture: tradeoffs and synergies. Philosophical Transactions of the Royal Society B, 365(1554), 2959-2971. https://doi.org/10.1098/rstb.2010.0143.

Richards, L., \& Morse, J. M. (2012). Readme first for a user's guide to qualitative methods. Thousand Oaks, United States of America: SAGE Publications. https://us.sagepub.com.

Rieb, J. T., Chaplin-Kramer, R., Daily, G. C., Armsworth, P. R., Böhning-Gaese, K., Bonn, A., Cumming, G. S., Eigenbrod, F., Grimm, V., \& Jackson, B. M. (2017). When, where, and how nature matters for ecosystem services: 
challenges for the next generation of ecosystem service models. BioScience, 67(9), 820-833. https://doi.org/10.1093/biosci/bix075.

Roberts, L., Brower, A. L., Kerr, G. N., Lambert, S. J., McWilliam, W. J., Moore, K., Quinn, J., Simmons, D. G., Thrush, S., Townsend, M., Blaschke, P., Costanza, R., Cullen, R., Hughey, K., \& Wratten, S. (2015). The nature of wellbeing: how nature's ecosystem services contribute to the wellbeing of New Zealand and New Zealanders. Wellington, New Zealand: Department of Conservation.

Royal Society New Zealand. (2016). Royal Society of New Zealand, 2016, Climate change implications for New Zealand. Retrieved from https://royalsociety.org.nz.

Royal Society of New Zealand. (2011). Ecosystem service: emerging issues. Retrieved from https://royalsociety.org.nz.

Ryan, P. A. (1991). Environmental effects of sediment on New Zealand streams: a review. New Zealand Journal of Marine and Freshwater Research 25(2), 207-221. https://doi.org/10.1080/00288330.1991.9516472.

Salvadore, E., Bronders, J., \& Batelaan, O. (2015). Hydrological modelling of urbanized catchments: A review and future directions. Journal of Hydrology, 529, 62-81. https://doi.org/10.1016/j.jhydrol.2015.06.028.

Sattari, M. T., Rezazadeh-Joudi, A., \& Kusiak, A. (2017). Assessment of different methods for estimation of missing data in precipitation studies. Hydrology Research, 48(4), 1032-1044. https://doi.org/10.2166/nh.2016.364.

Scarsbrook, M., Wright-Stow, A., van Houte-Howes, K., \& Joy, K. (2008). Aquatic Ecosystems of the Maniapoto Karst (1359453). Retrieved from Hamilton: http://www.waikatoregion.govt.nz.

Scion. (2017). Forest ecosystem services. In Scion (Ed.).

Scott, N. (2017). Facilitating informed land-use decisions through the modelling of ecosystem service trade-offs. (Master of Science), Victoria University of Wellington, New Zealand. Retrieved from http://hdl.handle.net/10063/6355

Searcy, J. K. (1959). Flow-duration curves (1542A). Retrieved from https://doi.org/10.3133/wsp1542A.

Sharps, K., Masante, D., Thomas, A., Jackson, B., Redhead, J., May, L., Prosser, H., Cosby, B., Emmett, B., \& Jones, L. (2017). Comparing strengths and weaknesses of three ecosystem services modelling tools in a diverse UK river catchment. Science of the total environment, 584-585, 118-130. https://doi.org/10.1016/j.scitotenv.2016.12.160.

Shi, P. J., Yuan, Y., Zheng, J., Wang, J. A., Ge, Y., \& Qiu, G. Y. (2007). The effect of land use/cover change on surface runoff in Shenzhen region, China. Catena, 69(1), 31-35. https://doi.org/10.1016/j.catena.2006.04.015. 
Simmons, D. G. (2013). Tourism and ecosystem services in New Zealand. In D. J.R. (Ed.), Ecosystem services in New Zealand - conditions and trends. Lincoln, New Zealand: Manaaki Whenua-Landcare Research New Zealand. Retrieved from https://www.landcareresearch.co.nzhttps://www.landcareresearch.co.nz

Singleton, P. L., \& Addison, B. (2000). Effects of cattle treading on physical properties of three soils used for dairy farming in the Waikato, North Island, New Zealand. Australian Journal of Soil Research, 37(5), 891-902. https://doi.org/10.1071/sr98101.

Smith, L. C. (1997). Satellite remote sensing of river inundation area, stage, and discharge: A review. Hydrological Processes, 11(10), 1427-1439. https://doi.org/10.1002/(SICI)1099-1085(199708)11:10<1427::AIDHYP473>3.0.CO;2-S.

Spiekermann, R., Betts, H., Dymond, J., \& Basher, L. (2017). Volumetric measurement of river bank erosion from sequential historical aerial photography. Geomorphology, 296, 193-208. https://doi.org/10.1016/j.geomorph.2017.08.047.

Statistics New Zealand. (2013). 2013 Census QuickStats about a place: Marokopa. Retrieved 2019, March 15 from http://archive.stats.govt.nz/Census/2013-census/profile-and-summaryreports/quickstats-about-aplace. aspx ?request_value $=13808 \&$ parent $\_i d=13804 \&$ tabname $=$.

Statistics New Zealand. (2018). Regional gross domestic product: Year ended March 2017. Information releases. Retrieved 2019, February 14 from https://www.stats.govt.nz/information-releases/regional-gross-domesticproduct-year-ended-march-2017\#waikato.

Stephens, S., Robinson, B., \& Bell, R. (2015). Analysis of Whitianga, Tararu and Kawhia sea-level records to 2014. Retrieved from Hamilton. New Zealand: http://waikatoregion.govt.nz.

Stevens, G. R. (2012). Otapirian and Aratauran sequences (latest Triassic and earliest Jurassic) along the northern Marokopa coast (SW Auckland, New Zealand) and observations on the Triassic/Jurassic boundary in New Zealand. New Zealand Journal of Geology and Geophysics, 55(1), 37-51. https://doi.org/10.1080/00288306.2011.615939.

Sweeney, B. W., Bott, T. L., Jackson, J. K., Kaplan, L. A., Newbold, J. D., Standley, L. J., Hession, W. C., \& Horwitz, R. J. (2004). Riparian deforestation, stream narrowing, and loss of stream ecosystem services. Proceedings of the National Academy of Sciences, 101(39), 14132-14137. https://doi.org/10.1073/pnas.0405895101.

Taylor, M. (2007). Community participation in the real world: opportunities and pitfalls in new governance spaces. Urban Studies, 44(2), 297-317. https://doi.org/10.1080/00420980601074987. 
Teng, J., Jakeman, A. J., Vaze, J., Croke, B. F. W., Dutta, D., \& Kim, S. (2017). Flood inundation modelling: A review of methods, recent advances and uncertainty analysis. Environmental Modelling, 90, 201-216. https://doi.org/10.1016/j.envsoft.2017.01.006.

Tilman, D., Cassman, K. G., Matson, P. A., Naylor, R., \& Polasky, S. (2002). Agricultural sustainability and intensive production practices. Nature, 418(6898), 671-677. https://doi.org/10.1038/nature01014.

Trodahl, M., Burkitt, L., Bretherton, M., Deslippe, J., Jackson, B., \& Metherell, A. (2017). Developing $N \&$ \& Export Coefficients for Rural Landscape Modelling in LUCI (30). Retrieved from Palmerston North, New Zealand: http://flrc.massey.ac.nz/publications.htm.

Trodahl, M., Deslippe, J., \& Jackson, B. (2016). Improving predictions of $N \& P$ export to waterways from rural landscapes in New Zealand using LUCI (29). Retrieved from Palmerston North, New Zealand:

https://www.massey.ac.nz.

Tunstall, S. M., Johnson, C. L., \& Penning-Rowsell, E. C. (2004). 28. Flood hazard management in England and Wales: from land drainage to flood risk management. Paper presented at the World Congress on Natural Disaster Mitigation, New Delhi, India.

van Beynen, P. E., Zhou, W., Beck, B. F., Milanović, P., Tolmachev, V., Leonenko, M., Coxon, C., Gillieson, D. S., Parise, M., Reeder, P., Fong, D. W., Northup, D. E., Worthington, S. R. H., Bakalowicz, M., Humphreys, F., Veni, G., Fleury, E. S., Brinkmann, R., Garren, S. J., van Beynen, K. M., Day, M., Halfen, A., Chenoweth, S., Ford, D. C., Day, M., \& Williams, P. W. (2011). Karst management (P. E. van Beynen Ed.). Dordrecht: Springer Science+Business Media https://doi.org/10.1007/97894-007-1207-2.

Van den Belt, M., McCallion, A., Wairepo, S., Hardy, D., Hale, L., \& Berry, M. (2012). Mediated Modelling of Coastal Ecosystem Services: A case study of Te Awanui Tauranga Harbour (4). Retrieved from Palmerston North, New Zealand: https://www.mtm.ac.nz.

van Ogtrop, F. F., Hoekstra, A. Y., \& van der Meulen, F. (2005). Flood management in the lower incomati river basin, Mosambique: two altrnatives. Journal of the American Water Resources Association, 41(3), 607-619. https://doi.org/10.1111/j.1752-1688.2005.tb03758.x.

Vercruysse, K., Grabowski, R. C., \& Rickson, R. J. (2017). Suspended sediment transport dynamics in rivers: multi-scale drivers of temporal variation. Earth-Science Reviews, 166, 38-52. https://doi.org/10.1016/j.earscirev.2016.12.016.

Viglizzo, E. F., Paruelo, J. M., Laterra, P., \& Jobbagy, E. G. (2012). Ecosystem service evaluation to support land-use policy. Agriculture, Ecosystems and Environment, 154, 78-84. https://doi.org/10.1016/j.agee.2011.07.007. 
Vojinovic, Z., Hammond, M., Golub, D., Hirunsalee, S., Weesakul, S., Meesuk, V., Medina, N., Sanchez, A., Kumara, S., \& Abbott, M. (2016). Holistic approach to flood risk assessment in areas with cultural heritage: a practical application in Ayutthaya, Thailand. Natural Hazards, 81(1), 589616. https://doi.org/10.1007/s11069-015-2098-7.

Wagener, T., Wheater, H., \& Gupta, H. V. (2004). Rainfall-runoff modelling in gauged and ungauged catchments. London, England: World Scientific Press. https://doi.org/10.1142/9781860945397.

Waikato Regional Council. (2018). Weather event - January 4-5 2018. Retrieved 2019, June 19 from https://www.waikatoregion.govt.nz/services/regionalservices/regional-hazards-and-emergency-management/floodroom/events/weather-event-january-4-5-2018/.

Waikato Regional Council. (n.d). Coastal inundation tool. Retrieved 2019, April 10 from http://waikatoregion.govt.nz/services/regional-services/regionalhazards-and-emergency-management/coastal-hazards/coastalflooding/coastal-inundation-tool.

Waikato Regional Council. (n.d.-a). Coastal flooding. Retrieved 2018, December 11 from https://www.waikatoregion.govt.nz/services/regionalservices/regional-hazards-and-emergency-management/coastalhazards/coastal-flooding/.

Waikato Regional Council. (n.d.-b). River levels and flow map. Retrieved 23/05/2019 from http://rainfallmap.waikatoregion.govt.nz/cgibin/hydwebserver.cgi/catchments/details?catchment=17.

Wainwright, J., \& Mulligan, M. (2013). Environmental modelling: finding simplicity in complexity (2nd ed.). Chichester, England: John Wiley \& Sons Ltd. https://doi.org/10.1002/9781118351475.

Wang, M., Li, Y., \& Yin, C. (2015). An assessment of the impacts of climate change in the Waikato region: Applying CMIP5 data. Retrieved from https://www.waikatoregion.govt.nz/assets/PageFiles/40610/TR201526.pdf

Ward, R. C., \& Robinson, M. (1990). Principles of hydrology (3rd ed.). London, New York: McGraw-Hill

Ward, R. C., \& Robinson, M. (2000). Principles of hydrology (4th ed.). London, England: McGraw-Hill.

Warrick, R. A., Kenny, G. J., Harman, J. J., Mullan, A. B., Salinger, M. J., Thompson, C. S., Porteous, A. S., Hall, A. J., Austin, P. T., McPherson, H. G., Jamieson, P. D., Cloughley, C. G., Clark, H., Mitchell, N. D., Newton, P. C. D., Campbell, B. D., Parshotam, A., Tate, K. R., Harman, J. J., Flux, T. L., \& Ye, W. (2001). The effects of climate change and variation in New Zealand: An assessment using the CLIMPACTS system. Hamilton, New Zealand: The International Global Change Institute (IGCI), University of Waikato. https://www.waikato.ac.nz/. 
Watson, A. J., \& Mardern, M. (2004). Live root-wood tensile strengths of some common New Zealand indigenous and plantation tree species. New Zealand Journal of Forestry Science, 34(3), 344-353. Retrieved from https://nzjforestryscience.nz

Wezel, A., Casagrande, M., Celette, F., Vian, J. r., Ferrer, A., \& Peigné, J. (2014). Agroecological practices for sustainable agriculture. A review. Agronomy for Sustainable Development, 34(1), 1-20. https://doi.org/10.1007/s13593013-0180-7.

Wheater, H., \& Evans, E. (2009). Land use, water management and future flood risk. Land Use Policy, 26, S251-S264.

https://doi.org/10.1016/j.landusepol.2009.08.019.

Whitman, Z. R., Wilson, T. M., Seville, E., Vargo, J., Stevenson, J. R., Kachali, H., \& Cole, J. (2013). Rural organizational impacts, mitigation strategies, and resilience to the 2010 Darfield earthquake, New Zealand. Natural Hazards, 69(3), 1849-1875. https://doi.org/10.1007/s11069-013-0782-z.

Williams, D. R. (2014). Making sense of 'place': Reflections on pluralism and positionality in place research. Landscape and Urban Planning, 131, 7482. https://doi.org/10.1016/j.landurbplan.2014.08.002.

Williams, P. W. (1983). The role of the subcutaneous zone in karst hydrology. Journal of Hydrology, 61(1-3), 45-67. https://doi.org/10.1016/00221694(83)90234-2.

Williams, P. W. (2004). Polygonal karst and palaeokarst of the King Country, North Island, New Zealand. Zeitschrift für Geomorphologie (Supplements), 136, 45-67. Retrieved from https://www.schweizerbart.de

Wolf, J. (2009). Coastal flooding: impacts of coupled wave-surge-tide models. Natural Hazards, 49(2), 241-260. https://doi.org/10.1007/s11069-0089316-5.

World Meteorological Organization. (2009). Integrated flood management: Concept paper (9263110476). Retrieved from Geneva, Switzerland: www.floodmanagement.info.

Worm, B., Barbier, E. B., Beaumont, N., Duffy, J. E., Folke, C., Halpern, B. S., Jackson, J. B. C., Lotze, H. K., Micheli, F., \& Palumbi, S. R. (2006). Impacts of biodiversity loss on ocean ecosystem services. Science, 314(5800), 787-790. https://doi.org/10.1126/science.1132294.

Yang, D., Kanae, S., Oki, T., Koike, T., \& Musiake, K. (2003). Global potential soil erosion with reference to land use and climate changes. Hydrological Processes: An International Journal, 17(14), 2913-2928. https://doi.org/10.1002/hyp.1441.

Zammit, C. (2014). Water Resource Inventory: Prepared for Maniapoto Māori Trust Board (CHC2014-093). Retrieved from Christchurch, New Zealand: http://www.maniapoto.iwi.nz. 
Zhang, W., Ricketts, T. H., Kremen, C., Carney, K., \& Swinton, S. M. (2007).

Ecosystem services and dis-services to agriculture. Ecological Economics, 64(2), 253-260. https://doi.org/10.1016/j.ecolecon.2007.02.024. 